


\section{PROPOSITIONS}

1. Pesticides are too cheap to discourage their use (this thesis).

2. The environmental risk assessment of insecticides should account for landscape scale effects (this thesis).

3. Phrasing a title is the hardest part of writing a paper.

4. Story telling is an essential skill for scientists.

5. Having a baby during your $\mathrm{PhD}$ increases your efficiency.

6. Thrift shopping offers often what you want, but seldom what you need.

Propositions belonging to the thesis entitled:

"Insect and insecticides in agricultural landscapes;

socio-ecological challenges and patterns"

Lieneke Bakker

Wageningen, 19 April 2021 



\section{INSECTS NND INSECTCLIDES IN AGRICULTURAL LNNDSCPPES; SOCIO-ECOLOGICCL CHALENGES NND PATERNS}




\section{Thesis committee}

\section{Promotor}

Dr Wopke van der Werf

Associate professor, Centre for Crop Systems Analysis

Wageningen University \& Research

\section{Co-promotor}

Dr Felix J.J.A. Bianchi

Associate professor, Farming Systems Ecology Group

Wageningen University \& Research

\section{Other members}

Prof. Dr D. Kleijn, Wageningen University \& Research

Dr C.E.P. Jansen, Wageningen University \& Research

Dr W. Geertsema, BoerenNatuur, Utrecht

Dr C. Lavigne, INRAe, Avignon, France

This research was conducted under the auspices of the C.T. de Wit Graduate School for Production Ecology and Resource Conservation. 


\title{
INSECTS AND INSECTICIDES IN AGRICULTURAL LANDSCAPES; SOCIO-ECOLOGICAL CHALLENGES AND PATTERNS
}

\author{
LIENEKE BAKKER
}

Thesis

submitted in fulfilment of the requirements for the degree of doctor at Wageningen University

by the authority of the Rector Magnificus,

Prof. Dr A.P.J. Mol,

in the presence of the

Thesis Committee appointed by the Academic Board

to be defended in public

on Monday 19 April 2021

at 4 p.m. in the Aula 
Lieneke Bakker

Insect and insecticides in agricultural landscapes; socio-ecological challenges and patterns.

190 pages

PhD thesis, Wageningen University, Wageningen, the Netherlands (2021)

With references, with summary in English

ISBN: 978-94-6395-672-7

DOI: https://doi.org/10.18174/538522 


\section{ABSTRACT}

Pest management is essential to prevent crop losses. Chemical pesticides are standard practice in conventional farming systems because they are simple to use, cheap, and usually highly effective in providing short-term reduction in pest densities. Yet, their use can also lead to impacts on human health and biodiversity, pollution of air and water, and evolution of resistance in target pests. Chemical-based pest management can lead to lock-in because of an interplay of reinforcing environmental factors, science and technology, and sociopolitical factors, the so-called pesticide treadmill. To reduce farmers' dependency upon pesticides and to lessen the associated environmental burden, a solid understanding of the socio-ecological features of pest management decision-making is needed. Using a multidisciplinary approach, I aimed to provide critically needed insight in the system dynamics underlying farmers' pest control practices, and elucidate key principles governing a transition towards sustainable pest management.

First, I conducted a literature review to identify drivers of the pesticide treadmill. I found that pest management decisions at the farm level, characteristics of farming landscapes, science \& technology, and societal demands are four domains with self-re-enforcing drivers for pesticide 'lock-in'. Current pesticide use showed similarities with historical pesticide treadmills, as farmers remain trapped in the pesticide treadmill. An important difference is that I studied neonicotinoids at a global scale and in several crops, while documented historical examples of the pesticide treadmill were reported more locally and on a few cash crops. Second, in a two-year landscape study I assessed how beneficial arthropods and biocontrol services are jointly impacted by local and landscape-wide pesticide use and by semi-natural habitats in the landscape. I found that the abundance of beneficial arthropods was negatively associated with landscape-wide insecticide use, but biocontrol services in field margins were not significantly associated with insecticide use in the adjacent field or the wider landscape. Furthermore, landscapes with greater area of woody semi-natural habitat moderated insecticide use effects for parasitoids, but not for pollinators and arthropod predators. Third, I conducted an online survey among Dutch farmers to identify barriers towards reducing pesticide use. Farmers' intention to reduce pesticide use was strongly determined by whether other farmers also acted, and farmers perceived limited capacity and autonomy to reduce pesticide use.

In this thesis I showed that current mainstream agriculture is trapped in a pesticide treadmill, which is reinforced by both a landscape and a social lock-in. Therefore, it is crucial that ecological information is integrated with social and behavioural understanding of pest management decision-making. Landscape management and increasing diversity is essential to facilitate beneficial insects. True costs of pesticide use and knowledge development on 
pest management alternatives could help farmers to overcome barriers to transition from chemical to ecologically-based pest management. 


\section{TABLE OF CONTENTS}

Chapter 1

General introduction

Chapter 2

Neonicotinoids in global agriculture: evidence for a new pesticide treadmill?

Chapter 3

Landscape-wide insecticide exposure impacts beneficial arthropod abundance

Chapter 4

No significant effects of insecticide use indicators and landscape variables on biocontrol in field margins

\section{Chapter 5}

Kicking the habit: what makes and breaks farmers' intentions to reduce pesticide use?

Chapter 6

General discussion

References

Summary

Samenvatting

Acknowledgements

About the author

PE\&RC Training and Education Statement 


\section{CHAPTER 1}

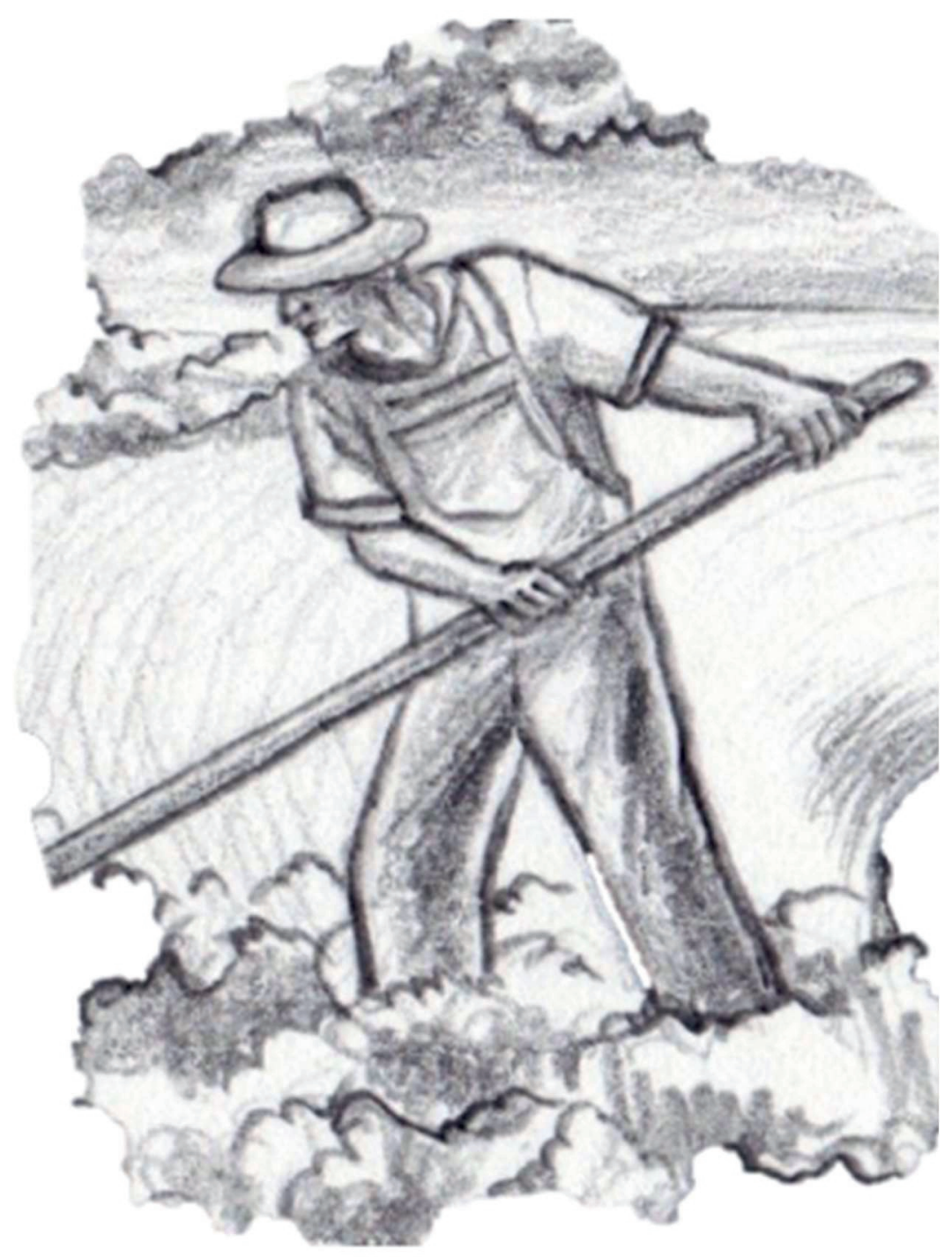




\section{GENERAL INTRODUCTION}

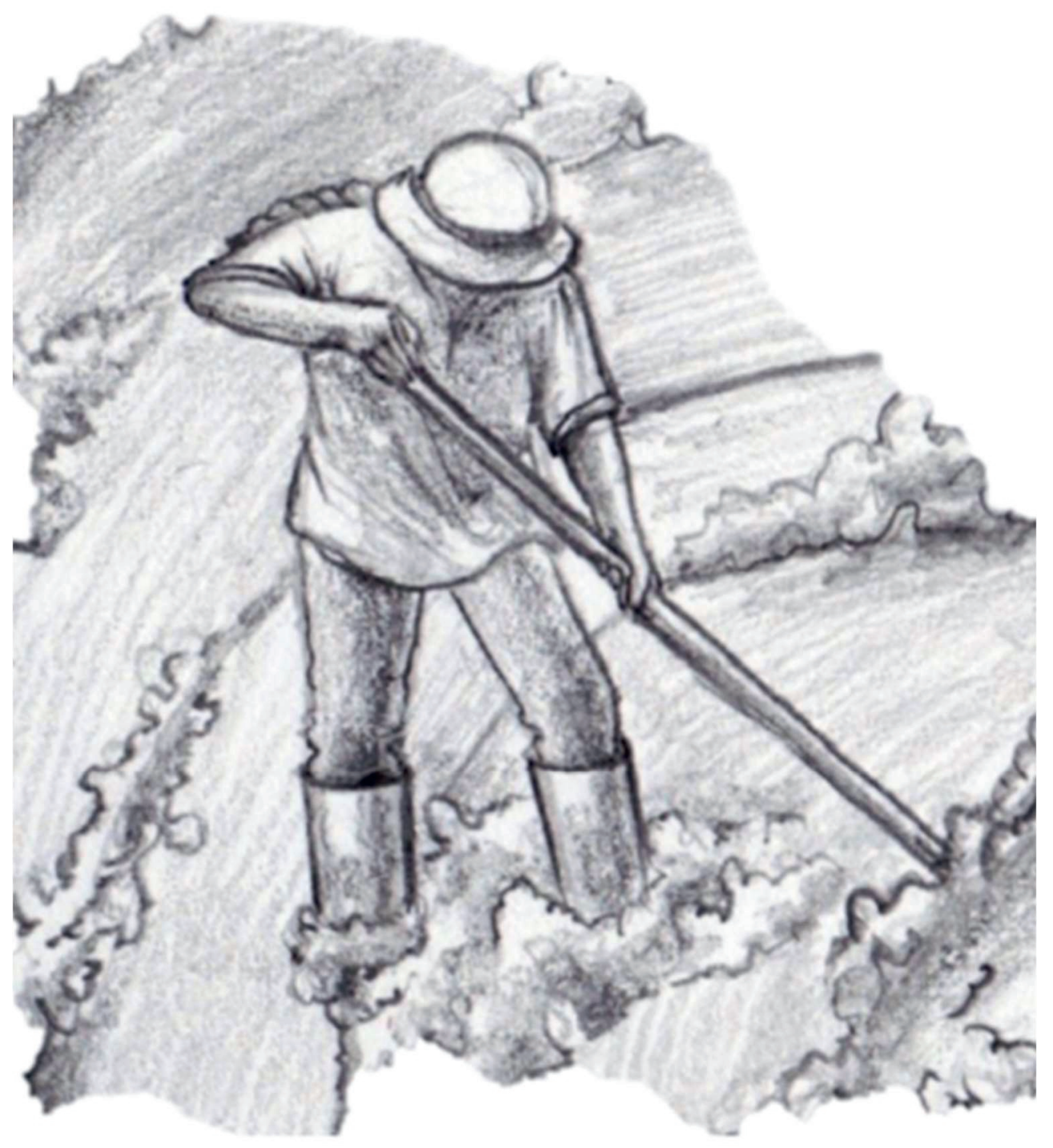




\section{PEST MANAGEMENT IN AGRICULTURE}

Crop losses are caused by insect pests and other biotic and abiotic factors (Oerke, 2006; Culliney, 2014). Pests reduce crop yields in two ways; i) quantitatively, through reduced productivity, and ii) qualitatively, through reduced content of valuable ingredients or reduced market quality (Oerke, 2006). Worldwide an estimated 70,000 different pest species damage agricultural crops, but less than $10 \%$ of these species are considered major pests (Pimentel, 2009). Between 2-20\% of potential crop production is destroyed by arthropod pests (Oerke, 2006; Deutsch et al., 2018). Crop losses by arthropod pests, however, would be higher without pest control measures (Oerke, 2006). Higher crop losses would cause significant economic loss and have negative impacts on the world food supply (Pimentel, 2009). Hence, pest management is essential for productive agriculture.

\section{Chemical pest control}

Synthetic pesticides have proven to be a very effective tool to manage pests, weeds, and diseases (Cooper and Dobson, 2007). Pesticides include a wide range of chemical components with many modes of action and application methods. Several characteristics of synthetic pesticides make it attractive to use them, e.g. pesticides are relatively easy to use, act quickly to reduce pest populations, and can be applied with only limited information about the agricultural ecosystem. For example, calendar sprays and curative treatments can be made at recommended concentrations according to a fixed schedule (Waterfield and Zilberman, 2012). The impacts of pesticides depend on many factors, such as quantities used, the effectiveness of the active ingredients, their toxicity, and the environment in which they are used (Kniss, 2017).

\section{Trends in pesticide use}

Since the introduction of the first synthetic pesticides in the 1930s there has been a continuous succession of chemical classes and modes of action (Sparks and Lorsbach, 2017). For example, the use of insecticide products with organochlorines and organophosphates shifted to the use of carbamates and pyrethroids because the latter were less toxic to humans and wildlife (Pretty, 2005) (Fig. 1.1). Another key driver for pesticide development is pest resistance to pesticides, limiting the timespan that a pesticide is effective (Dyer, 2014; Borel, 2017; Sparks and Lorsbach, 2017). The agrochemical industry has responded to this by developing new pesticides, and currently neonicotinoids are the most used class of insecticides (Alburaki et al., 2015; Sparks and Lorsbach, 2017). Global pesticide use is increasing, though there are regional differences (Fig. 1.2). Some regions, such as Europe, have focused on decreasing pesticide usage due to concerns about environmental impacts and consequently developed a legislation known as the EU Directive on Sustainable Use of Pesticides (2009/128/EC) (Lamichhane et al., 2016). Other regions, like the Americas, show high variability in pesticide use. Insecticide use in North America is stagnating (Liu, Pan and $\mathrm{Li}, 2015$ ), while many counties in South America have increased their use due to a shift from small-scale peasant farming to more intensive farming systems like soybean cultivation 
(Dudley and Alexander, 2017). Asia accounts for the largest market in pesticides (US $\$ 12$ billion in 2012), with China alone using half of pesticides worldwide (Pretty and Bharucha, 2015). This unevenness in global pesticide use is due to differences in national policies, economic development, and difference in agricultural practices caused by e.g. nutrient imbalances (Vitousek et al., 2009). It also reflects the difference in regional reliance on pesticides for pest control in agriculture (Liu, Pan and Li, 2015; Pretty and Bharucha, 2015).

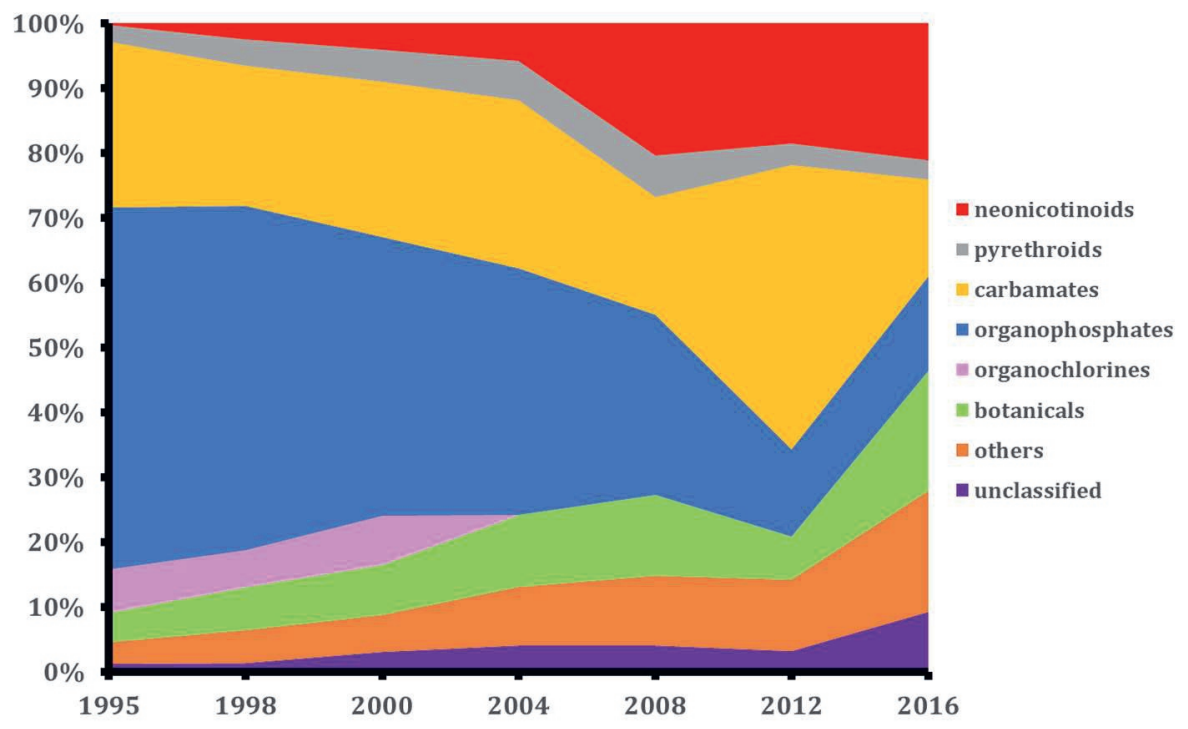

Figure 1.1: Changes in relative use of different chemical insecticide classes in Dutch agriculture from 1995-2016. Source: Statline (2019).

\section{Impacts of chemical pest control}

In 1962 Rachel Carson raised concerns about pesticide impacts on the environment and wildlife (Carson, 1962) and inspired early environmentalist movements (Zadoks, 1991). Currently, there are many problems associated with pesticide use. First, pesticide resistance in pest populations is growing (Mota-Sanchez and Wise, 2020). Second, ecological studies have found negative effects of pesticides on a wide range of non-target taxa including beneficial insects, pollinators, amphibians, and birds (Geiger et al., 2010; Hallmann et al., 2014; Mancini, Woodcock and Isaac, 2019). Third, pesticide residues and pesticide degradation products in ecosystems create environmental problems through e.g. pollution, accumulation in wildlife, and alterations in species community composition (Hallmann et al., 2014; Bernhardt, Rosi and Gessner, 2017; Clark and Tilman, 2017; Mancini, Woodcock and Isaac, 2019). Lastly, pesticides can be harmful to people that are exposed to pesticides directly through polluted water and air, via residues on food products, and due to occupational exposure (Pretty and Bharucha, 2015; Kim, Kabir and Jahan, 2017). Such hazards range from short-term health effects, e.g. irritation of the skin and eyes and 
headaches, to chronic conditions such as cancer, asthma, and diabetes (Kim, Kabir and Jahan, 2017).

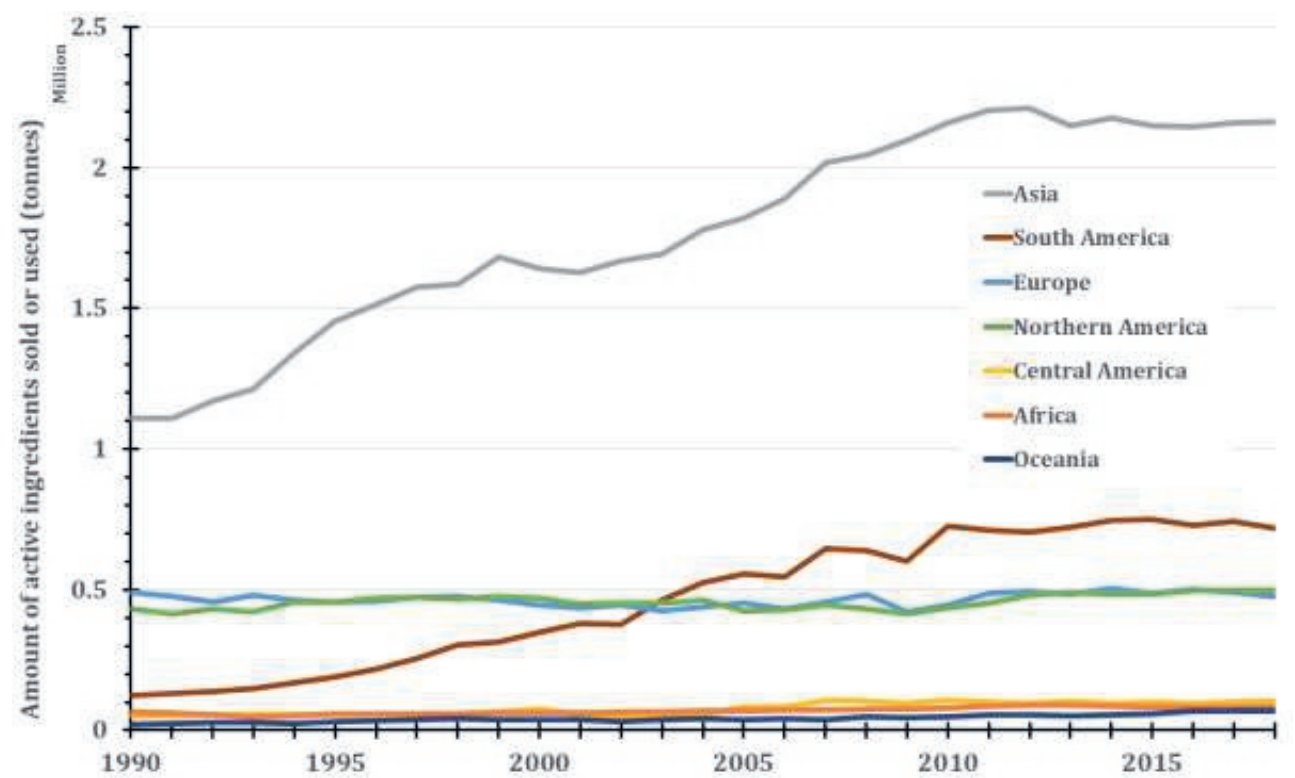

Figure 1.2: Geographical distribution of total pesticide used or sold (in tonnes of active ingredient) from 1990-2018. Source: FAOSTAT (2020).

Pesticides vary widely in use rates, toxicological profiles, and potential adverse effects on the environment and human health (Kniss, 2017). While some pesticides are used in doses of just a few grams per hectare (e.g. insecticides), others, like herbicides or mineral oils, need to be applied in kilograms per hectare (Lamichhane et al., 2016). Quantity-based indicators of pesticides, such as the Quantity of Active ingredients (QA) and the Treatment Frequency Index (TFI), do not necessarily capture the potential risks for human health and the environment because the relative risk of an applied pesticide depends not only on the amount of pesticide applied but also on the toxicity of - and the exposure to - the product (Kniss, 2017; Möhring, Gaba and Finger, 2019). For example, one high-dose application could have more impact on human health and environment than several low-dose applications that amount to a similar quantity applied (i.e. chronic toxicity hazard) (Kniss, 2017; Larsen, Patton and Martin, 2019). Given these uncertainties in assessing the potential risk of pesticides, impacts of pesticides could currently be underestimated (Topping, Aldrich and Berny, 2020).

\section{Biological pest control}

Biological pest management can be defined as 'the use of an organism that reduces the population density of another organism' (van den Bosch and Stern, 1962; Bale, van Lenteren and Bigler, 2008). Biological control is based on the principle of reducing rather than 
eradicating pest populations, and maintaining pest populations below economic threshold levels without requiring continuous retreatment (Bale, van Lenteren and Bigler, 2008; Waterfield and Zilberman, 2012). Biological control can be achieved using microbial agents like bacteria, viruses, and fungi, or macrobial agents like nematodes, predatory arthropods, and parasitoids (Bale, van Lenteren and Bigler, 2008). The latter two diverse functional groups are important for biological control. Both groups provide a regulatory service by controlling pest species populations (Bale, van Lenteren and Bigler, 2008; Savary et al., 2012). Predators feed on prey species, while parasitoids (e.g. parasitic wasps) lay eggs in or on other insects. The emerging parasitoid larvae feed during their development on their host insects, eventually killing the host (Crofton, 1971).

Biological pest control is appealing to implement in farm management due to several characteristics. First, biocontrol does not pollute soil, water, or air, nor does it have any direct consequences for the health of workers, nearby communities, and consumers through food residues. Furthermore, by incorporating biocontrol in farm management, farmers do not have to consider factors like harvesting interval (i.e. the time between pesticide applications and harvesting) or re-entry periods to the field after pesticide applications. In addition, predators and parasitoids do not give rise to resistance development (Bale, van Lenteren and Bigler, 2008; Waterfield and Zilberman, 2012; van Lenteren et al., 2018).

\section{Trends in biological control}

Biological control is classified into four types: i) natural biological control from naturally occurring natural enemies, ii) conservation biological control, which consists of human actions to conserve and stimulate naturally occurring populations of natural enemies, iii) classical biological control in which natural enemies are released into areas where an invasive pest is active, and iv) augmentative biological control where natural enemies are mass-reared and released into crops (van Lenteren et al., 2018). In classical and augmentative biological control, almost 350 natural enemy species are commercially used in a variety of crops, such as fruit and vegetable crops, cereals, maize, cotton, and greenhouse crops. At the moment there are around 500 commercial producers of arthropod biological control agents for augmentative biocontrol (van Lenteren et al., 2018). Currently, the biocontrol market is growing with an annual increase of more than $15 \%$ per year since 2005 (van Lenteren et al., 2018). Still, the market value of augmentative and classical biological control is only $2 \%$ of the global pesticide market (Dunham, 2015).

Conservation biological control is based on the conservation of the natural enemy populations in agricultural landscapes to ensure timely arrival of natural enemies to effectively suppress pest populations. Conservation of habitat for natural enemies can be facilitated through modifying the proportion of semi-natural habitats in agricultural landscapes. For example, through the establishment of flower strips, hedgerows, and buffer strips, farmers can implement agri-environmental schemes that support natural enemy 
populations (Mills et al., 2017). In the European Union these schemes cover around 22\% of farmland (Pavlis et al., 2016), but adoption and implementation of conservation biological control is still limited (Holland et al., 2016; Chaplin-Kramer et al., 2019).

\section{Impacts of biological pest control}

Implementing biological pest control in farm management is knowledge-intensive. For example, farmers need to understand pest species biology and morphology, and consider the biological and ecological needs of natural enemies to implement biocontrol effectively (Wyckhuys et al., 2019). Furthermore, natural enemies are specific in their range of prey and slower in suppressing pest populations than pesticides. Thus, biocontrol cannot be used as easily in responsive pest treatments as pesticides (Bale, van Lenteren and Bigler, 2008; Waterfield and Zilberman, 2012). While pest populations can be significantly reduced by natural enemies, repeated releases or additional methods could be needed to achieve an adequate level of control (Bale, van Lenteren and Bigler, 2008).

\section{PEST MANAGEMENT DECISION MAKING}

Pest management is one of the many facets of farm management, but it is one that has major implications for the environment and human health (Pretty, 2005). Pest management decisions are shaped by environmental factors, science and technology, and socio-political factors (Meek, 2016). For example, farmers base their decision to use pesticides on their knowledge of the farming system, their education, and farming experience. Moreover, these decisions on pest management are mediated by regulatory considerations, extension services offered, influence of advertising and media, and the effectiveness of implementing alternative pest management options (Jepson et al., 2014). Hence, to reduce farmers' dependency upon pesticides and to lessen the associated environmental burden, a solid understanding of the socio-ecological features of pest management decision making is needed (Wyckhuys et al., 2019).

\section{Lock-in effects of pesticide use}

Misuse and overuse of pesticides causes environmental problems (Pretty, 2005). Furthermore, frequent applications, high dosages, and the use of a limited range of active ingredients or modes of action decrease pesticide effectiveness through resistance development in pest populations (Hansen, 1988; Thrupp, 1990; Deguine, Ferron and Russell, 2008; Turnbull and Hector, 2010; Ekström and Ekbom, 2011; Jørgensen et al., 2018). Broad-spectrum insecticides reduce natural enemy populations and disrupt biological control. This creates an increased dependence on insecticides, which reduces natural enemy populations even further (DeBach, 1951; Roush and Tabashnik, 1990; Turnbull and Hector, 2010). Hence, a positive feedback is created in which a farmer increasingly relies on chemical pest control while simultaneously, biological control is weakened. This process has been referred to as 'the pesticide treadmill' (DeBach, 1951; Hansen, 1988). The pesticide treadmill is an example of path dependence, in which farmers 
increasingly keep using insecticides, which makes it harder to return to an insecticideindependent system (Wilson and Tisdell, 2001).

Chemical-based pest management follows specific trajectories which are difficult (and costly) to change, and tend to be inflexible and path-dependent (Cowan and Gunby, 1996). The transition to more ecologically-based pest management agriculture is difficult to achieve because of the aforementioned pesticide treadmill. A pesticide-dependent agriculture suppresses beneficial biota that are needed for the transition to a pesticide-free agriculture, causing a lock-in. The concept of lock-in stresses the condition that interactions and feedbacks constrain a system from within, resulting in low potential to change (Liebowitz and Margolis, 1995). Lock-ins impede the development, adoption or implementation of alternative techniques and strategies to manage pests (Liebowitz and Margolis, 1995; Vanloqueren and Baret, 2009). This is demonstrated by low adoption rates of alternative pest management options, such as Integrated Pest Management and biocontrol, despite research showing the benefits (Cowan and Gunby, 1996; Lamine, 2011; Tracy, 2014).

\section{Ecological characteristics of lock-in}

Arthropod pests and natural enemy populations are influenced by the surrounding landscape through i) the proportion of agricultural area (and thus disturbed area), ii) the diversity of habitats, and iii) the spatial arrangement of habitats (Haan, Zhang and Landis, 2020). For instance, local extinction of natural enemy populations could be driven by land conversion to agriculture and removal of semi-natural habitat (Tscharntke et al., 2012). Consequently, natural enemy populations are unable to effectively control pest populations. Landscapes with large agricultural areas are generally dominated by a few species of the predator community (Tscharntke et al., 2007), while a complex, more diverse landscape can harbour a diverse range of natural enemies (Tscharntke et al., 2005; Bianchi, Booij and Tscharntke, 2006). The size of habitats, spatial arrangement of habitats, and habitat connectivity influences natural enemy species movement in the landscape (Bianchi, Goedhart and Baveco, 2008; Haan, Zhang and Landis, 2020). Furthermore, dispersal capacity and adaptive ability of natural enemies influences the efficacy of biological control (Tscharntke et al., 2007; Bale, van Lenteren and Bigler, 2008; Bianchi, Goedhart and Baveco, 2008), as does composition of the predator community (Tscharntke et al., 2007). Biocontrol rates are thought to be higher in landscapes consisting of smaller patches (Roubos, Rodriguez-Saona and Isaacs, 2014) because a shorter distance between source habitats and crop fields allows natural enemies to (re-)colonize crop fields and reduce pest populations faster (Bianchi and van der Werf, 2003; Bianchi, Booij and Tscharntke, 2006; Albrecht et al., 2020; Larsen and Noack, 2020).

Nowadays, agricultural landscapes range from structurally complex, with much non-crop habitat, and structurally simple, in which agricultural fields have increased in size and are 
dominated by a few crops (Tscharntke et al., 2007). Especially in structurally simple landscapes, low background populations of natural enemies could lead to low biological control levels. This, in turn, could lead to an increase in insect pest pressure, decreased biological control rates, resulting in an increased need for insecticides (Meehan et al., 2011, 2013; Letourneau, 2012). Consequently, farmers' decisions on pest management are also influenced by the surrounding landscape.

\section{Social and technological characteristics of lock-in}

Biological control is based on preventative measures to control pests, as opposed to curative measures taken with insecticides, and viable populations of natural enemies need to be maintained at scales larger than the field (Ricci et al., 2019). Consequently, participation of neighbouring farmers is needed to successfully implement biological pest control, e.g. through collective action (Parsa et al., 2014). To implement an approach of managing pests through agricultural practices that enhance the abundance or activity of their natural enemies requires cooperation and coordination among farmers (Stallman and James, 2015; Chaplin-Kramer et al., 2019). Consequently, reducing pesticide dependency necessitates a consensus among all levels in the agricultural system, including farmers communities, agroindustry, governments, and consumers (Dyer, 2014; Sponsler et al., 2019).

Research and development of chemical pest control receives more investments than research into biological pest control agents (Cowan and Gunby, 1996). Between 1945 and 1960 the focus on - and investment in - chemical pest control accelerated because of its relatively low cost and high effectiveness on maximising yields (Cowan and Gunby, 1996). A stronger focus on chemical pest control resulted in more funds and developments focused on chemical pest control, hindering the advancement of alternative pest control methods. Pest control development has become inflexible in a way that alternatives are hardly offered and adopted (Cowan and Gunby, 1996).

Establishing a transition from chemical to biological pest control requires a change in traditional practices and approaches, established infrastructures, and way of thinking (Dyer, 2014). Adopting a new way of thinking and implementing a new pest management system requires courage, risk-taking and participation of all stakeholders involved, i.e. policy makers, farmer communities, consumers, industry, and research institutions (Rodriguez et al., 2009; Dyer, 2014; Parsa et al., 2014). However, changes in pest management practices could also include large costs due to new work practices, skills and patterns of behaviour, network coordination, and technological interdependencies (Perkins, 2003). The difficulty of changing practices is shown in many countries (including the Netherlands) where farm and pest management structures that were established in the 1960s and 1970s have not significantly changed in their organization (Savary et al., 2012; Westerink et al., 2019). 


\section{PEST MANAGEMENT IN THE NETHERLANDS}

Agricultural production in the Netherlands is highly dependent on external inputs, like pesticides. Pesticide use in the Netherlands is relatively high compared to average pesticide use in the world ( $8.79 \mathrm{~kg} /$ ha versus $2.63 \mathrm{~kg} / \mathrm{ha}$ in 2018) (FAOSTAT, 2020). Dutch agriculture consists of intensive specialized production systems with narrow rotations of around four crops. Main crops include high-input crops such as flower bulbs and (seed) potatoes. Additionally, crop yields are relatively high, thus increasing potential damage risk by pests and consequential loss of income (Oskam et al., 1992). Moreover, many crops produced in the Netherlands are exported and subject to international phytosanitary regulations to reduce the risk of introducing pests through international trade (Eschen et al., 2015). In $2016,88 \%$ of total agricultural pesticide use (5.7 million kg active ingredients) was applied to eleven commodity crops ${ }^{1}$. Potatoes received most pesticides $(40 \%$ of total agricultural use), whereas lily bulbs were the most intensively sprayed in terms of usage per hectare (Statline, 2019). This combination of specialized intensive farming, and a substantial export market of non-food products, has led to high per hectare usage of pesticides, increasing the dependency of Dutch agriculture on chemical pest control (Zadoks, 1991; de Jong, de Snoo and van de Zande, 2008).

Since 2011, European pesticide policies include mandatory National Action Plans to reduce risks and impacts of pesticide use on human health and the environment (Directive No. 2009/128/EC) (Möhring et al., 2020). Many Member States, including the Netherlands, have established comprehensive systems for the training and certification of operators, and a range of measures for water protection and the safe handling and storage of pesticides (EC, 2020). While Dutch policies have been focused on reducing environmental impacts of pesticides used in agriculture, quantities of pesticides sold and used remain relatively constant (Fig. 1.3). Furthermore, pesticide residues in groundwater and surface water are still a major concern in drinking water sources, exceeding water quality standards according to the Water Framework Directive (Sjerps et al., 2019). Under the recent 'Farm to Fork' and 'Biodiversity strategies' of the European Union, actions need to be taken by Member States to reduce the use and risk of chemical pesticides by $50 \%$ by 2030 and reduce the use of the more hazardous pesticides by $50 \%$ by 2030 (EC, 2020).

\footnotetext{
1 Ware potatoes, starch potatoes, seed potatoes, lily bulbs, onions, tulips, pears, sugar beets, apples, corn, winter wheat (Statline, 2019).
} 


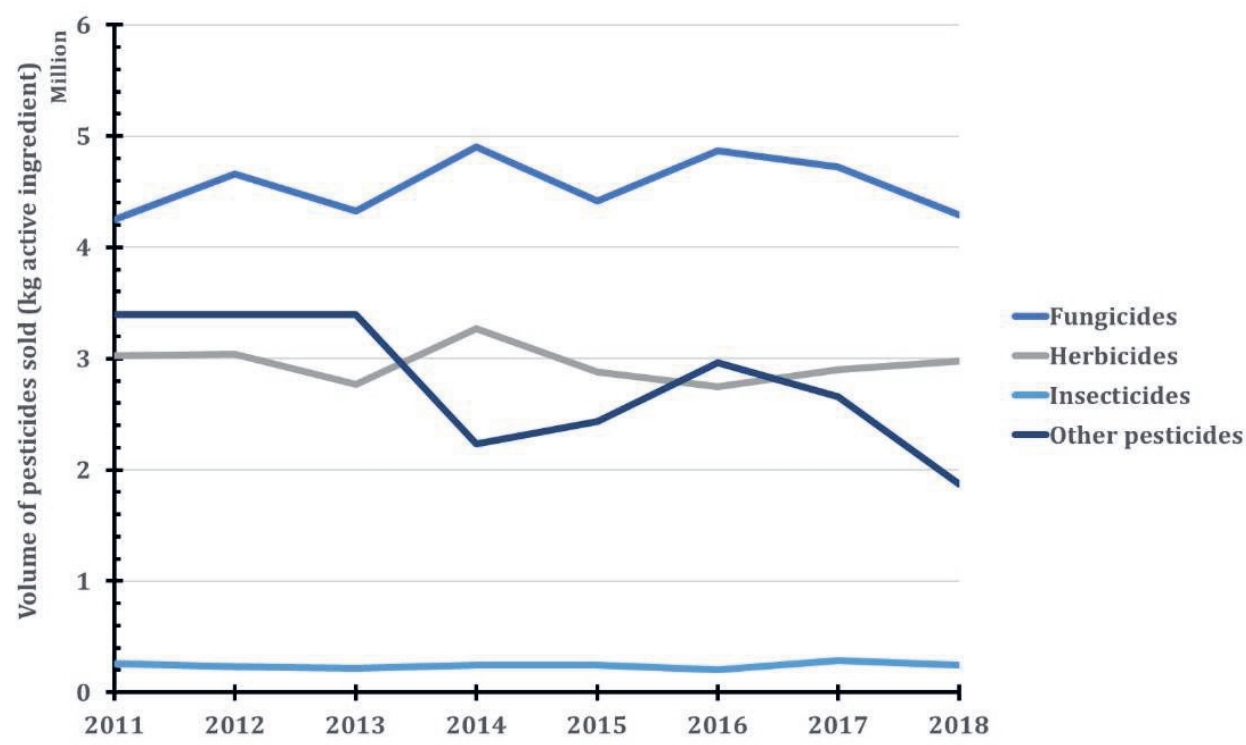

Figure 1.3: Annual volume of pesticides sold in the Netherlands by type of pesticide. Fungicides include fungicides and bactericides; herbicides include herbicides, haulm destructors, and moss killers; insecticides include insecticides and acaricides; and 'Other pesticides' are molluscicides, plant growth regulators, and other plant protection products like mineral oils. Source: Eurostat (2020).

\section{RATIONALE OF THE THESIS}

Pesticide use and its effects on the environment and human health have received much attention in research, policy, and society, but these issues have been approached in a compartmentalized and intradisciplinary way. That is, a comprehensive assessment of both social and ecological lock-in mechanisms of pest management has received little consideration. There are complex interactions between pests, natural enemies, the landscape, and farmers' decision making in pest management, and lock-in mechanisms and path dependence play an important role in pesticide dependency. Furthermore, there is a lack of understanding of which factors influence pesticide decision making in the context of a potential transition from chemical pest control to more ecologically-based pest management.

This $\mathrm{PhD}$ project aims to provide critically needed insight in the system dynamics underlying farmers' pest control practices, and to elucidate key principles governing a transition towards sustainable pest management. Using a multidisciplinary approach, I explored socio-ecological features of pesticide dependency and aimed to establish under which set of conditions there is potential to tip the pest control system to an insecticideindependent state. As such, I addressed the following objectives: 
1. To assess lock-in mechanisms and drivers of pesticide dependency (Chapter 2).

2. To describe and quantify the effects of insecticide use on beneficial arthropods within different landscape contexts (Chapter 3).

3. To describe and quantify the effects of insecticide use on biocontrol services provided by natural enemies within different landscape contexts (Chapter 4).

4. To identify drivers and barriers of farmers' intentions to decrease pesticide use (Chapter 5).

\section{METHODOLOGY AND THESIS OUTLINE}

I used a multidisciplinary approach to examine the different lock-in mechanisms related to pesticide dependency and develop insight into factors that could drive the transition from chemical to biological pest control. Related to objective one, I conducted a systematic literature review on historical cases describing the pesticide treadmill in Chapter 2. I presented a conceptual framework of the pesticide treadmill encompassing four domains and generated an overview of the evidence for pesticide treadmills. I analyzed historical case studies with reference to this framework and compared this with current patterns in neonicotinoid use. The review provided insight in the role of possible drivers of the pesticide treadmill and related lock-in mechanisms.

For objective two and three I undertook an empirical landscape study to assess the impacts of local and landscape-wide pesticide use on beneficial arthropods and biocontrol services. The relationship between beneficial arthropods, biocontrol and the intensity of insecticide use was investigated in a 2-year experiment at the landscape scale. Thirty-eight landscapes (circles of $1 \mathrm{~km}$ radius) were selected to represent a range from simple to complex landscapes as indicated with the proportion of semi-natural habitat. In the center of each landscape, arthropod abundances in field margins were assessed by sweep netting and sticky traps, while biocontrol services were assessed measuring predation and parasitism of eggs of the cabbage moth (Mamestra brassicae) on potted cabbage plants. M. brassicae is a widespread and abundant butterfly feeding on wild crucifers which are ubiquitous in Dutch landscapes. It also feeds on cultivated cabbage. M. brassicae is parasitized by parasitoids and predated by a range of predators. The $M$. brassicae eggs were retrieved from the sentinel plants after two days to determine parasitism and predation. In Chapter 3 I assessed how the abundance of predators, parasitoids, and pollinators is influenced by localand landscape-wide insecticide use across landscapes that span a range in proportion of semi-natural habitat. I further investigated in Chapter 4 how insecticide use in crops affected biological control services in nearby semi-natural landscape elements.

Related to objective four, I conducted an online survey among Dutch farmers to identify barriers towards farming systems with reduced environmental impacts. I used the 
Reasoned Action Approach to find what beliefs pose barriers and drive the motivation of farmers to decrease their pesticide use. Structural equational modelling was conducted to obtain the most important socio-psychological components of behaviour and underlying beliefs that were driving farmers' intentions. The results are discussed in Chapter $\mathbf{5 .}$

In Chapter 6 I integrate the findings of the previous chapters and synthesize what socioecological patterns and challenges are caused by insects and insecticides in agricultural landscapes. In this final chapter I make recommendations based on the findings in this project and propose future research directions. 



\section{CHAPTER 2}

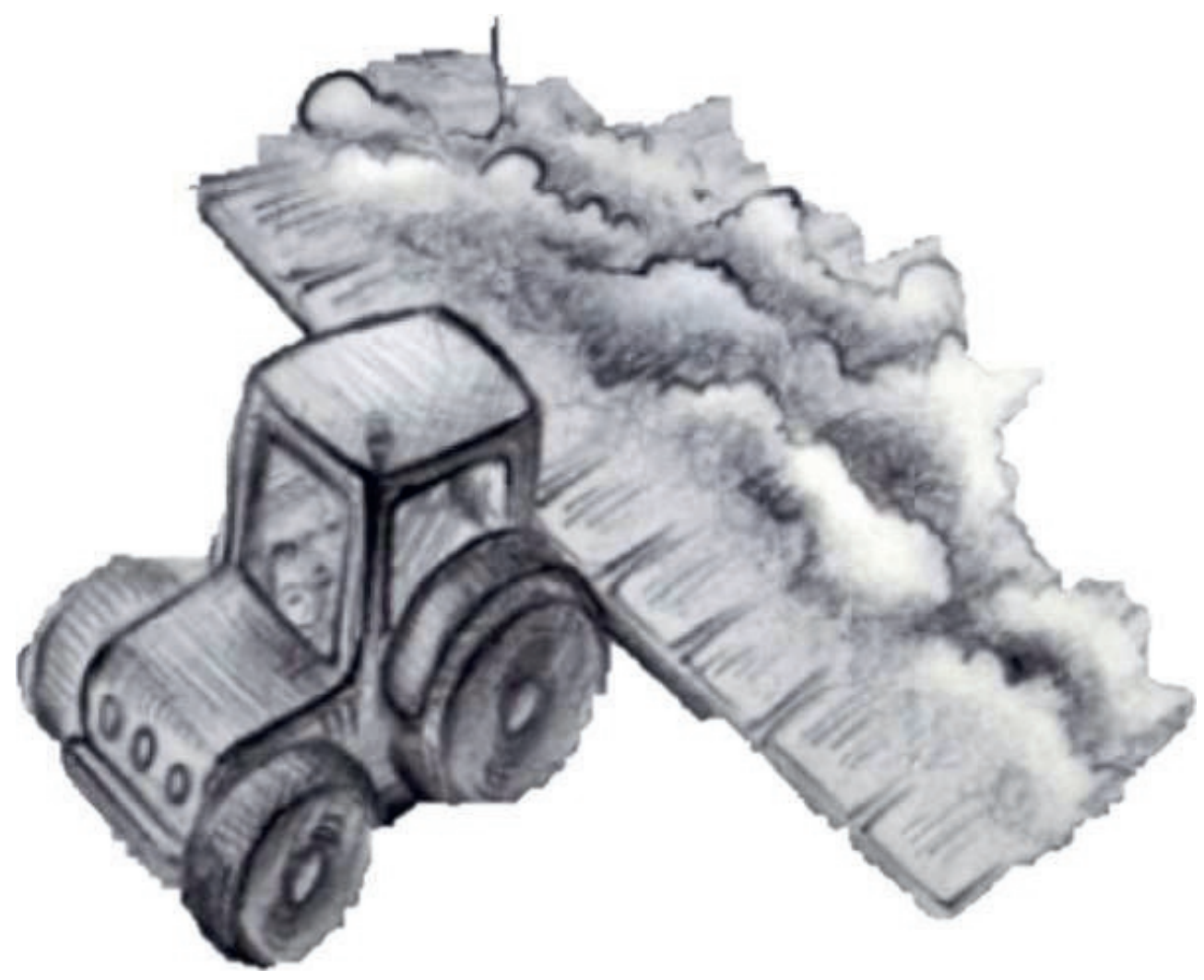




\section{NEONICOTINOIDS IN GLOBAL AGRICULTURE: EVIDENCE FOR A NEW PESTICIDE TREADMILL?}

L. BAKKeR, W. van DER WeRf, P. TItTONELL, K.A.G. WyCKhUYS, AND F.J.J.A. BIANCHI

\section{PUBLISHED AS:}

BAKKER, L., VAN DER Werf, W., TItTONELL, P., WYCKhUYS, K.A.G., \& BianCHI, F.J.J.A. (2020). NEONICOTINOIDS IN GLOBAL AGRICULTURE: EVIDENCE FOR A NEW PESTICIDE TREADMILL? ECOLOGY AND SOCIETY, 25(3), ART26. HTTPS://DOI.ORG/10.5751/ES-11814250326 


\begin{abstract}
Overreliance on synthetic insecticides in global agriculture is the outcome of a 'pesticide treadmill', in which insecticide-induced pest resistance development and the depletion of beneficial insect populations aggravate farmers' pesticide dependencies. Examples of the pesticide treadmill have been witnessed repeatedly over the past seven decades, prompting the question whether the rapid uptake and usage patterns of neonicotinoid insecticides and their associated environmental impact are in accordance with this recurrent phenomenon. We hypothesize a conceptual framework in which treadmills are enforced by enabling or disabling drivers within four domains: pest management decisions at the farm level, characteristics of farming landscapes, science \& technology, and societal demands. These drivers then tend to create a self-enforcing pesticide 'lock-in'. We then analyse several post1950s historical case studies with reference to this framework, e.g., those involving sprays of the highly-hazardous DDT and methyl-parathion, in which the pesticide treadmill was initiated, sustained and broken, and compare this with current patterns in neonicotinoid use. Historical case studies further illustrate how treadmills occur in three phases in which (i) a limited number of insecticides are routinely used, (ii) resistance development of pests results in the increased crop injury, prompting increased frequency of applications with a wider range of products, (iii) breaking out of the pesticide 'lock-in' by policy change and adoption of alternative technologies that lowered chemical inputs and improved agroecosystem functioning. The analysis shows similarities as well as differences between neonicotinoid usage patterns and historic pesticide treadmills and provides guidance on how to effectively avoid or dismantle pesticide treadmills in global agriculture.
\end{abstract}

Keywords: agrochemical pollution; biodiversity loss; farmer decision-making; global change; insecticide dependency; lock-in; neonicotinoids; pest management; pesticide treadmill; technological change 
Over the past years, there has been increasing concern over the broad environmental risks of neonicotinoid insecticides (EASAC, 2015; Giorio et al., 2017; Pisa et al., 2017; Goulson, 2018). Since their introduction in the 1990s, neonicotinoids have rapidly diffused because of their systemic mode of action (MoA), high efficiency at low doses and their presumed low toxicity to vertebrates including humans (but see Cimino et al.. 2017, Berheim et al.. 2019). Today, neonicotinoids are the most widely used insecticides in the world, being employed in more than 120 countries and 450 crops (Douglas and Tooker 2015, Simon-Delso et al.. 2015). Neonicotinoids are increasingly used in a prophylactic fashion (e.g., seed treatments), thus intended to prevent build-up of pest populations. However, their widespread and unguided usage combined with a myriad of non-target effects has prompted environmental concerns (Hallmann et al.. 2014, Zimmermann and Stout 2016, Krupke et al.. 2017, CalvoAgudo et al.. 2019), and has sparked calls for an all-out suspension of prophylactic insecticide usage and more sustainable pest management strategies (Foley et al., 2011; Ge et al., 2016; Milner and Boyd, 2017).

While efforts to promote ecologically-based pest management, including Integrated Pest Management (IPM), have been successful in certain cases, such as protected cultivation, US cotton, Brazilian sugarcane or Mexico's mango (Naranjo and Ellsworth, 2009; van Lenteren et al., 2018), they have fallen short of expectations in a large number of broad-acre field crops and vegetable systems (Orr, 2003; Zalucki, Adamson and Furlong, 2009; Parsa et al., 2014). The overall net result has been an increase in global pesticide use (Popp, Peto and Nagy, 2013) and a rise in their total toxicity loading in, e.g., US agriculture (DiBartolomeis et al., 2019).

The vicious cycle by which resistance development to insecticides and decline of natural enemies of pests due to insecticides increases farmers' usage of and dependence on chemical-based pest management has been referred to as the 'pesticide treadmill' (DeBach, 1951; Hansen, 1988; Turnbull and Hector, 2010), and is an example of what is broadly called a 'lock-in' in social sciences. A system is 'locked-in' in a certain state if self-enforcing mechanisms in that state perpetuate the dominant behaviours, making it hard to change to other, potentially more desirable, states (Liebowitz and Margolis, 1995; Cowan and Hultén, 1996; Kline, 2001; Perkins, 2003; Kallis and Norgaard, 2010). In agriculture, 'lock-ins' have historically been examined in a reductionist manner by focusing on parts of the system, e.g., ecological interactions, economics or technology adoption (Cowan and Gunby, 1996; Vanloqueren and Baret, 2009; Magrini et al., 2016; Flor et al., 2019). Here, we argue that dynamic changes in these domains are inextricably linked, and that the 'lock-in' in the technology and agro-ecological domains cannot be understood without consideration of other relevant domains.

The rapid uptake of neonicotinoid insecticides and the associated environmental impacts prompt the question whether today's neonicotinoid use patterns are in accordance with the 
pesticide treadmill phenomenon. To address this question, we first propose a theoretical framework of the pesticide treadmill, considering four conceptual, interlocking domains within a socio-ecological system. Second, to test this framework, we examine historic case studies of pesticide treadmills to identify potential enabling and disabling drivers. Third, we describe to what extent dynamics in global neonicotinoid use are consistent with the observed characteristics of historic cases. Finally, we discuss pathways to escape from the pesticide treadmill and implications of our findings for current pest management.

\section{FRAMEWORK OF THE PESTICIDE TREADMILL}

The pesticide treadmill is characterized by overuse of pesticides with frequent applications, high dosages and the use of a limited range of active ingredients or MoA's, ultimately decreasing pesticide effectiveness through, for example, resistance development (Hansen, 1988; Thrupp, 1990; Deguine, Ferron and Russell, 2008; Turnbull and Hector, 2010; Ekström and Ekbom, 2011; Jørgensen et al., 2018). However, the pesticide treadmill is also typified by other ecological and social features with complex socio-ecological interdependencies. An adequate understanding of these interdependencies requires insight in the interconnections within the socio-ecological system, as lock-in situations in the ecological system are enforced by drivers from the social system (Yletyinen et al., 2019). Conversely, to devise lasting resolutions and pursue long-term change (e.g., from a chemicaldependent towards an ecologically-based pest management), a so-called 'total systems approach' is needed (Lewis et al., 1997) in which the complexities of underlying farm-level decisions and barriers for change are duly taken into account (Schut et al., 2014; Wyckhuys et al., 2018; Yletyinen et al., 2019). We hypothesize that there are four main domains that encompass feedback cycles which are embedded in the complex social-ecological system of global agriculture (Fig. 2.1). These domains in the agri-food system are interrelated and can possibly enforce or disable the pesticide treadmill. In following section, we discuss these domains and associated drivers.

\section{Farming}

The first domain, farming, is centred around on-farm pest management decision-making. Modern farming systems are often typified by large-scale, genetically-uniform monocultures with high input dependence and superior yields. In such systems, pest outbreaks are regularly facilitated by chemical fertilizer use, narrow rotations and nearby sources for pest colonization (Brust and King, 1994; Settle et al., 1996; Meehan et al., 2011). Also, the ephemeral nature, low plant diversity and intense disturbance regime of many cropping systems constrain the potential of resident natural enemies to exert top-down control and contribute sufficiently to pest suppression (Wiedenmann and Smith, 1997; Letourneau, Bothwell Allen and Stireman, 2012; Lundgren and Fausti, 2015). These patterns are aggravated through an overuse of synthetic pesticides, which are often harmful for natural enemies (Hansen, 1988; Settle et al., 1996), trigger pest resistance development (SimonDelso et al., 2015), and induce secondary pest outbreaks (Gross and Rosenheim, 2011; Hill, 
Macfadyen and Nash, 2017). In turn, weakened biological control services further enforce farmers' dependency on insecticides (DeBach, 1951; Hansen, 1988; Turnbull and Hector, 2010).

\section{Agro-landscapes}

Farm-level decisions on crop choice and management style play out at the landscape scale (Schellhorn et al., 2008), with agro-landscape simplification and area-wide disturbance regimes compromising life support functions for natural enemies (Meehan et al., 2011; Karp et al., 2018). Agriculture-dominated landscapes tend to harbour simplified, species-poor natural enemy communities (Tscharntke et al., 2007), while more diverse settings tend to benefit from a broader variety of natural enemies and enhanced pest suppression (Bianchi et al., 2006, Schellhorn et al., 2014, Liu et al.. 2016, but see Karp et al., 2018). Conversion of (semi-)natural habitats into intensively managed farmland deteriorates resource provision levels for natural enemies, thus hampering their ability to colonize crops and impact pest populations (Meehan et al., 2011, 2013; Letourneau, 2012; Bianchi, Ives and Schellhorn, 2013). Also, certain pest management strategies are most effective when neighbouring farmers, who operate under similar bio-physical and socio-economic contexts, adopt the same strategy. This could foster exchange of machinery and knowledge, increase cost effectiveness and reduce costs, also referred to as 'agglomeration economies' (Liebowitz and Margolis, 1995; Bowman and Zilberman, 2013; Parsa et al., 2014; Bell, Zhang and Nou, 2016). Yet, farmers are no passive recipients of technologies. The potential of innovation and active experimentation by individual farmers should not be downplayed, and compelling examples exist of farmers developing effective context-specific integrated pest management strategies (Van den Berg \& Jiggins, 2007; Wyckhuys et al., 2019)

\section{Science \& technology}

The ultimate fate of any (agricultural) innovation depends on coordination, pay-offs and user perceptions, as well as on the investments made by end-users and myriad actors in both the private and public sector (Feder, Just and Zilberman, 1985; Schut et al., 2014; Juma, 2016). Subsequently, preference for a given pest management technology and ensuing pest problems trigger further investments in research and development to enable technological improvement and sustain user uptake (Liebowitz and Margolis, 1995; Cowan and Gunby, 1996; Pardey, Alston and Ruttan, 2010). Such is often an incremental process that builds upon existing dominant technologies (Perkins, 2003), and which is guided by vested interests, e.g., of owners of incumbent 'legacy'. technologies (Juma, 2016). Central actors in the pesticide treadmill are the agrochemical industry, farmers and the agro-advisory sector. While the commercialisation and privatisation of knowledge can slow down innovation diffusion (Labarthe, 2009; Lamine et al., 2010; Lamprinopoulou et al., 2014), this can also create 'path dependencies', with farmers that have invested in particular types of equipment, knowledge and skills becoming less likely to adopt agro-ecological innovations (Ruttan, 1996; Wilson and Tisdell, 2001; Vanloqueren and Baret, 2009). These 
dependencies are often exacerbated for large-scale farmers who are prone to rely on riskreducing technologies such as prophylactic seed treatment. The substitution of public advisory services by private-sector actors, e.g., commercial agro-consultancy firms, can reinforce some of these path dependencies (Lamine et al., 2010; Lamprinopoulou et al., 2014).

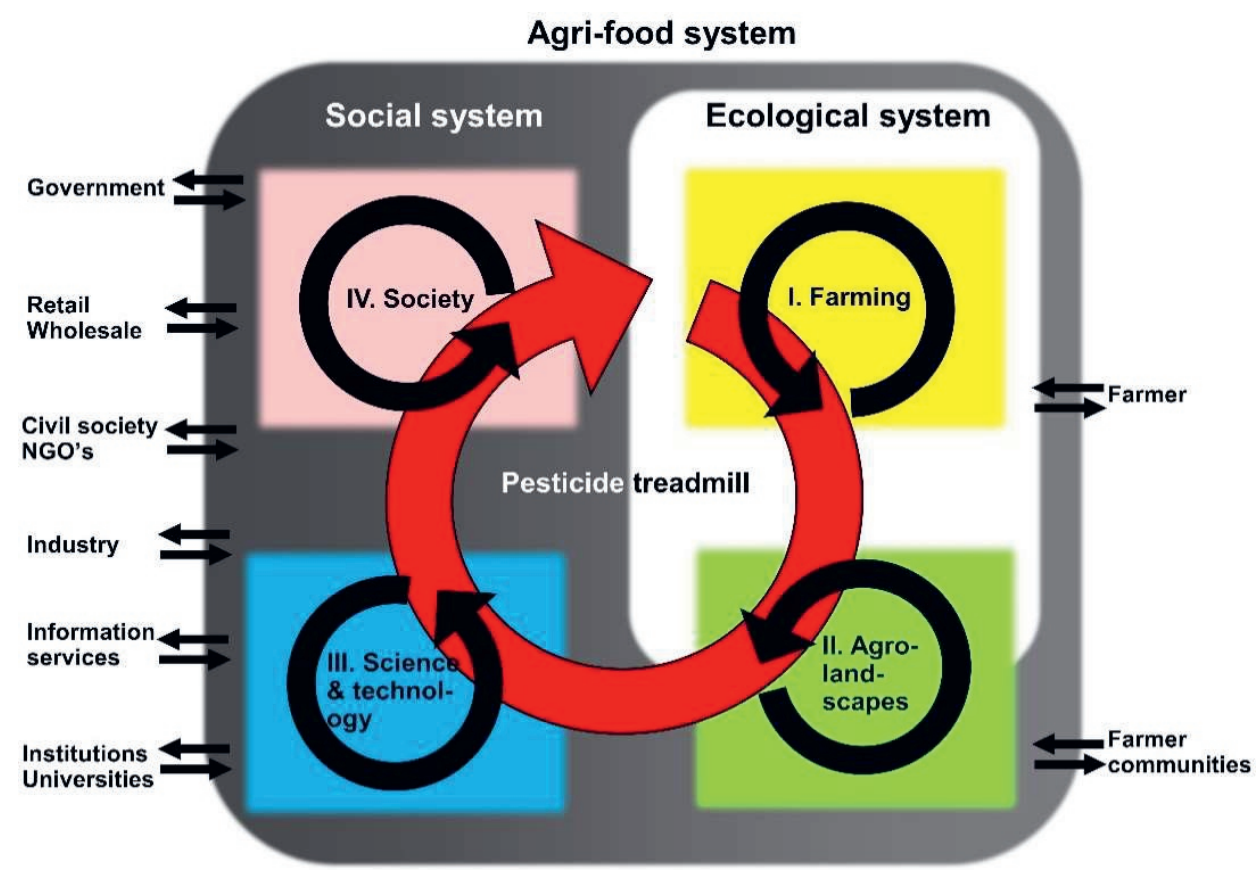

Figure 2.1: A conceptual framework of the 'pesticide treadmill'. Drivers of 'pesticide lock-in' exist within the ecological or social sub-systems of the global agri-food system and can be located in the following domains: I: farming (yellow), II: agro-landscapes (green), III: science \& technology (blue), and IV: society (pink). Each domain contains internal positive feedbacks (black cycles), but also interacts externally with other mechanisms and drivers of the pesticide treadmill (red cycle), enforcing the lock-in situation of pesticide use. Each domain is embedded in either the social (grey) or ecological system (white), except for agro-landscapes, which is linked to both. Influential actors are depicted on the sides and interactions with the agri-food system are indicated by black arrows. Actors can be of influence in different domains, and can play an enforcing or disabling role with respect to the 'pesticide lock-in'.

Breaking the cycle is particularly difficult, as agro-industry has its own interest to maximize pesticide sales (Thrupp, 1988; van den Bosch, 1989), favouring technologies that capitalize on its in-house expertise and knowledge-base, such as genetically modified crops, seed coatings or agro-chemistry (Popp, Peto and Nagy, 2013). Diverging innovations in pest management are routinely perceived as threats by agrochemical industry actors, triggering 
active lobbying, distorted public sensitization and an active deployment of roadblocks (van den Bosch, 1989; Lamine et al., 2010; Juma, 2016).

\section{Society}

Government, retail, wholesalers, consumers and civil society organizations are important actors in the societal domain. Governments regulate the admission of pesticides and may influence farmers' decision-making by imposing taxes or providing incentives, such as subsidies for greening measures or environmental schemes (Thrupp, 1988; Boyd, 2018). Regulatory bodies, such as the Environmental Protection Agency in the USA (US-EPA) and the European Food Safety Authority in Europe, evaluate pesticide safety and advise governments on risks. Though these organizations solicit input from scientists, industry and other stakeholders, their assessments are not flawless (Brühl and Zaller, 2019). On the other hand, retail sets standards for quality and physical characteristics, e.g., cosmetic appearance of harvested produce (Pimentel et al., 1977), and pesticides are widely used by farmers to meet these standards (Norgaard, 1976; Lamine et al., 2010; Lamine, 2011; Morrissey, Mirosa and Abbott, 2014). Food retailers can encourage farmers to change their production practices, for example by issuing production mandates that include judicious use of pesticides by farmers (Macfadyen et al., 2015). Conversely, the presence of pesticide residues in agricultural produce and the associated -often unknown- risks for human health can generate demand and incentivisation for pesticide-restrictive policies and pesticide-free production schemes (Boccaletti and Nardella, 2000; Cimino et al., 2017). 


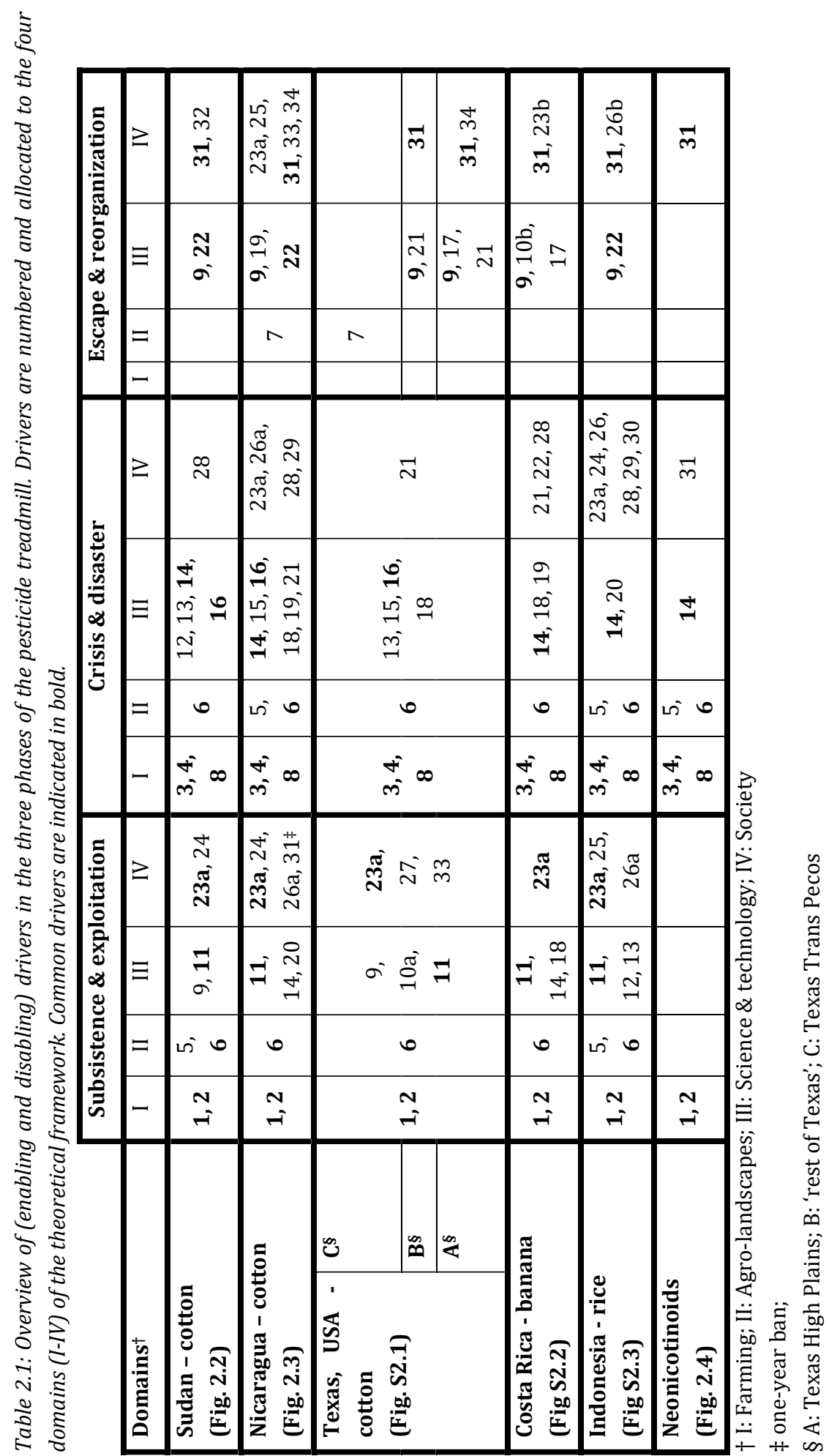




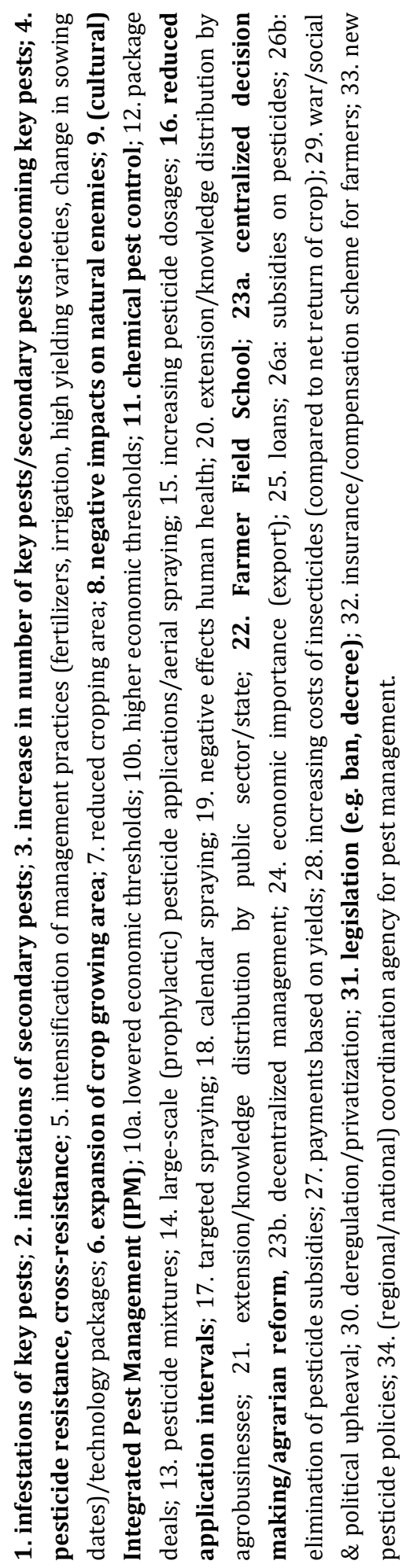




\section{LESSONS FROM THE PAST: LOCK-IN AND ESCAPE FROM THE PESTICIDE TREADMILL}

We hypothesize that the pesticide treadmill involves a complexity of interacting enabling and disabling factors, which can be found in all four domains described above. To test this hypothesis, we selected historic case studies that met the following criteria: (i) availability of data on pesticide use in a cropping system of 30 years or more, (ii) availability of information on drivers of pesticide use, and (iii) documentation of lock-in and escape from the pesticide treadmill. We found five case studies that met these criteria: cotton production in Sudan, cotton production in Nicaragua, cotton production in Texas, USA, banana production in Costa Rica and rice production in Indonesia.

To identify which drivers governed the lock-in and escape of the pesticide treadmill, we further divided the pesticide treadmill into three phases (Doutt and Smith, 1971): subsistence \& exploitation, crisis \& disaster, and escape \& reorganization (Table 2.1). The 'subsistence \& exploitation' phase is characterized by an expanding crop production, but with still limited reliance on pesticides. Pest control measures are generally basic and limited in scope. The 'crisis \& disaster' phase is often triggered by the development of resistance against pesticides, and often results in soaring pest problems, increasing pesticide applications and decreased profitability of crop production. The 'escape \& reorganization' phase is initiated by the notion that further increases in pesticide use will not solve the crises and alternative pest management approaches are explored (Doutt and Smith, 1971; Eveleens, 1983; Castle, 1999). The Sudan and Nicaragua case studies are described below, while the case studies of the USA, Costa Rica and Indonesia are given in the Supplementary Materials.

\section{Case study Sudan}

\section{Subsistence \& exploitation}

During the 1950s, the Sudan Plantation Syndicate centrally managed a major irrigation project in the state of Gezira and effectively developed cotton production during the 1950s (Eveleens, 1983; Castle, 1999). The cotton growing area increased from 90,000 ha in 1945 to 250,000 ha in 1975 , and only a limited number of cotton varieties were used. Cotton export was good for 71\% of Sudan's national export in 1956 (Castle, 1999). Crop management was the responsibility of tenants, but crop protection decisions were made by the central administration of the Gezira scheme. Cotton whitefly (Bemisia tabaci), a secondary pest, was controlled successfully with a combination of cultural and sanitary practices, and the cotton jassid (Jacobiasca lybica) was managed with broad-spectrum pesticides. While there was a rapid expansion of the total cotton area treated with the organochlorine DDT to $60 \%$ in 1950s, the application frequency was still limited with one early season application per season until the 1960s (Fig. 2.2) (Eveleens, 1983; Castle, 1999). 


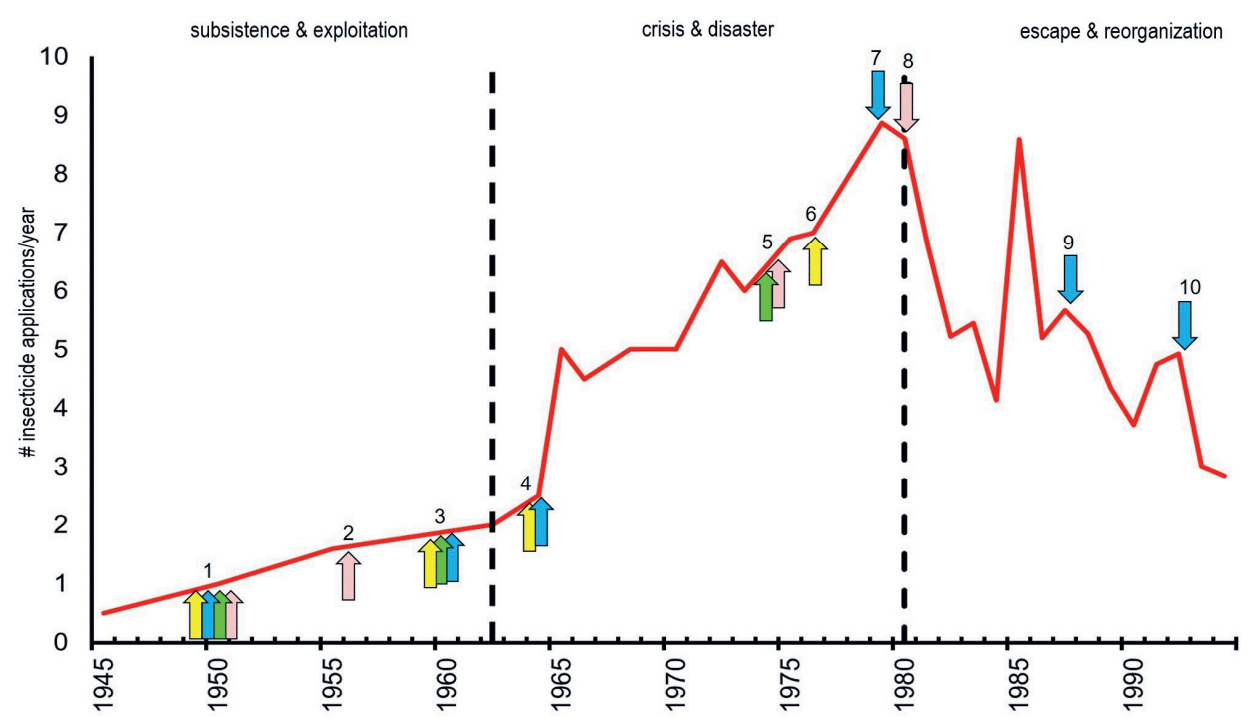

Figure 2.2: Timeline representing enabling (upward arrows) and disabling (downward arrows) drivers of pesticide use in cotton production in Sudan from 1945-1995. The graph indicates the number of insecticide applications per year (Eveleens 1983, Bashir et al. 2003). Dashed lines indicate approximate times of the transition to a new phase of the treadmill. Colours referring to domains (I-IV) in the framework: I: farming (yellow), II: agro-landscapes (green), III: science \& technology (blue), and IV: society (pink). Numbers \& arrows indicate drivers of the treadmill; 1. pest outbreaks (yellow), cropping intensification (green), early season sprays (blue), centralized crop protection decision making (pink); 2. cotton export 71\% of national export; 3. pesticide resistance \& secondary pest resurgence (yellow), expansion of cotton growth area (green), pesticide mixtures \& pesticides with different MoAs (blue); 4. secondary pest outbreaks (yellow), package deals (blue); 5. maximum cotton acreage (green), increasing crop protection costs (pink); 6. pesticide resistance to organophosphates; 7. start IPM program; 8. ban on DDT \& package deals; 9. development of biological control strategies, and large-scale demonstrations that fewer pesticides could be used; 10. economic threshold levels for four major cotton pest species were revised, improvement of the role of biological control agents in cotton crop protection, implementation of food crops in the cotton rotation.

\section{Crisis \& disaster}

Pest problems emerged with DDT applications becoming ineffective in resolving $J$. lybica outbreaks. Concurrently, B. tabaci reached the status of key pest due to negative effects on natural enemies by broad-spectrum pesticides (Eveleens, 1983; Castle, 1999). This increasing pest pressure resulted in more frequent and higher dose applications of organochlorine insecticides. In the 1970s pest problems aggravated due to insecticide resistance, pest resurgence and the appearance of several secondary pests, such as B. tabaci and cotton bollworm (Helicoverpa armigera), triggering more applications with a wider spectrum of insecticides (including DDT, endrin, dimethoate) (Eveleens, 1983; Stam, 
Abdelrahman and Munir, 1994; Castle, 1999; Bashir, Elamin and Elamin, 2003). Contractual 'package deal' agreements were made between cotton growers and agrochemical companies to ensure the control of H. armigera, whereby the agrochemical companies were responsible for all pest control operations and guaranteed a minimum yield to farmers. While cotton acreage under these package deals quickly increased from 30,000 ha in 1973 to 80,000 ha in 1978 , cotton pests continued to reach outbreak levels and broad-spectrum pesticides, such as monocrotophos, were applied using aerial spraying. While this approach was initially effective against $H$. armigera, whitefly populations were unaffected and caused severe crop damage. Over time, pesticide application frequency increased from an average of one spray per season in 1960-1961 to eight sprays per season in 1980-1981 (Eveleens, 1983).

\section{Escape \& reorganization}

By the mid-1970s cotton production was no longer economically viable, due to emerging outbreaks of pesticide-resistant whitefly populations. This led to a ministerial decree issuing a ban on package deals and (mixtures containing) DDT (Eveleens, 1983; Castle, 1999). The immediate result was a shift in insecticide classes towards endosulfan, newly-registered pyrethroids and aldicarb (Eveleens, 1983). Concurrently, IPM programs were developed based on biological control of $H$. armigera and higher economic damage threshold levels, permitting a reduction in pesticide application frequency from eight to three per season without yield reduction (Bashir, Elamin and Elamin, 2003). While farmer training and education were central to reach this achievement, another key success factor was the launch of innovative insurance schemes for early IPM adopters - thus compensating farmers for pest-induced yield loss. This insurance reduced farmers' uncertainty and associated riskaversive behaviour, and enabled uptake of IPM packages that involved improved water management, insect-resistant varieties, and biological control (Stam, Abdelrahman and Munir, 1994; Bashir, Elamin and Elamin, 2003).

In summary, in the case of Sudan we identified drivers from all four domains in the conceptual framework (Table 2.1; Fig. 2.1). Drivers from the 'farming' and 'agro-landscapes' domain were most prominent in the 'subsistence \& exploitation' phase, while drivers of the 'science \& technology' and 'society' domain were dominant in the 'escape \& reorganization' phase (Table 2.1). While pest problems emerged with the expansion of cotton production and intensive management practices, Castle (1999) argues that the centralized decision making of the Gezira scheme contributed to a range of socio-economic problems influencing the agricultural system, such that tenant farmers cared less about cotton production. Ultimately, the crises were resolved by deploying IPM measures (Eveleens, 1983; Stam, Abdelrahman and Munir, 1994; Castle, 1999; Bashir, Elamin and Elamin, 2003). Several economic, social and political drivers contributed to the IPM success, with a central element being a compensation scheme for yield reduction for early IPM adopters, reducing farmers' uncertainty and influencing risk perception (Table 2.1) (Bashir, Elamin and Elamin, 2003). 


\section{Case study Nicaragua}

\section{Subsistence \& exploitation}

Before the 1950s, 3,000 ha of cotton was grown in western Nicaragua and the boll weevil (Anthonomus grandis) was the main pest. Boll weevil outbreaks were combatted with largescale applications of DDT and methyl-parathion (Fig. 2.3). During the 1960s, cotton acreage expanded to 150,000 ha and cotton became an engine of growth of the Nicaraguan national economy. Not only did the national government provide direct subsidies to facilitate farmers' purchasing of pesticides (Vandermeer, 1991; Murray, 1994), chemical producers enjoyed free rein, as there was a lack of public-sector infrastructure and knowledge distribution of cultural and non-chemical pest control practices (Murray, 1994). Even though human poisonings and deaths urged the government to ban methyl-parathion in 1953, cotton grower associations and related lobby groups forced the ban to be lifted in the same year (Swezey, Murray and Daxl, 1986).

\section{Crisis \& disaster}

By the mid-1960s the area of cotton production exceeded 150,000 ha ( $40 \%$ of the cultivated area in the whole of Nicaragua) and further increased to 175,000 ha in 1973. Yet, from 1965 onward, cotton yields dropped and pesticide-inflicted ecological disruption became evident with an emergence of several secondary pests, including the American cotton bollworm (Helicoverpa zea), armyworm (Spodoptera sunia) and B. tabaci (Swezey, Murray and Daxl, 1986). To safeguard yields from pest attacks, pesticide usage rates increased from five per year in the mid-1950s to 28 by the late 1960 s, primarily through calendar-based application schemes devised by the agro-chemical industry. In addition, farmers that cultivated cotton depended heavily on bank loans, which were directly tied to crop yields. Loan contracts prescribed the type of chemicals to be used and the number of applications to obtain target yields (Murray, 1994). Yet, average yields fell by 15-30\%, and insecticide resistance and the emergence of secondary pests became more prevalent (Swezey, Murray and Daxl, 1986).

\section{Escape}

In 1966 a national cotton commission was established to mitigate the increasing cotton pest problems and a cotton research station was opened in 1967. These initiatives coincided with an initiative of the Food and Agriculture Organization (FAO) to develop an IPM program and reorient pest control practices in Nicaragua. This IPM program included training of researchers and technicians, establishment of demonstration fields, and the monitoring of insect populations. Non-chemical and low-chemical agronomic practices were promoted to prevent ecological disruption, which included scouting, increased economic damage thresholds, coordinated releases of parasitic wasps, and the promotion of microbial pesticides and other biological control agents (Murray, 1994). The IPM program was implemented in the 1970s, and achieved a 30\% reduction in pesticide use, higher cotton yields and a substantial increase in farmer profits (Swezey, Murray and Daxl, 1986). 


\section{Crisis \& disaster}

Yet, the promotion of IPM was hindered by insufficient capacity of trained technicians and poorly-developed national agricultural research and extension programs (Murray, 1994). Drought-induced outbreaks of cotton leaf miners (Buccalatrix thurburiella), whiteflies (B. tabaci) and bollworms contributed to a relapse in the use of pyrethroids (Swezey, Murray and Daxl, 1986; Murray, 1994). Declining yields and escalating pest problems favoured the 'quick fix' that pesticides promised, prompting a relapse to pesticide use. In addition, banks offered incentives (e.g. bonuses) to farmers that harvested cotton at yield levels that exceeded normal yield levels, which spurred farmers short-term vision instead of a longterm approach, such as IPM. Although pesticide application frequencies did not increase in the late 1970s, farmers did increase dosages (Murray, 1994).

\section{Escape \& reorganization}

The Sandinista-led revolution changed the political landscape of Nicaragua. A second transition to IPM was attempted in 1982, this time driven by a ban on organochlorine-based insecticides, the initiation of a National Pesticide Commission to regulate pesticide imports, and a renewed effort to implement IPM programs. The latter was attempted through coordinated training of IPM specialists and extension officers, and with a special focus on the suppression of the primary pest, the boll weevil (Swezey, Murray and Daxl, 1986). For example, the establishment of trap crops for boll weevil as a prophylactic treatment reduced the number of pesticide applications needed to suppress boll weevil. The importance of this measure was emphasised with a state decree that made it mandatory to take measures to suppress boll weevil between cropping seasons (Vandermeer and Andow, 1986). In addition, there was a focus on experiments with bacterial pesticides to replace existing chemical products. This was a popular measure for farmers as it did not imply major changes in the cotton production process. This IPM approach reduced the number of insecticide applications in cotton, and by 1984 became one of the largest IPM programmes in Central America (Swezey, Murray and Daxl, 1986). However, the success of this program was undermined by the social and economic difficulties in Nicaragua in the late 1980s (Murray, 1994), and cotton acreage decreased to 35,000 ha in 1990. Although a decline in pesticide use was observed (Fig. 2.3), this may be ascribed to a decline in cotton acreage, the economic crisis in Nicaragua resulting in soaring pesticide prices, and declining international market prices for cotton (Swezey, Murray and Daxl, 1986; Thrupp, 1988; Vandermeer, 1991; Murray, 1994). Moreover, the Contra War hindered IPM workers and pesticide inspectors (Thrupp, 1988).

In summary, most of the identified drivers in Nicaragua fit in one of the four domains of the conceptual framework (Table 2.1; Fig. 2.1). Enabling drivers from the 'farming' and 'agrolandscapes' domain were mainly found in the 'subsistence \& exploitation' phase but were virtually absent in the 'escape \& reorganization' phase (Table 2.1). Ultimately, the escape 
from the insecticide use lock-in was fostered by drivers of the 'science \& technology' and 'social' domain, resulting in the implementation of the IPM approach.

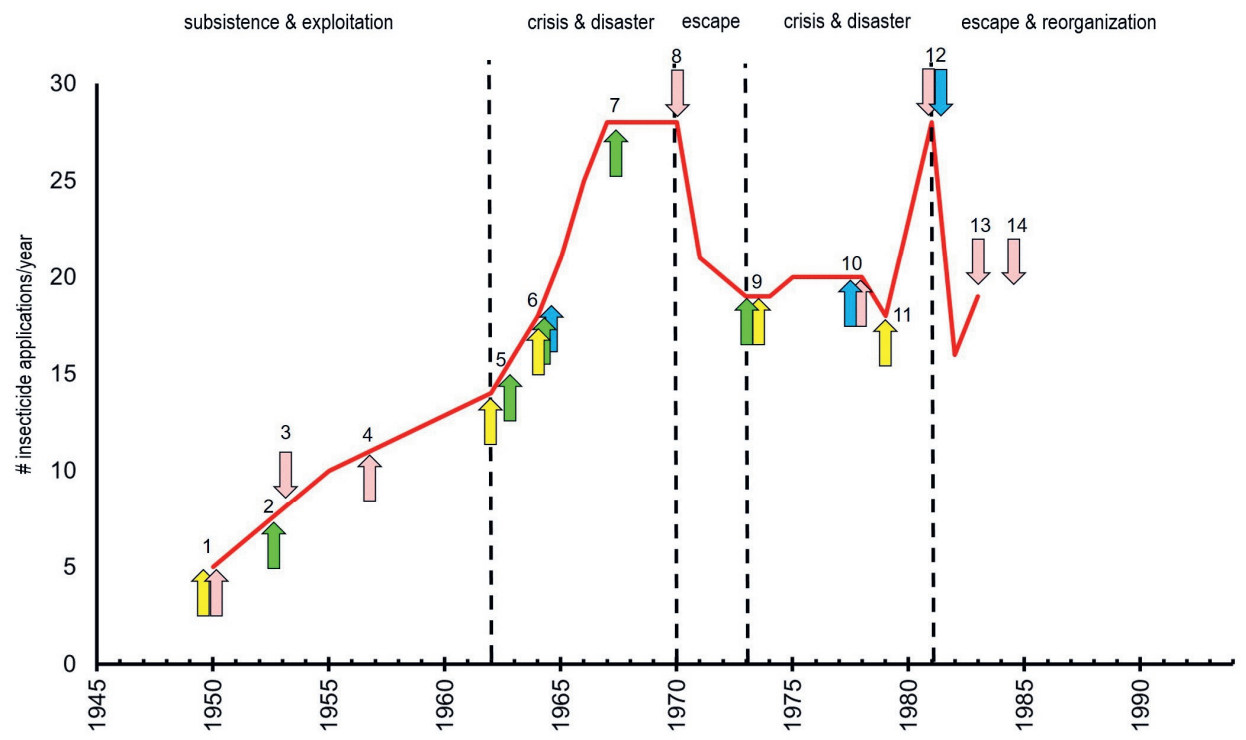

Figure 2.3: Timeline representing enabling (upward arrows) and disabling (downward arrows) drivers of pesticide use in cotton production in Nicaragua from 1945-1995. The graph indicates the number of insecticide applications per year (Swezey, Murray and Daxl, 1986; Murray, 1994). Dashed lines indicate approximate times of the transition to a new phase of the treadmill. Colours referring to domains (I-IV) in the framework: I: farming (yellow), II: agro-landscapes (green), III: science \& technology (blue), and IV: society (pink).. Numbers \& arrows indicate drivers of the treadmill; 1. key pest outbreaks (yellow), economic importance of cotton (pink), 2. increased acreage of cotton production (10500 ha); 3. one-year ban on methyl parathion; 4. agrarian reform; 5. insecticide resistance (yellow) \& decrease natural enemy populations (green); 6. key pests from 5 to 9 (yellow), cotton on $40 \%$ of all agricultural land (green), calendar scheduled pesticide applications (blue); 7. drift of pesticide applications; 8. IPM program; 9. increase in cotton acreage (175000 ha), 5-year drought (green), pest outbreaks (yellow); 10. few IPM specialists (blue), loans for pesticide imports, nationalized cotton farms, war (pink); 11. pest outbreak; 12. ban \& innovative pesticide policies (pink), regional IPM programs (blue); 13. state decree on mandatory IPM measures; 14. economic crisis, Contra War.

\section{THE CASE OF NEONICOTINOID INSECTICIDES}

\section{Subsistence \& exploitation}

Imidacloprid was the first neonicotinoid introduced on the market in the early 1990s, quickly followed by acetemiprid (1995), nitenpryam (1995), thiamethoxam (1998), thiacloprid (2000), clothianidin (2001), and dinotefuran in 2002 (Jeschke et al., 2011). A pre-emptive approach (using pre-treated or 'neonicotinoid-coated' seeds) is routinely applied to large areas of grain and oilseed crops in developed countries, irrespective of pest 
presence, infestation pressure or cropping history (Douglas and Tooker, 2015; EASAC, 2015; Simon-Delso et al., 2015). For example, 42 million hectares of cropland in the U.S. were planted with neonicotinoid-coated seeds, equalling $57 \%$ of total area planted with maize, soybean and cotton in 2011 (Douglas and Tooker, 2015). Currently, neonicotinoids are used in over 120 countries as seed treatment in more than 140 crops, including cotton, corn, cereals, sugar beet, oilseed rape, and others (Jeschke et al., 2011). With a 24\% market share neonicotinoids are currently the most used class of insecticides (Jeschke et al., 2011; Alburaki et al., 2015; Simon-Delso et al., 2015; Sparks and Lorsbach, 2017). As the patents on all neonicotinoids have expired, the supply of generic products is likely to increase and open up the market, possibly leading to a price reduction of neonicotinoids (Jeschke et al., 2011). Given this expansion of neonicotinoids into major markets worldwide, the number of resistance cases is expected to rise (Whalon, Mota-Sanchez and Hollingworth, 2008).

\section{Crisis \& disaster}

The widespread use and environmental persistence of neonicotinoids has raised concerns about exposure and associated impacts on non-target organisms (Chagnon et al., 2015; Douglas and Tooker, 2016; Woodcock, Isaac, et al., 2016; Calvo-Agudo et al., 2019). Exposure to neonicotinoids can occur via different pathways, including pollen, nectar, guttation fluids, soil, air and non-crop vegetation (Roubos, Rodriguez-Saona and Isaacs, 2014; Chagnon et al., 2015; Mogren and Lundgren, 2016; Calvo-Agudo et al., 2019) and sublethal and lethal effects have been reported for pollinators (Blacquière et al., 2012; Whitehorn et al., 2012; Rundlöf et al., 2015) and natural enemies, potentially undermining vital pollination and biological control services (Pisa et al., 2015, 2017; Calvo-Agudo et al., 2019). High levels of exposure were reported for different species of farmland birds (Humann-Guilleminot et al., 2019), and sublethal impacts have been reported for large vertebrates, such as deer (Gibbons, Morrissey and Mineau, 2015; Berheim et al., 2019). Residues of neonicotinoids have been found in honey all over the world, at potentially harmful concentrations for nectar-feeding insects in 48\% of the samples (Mitchell et al., 2017).

Since the introduction of neonicotinoids more than a 1000 cases of resistance have been reported (Mota-Sanchez and Wise, 2020). More than half of these resistance cases have been reported for economically important pests of different crops across the world, especially in America, Europe and Asia (Nauen and Denholm, 2005; Jeschke et al., 2011). For instance, 250 and 105 resistance cases are reported for B. tabaci and A. gossypii, which are important polyphagous pests in cotton and vegetables (Mota-Sanchez and Wise, 2020). The green peach aphid, M. persicae (Sulzer), is the most economically important aphid pest worldwide and 120 cases of neonicotinoid resistance have been reported in flower, crops, fruit, trees, grains, tobacco, or vegetables (Bass et al., 2015; Mota-Sanchez and Wise, 2020). The brown planthopper $N$. lugens is the most economically significant pest of rice (Mota-Sanchez and Wise, 2020) and populations of N. lugens (Stål) show widespread resistance across Asia (Bass et al., 2015). Insecticide resistance has led in some cases to increased application rates 
of neonicotinoids, or replacement of neonicotinoids by older and more harmful insecticides (Jeschke et al., 2011; Chagnon et al., 2015; Simon-Delso et al., 2015; Douglas and Tooker, 2016).

The prophylactic use of neonicotinoids has deepened farmer dependency on insecticides, and created a system in which farmers experience 'deskilling' and lack sufficient resources or experience to transition towards more ecologically-based pest management approaches (e.g., LaCanne and Lundgren 2018, Wyckhuys et al. 2019). Core components of the IPM approach, such as pest monitoring and threshold-based decision-making, have become redundant with prophylactic use of neonicotinoids (EASAC, 2015). Moreover, the current use of neonicotinoids is facilitated by relatively low costs, convenient application modes, existence of tailored supply chains and the necessary technology and machinery for on-farm application. Even if farmers prefer to use non-treated seed, accessing non-treated seed can be challenging (Simon-Delso et al., 2015; Busch et al., 2020).

\section{Escape \& reorganization?}

Currently, there are several cases of legislation to regulate neonicotinoid use. In 2018, the European Union (EU) prohibited the use of seeds treated with the neonicotinoids clothianidin, thiamethoxam and imidacloprid for open-field cultivation (Regulation (EU) 2018/784) (EU, 2018). The US-EPA has announced a registration review update on imidacloprid, clothianidin, thiamethoxam and dinotefuran for 2020 (US-EPA, 2020), and the state of Maryland in the USA has issued a ban on the sales of neonicotinoids effective in 2018 (State of Maryland, 2016). Though some restrictions are aimed at flowering field crops to prevent their impacts on pollinators and other flower visitors, non-flowering crops can pose equally high risks to these organisms (Calvo-Agudo et al., 2019). In response to an earlier EU moratorium on neonicotinoids, multiple EU member states have applied for emergency authorisations to continue the use of neonicotinoids (EFSA, 2016). Some farmers and associated lobby groups are trying to obtain derogations because neonicotinoids are considered 'indispensable in modern agriculture'. Clearly, the outcome of this debate will have important implications for farmers, agrochemical industry and society as a whole. 


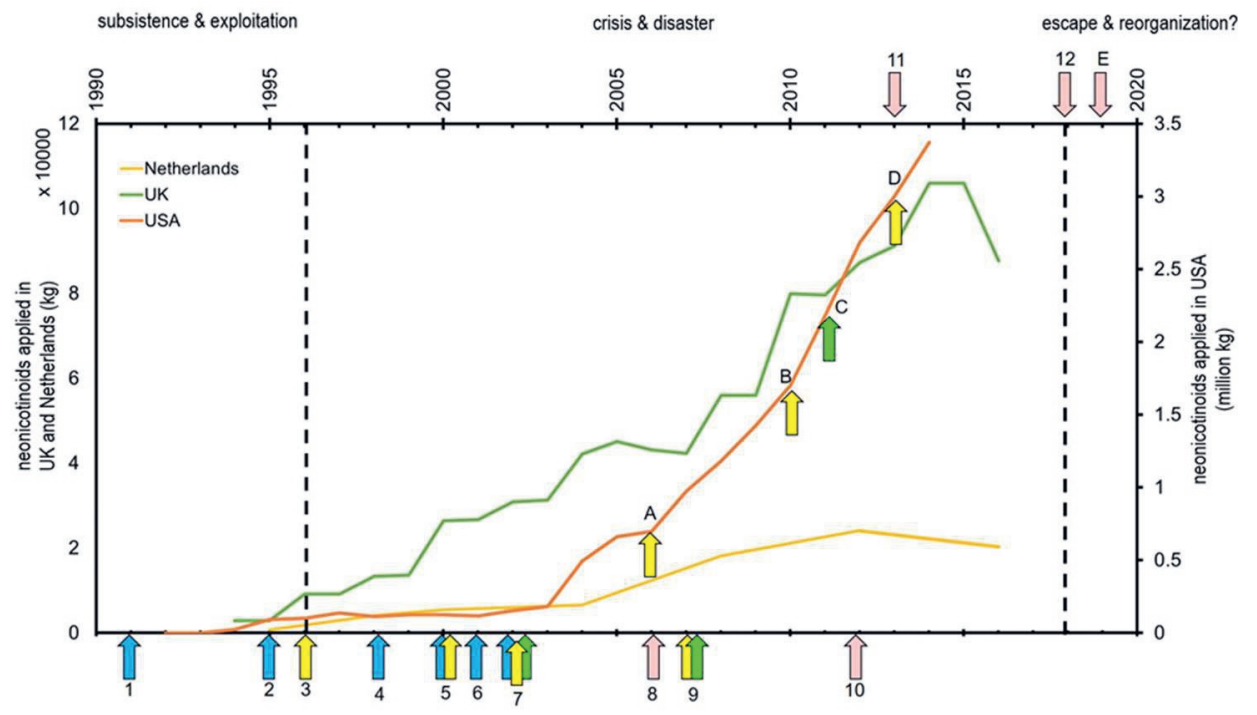

Figure 2.4: Timeline of neonicotinoid use and developments from 1990-present. The graphs indicate the amount of neonicotinoid use per year, including seed treatments for three countries; USA (orange; million kg applied/year from 1992-2014), UK (green; kg applied/ year from 1994-2016) and the Netherlands (yellow; $\mathrm{kg}$ applied/year from 1995-2016). Data are obtained from USGS (EPest-Low estimate) for the USA (USGS, 2019), from Pesticide Usage Surveys for the UK (Fera, 2020), and from CBS StatLine for the Netherlands (Statline, 2019). Dashed lines indicate the possible timing of the transition to a new phase of the treadmill. Colours referring to domains (I-IV) in the framework: I: farming (yellow), II: agro-landscapes (green), III: science \& technology (blue), and IV: society (pink). Numbers \& arrows indicate drivers of the treadmill; 1. introduction of imidacloprid; 2. introduction of acetamiprid \& nitenpryam; 3. neonicotinoid resistance in B. tabaci; 4. introduction of thiamethoxam; 5. introduction of thiacloprid (blue), neonicotinoid resistance in Leptinotarsa decemlineata (Colorado potato beetle) (yellow); 6. introduction of clothianidin; 7. introduction of dinotefuran (blue), honeybee mortality linked to neonicotinoids (green), neonicotinoid resistance in A. gossypii (yellow); 8. patent expiry on imidacloprid; 9. neonicotinoid resistance in $N$. lugens and M. persicae (yellow), $80 \%$ seed treatments with neonicotinoids (green); 10. patent expiry other neonicotinoids; 11. two year moratorium on three neonicotinoids in EU; 12 . ban on three neonicotinoids in EU.

For USA specifically: A. imidacloprid resistance in L. decemlineata; B. imidacloprid and thiamethoxam resistance in $\mathrm{M}$. persicae and $\mathrm{B}$. tabaci; $C$ more than $50 \%$ of area planted with maize, soybean and cotton treated with neonicotinoids; $D$. thiamethoxam resistance in A. gossypii; $E$. registration review update in the USA. 


\section{DISCUSSION}

Here, by contrasting the rapid global use of neonicotinoid insecticides with five historic cases of the pesticide treadmill (Table 2.1; Fig. 2.2, 2.3, and 2.4; Fig. S2.1-S2.3), we generated three key insights: (i) the uptake and reduction of insecticides are influenced by drivers from different socio-ecological domains, including 'farming', 'agro-landscapes', 'science \& technology' and 'society', (ii) a pesticide treadmill is enforced by drivers from all four domains, while drivers from 'science \& technology' and 'society' are most important for the escape from the pesticide treadmill, and (iii) the neonicotinoid case shows many similarities with historic case studies, but also deviates in some respects. Important differences are that the uptake of neonicotinoids occurred at a fast pace and a global scale for several crops, while documented historic examples of the pesticide treadmill are rather restricted to particular geographies and cash crops. Furthermore, while the pesticide treadmill in the historic case studies was only counteracted after major crop losses, current legislation to regulate the use of neonicotinoids is strongly motivated by concerns about impacts on nontarget organisms and the environment, and less by mitigating resistance development and the associated crop losses.

Historical case studies revealed that the identified drivers can be categorized in the four domains of the conceptual framework (Table 2.1), with similar patterns in Sudan, Nicaragua, USA, Costa Rica and Indonesia (Table 2.1; Supplementary Materials). The case studies show that there are two important elements initiating the pesticide treadmill that can be found in the 'farming' and 'agro-landscapes' domains; (i) frequent pesticide use triggers resistance development and pest outbreaks, and (ii) impacts of pesticides on natural enemies release pests from top-down control (Settle et al., 1996), thus locking farmers into pesticide-based management (Swezey et al., 1986). However, farm-level decisions may also be influenced by drivers in the social and technological domains (Fig. 2.1), many of which are beyond control of individual farmers and the 'farming' domain. Hence, it is important to consider on which level transitions could be initiated (Kinzig et al., 2006).

While the pesticide treadmill may be enforced by drivers from all four domains, agroecological problems lie often at the base of the pesticide treadmill (Table 2.1). The largescale monocropping of a limited number of crops offers an abundant and high-quality food resource for herbivores and often initiates the build-up of pest populations. Resistance of key pests to pesticides, pest resurgence and secondary pest species usually result in increases in the quantity, frequency and diversity in MoA of the pesticides used to manage pests. In addition, centralized management and decision-making, e.g. through bank loans tied to crop yields, subsidies on pesticides, and package deals with agro-industry, accelerated the pesticide treadmill in historic case studies. Yet, 'science \& technology' and 'society' regularly helped unlock and accelerate the 'escape \& reorganization' phase. That is, scientific progress and farmer-led innovation, e.g. in agro-ecology and biological control, became the central element of Farmer Field Schools (FFS) in e.g. Sudan, Nicaragua, and 
Indonesia (Swezey, Murray and Daxl, 1986; Settle et al., 1996; Bashir, Elamin and Elamin, 2003). On-farm validation of IPM and biological control directly contributed to the escape of the treadmill by millions of farmers (Matteson, 2000; Sigsgaard, 2000). For example, the FFS movement in Indonesia consisted of three pillars in which (i) pesticide use was widely recognized as a key driver of pest outbreaks, (ii) millions of farmers were trained on nonchemical pest management, and (iii) pesticide use was cut substantially and biological control experienced a bonanza (Settle et al., 1996; Matteson, 2000; Thorburn, 2015).

Our analysis suggests that current neonicotinoid use is in the 'crisis \& disaster' phase of the pesticide treadmill (Fig. 2.4). The widespread use, persistent nature, and toxicity of neonicotinoids to a broad range of beneficial organisms are strong indications that many ecological and societal problems that accompanied the developments of pesticide use as described in our case studies still persist (Fig. 2.2 \& 2.3 vs. 2.4) (Chagnon et al., 2015). Cases of resistance against neonicotinoids are continuously increasing both in terms of number of pest species and countries (Mota-Sanchez and Wise, 2020). For instance, neonicotinoids are identified as the driver of renewed pest problems and increased pesticide use in Asian rice systems (Bottrell and Schoenly, 2012), suggesting that the lessons learned from IPM training have been abandoned. While resistance has commonly been solved by replacing one active ingredient by another (e.g., organochlorines were replaced by carbamates and pyrethroids (Sparks and Lorsbach, 2017)), the case studies indicate that this is not a sustainable strategy for future agricultural production. From a socio-technological perspective, especially prophylactic use of neonicotinoids as a standard practice has created a system in which many farmers lack resources, skills and experience to implement a different pest management strategy (EASAC, 2015). While a diverse range of alternatives can replace neonicotinoids (e.g. scouting, decision-support tools, low-impact pesticides, biological control), accurate and unbiased information on the efficacy and cost-effectiveness of (prophylactic) neonicotinoid usage is needed. As extension services are commonly provided by chemical companies (Giannakas and Fulton, 2005; Savary et al., 2012), information on neonicotinoid use is often one-sided as it reaches the farmer through programs sponsored by pesticide manufacturers (Tooker, Douglas and Krupke, 2017). Farmers are regularly led to believe that a phase-out of neonicotinoids will entail yield reductions and loss of profit, and they are therefore reluctant to reduce their use of insecticides (Goulson, 2013; Furlan et al., 2018), with such claims possibly being part of a deliberate 'mis-information' strategy (Oreskes and Conway, 2011; Juma, 2016; Furlan et al., 2018). Yet, yield gains of neonicotinoid seed coatings were negligible in US soybean (Myers and Hill, 2014; Mourtzinis et al., 2019), questionable in US maize (Seagraves and Lundgren, 2012; Krupke et al., 2017), and farm-level profits can increase substantially for growers that abandon these technologies (LaCanne and Lundgren, 2018). 


\section{Escape \& reorganization of neonicotinoid use}

Cowan and Hultén (1996) formulated six conditions for a lasting escape from technology lock-in. These are a crisis in the existing technology, changing regulations, technological or cost breakthrough, changes in 'taste' by society, active niche markets \& early adopters of emerging technologies, and scientific results questioning the technology in use. Given the above, we consider that a slow but steady escape from the neonicotinoid use 'lock-in' is underway. First, the continuous resistance development, stricter residue requirements and changing regulatory landscape are posing major challenges to the agrochemical industry and farmers (Sparks and Lorsbach, 2017; Jørgensen et al., 2018; Pretty, 2018). While we recognize the multiple challenges associated with a ban of a popular insecticide, a properly aligned design and implementation of effective, economically viable and practicable alternatives and broader 'agricultural systems redesign' can enable a large-scale, lasting transformation of pest management systems (Pretty, 2018; Sponsler et al., 2019). In society, change in 'taste' is reflected in the swelling support of consumers, NGOs, governments and farmers for 'green' and environmentally-friendly agriculture (Byerlee, de Janvry and Sadoulet, 2009; van Lenteren et al., 2018). In the meantime, scientific reports emphasize the environmental and non-target impacts of neonicotinoids and question their efficacy (Seagraves and Lundgren 2012, EASAC 2015, Cimino et al., 2017, Mourtzinis et al., 2019). Finally, the development of agroecological niches, innovations across agri-food value chains and the uptake of no or low-pesticide practices by 'early adopters' allow adaptive learning and permit broader diffusion of non-chemical alternatives (Cowan and Hultén, 1996; Vanloqueren and Baret, 2009).

The case studies illuminate various elements that are central to effectively mitigate pesticide use in agri-food systems, and thus create room for more equitable and sustainable forms of agricultural production. For example, the Sudan IPM initiative proved successful because of compensation schemes for yield reduction tailored to early IPM adopters, thus reducing farmers' uncertainty and influencing risk perception (Bashir, Elamin and Elamin, 2003). In Nicaragua, key components were the coordinated training of IPM specialists and extension officers, and the promotion of microbial pesticides which could be easily incorporated in farming operations (Swezey, Murray and Daxl, 1986). The case of Texas cotton shows how a coordinated effort by farmers was needed to switch practices (Cowan and Gunby, 1996). In Costa Rica, an increased awareness of pest issues, the development of economic damage threshold levels, and an ultimate ban on all insecticide treatments brought about change (Thrupp, 1990). While a country-wide ban on 57 pesticides constituted a first step towards change in Indonesia, the official (government) endorsement of IPM and 'hands-on' training of millions of farmers on non-chemical pest management ultimately permitted an up to $60 \%$ decrease of insecticide use (Oka, 1991; Settle et al., 1996; Thorburn, 2015). The IPM FFS movement fostered the escape of the treadmill by millions of farmers through farmer innovations, tailored extension programs and on-farm validation of IPM and biological 
control. Endorsement of these developments by national governments and international organizations, like FAO, permitted a fast transition towards ecologically-based management techniques (Swezey, Murray and Daxl, 1986; Bashir, Elamin and Elamin, 2003).

At present, a suite of alternative pest control methods are available, including economic damage threshold levels, microbial control agents, semio-chemical methods and biological control (Barzman et al., 2015; Furlan and Kreutzweiser, 2015; Furlan et al., 2018; Jactel et al., 2019), even though not all alternatives rank well in terms of efficacy, applicability, durability and practicability (Jactel et al., 2019). The recent emergence of 'disruptive innovations' (Juma, 2016), such as robotic weeders, farm-level sensing, weed-suppressing intercrops or drone-based delivery of natural enemies carries ample promise (Lamichhane et al., 2016; Iost Filho et al., 2019). Political initiatives are needed to overcome eventual economic constraints, ease farmer transitions and influence the trade-off between costs and benefits of insecticide use (Clark and Tilman, 2017; Milner and Boyd, 2017; van Lenteren et al., 2018). Once alternative technologies are permitted to mature and reach scalability, without involvement of the agrochemical industry, they can break the multi-decade model of chemically-dependent agriculture. Yet, transitions also need to occur in social domains, with effective (two-way) scientist-farmer communication, coordination and cooperation being determinants of success. Tailored education of farmers, e.g. to fill existing agroecological knowledge gaps (Wyckhuys et al., 2019), possibly can spark on-farm experimentation and adoption of non-chemical management alternatives (Pretty, 2018).

To conclude, transitions in pest management cannot be seen in isolation from other components of the socio-ecological system (Lewis et al., 1997; Lamine et al., 2010; Lamine, 2011; Letourneau, 2012; Barzman et al., 2015). The case studies show that regulations (e.g. bans, state decrees), IPM programs and introduction of biological control tactics help to develop systems that are less pesticide dependent (Table 2.1). Thereby, fostering the adoption of sustainable management practices requires training, education and acceptance of new approaches by farmers, parallelled by facilitation through policymakers and regulators (EASAC, 2015; Furlan and Kreutzweiser, 2015; Dudley et al., 2017; Milner and Boyd, 2017; Sponsler et al., 2019). To facilitate 'escape \& reorganization' of current neonicotinoid-based pest management, top-down regulations need to be paired with bottom-up 'farmer first' approaches of pest management (Matteson, 2000; MacMillan and Benton, 2014; Wyckhuys et al., 2019), and the active pursuit of management practices that do not involve synthetic pesticides, such as agro-ecology. Neonicotinoid use has triggered a new, globe-spanning cycle of the pesticide treadmill, yet promising and resolute steps are being taken to escape this 'lock-in'. When paired with adequate technological innovation, supporting policies, sound public education and institutional change, the current product bans can enable a large-scale, lasting adoption of ecologically-underpinned farming schemes that will concurrently benefit farmers, consumers and the environment. 


\section{ACKNOWLEDGEMENTS}

Support for this paper was provided by The Netherlands Organization for Scientific Research (NWO), grant 824.15.022. We would like to thank Douglas Landis who provided helpful comments on an earlier draft of the manuscript. Lastly, we are grateful to the reviewers for their help in improving the manuscript. 


\section{SUPPLEMENTARY MATRIALS}

\section{Case study USA}

\section{Subsistence \& exploitation}

During the 1940s, the USA government policies incentivized the uptake of high yielding crop varieties to enhance agricultural productivity. Cotton growers in southern Texas readily switched to these high yielding cotton varieties that were susceptible to insect attack (e.g. boll weevil, A. grandis), which made growers extremely reliant on the use of pesticides (Fig. S2.1). Growers lowered their pest damage thresholds in cotton, reinforcing the adoption of chemical pesticides (Cowan and Gunby, 1996). By the mid-1950s key pests of cotton ( $A$. grandis, cotton fleahopper (Pseudatomoscelis seriatus) and pink bollworm (Pectinophora gossypiella)) had developed resistance to frequently applied insecticides (e.g. DDT, dieldrin). As a response, new mixtures of insecticides were introduced, and dosages and application frequencies increased.

\section{Crisis \& disaster}

The response to pest outbreaks resulted in initial effective control of key pests, but stimulated a resurgence of secondary pests, which became key pests. By 1968 almost 200,000 ha of cotton was grown in Texas (Adkisson et al., 1982). Secondary pests developed resistance against all insecticides used and inflicted severe damage to cotton, causing complete crop failure, and resulting in a shrinking of the cotton production area in Texas to 64,000 ha in 1975 (Adkisson et al., 1982; Cowan and Gunby, 1996).

In the 'rest of Texas' (Fig. S2.1B) and the area of Trans-Pecos (Fig. S2.1C) new insecticides (organophosphates) were introduced as a response to resistance development to organochlorines, and dosages and application frequencies increased. This response resulted in effective suppression of key pests, but stimulated a resurgence of secondary pests (H. zea, tobacco budworm (Heliothis virescens) and cabbage looper (Trichoplusia ni)), which in turn became key pests (Adkisson et al., 1982; Cowan and Gunby, 1996). In the 'rest of Texas' (Fig. S2.1B), at the end of the 1960s, cotton pests, such as A.grandis, P. seriatus and P. gossypiella, were not controlled by organophosphates due to resistance. In the Trans-Pecos area (Fig. S2.1C) cotton growers continued using pesticides, because they thought the alternative was too complex and pesticides were simple to use based on calendar applications or signs of crop damage. Uncertainty about the efficacy of IPM contained growers locked-in in a pesticide dependent state (Cowan and Gunby, 1996).

\section{Escape \& reorganization}

In response to insecticide resistance alternative paths were explored by cotton growers in Texas. Cotton growers on the High Plains of Texas (Fig. S2.1A) were quickly returning to IPM practices. In a coordinated effort to control pests, cotton growers in this area applied uniform delayed planting of cotton, limiting the need to use insecticides. Cotton growers in 'the rest of Texas' (Fig. S2.1B) also switched back to IPM as a pest management method, but 
switching costs were alleviated by government extension programs and state legislation was implemented to coordinate the adherence of farmers to a short growing season (Cowan and Gunby, 1996). This addresses the importance of coordination efforts to overcome 'excess inertia' - the willingness to adopt a new technology knowing other will adopt the technology as well. Despite these efforts only a small group of farmers in Trans-Pecos switched to IPM (Fig. S2.1C), which was attributed to a lack of coordination mechanisms in overcoming the lock-in (Adkisson et al., 1982; Cowan and Gunby, 1996).

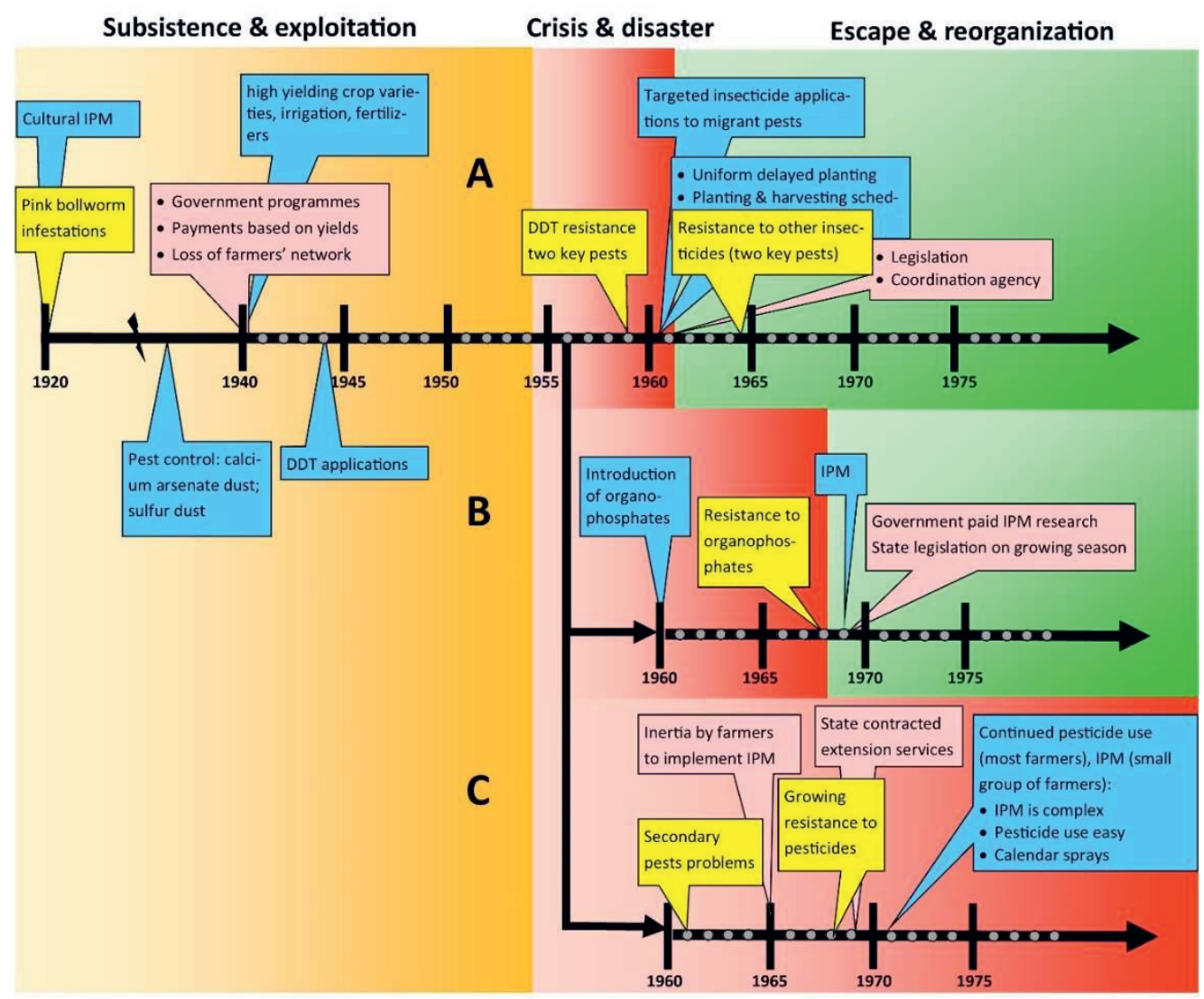

Figure S2.1: Timeline representing enabling and disabling drivers (text balloons) of pesticide use in cotton production in Texas, USA from 1920-1980. Colours referring to domains in the framework: farming (yellow), agro-landscapes (green), science \& technology (blue), and society (pink). The colours in the background (orange-red-green) indicate the transition to a new phase of the treadmill. 


\section{Case study Costa Rica}

\section{Subsistence \& exploitation}

The pest management dynamics in banana production in the Golfito zone in Costa Rica (Fig. S2.2) provides another case study of interactions within the framework driving the pesticide treadmill. Thrupp (1990) portrays how a combination of ecological and socio-political drivers resulted in overuse of broad-spectrum pesticides, leading to insecticide resistance and secondary pests. A pesticide treadmill was initiated with calendar-scheduled applications of dieldrin against red rust thrips (Chaetanophothrips orchidii) and the banana corn weevil (Cosmopolites sordidus), which caused a resurgence of a secondary pest banana stalk borer (Castniomera humbolti) and the platynota moth (Platynota rostrana) (Stephens, 1984; Thrupp, 1990).

\section{Crisis \& disaster}

Despite heavy spraying with organochlorine insecticides (dieldrin, DDT, endrin and heptachlor) and malathion and diazinon, these pests were not controlled, and by the late 1960s high economic losses undermined profits (Thrupp, 1990). The pressure to fulfil production goals, maximizing yields and comply with aesthetic quality standards led to high risk attitude among managers of banana plantations and resulted in a high-input response to control pests (Thrupp, 1990). To control resistant insects by 1960, dieldrin was replaced by carbaryl to control insect defoliators and the banana moth (Antichloris viridis), and toxaphene was used for control of West Indian Bagworm (Oiketicus kirbyi). By 1962 banana moths and corn weevils had developed resistance against dieldrin, but heavy spraying continued. There was an information gap regarding pesticide resistance, resurgence and secondary outbreaks, and the agrochemical industry was the most dominant source of information and publicity on pest control from 1950-1980. When resistance problems arose, industry advised banana plantation managers to switch to new insecticides. Although additional sources of information (e.g. government agencies or scientific journals) were consulted, they were given little attention. Risk perception of the managers was mainly shaped by production goals, information from the agrochemical industry and their fear of pests, which refrained managers from adopting alternative methods or approaches (Thrupp, 1990). For example, even though it was already demonstrated in 1965 that banana plants could tolerate some defoliation, it took another thirteen years before a damage threshold level was adopted that took this into account (Stephens, 1984). While field staff was well positioned to make informed location-specific decisions on pest management, the top-down centralized decision making on pest management did not allow this (Thrupp, 1990).

\section{Escape \& reorganization}

The overuse of insecticides in banana production in Costa Rica (Fig. S2.2) began to undermine profits in the early 1970s. Combined with an increased awareness of the pest problem this led to an increase in economic damage threshold levels. After raising this 
threshold, insecticide use began to decrease gradually. However, a successful change in insect control was initiated in 1973 with a total ban on all insecticides. This allowed for the re-establishment of natural enemies and within two years insect pests nearly disappeared (Stephens, 1984; Thrupp, 1990).

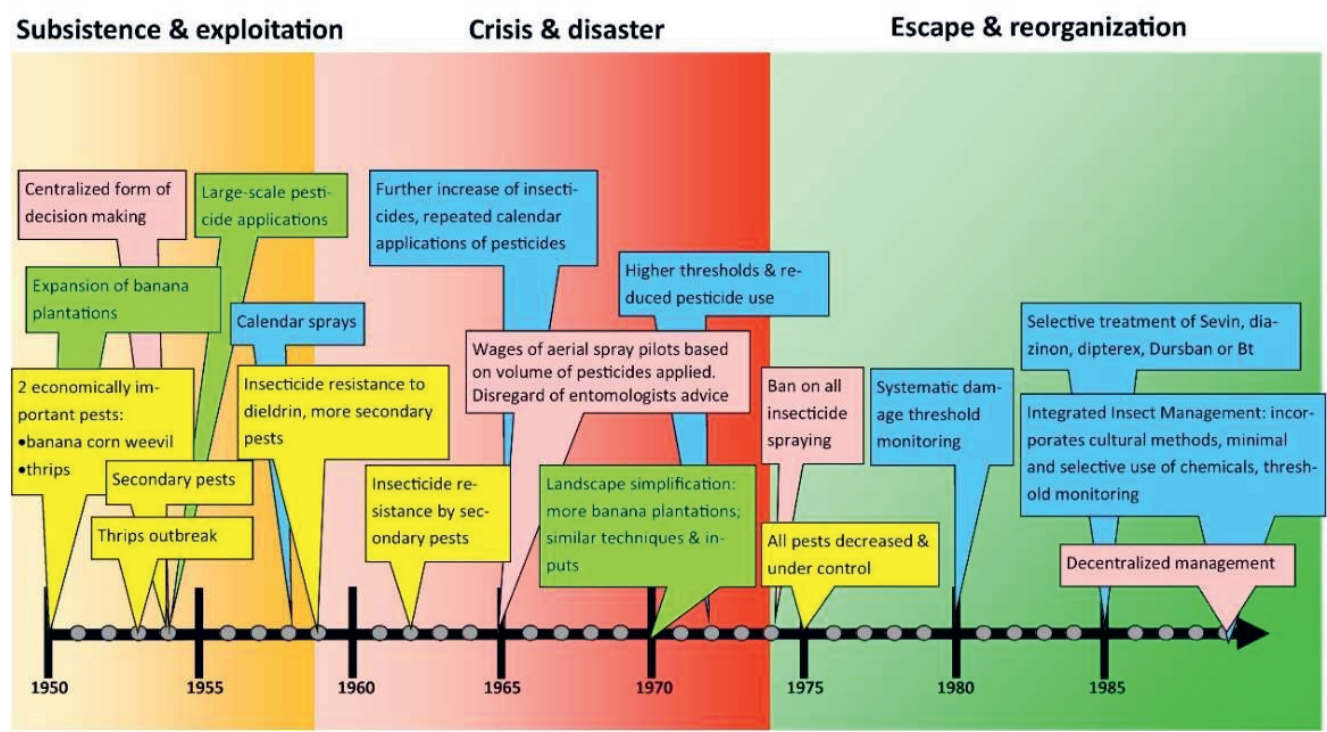

Figure S2.2: Timeline representing enabling and disabling drivers (text balloons) of pesticide use in banana production in the Golfito zone, Costa Rica from 1950-1990. Colours referring to domains in the framework: farming (yellow), agro-landscapes (green), science \& technology (blue), and society (pink). The colours in the background (orange-red-green) indicate the transition to a new phase of the treadmill.

\section{Case study Indonesia}

Subsistence \& exploitation

A fifth case is on rice production in Indonesia (Fig. S2.3). Rice production in Indonesia intensified in the 1960s as a result of rice intensification programs. Farmers were provided with a technology package consisting of short-duration, high-yielding rice varieties, nitrogen and phosphate fertilizers, insecticides and fungicides by the government. Farmers were obliged to use the whole package and applied pesticides on calendar-based regime, while problems due to yellow stem borers (Scirpophaga incertulas) maintained (Oka, 1991; Settle et al., 1996; Thorburn, 2015).

\section{Crisis \& disaster}

Government undertook contracts with insecticide firms for pest management activities, which included aerial applications of phosphamidon and diazinon to control stemborers. When a secondary pest, the brown planthopper (Nilaparvata lugens), emerged, the government provided loans and subsidies for agrochemicals to farmers. Another method to 
manage the brown planthopper was the development of resistant rice varieties (IR36) in the early 1980s, and the brown planthopper stopped being a problem until 1986. In 1984 Indonesia became self-sufficient in rice production. However, rice farmers were still dependent on chemical-based pest management to control pest outbreaks from green leaf hoppers (Nephotettix malayanus and Nephotettix virescens) and white stemborer (Scirpophaga innotata) (Oka, 1991; Settle et al., 1996; Thorburn, 2015).

\section{Escape \& reorganization}

A large outbreak of the brown plant hopper in 1986 urged the president to ban 57 pesticides, along with the elimination of subsidies for insecticides. At the same time, IPM was introduced as the official state-endorsed approach to pest management and a large-scale program for farmer training in IPM was initiated. The program emphasized on-farm training that increased farmers' independence to implement IPM with as little external assistance as needed. Specific training was on pest surveillance, host-plant resistance, natural enemies of pests, judicious use of pesticides and field demonstrations that gave farmers first-hand experience with IPM practices and ecological concepts (Oka, 2003; Bottrell and Schoenly, 2012). Around 1.5 million farmers in Indonesia received training, and together with national IPM policies, insecticide use was reduced by as much as 75\% (Oka, 1991, 2003; Settle et al., 1996; Bottrell and Schoenly, 2012).

\section{Crisis \& disaster}

The Asian Financial crisis in 1997-1998 hit Indonesia hard, and in combination with the political and economic turmoil in Indonesia during that period, many political and institutional changes have caused the National IPM Program to be degraded. In 2009, new outbreaks of the brown planthopper were reported with significant crop losses (Bottrell and Schoenly, 2012). Concurrently, farmers started spraying again. This relapse to pesticide use is, amongst others, caused by insecticide resistance, deregulation and liberalization of trade and investment, decentralization of decision-making, and loss of communication pathways between agricultural research and extension services (Thorburn, 2015). 


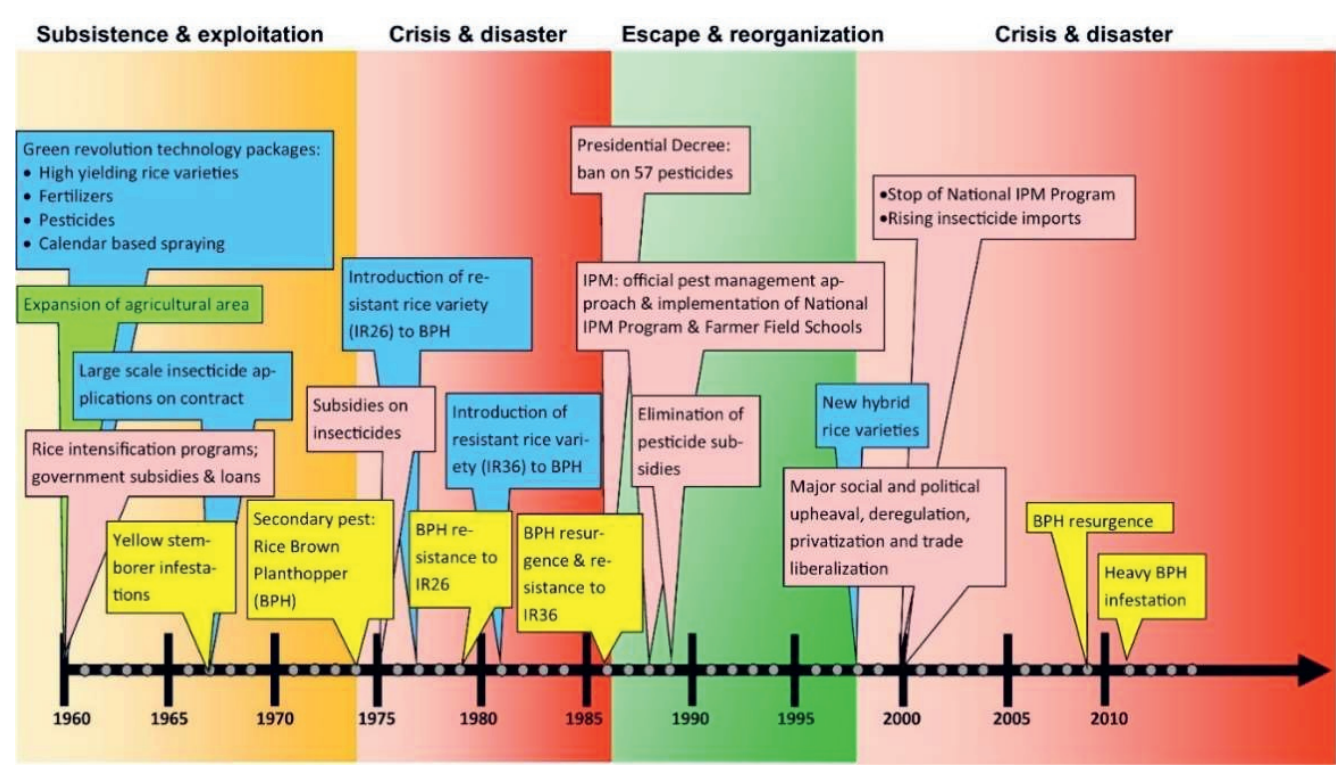

Figure S2.3: Timeline representing enabling and disabling drivers (text balloons) of pesticide use in rice production in Indonesia from 1960-2015. Colours referring to domains in the framework: farming (yellow), agro-landscapes (green), science \& technology (blue), and society (pink). The colours in the background (orange-red-green) indicate the transition to a new phase of the treadmill. 


$$
\text { 烈 }
$$




\section{LANDSCAPE-WIDE INSECTICIDE \\ EXPOSURE IMPACTS BENEFICIAL ARTHROPOD ABUNDANCE}

L. BAKKER, W. VAN DER WERF, AND F.J.J.A. BIANCHI

UNDER REVIEW 


\begin{abstract}
Insecticide use and landscape context are considered major drivers for the abundance of beneficial arthropods. However, the impacts of local and landscape-wide insecticide use are still poorly understood, and it is unclear to what extent impacts of insecticides on beneficial arthropod populations can be mitigated by landscape context. We assessed how the abundance of predators, parasitoids and pollinators are influenced by local and landscape wide insecticide use across landscapes that span a range in proportion of semi-natural habitat. We sampled beneficial arthropod populations by sweep netting and placing yellow sticky traps at 38 focal field margins of paired conventional and organic arable fields in June and July of 2017 and 2018. Paired fields were located in landscapes with different proportions of semi-natural habitat. We used three indicators of insecticide use: management in the adjacent field (conventional vs. organic), Treatment Frequency Index of insecticides of the field adjacent to the sampling site, and the estimated quantity insecticide applied within a $1 \mathrm{~km}$ radius around the sampling site. We collected a total of 2803 predators, 24004 parasitoids, and 895 pollinators by sweep netting and placing sticky traps in field margins. Beneficial arthropod populations in field margins, assessed by sweepnetting, were negatively associated with insecticide loading at the landscape scale, while arthropod sampling by sticky traps did not show these relationships. Pollinator abundance was negatively associated with conventional farming in the adjacent field and with the frequency of insecticide applications, while predator and parasitoid abundance did not show significant associations with local insecticide use indicators. Finally, we found that associations between beneficial arthropods and insecticides were for some functional groups moderated in landscapes with higher amounts of woody semi-natural habitat. Estimated insecticide load at the landscape scale was the variable most strongly influencing the measured arthropod abundances. Insecticide impacts on arthropod populations do thus extend beyond the fields in which they are used. Risk assessments of environmental impacts of insecticides and regulations on the safe use of pesticides need to account for potential spill-over effects and consider a landscape approach.
\end{abstract}

Keywords: agricultural landscape; pesticide; ecosystem services; insecticide use; parasitoids; pollinators; predators 
Beneficial arthropods provide important ecosystem services, such as biological pest control and pollination, and are therefore vital for ecosystem health and global food production (Goulson, 2019). However, concerns have risen on the widespread decline of arthropods (Lichtenberg et al., 2017; Martin et al., 2019; Albrecht et al., 2020; Harvey et al., 2020). While these arthropod declines can be explained by many causes and their interactions, landscape simplification and agricultural intensification are considered key drivers (Meehan et al., 2011; Hallmann et al., 2017; Seibold et al., 2019; van Klink et al., 2020). There is a mature body of studies that explored associations between farm management (often organic versus conventional management) and landscape context, showing that organic farm management has positive benefits for arthropod abundance (see e.g. Clough et al., 2005; Gabriel et al., 2010; Muneret et al., 2019; Schmidt et al., 2005), but these impacts are influenced by the landscape surrounding the farms (Muneret et al., 2018). Furthermore, farm management encompasses a wide range of practices, including soil tillage intensity, crop rotation and pesticide use, and the impacts of specific practices on arthropod communities are difficult to disentangle. We still lack a thorough understanding of how specific management practices influence arthropod communities in different landscape settings, and at what spatial scales such impacts manifest.

Landscape simplification comprises a range of changes, including the loss of semi-natural habitats and increasing field sizes. Furthermore, landscape simplification is often accompanied by agricultural intensification, with greater inputs of fertilizer and biocides per unit area. While positive associations between landscape heterogeneity and the abundance of beneficial arthropods have often been reported (Chaplin-Kramer et al., 2011; Dainese et al., 2019; Letourneau et al., 2012; Veres et al., 2013), these relationships are context dependent and therefore difficult to predict for a specific landscape setting without first collecting context specific data (Karp et al., 2018; Zhang, Haan and Landis, 2020). One of the factors underlying this context dependency may be the intensity of insecticide use, which is often region, farming system and crop specific (Geiger et al., 2010; Rusch et al., 2010; Sánchez-Bayo and Wyckhuys, 2019; Zou et al., 2020).

Insecticide use may impact non-target organisms through the presence of active ingredients on plants, in soil and water, sublethal toxic effects and reduced availability of prey or hosts (Desneux, Decourtye and Delpuech, 2007; Devine and Furlong, 2007; Wagner, 2020). These effects may play out at larger spatial scales than just the area treated with insecticides (Spromberg, John and Landis, 1998; Topping, Aldrich and Berny, 2020). For example, impacts of insecticides on natural enemy communities may extend beyond the place of application due to pesticide drift, and may disrupt natural enemy populations in non-target areas (de Jong, de Snoo and van de Zande, 2008; D. Goulson, 2013; Chagnon et al., 2015). In addition, natural enemies are mobile and natural enemies that end up in insecticide treated fields may suffer from (sub)lethal insecticide impacts. As such, insecticide treated fields may act as sink habitats and reduce the population size of natural enemies at the landscape scale 
(c.f. the 'action at a distance' mechanism) (Sherratt and Jepson, 1993; Spromberg, John and Landis, 1998; Bianchi, Ives and Schellhorn, 2013; Topping et al., 2015; EFSA Scientific Committee, 2016). While there is theoretical support for such landscape scale impacts of insecticides on arthropods from models, relatively few field studies have investigated at what spatial scale insecticides impact arthropod communities and how this is influenced by landscape context (but see Gagic et al., 2019, 2017; Geiger et al., 2010; Jonsson et al., 2012; Martin et al., 2020; Rundlöf et al., 2015).

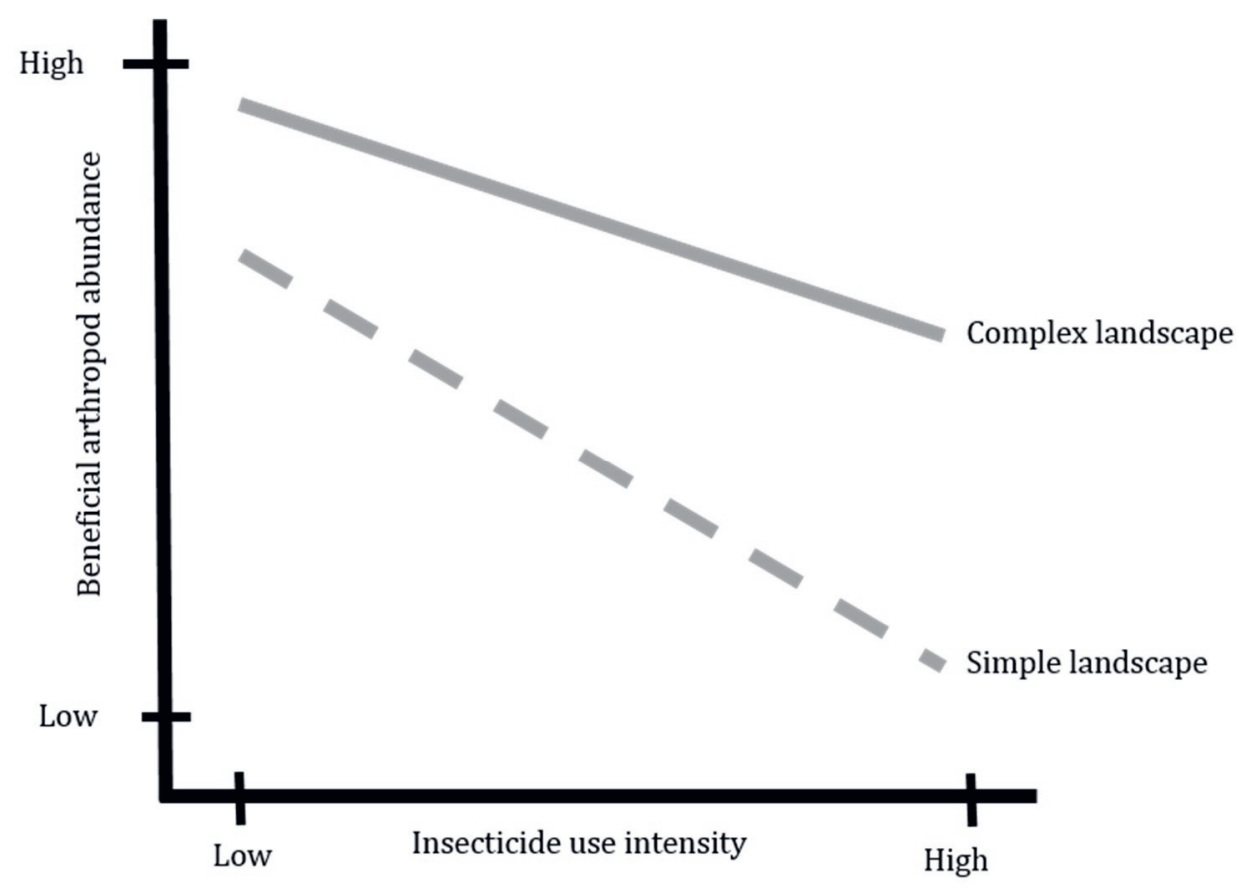

Figure 3.1: Hypothesised relationship between the abundance of beneficial arthropods and insecticide use in different landscape settings. Arthropod abundance is expected to be negatively affected by the intensity of insecticide use and landscape simplification. Moreover, arthropod abundance in complex landscapes is expected to be less affected by insecticides than in more simplified landscapes due to more efficient recolonization from nearby source habitats. After Roubos et al. (2014) and Tscharntke et al. (2005).

In this study we ask how the abundance of arthropod predators, parasitoids and pollinators is influenced by local and landscape wide insecticide use, and whether this response is moderated by the composition of the surrounding landscape. Arthropod predators, parasitoids and pollinators represent three ubiquitous functional groups that are responsible for regulating ecosystem services and they represent a wide range in feeding behaviours, habitat requirements and dispersal abilities, and susceptibility to insecticides (Chaplin-Kramer et al., 2011; Krauss, Gallenberger and Steffan-Dewenter, 2011; Karp et al., 2018). These functional groups might therefore respond differently to the use of insecticides 
and they might also respond at different spatial scales (Tscharntke et al., 2007). We hypothesized that the abundance of beneficial arthropods is negatively related to insecticide use at the local and landscape level. Furthermore, we expected that insecticide use has a stronger impact on the abundance of beneficial arthropods in simple landscapes than in more complex landscapes, because in complex landscapes beneficial insect can more efficiently recolonize insecticide treated areas from semi-natural habitats than in simple landscapes (Fig. 3.1).

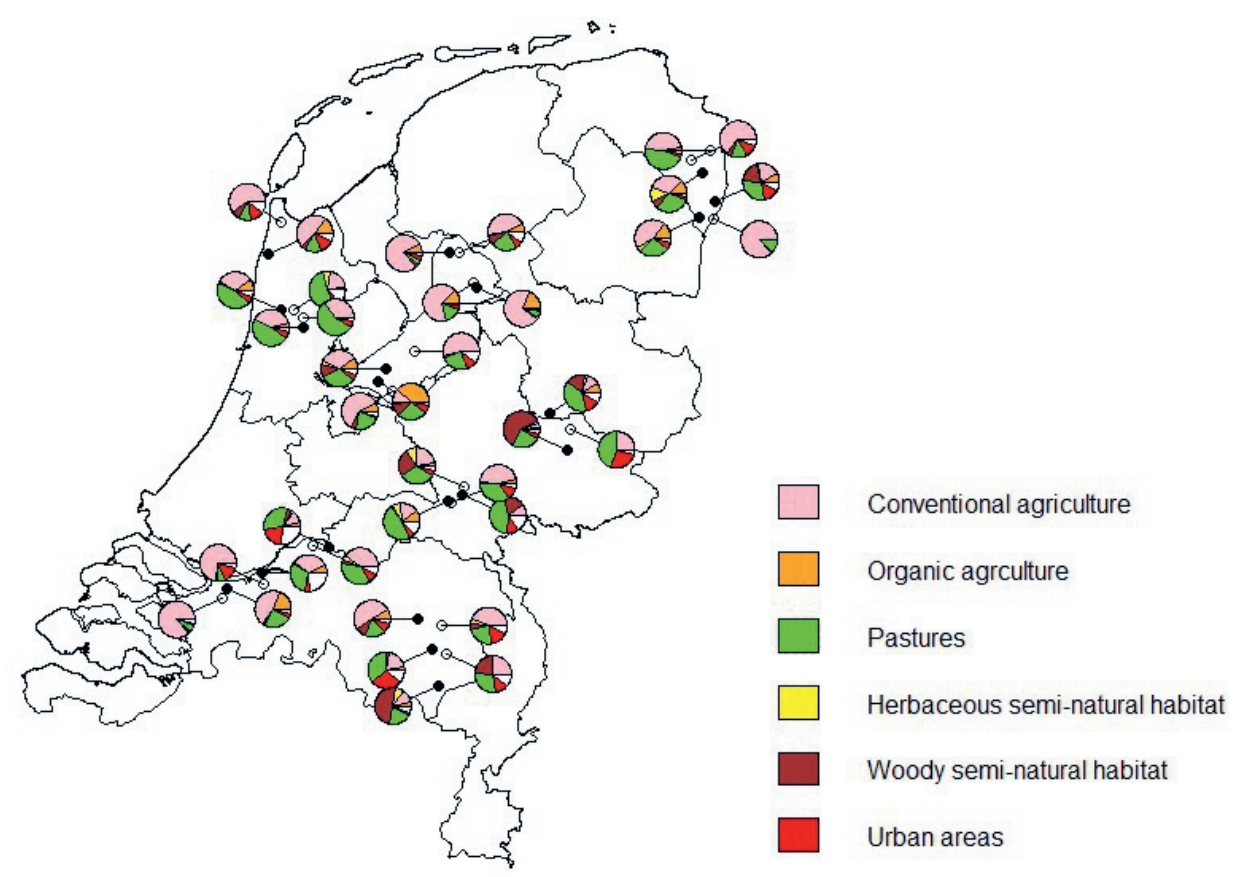

Figure 3.2: Locations of the 38 sampling sites in the Netherlands. Open and closed circles indicate conventionally and organically managed sites, respectively. Pies show the composition of the landscape at $1 \mathrm{~km}$ radius around the focal fields. Map of the Netherlands downloaded from GADM (https://gadm.org/index.html).

\section{MATERIALS AND METHODS}

\section{Landscape and site selection}

We selected thirty-eight sampling sites embedded in twenty landscapes, ranging from structurally simple to structurally complex, spread across the Netherlands (Fig. 3.2). Sites were paired within each landscape, and focal fields were located adjacent to an organically or conventionally managed arable field. To avoid direct impacts of on-field insecticide applications, we assessed arthropod abundances in field margins. All fields were managed according to farmers' practice. 


\section{Land use variables}

Six land use categories were used to describe land cover within a $1 \mathrm{~km}$ radius scale around each sampling site: i) organic agriculture (including orchards); ii) conventional agriculture (including orchards); iii) herbaceous semi-natural habitat (including extensively managed perennial grassland, nature areas/reserves, flower strips, grassy field margins), iv) wooded habitats; v) grasslands (annual and perennial); and vi) urban area.

\section{Quantification of insecticide use}

We used three indicators for insecticide use, which account for the intensity of insecticide use at different level of detail and spatial scale. First, we used the management system of the adjacent field (conventional vs. organic) as a simple metric to capture the likely presence or absence of exposure to synthetic insecticides in the nearby field. Second, we used the Treatment Frequency Index (TFI) of applied insecticides in the adjacent field of the sampling site as a quantitative indicator of insecticide use (Gravesen, 2003). TFI was calculated as the sum total of applied dosages divided by maximum label-recommended dosage (CTGB, 2019), and is considered a measure of the level of dependence on insecticides (Lechenet et al., 2014). Insecticide use data were provided by the farmers of the focal fields. Third, we estimated the insecticide load within a $1 \mathrm{~km}$ radius around the sampling site using cropspecific insecticide use data in The Netherlands from 2016 (Statline, 2019) (Table S3.1). The insecticide load was calculated as a weighted average across the proportion of crops in the landscape circles, from which we derived the estimated quantity of insecticides applied (QIA) in kilograms per hectare. For a more detailed explanation of the experimental design, landscape variables and quantification of insecticide use we refer to Bakker et al. (2021b).

\section{Arthropod sampling}

Arthropods were collected by sweep net sampling (gauze net with $40 \mathrm{~cm}$ diameter) and yellow sticky traps (Horiver, 25x10 cm, double-sided, Koppert Biological Systems). At each sampling site we sampled two transects by sweep netting. Each transect was located in a field edge on adjoining sides of the arable field, and consisted of 50 sweeps of a full $180^{\circ}$ arc through the field margin canopy. Each transect was swept twice, at a $48 \mathrm{hr}$ interval, at the time of drop-off and pick-up of sticky traps in the fields. The collected specimens of each transect were stored in a separate killing jar, and stored in bottles with $70 \%$ ethanol in the laboratory. Two sticky trap cards were placed in the field margin at approximately $50 \mathrm{~m}$ from each other. Sticky cards were attached to a wooden stake with the lower edge of the card above the canopy of the field margin. Sticky traps were collected after $48 \mathrm{hr}$, placed in a plastic bag, and stored in a freezer until processing. Sampling rounds lasted approximately three weeks, and were replicated four times across two years (June 20 - July 7, 2017; July 24 - August 11, 2017; June 12 - June 29, 2018; and July 17- August 3, 2018).

Sweep net and sticky trap samples were sorted to separate beneficial arthropods; (bumble)bees (Apoidae), hoverflies (Syrphidae), parasitoids (Hymenoptera Apocrita), 
lacewings (Chrysopidae), rove beetles (Staphylinidae), ladybeetles (Coccinellidae), and spiders (Aranae). Specimens were identified to (sub)order or family, with hoverflies, (bumble)bees, and ladybeetles identified to species level. For sweep net samples, we counted all other arthropods and identified them to order level where possible. Orders included Heteroptera, Hemiptera, Coleoptera, Diptera, Thysanoptera, Aphidoidea, and Acari. Beneficial arthropods were categorized into three functional groups: predators (lacewings, rove beetles, ladybeetles, and spiders), parasitoids, and pollinators (hoverflies and bees).

\section{Data analysis}

To assess whether the abundance of beneficial arthropods was associated with local and landscape-wide insecticide use, we used three indicators for insecticide use; management (organic or conventional management in the adjacent field), TFI (Treatment Frequency Index in adjacent field), and QIA (Quantity of insecticides applied at landscape level). The effect of each insecticide indicator was modelled separately to distinguish effects of local and landscape-wise insecticide use. In all models we included five explanatory landscape variables (fixed factors) to explore the interaction between insecticide use and landscape: proportion of herbaceous semi-natural habitat ('herbSNH'), proportion of woody seminatural habitat ('woodySNH'), proportion organic farming ('propORG), proportion conventional farming ('propCONV') and proportion grassland ('propPastures'). Since the number of captured individuals can be influenced by activity patterns or weather conditions, we used 'sampling day' as a random factor for sweep net data. For sticky traps we used 'sampling round' as a random factor to account for time of year and weather conditions during the $48 \mathrm{hr}$ exposure time in the field. To assess the influence of the adjacent crop and its management apart from what was captured in the insecticide use variables, we also included 'crop type' in adjacent fields as a random effect in all models. Eleven crop types were included: seed potatoes, ware potatoes, cereal crops, cover crops, corn, herbs, tulips, sugar beets, beans, carrots, and other vegetables.

Predator and parasitoid abundance was analysed using generalized linear mixed-effects models (GLMM) with a negative binomial error distribution. Pollinator abundance was analysed using generalized linear models (GLM) with a negative binomial error distribution because GLMs received more support from the data than GLMMs (based on Akaike's information criterion (AIC)). Sweep net data consisted of 573 observations (38 sites x two transects per sampling site $\mathrm{x}$ two sampling days $\mathrm{x}$ four sampling rounds; 35 missing observations). Sticky trap data consisted of 287 observations (38 sites x two sticky traps per sampling site $\mathrm{x}$ four sampling rounds; 17 missing observations). Missing observations were due to the inability to visit all sites in sampling round three, and some sticky cards were lost due to hard wind. We also had 13 missing values for TFI, because not all farmers were able to provide us with pesticide use information. As a consequence, the models for insecticide 
indicator 'TFI' consisted of 481 observations for sweep net samples and 242 observations for sticky trap samples.

We used model selection with the corrected Akaike's criterion (AICc) $<2$ of the most parsimonious model to rank models, and then conducted model averaging for this subset of 'best' models (Burnham and Anderson, 2002; Feld et al., 2016; Grueber et al., 2011). Model averaging accounts for the relative importance of explanatory variables in a set of 'best' models. For a more detailed explanation on the model averaging procedure we refer to Bakker et al. (2021b). Separate analyses were conducted for predators, parasitoids and pollinators for sweep netting and sticky trap data. All analyses were performed in R ( R Development Core Team, 2019) using the glmmTMB package (Brooks et al., 2017). Model selection and averaging was conducted with the MuMIn package (Barton, 2019). Plots were made using ggplot2 (Wickham, 2016) and marmap (Pante and Simon-Bouhet, 2013).

\section{RESULTS}

\section{Sweep net}

In total, we collected 48,743 arthropods by sweep netting. We identified 535 pollinator individuals (474 hoverflies (25 taxa; (Table S3.2)) and 61 (bumble)bees (12 taxa; Table S3.3)), 1541 predators (102 lacewings, 75 ladybeetle adults and 10 juveniles (12 taxa; Table S3.4), 1288 spiders, and 66 rove beetles), and 5121 parasitoids.

Pollinator abundance in sweep net samples was negatively associated with conventional management $(\beta=-0.54, \mathrm{z}=3.07, \mathrm{p}<0.001)$ and TFI $(\beta=-0.63, \mathrm{z}=3.44, \mathrm{p}<0.001)$, while predator and parasitoid abundance were not significantly associated with organic or conventional management in the adjacent field (Table 3.1; Fig. 3.3). The abundance of predators, parasitoids and pollinators was significantly negatively associated with the quantity of insecticides applied at landscape level (QIA; $\mathrm{p}<0.01$; Table 3.1; Fig. 3.3).

Predator abundance was positively associated with the proportion of woody semi-natural habitat in all models (Table 3.1). Furthermore, in the model with insecticide indicator 'Management' and 'TFI', predator abundance was positively associated with the proportion of pasture (Table 3.1). Parasitoid abundance was negatively associated with the amount of herbaceous semi-natural habitat, and positively associated with the amount of woody seminatural habitat in the models that contained the insecticide indicator 'Management' or 'QIA' (Table 3.1). Moreover, in the model for parasitoid abundance and the insecticide indicator QIA, there was a significant positive interaction between QIA and woodySNH $(\beta=0.30, z=$ 2.51, $\mathrm{p}<0.05$; Table 3.1), indicating that the positive effect of woodySNH on parasitoid abundance was greater in landscapes with higher QIA and lower in landscapes with lower QIA (consistent with the hypothesis in Fig. 3.1). For pollinator abundance there was, however, a significant negative interaction between QIA and woodySNH, as well as between QIA and herbSNH (Table 3.1), contradicting the hypothesis in Fig. 3.1. Furthermore, in the 
model with insecticide use indicator 'QIA', pollinator abundance was negatively associated with the proportion of herbaceous and woody semi-natural habitat and the proportion of pastures, but positively associated with the proportion of organic agriculture (Table 3.1).

\section{Sticky traps}

We captured 360 pollinators (351 hoverflies (22 taxa; Table S3.2) and 9 (bumble)bees (5 taxa; Table S3.3)), 1262 predators (196 lacewings, 532 rove beetles, 285 ladybeetles (13 taxa; Table S3.4), and 249 spiders) and 18,883 parasitoids on yellow sticky traps.

The abundance of predators, parasitoids and pollinators on sticky traps was not significantly associated with insecticide indicators (Table 3.2; Fig. S3.1). Predator abundance was negatively associated with the proportion of herbaceous semi-natural habitat in the models for insecticide indicator 'Management' and 'TFI' (Table 3.2). Parasitoid abundance was negatively associated with the proportion of pastures in the landscape in the models for insecticide indicator 'QIA' (Table 3.2). The abundance of pollinators was negatively associated with the proportion of herbaceous semi-natural habitat $(\beta=-0.49, \mathrm{z}=2.12, \mathrm{p}<$ 0.05 ) in the model for insecticide indicator ' $Q I A$ ', and there was a significant negative interaction between QIA and herbSNH (Table 3.2), indicating that a positive effect of herbSNH on pollinator abundance was smaller in landscapes with high QIA than in landscapes with low QIA. 


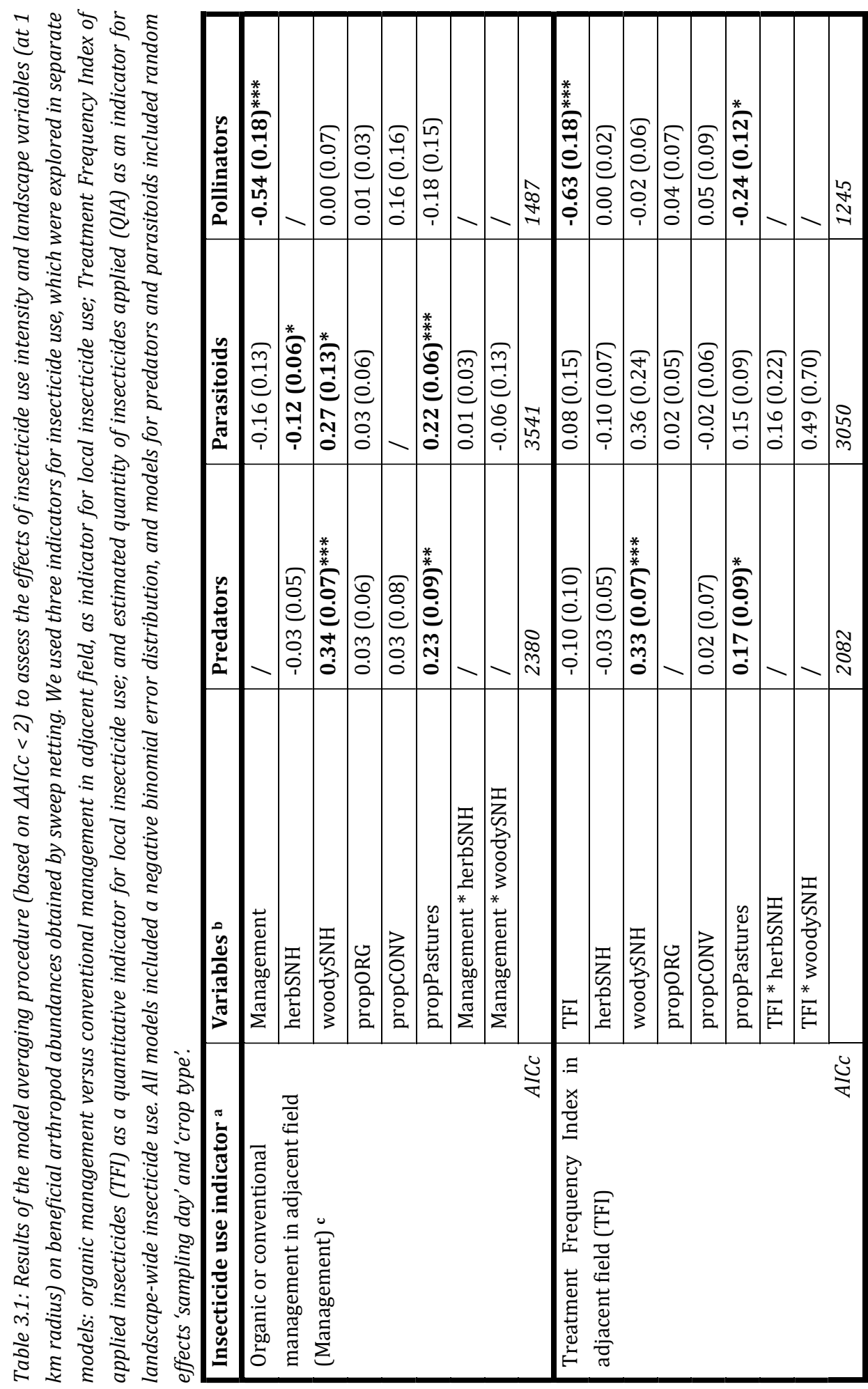




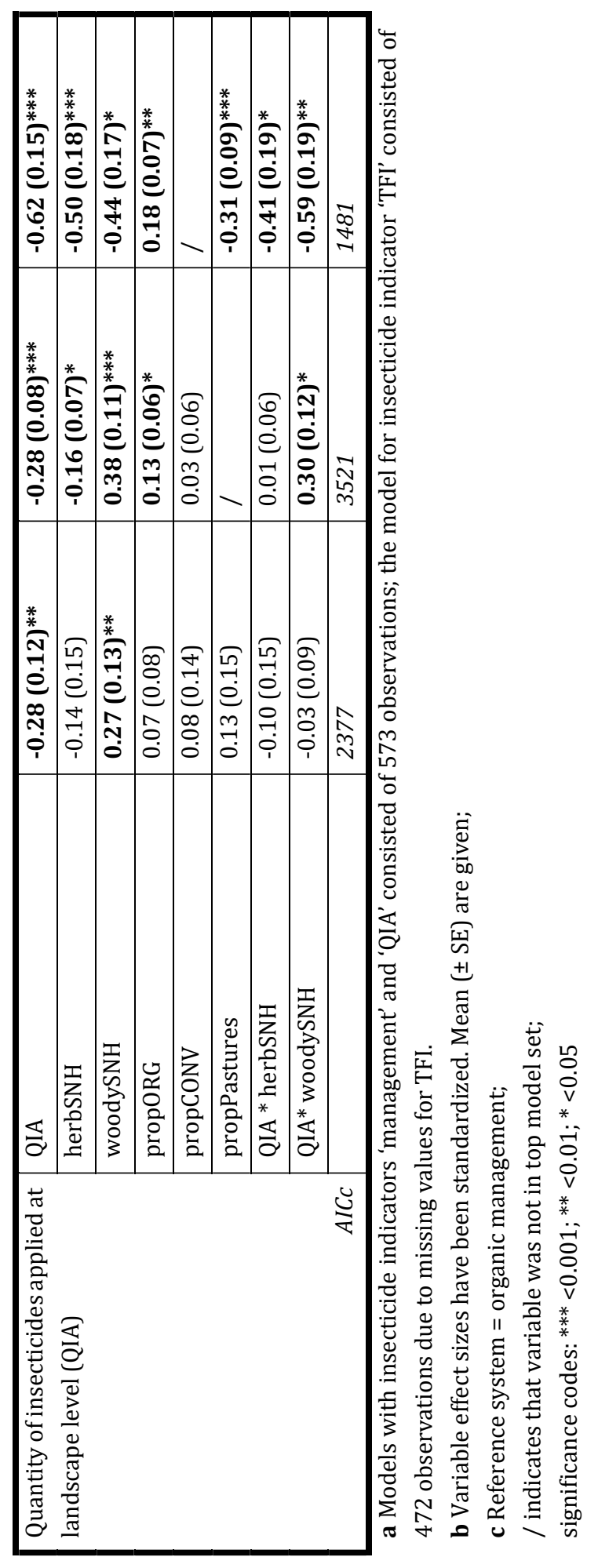




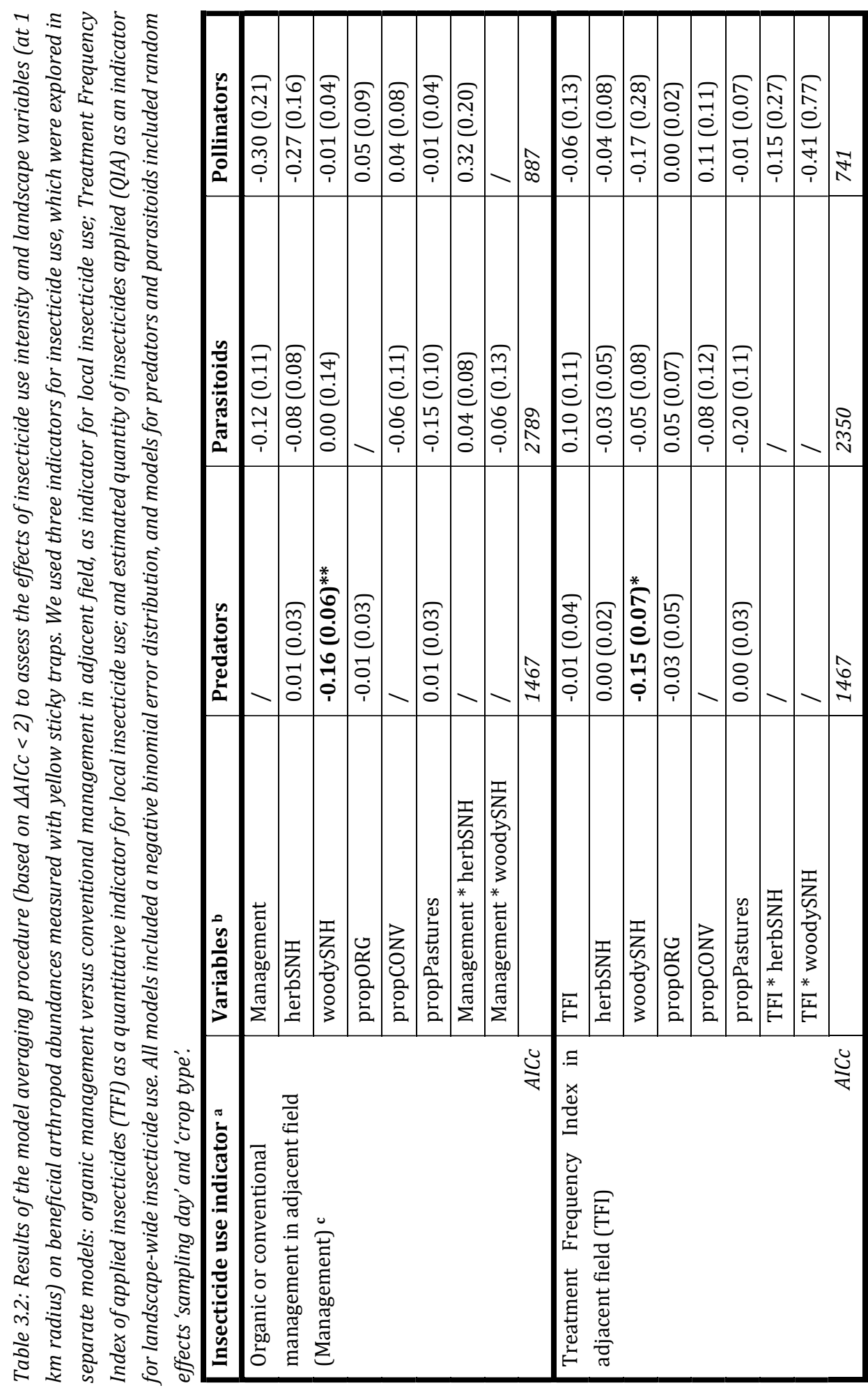




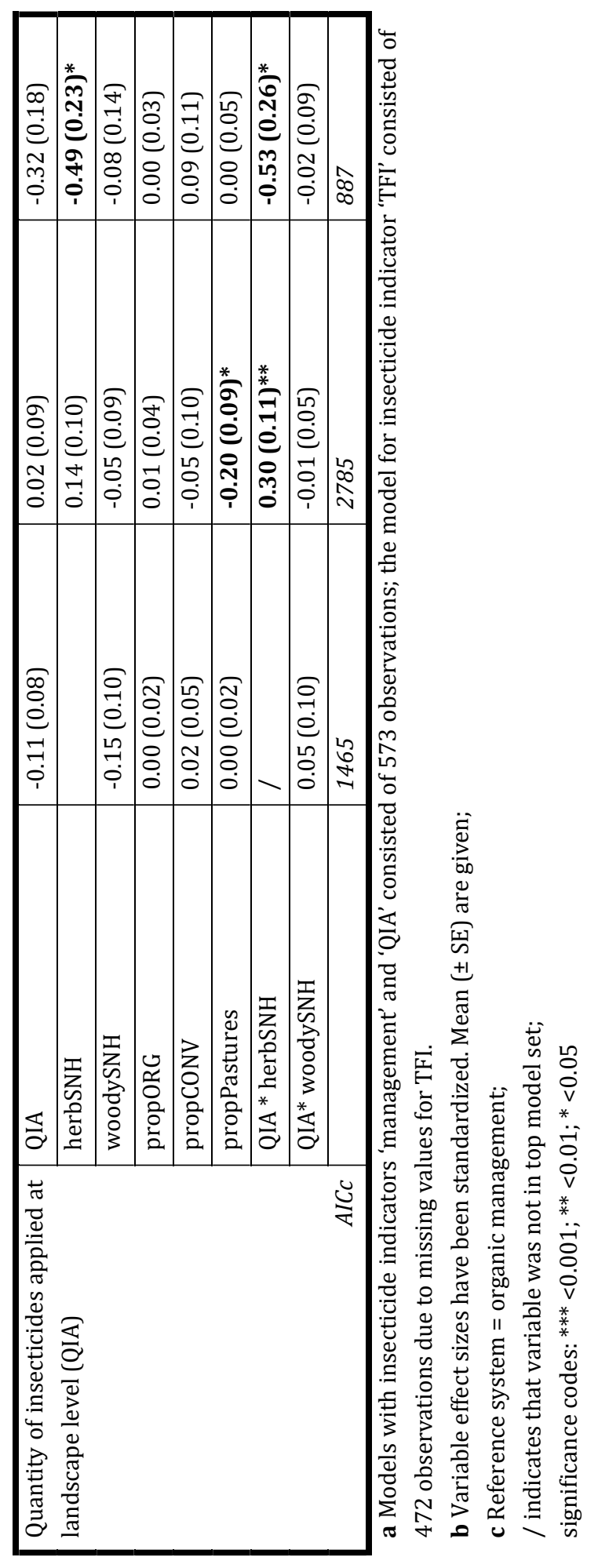



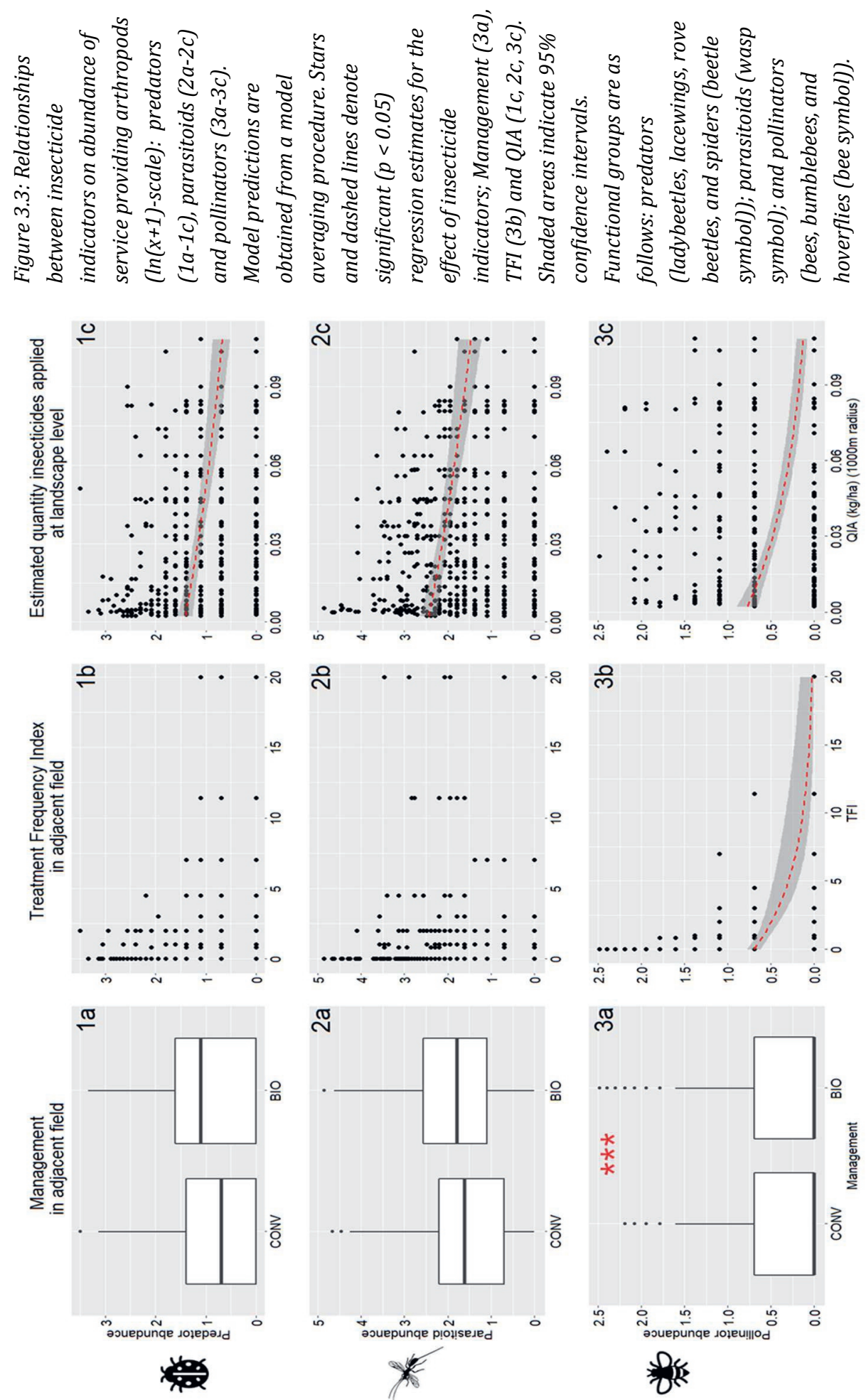


\section{DISCUSSION}

In this two-year study we assessed relationships between the abundance of beneficial arthropods, indicators for insecticide use at the local and landscape scale, and landscape context. Beneficial arthropod populations in field margins, assessed by sweep-netting, were negatively associated with insecticide loading at the landscape scale, while arthropod sampling by sticky traps did not show significant relationships. Pollinator abundance was negatively associated with conventional farming in the adjacent field and with the frequency of insecticide applications, while predator and parasitoid abundance did not show significant associations with local insecticide use indicators. Some of the associations between beneficial arthropods and insecticides interacted with the composition of the surrounding landscape, but both positive and negative interactions were found, and the responses were functional group specific. We thus did not find unequivocal support for the hypothesis that diverse landscapes can moderate negative impacts of insecticide use.

Impacts of insecticide use on functional groups of beneficial arthropods manifested at the landscape scale rather than on the field scale. A possible explanation for this finding is the 'action at a distance' mechanism, which posits that mobile arthropod populations in areas that are not directly affected by pesticides can still be affected indirectly through arthropod source-sink dynamics (Spromberg, John and Landis, 1998; Bianchi, Ives and Schellhorn, 2013; Topping et al., 2014; EFSA Scientific Committee, 2016). This mechanism is demonstrated by spatially-explicit modelling studies that show that insecticide-treated fields act as sink habitats and can deplete beneficial arthropod populations at the landscape scale (Bianchi, Ives and Schellhorn, 2013; Topping et al., 2015). Landscape scale impacts of insecticides can also be expected because insecticides can spread over larger areas through drift, emission and erosion of residues in soil and water, providing different potential pathways for run-off to non-target areas (de Jong, de Snoo and van de Zande, 2008; D. Goulson, 2013; Chagnon et al., 2015). Hence, when populations of beneficial arthropods are exposed to insecticides at relatively large spatial and temporal scales, this could diminish their population sizes due to lethal and sublethal effects, such as reduced reproduction rates (Desneux, Decourtye and Delpuech, 2007; Devine and Furlong, 2007; Woodcock, Bullock, et al., 2016).

We found positive and negative interactions between the effects of insecticides and proportion semi-natural habitat in the landscape, partly contradicting the expectation that impacts of insecticides on beneficial arthropods could be mitigated in landscapes with greater proportions of semi-natural habitat (Fig. 3.1; Roubos et al., 2014; Tscharntke et al., 2005). Parasitoid and predator abundance was positively associated with the proportion of woody semi-natural habitat, and for parasitoids the positive effect of woody SNH was greater if there was higher insecticide use in the landscape. Surprisingly, pollinator abundance was negatively associated with the proportion of herbaceous semi-natural habitat, and this effect was greater in landscapes with higher insecticide use. This is contrary 
to findings that report positive associations between pollinator abundance and semi-natural habitat (see e.g. Holzschuh et al., 2007; IPBES, 2016; Kennedy et al., 2013; Kremen et al., 2002). Semi-natural habitats are considered important habitats for beneficial arthropods because they may limit the spread of agrochemicals by serving as a barrier against drift (Marshall and Moonen, 2002), provide alternative sources for food and overwintering habitats (Landis, Wratten and Gurr, 2000), and sustain populations that may recolonize insecticide treated fields (Rusch et al., 2010). The differential responses of natural enemies and pollinators to semi-natural habitat in our study could be explained by functional group specific traits (Martin et al., 2019). For example, pollinators are very mobile and sensitive to habitat quality of semi-natural habitats (Li et al., 2020), and the spatial scale of $1 \mathrm{~km}$ radius may not have captured the functional spatial scales of the pollinator community (Martin et al., 2020). Thus, the response of beneficial arthropods to semi-natural habitat may be species specific, while it also depends on their biology and resource requirements (Karp et al., 2018; Martin et al., 2019). This emphasizes the need for landscape-wide management strategies to differentiate between the responses of predators, parasitoids and pollinators (Kleijn et al., 2006).

The analysis of sweep net sampling data revealed significant associations of beneficial insect abundance with indicators of insecticide use and landscape context, while this was much less the case for data collected by placing yellow sticky traps. This finding is in line with results of Ohnesorg et al. (2009), who detected significant differences in natural enemies collected with sweep netting between insecticide treatments, but not with sticky traps. Sweep netting captures arthropods that are present in the vegetation canopy, including less mobile species . For example, we collected significantly more spiders with sweep netting than with sticky traps (Table S3.5; Fig. S3.2). Yellow sticky traps catch arthropods that are flying above the vegetation. The traps are visually attractive to some arthropods and may therefore overrepresent species that are attracted to this colour. In addition, larger-bodied species, such as bumble bees, do not stick well to sticky traps. With our sticky traps we collected a total of nine (bumble)bees, compared to 61 with sweep netting (Table S3.5; Fig. S3.2). Hence, the differences in the catches between the two sampling methods in our study may reflect differences in behaviour and activity of species groups (Doxon, Davis and Fuhlendorf, 2011). As such, sweep netting and sticky traps sample a different arthropod community (Schmidt, O'Neal and Dixon, 2008; Hambäck et al., 2020), and this may blur relationships between arthropod abundance, insecticide intensity and landscape context.

We estimated the quantity of applied insecticides based on national pesticide use data of crops with high pesticide dependency and the area of those crops within the landscapes. This approximation was used because pesticide use data were not available at the landscape level. However, while this method allowed to make a reasonable estimate of the expected insecticide load at the landscape scale, it did not capture variation in the frequency of insecticide applications between farmers, regions and weather conditions. The indicator of 
insecticide use at the landscape level was consistently and significantly negatively associated with the abundance of predators, parasitoids and pollinators, which was in line with our hypothesis. Given the substantial evidence base of potential environmental and health impacts from pesticides (Popp, Peto and Nagy, 2013; van der Sluijs et al., 2015; Larsen, Patton and Martin, 2019) it is remarkable that there is no public accessible data on pesticide use available in the Netherlands like there is in, for instance, the US where pesticide data are available at the county level (Meehan and Gratton, 2016; Larsen, Patton and Martin, 2019). The availability of such data would allow a better informed analysis of impacts of pesticides at the landscape scale.

\section{Policy implications}

Reducing the risks and impacts of pesticides is central in current European agricultural pesticide policies (European Commission, 2020). Yet, despite years of policy efforts to decrease pesticide use (e.g. National Action Plans on sustainable plant protection in Europe), pesticides are still commonly used in conventional agriculture, pesticide sales are stable (Möhring et al., 2020), and environmental quality standards in aquatic habitats are still breached (Leendertse et al., 2019; Sporenberg, Verstand and Beerling, 2019). Our data indicate that insecticide impacts on insect populations extend beyond the field in which they are applied, and these effects play out at the landscape scale. This notion puts a new perspective on the debate on the risks and benefits pesticide use, and calls for a landscape approach to regulate pesticide use. The assessment of the spatial scale at which pesticides impacts the environment requires a systematic monitoring and publishing of data on pesticide use (Milner and Boyd, 2017; Topping, Aldrich and Berny, 2020). In fact, in the Netherlands farmers are already required to register their pesticide use data as obliged in the Dutch National Action Plan on sustainable plant protection (European Commission, 2012), but this information is not public because this is considered private even though the potential impacts affect public goods. Information on where, when, and why pesticides have been used could provide insights of pest management decision making and contribute to developing regulations for judicious pesticide use (Milner and Boyd, 2017).

\section{ACKNOWLEDGEMENTS}

The work reported in this paper was financially supported by the Dutch Research Council (NWO), grant 824.15.022. We thank Patric Brandt for his help with the landscape analysis and work in ARCGIS, and Matthijs Courbois for his help on insect species identification. Furthermore, a big thanks to the following people for their assistance in the field work: Yavanna Aartsma, Liron Chen, Lenora Ditzler, Henk Eshuis, Julia van Oord, Kim van Oost, Chris Oosterhof, and Francine Pacilly. Finally, we are very grateful to all farmers that participated in the study and provided us with access to their fields, and who were willing to share information on their farming practices. 


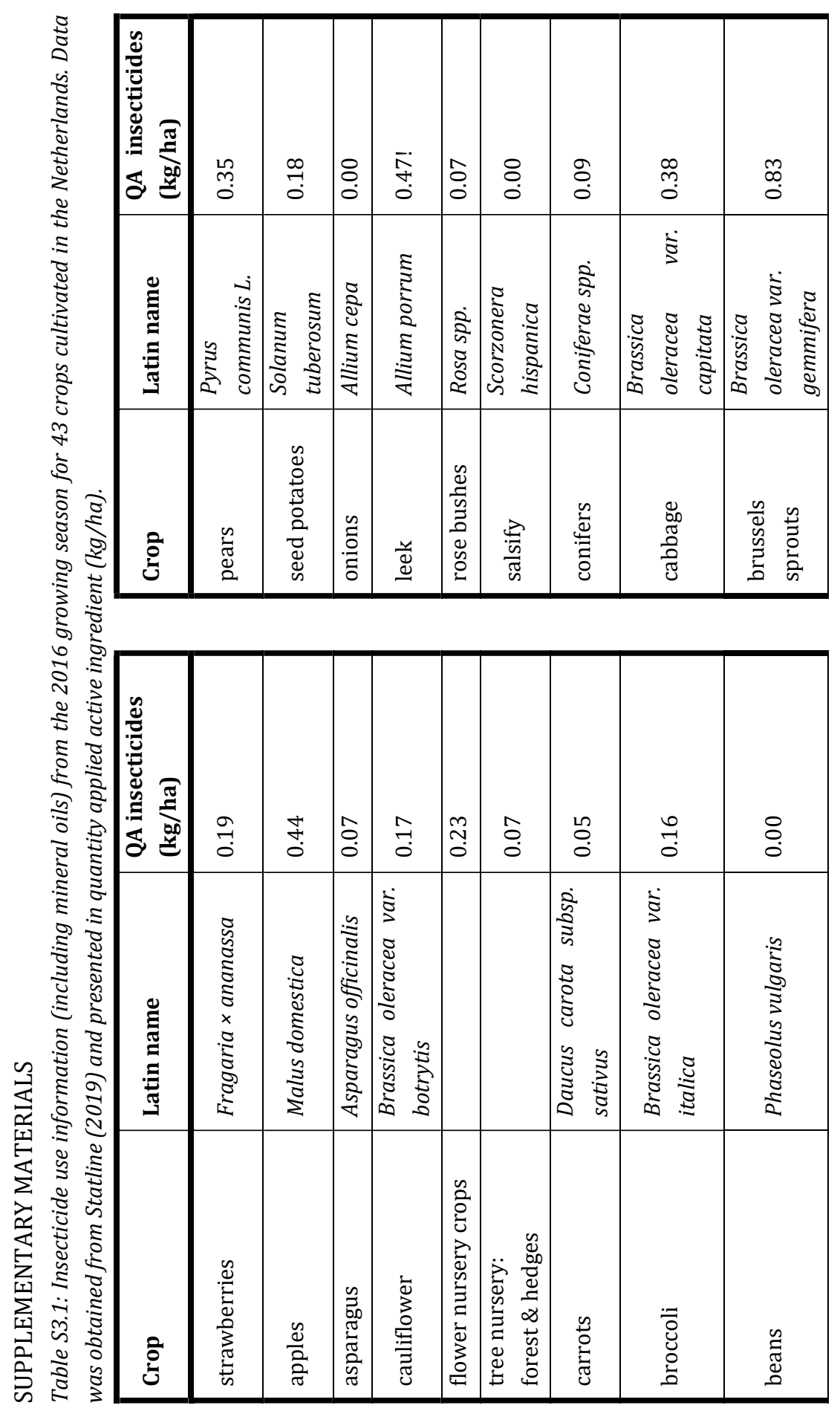



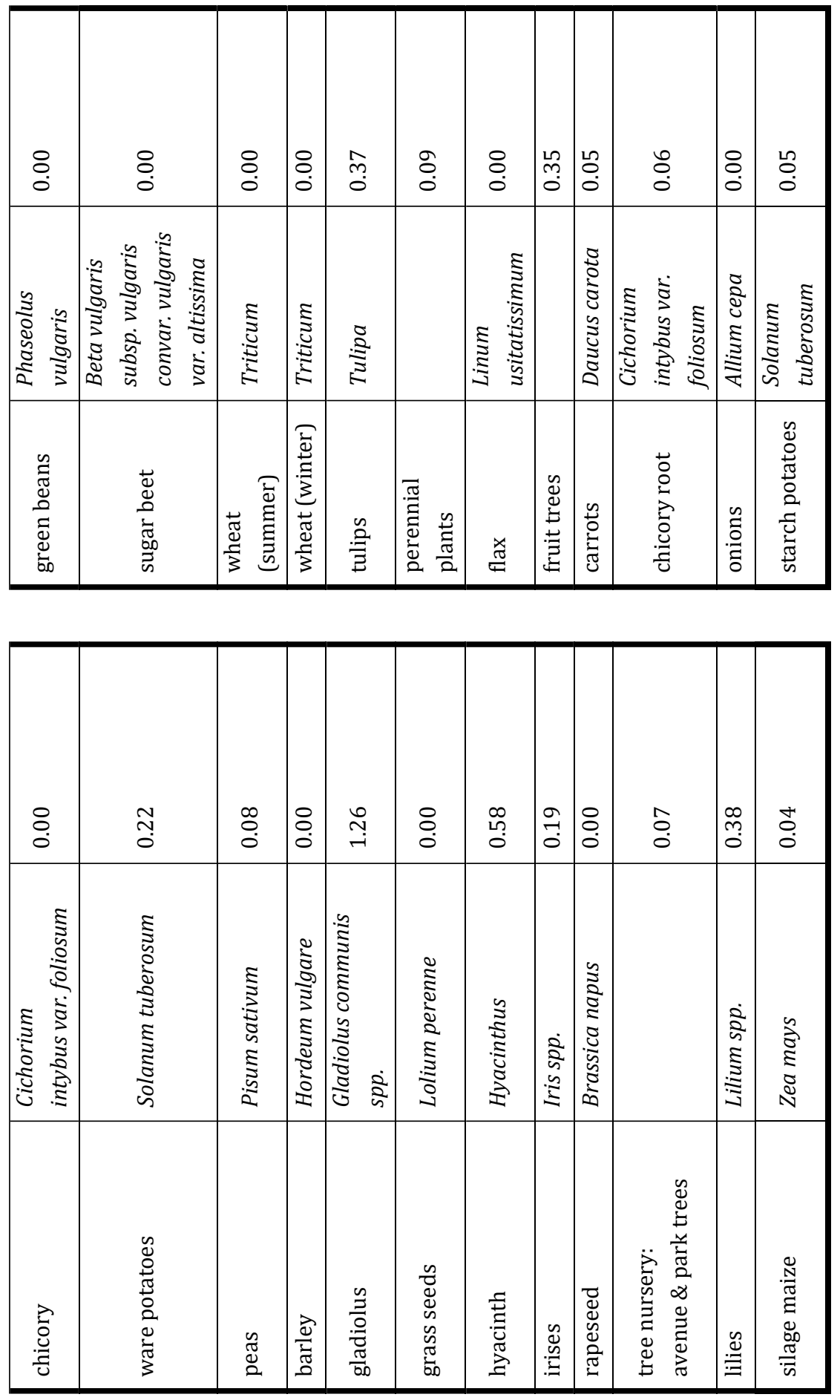
Table S3.2: Hoverfly species collected with sweep net sampling and yellow sticky traps in four sampling periods. 'Sampling period' relates to the respective sampling rounds: 1 (June 20 - July 7 2017), 2 (July 24 - August 11 2017), 3 (June 12 - June 29 2018), and 4 (July 17 August 3 2018).

\begin{tabular}{|l|l|l|l|l|l|l|l|l|}
\cline { 2 - 8 } \multicolumn{2}{l}{} & \multicolumn{3}{l}{ Sweepnet } & \multicolumn{3}{l|}{ Sticky Trap } \\
\hline sampling period & $\mathbf{1}$ & $\mathbf{2}$ & $\mathbf{3}$ & $\mathbf{4}$ & $\mathbf{1}$ & $\mathbf{2}$ & $\mathbf{3}$ & $\mathbf{4}$ \\
\hline Cheilosia & 1 & & & & & & & 1 \\
\hline Epistrophe nitidicollis & 1 & & & & 1 & & & \\
\hline Episyrphus balteatus & 20 & 11 & 6 & 3 & 56 & 19 & 11 & 1 \\
\hline Eristalis arbustorum & & & & & & 1 & & 1 \\
\hline Eristalis nemorum & & 1 & & & & & & 4 \\
\hline Eristalis pertinax & & & 1 & & 1 & & & \\
\hline Eristalis spp. & & & & & 1 & 1 & & 5 \\
\hline Eristalis tenax & 1 & 2 & & 1 & 5 & 13 & 1 & 9 \\
\hline Eupeodes corollae & 13 & 1 & 2 & 14 & 5 & 7 & 14 & 29 \\
\hline Melanostoma mellinum & 28 & 84 & 67 & 32 & 3 & 2 & 22 & 2 \\
\hline Melanostoma/Platycheirus spp. & & & & 5 & 1 & 2 & 2 & \\
\hline Myathropa florea & 1 & & & 1 & & & & \\
\hline Neoascia spp. & & 1 & & & & 1 & & \\
\hline Platycheirus & 1 & & & & & & 1 & \\
\hline Platycheirus albimanus & & 1 & 1 & & & 1 & & \\
\hline Platycheirus angustatus & 1 & 1 & & & & 1 & & \\
\hline Platycheirus clypeatus & 20 & 10 & 4 & 2 & & & & \\
\hline Platycheirus fulviventris & & & 1 & & & & & 1 \\
\hline Scaeva pyrastri & 1 & & & & 2 & 9 & 7 & \\
\hline Sphaerophoria spp. & 3 & 4 & 9 & 15 & 10 & 31 & 4 & 9 \\
\hline Sphaerophoria rueppelli & & 4 & & & & & & \\
\hline Sphaerophoria scripta & 29 & 37 & & 15 & & & & \\
\hline Sphaerophoria taeniata & 1 & 2 & & & & & & \\
\hline Syritta pipiens & & 3 & 3 & & & 1 & & \\
\hline Tropidia scita & & & & 6 & & & 2 & 15 \\
\hline Xylota segnis & & & & & & 1 & 1 & 1 \\
\hline Syrphus spp. & & & & & & & \\
\hline Syrphidae spp. (indet) & & & 3 & 12 & 10 & 8 & 4 \\
\hline
\end{tabular}


Table S3.3: Bumble bee, bee and wasp species collected with sweep net sampling and yellow sticky traps in four sampling periods. 'Sampling period' relates to the respective sampling rounds: 1 (June 20 - July 7 2017), 2 (July 24 - August 11 2017), 3 (June 12 - June 29 2018), and 4 (July 17- August 3 2018).

\begin{tabular}{|l|l|l|l|l|l|l|l|l|}
\multicolumn{2}{l}{} & \multicolumn{3}{l}{ Sweep net } & \multicolumn{3}{l|}{ Sticky Trap } \\
\hline Sampling period & $\mathbf{1}$ & $\mathbf{2}$ & $\mathbf{3}$ & $\mathbf{4}$ & $\mathbf{1}$ & $\mathbf{2}$ & $\mathbf{3}$ & $\mathbf{4}$ \\
\hline Aculeata sp. & & & & & & & 1 & \\
\hline Anthophila & & & & & 1 & & 1 & 1 \\
\hline Andrena sp. & & 1 & 4 & 3 & & & & \\
\hline Apis melifera & 2 & 2 & & 11 & & & & \\
\hline Bombus pratorum & & & & 2 & & & & \\
\hline Bombus pascuorum & 1 & & 4 & 2 & & & & \\
\hline Bombus terrestris & 1 & 2 & 1 & & & & & \\
\hline Dasypoda hirtipes & 1 & & & & & & & \\
\hline Heriades truncorum & 2 & & & & & & & \\
\hline Halictur sp. & & 1 & 1 & & & & & \\
\hline Hylaeus sp. & & & & & 1 & & & \\
\hline Lasioglossum sp. & & 1 & 2 & 2 & & & & 3 \\
\hline Panurgus calcaratus & & & 1 & 1 & & & & \\
\hline Polistes dominula & & & & 1 & & & & \\
\hline Vespula spp. & & 1 & 2 & 9 & & & & 1 \\
\hline
\end{tabular}


Table S3.4: Ladybeetle species collected with sweep net sampling and yellow sticky traps in four sampling periods. 'Sampling period' relates to the respective sampling rounds: 1 (June 20 - July 7 2017), 2 (July 24 - August 11 2017), 3 (June 12 - June 29 2018), and 4 (July 17 August 3 2018).

\begin{tabular}{|l|l|l|l|l|l|l|l|l|}
\cline { 2 - 9 } \multicolumn{2}{l}{} & \multicolumn{3}{l}{ Sweepnet } & \multicolumn{3}{l|}{ Sticky Trap } \\
\hline Sampling period & $\mathbf{1}$ & $\mathbf{2}$ & $\mathbf{3}$ & $\mathbf{4}$ & $\mathbf{1}$ & $\mathbf{2}$ & $\mathbf{3}$ & $\mathbf{4}$ \\
\hline Adalia bipunctata & & & 1 & & & & & 2 \\
\hline Adalia decempunctata & & & & & 1 & 1 & & \\
\hline Coccinella quinquepunctata & & & & 1 & 6 & & & 3 \\
\hline Coccinella septempunctata & 9 & 3 & 1 & 3 & 5 & 3 & 2 & 64 \\
\hline Coccinella septempunctata larvae & 4 & 2 & & & & & & \\
\hline Cocinella undecimpunctata & 1 & 3 & & 3 & 16 & 6 & & 11 \\
\hline Coccinella magnifica & 2 & & & & & & & \\
\hline Harmonia axiridys & 7 & 16 & 2 & & 32 & 29 & 1 & 5 \\
\hline Harmonia axyridys larvae & 1 & 1 & & & & & & \\
\hline Hippodamia tredecimpunctata & & & & & & & & 4 \\
\hline Hippodamia variegata & & 2 & & 2 & & & & 5 \\
\hline Oenopia conglobata & & & & & & & & 5 \\
\hline Propylea quatordecimpunctata & 3 & 4 & 1 & 7 & 27 & 4 & 19 & 25 \\
\hline Psyllobora vigintiduopunctata & 1 & 1 & & & 4 & & & 3 \\
\hline Psyllobora vigintiduopunctata larvae & 1 & & & & & & & \\
\hline Tytthaspis sedecimpunctata & & & 1 & 1 & & & & 2 \\
\hline Coccinellidae larvae spp. & 1 & & & & & & & \\
\hline
\end{tabular}

Table S3.5: Results of one-way ANOVA tests to determine differences in catches of arthropods between sampling methods. Stars denote significant differences in mean values; ${ }^{* * *}<0.001$; ** $<0.01 ; *<0.05$

\begin{tabular}{|l|l|l|}
\cline { 2 - 3 } \multicolumn{1}{c|}{} & F-value & p-value \\
\hline Parasitoid wasps & 19.31 & $* * *$ \\
\hline Syrphids & 4.345 & $*$ \\
\hline Lacewings & 5.194 & $*$ \\
\hline Rove beetles & 36.26 & $* * *$ \\
\hline Ladybeetles & 21.33 & $* * *$ \\
\hline Spiders & 73.19 & $* * *$ \\
\hline (Bumble)bees & 14.15 & $* * *$ \\
\hline
\end{tabular}




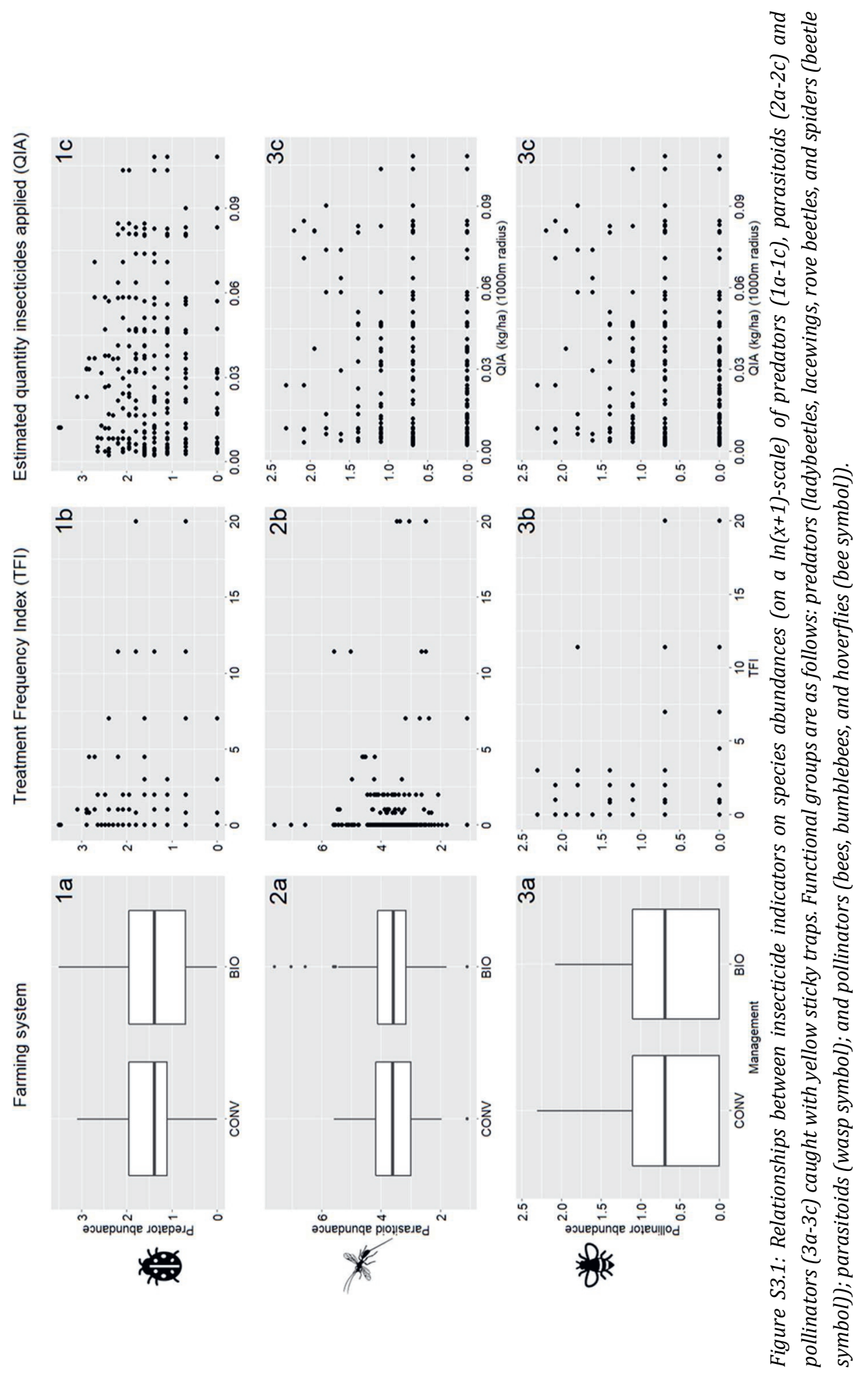



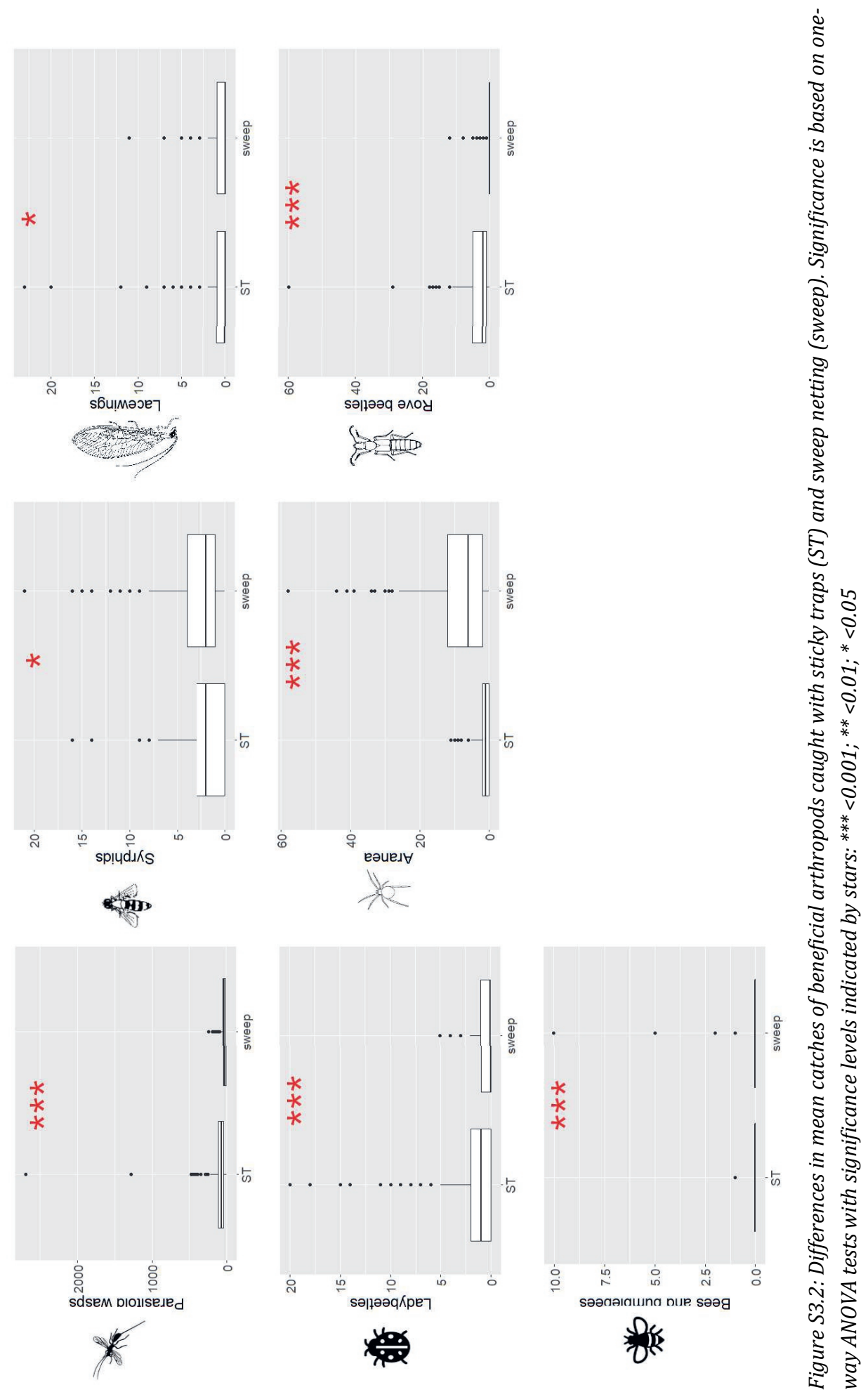



\section{CHAPTER 4}

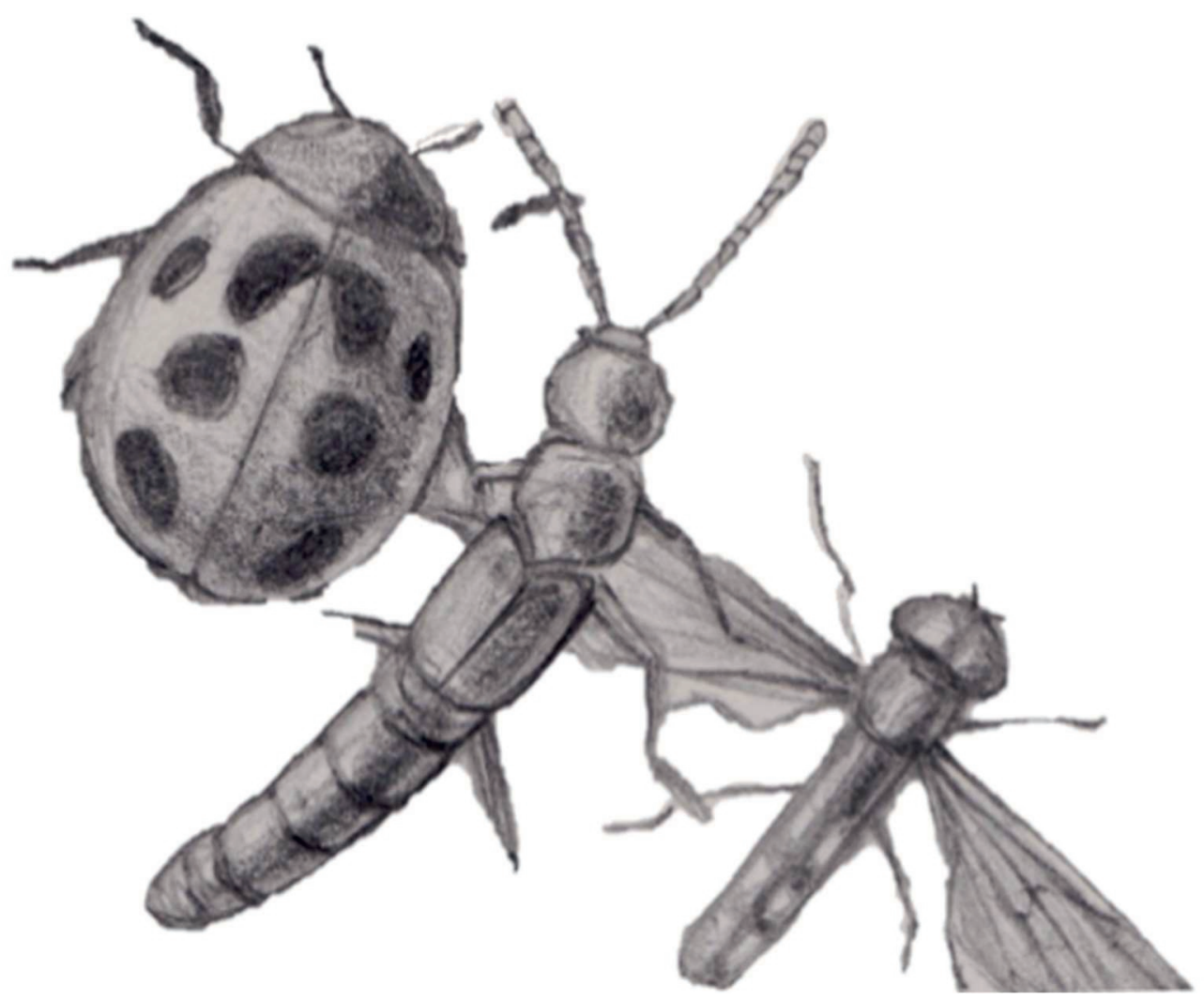




\section{NO SIGNIFICANT EFFECTS OF}

INSECTICIDE USE INDICATORS AND

\section{LANDSCAPE VARIABLES ON BIOCONTROL}

IN FIELD MARGINS.

L. BAKKER, W. VAN DER WERF, AND F.J.J.A. BIANCHI

\section{PUBLISHED AS:}

BAKKER, L., VAN DER WERF, W. \& BIANCHI, F.J.J.A. (2021) NO SIGNIFICANT EFFECTS OF

INSECTICIDE USE INDICATORS AND LANDSCAPE VARIABLES ON BIOCONTROL IN FIELD MARGINS, AGRICULTURE, ECOSYSTEMS \& ENVIRONMENT, 308, 107253.

HTTPS://DOI.ORG/10.1016/J.AGEE.2020.107253 


\begin{abstract}
Insecticides are used widely to manage pests, but they may cause mortality in natural enemy populations and non-target prey. On the other hand, resources provided by the landscape often associated with semi-natural habitat - may enhance natural enemy communities. While there is substantial information on how insecticide use and semi-natural habitats influence biocontrol in crop fields, little is known about how local insecticide use interacts with landscape variables to govern natural biocontrol in field margins. In this 2-year study we assessed predation and parasitism rates of eggs of the cabbage moth (Mamestra brassicae) on potted cabbage plants in field margins adjacent to 20 organically managed fields and 18 conventionally managed fields We analysed egg predation and parasitism rates in field margins using three predictors for insecticide use: (i) farming system (organic or conventional), (ii) frequency of insecticide use in the adjacent focal fields, and (iii) estimated insecticide use quantity within a radius of $1 \mathrm{~km}$ from the sampling sites. Insecticide use included foliar or soil-applied applications, including mineral oils. Landscape variables were used as covariables to account for landscape effects. Mean predation and parasitism rates were $14 \%$ and $6 \%$, respectively. There were no significant associations between predation and parasitism rates in field margins with insecticide use in the adjacent field or the wider landscape. Our findings suggest that field margins can be valuable habitats for natural enemies in agricultural landscapes, irrespective of the insecticide use intensity at the local and landscape scale.
\end{abstract}

Keywords: farming systems; biological control; semi-natural habitats; agricultural landscapes; pesticide use; predation; parasitism 
Agricultural intensification has been associated with declines in biodiversity and regulating ecosystem services (Kleijn et al., 2019). Intensive management practices, including insecticide use, can impact biological pest control in arable crops (Bianchi, Booij and Tscharntke, 2006; Pretty, 2018; Tooker, O’Neal and Rodriguez-Saona, 2020). In contrast, resources provided by the landscape - often associated with semi-natural habitat - may enhance natural enemy communities (Harvey et al., 2020). While we have a fairly good understanding of how insecticide use and semi-natural habitat influence biocontrol in crop fields, little is known about how local insecticide use interacts with landscape variables to govern natural biocontrol in field margins.

Insecticides cause mortality in natural enemy populations and their prey in crop fields (Woodcock, Isaac, et al., 2016; Sponsler et al., 2019; Busch et al., 2020; Wagner, 2020), but also affect beneficial insect populations in surrounding non-target habitats (Marshall and Moonen, 2002; Geiger et al., 2010). Non-target habitats, such as field margins, are often in close proximity to arable fields and are widespread in agricultural landscapes. These habitats may have an important function for beneficial insects within the agroecosystem, e.g. by providing overwintering sites, food resources due to presence of alternate prey or flower resources, reproduction sites, or dispersal corridors (Marshall and Moonen, 2002; Pywell et al., 2015; Dover, 2019; Li et al., 2020). Drift or overspray of insecticides impacts plant community structure and plant diversity (Schmitz, Hahn and Brühl, 2014), and affects non-target insects in field margins through (i) close contact to polluted areas, (ii) eating of contaminated food, and (iii) uptake through mouth and nose airways (Marshall and Moonen, 2002; Botías et al., 2019). However, impacts of insecticides on arthropod communities can reach further than would be expected based on drift or direct overspray alone (EFSA Scientific Committee, 2016), as arthropod populations are mobile and may give rise to 'action at a distance' effects (Spromberg, John and Landis, 1998). For instance, insecticideinflicted mortality in sprayed fields may turn these fields into sink habitats, thereby also reducing population densities elsewhere in the landscape (Spromberg, John and Landis, 1998; EFSA Scientific Committee, 2016).

Resources associated with (semi-natural) habitats may enhance the abundance and diversity of natural enemies and the associated biological control services (Tscharntke et al., 2005; Chaplin-Kramer et al., 2011; Rusch et al., 2016). Spill-over of natural enemies from source habitats can be influenced by patch size, patch shape, shared edges, or through complementation of resource availability across habitats (Bianchi, Schellhorn and Cunningham, 2013; Haan, Zhang and Landis, 2020). In diversified landscapes with high levels of natural enemy activity, insecticide-treated areas may be readily recolonized by natural enemies from source habitats once the insecticide residue has declined (Spromberg, John and Landis, 1998; Schellhorn, Bianchi and Hsu, 2014; EFSA Scientific Committee, 2016). In these cases, spill-over of natural enemy populations from semi-natural habitats to agricultural fields may counterbalance non-target impacts of insecticides on natural 
enemies in fields (Roubos, Rodriguez-Saona and Isaacs, 2014; Tscharntke et al., 2016). Whereas spill-over effects of natural enemy populations from field margins to agricultural fields have been relatively well studied (e.g. Dainese et al., 2017; Holzschuh et al., 2007; McHugh et al., 2020; Woodcock et al., 2016a), the impacts of insecticides on ecosystem services in field margins have received little attention.

Here, we explore the effects of insecticide use on biocontrol services (egg predation and parasitism of Mamestra brassicae) in field margins. Our study focusses on the assessment of the biocontrol potential of flying natural enemies. We assess whether insecticide use in adjacent fields or the surrounding landscape affects biological control in field margins. Furthermore, we study whether the proportion of semi-natural habitats in the surrounding landscapes counteracts potential impacts of insecticide use on the biocontrol potential of natural enemies in field margins. We hypothesize that (i) biocontrol services in field margins adjacent to conventionally managed fields are lower than in organically managed fields due to drift of insecticides in conventionally managed fields, and 'action at a distance' mechanisms; (ii) biocontrol services in field margins are positively associated with the proportion of semi-natural habitat at the landscape scale because semi-natural habitats may act as source habitats for natural enemies, and (iii) the proportion of semi-natural habitat at landscape level counterbalances the impacts of insecticide use on biocontrol services in field margins.

\section{MATERIALS AND METHODS}

\section{Experimental design}

Thirty-eight field margins (sites) were selected across twenty landscape settings, ranging from structurally simple to structurally complex. Sites were located adjacent to organically or conventionally managed arable fields (Fig. 4.1), and paired within landscapes to account for possible effects of the surrounding landscape. This resulted in 18 paired organic and conventional sites, while there were two non-paired organic sites in addition. The mean distance between sites was $6.75 \pm 4.22 \mathrm{~km}$ (range $1.72-18.1 \mathrm{~km}$ ). Field margins consisted of mown grass-dominated vegetation, unmown grass-dominated vegetation, or flower strips. All fields were managed according to farmers' practice, and cultivated crops included potatoes (21 fields over 2 years), cereal crops (18), cover crops (4), corn (3), herbs (2), tulips (1), sugar beets (5), beans (3), cabbage (2), and other vegetables (17). Field data were collected in June and July 2017 and 2018 at each of the 38 sites to obtain replication over time and assess the consistency of effects and relationships across early and late season and years. 


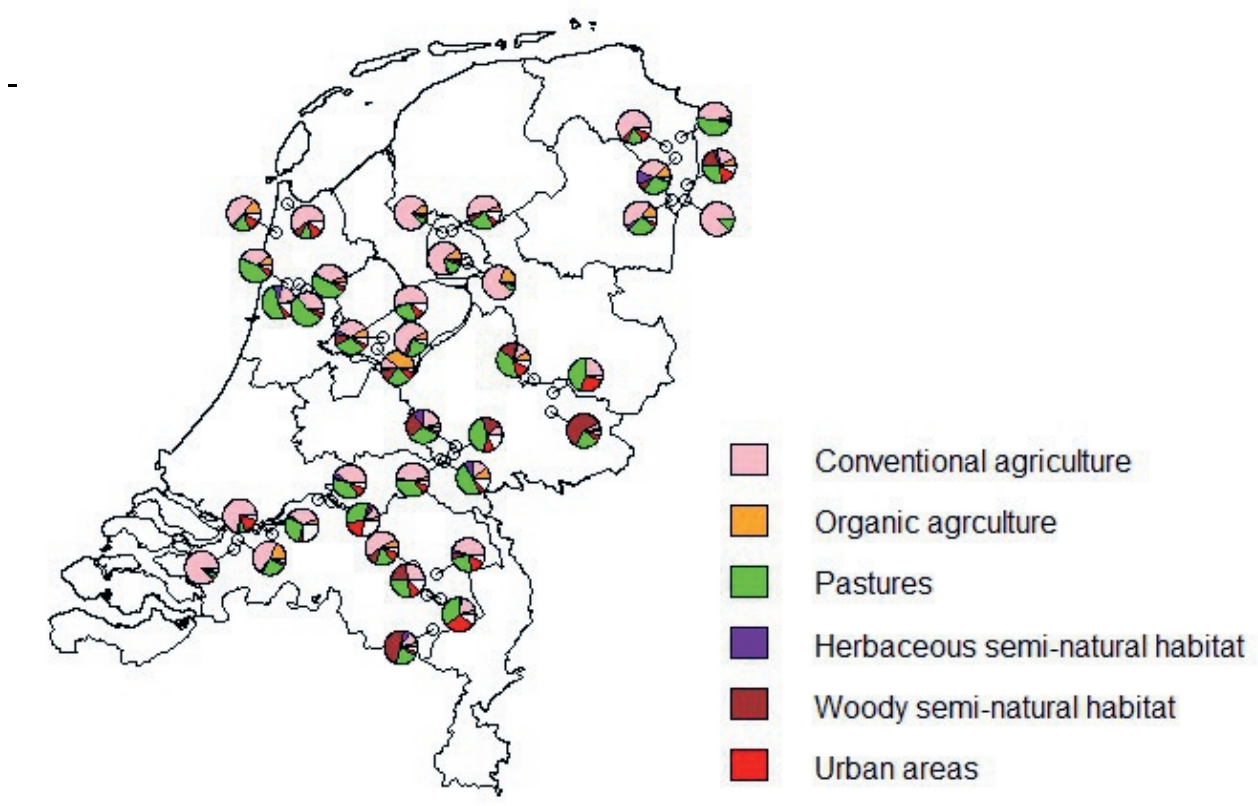

Figure 4.1: Locations of the 38 sampling sites in the Netherlands. Pies show the composition of the landscape at $1 \mathrm{~km}$ radius around the focal fields. Map of the Netherlands downloaded from GADM (https://gadm.org/index.html).

\section{Field experiment}

At each site we placed four plastic pots with a single 5-weeks old cabbage plant (Brassica oleracea) in the field margin for $48 \mathrm{hr}$. The four plants were placed in sets of two, at approximately $50 \mathrm{~m}$ from each other. To quantify predation and parasitism, we pinned a card with an egg batch of the cabbage moth (Mamestra brassicae) on each plant on the lower side of a newly mature leaf. Egg batches were obtained from a laboratory colony of cabbage moth and were not older than one day. We chose this species because it is a prominent pest in cabbage crops and predated by a range of generalist predators, including spiders, staphylinids and carabids (Bianchi et al., 2005; Pfiffner et al., 2009). We assumed that ground-dwelling arthropods were not able to climb the pots in which the plants with egg cards were placed. The exposure and retrieval of egg batches was completed in a period of 3 weeks during each sampling round, and four sampling rounds were conducted in two years; weeks 25-27 and weeks 30-32 in 2017, and weeks 24-26 and weeks 29-31 in 2018. After a two day-exposure period, all egg cards were collected. Egg predation was assessed by taking photographs of the egg card before and after exposure in the field, and counting the number of eggs per egg card before and after field exposure. Empty, damaged or missing eggs were considered as destroyed or removed by predators ('predation'). Parasitism was assessed in the laboratory. The collected egg cards were incubated for at least one 1 week at $22{ }^{\circ} \mathrm{C}$ to allow egg parasitoids larvae to develop within the moth egg, which then turns brown or black as the larvae pupate. After one week the number of darkened, parasitized eggs were counted ('parasitism'). 


\section{Land use variables}

Land use data were extracted from a publicly available land-use database (TOP10NL) and crop field registrations (BRP2017 and BRP2018) (PDOK, 2018). A third database consisted of organic and conventional crop field registrations in 2017. A polygon map, based on these three databases, was developed to derive landscape parameters within a $1 \mathrm{~km}$ radius scale around each sampling site. The $1 \mathrm{~km}$ spatial extent was chosen because this captures the functional spatial scale for a range of flying natural enemies (Thies, Steffan-Dewenter and Tscharntke, 2003; Bianchi, Goedhart and Baveco, 2008). Six land use categories were used to describe land cover: i) organic agriculture (including orchards); ii) conventional agriculture (including orchards); iii) herbaceous semi-natural habitat (extensive perennial grassland, nature areas/reserves, flower strips, grassy field margins); iv) wooded habitats (hedgerows and forests); v) pasture, both perennial and annual grasslands (either organic or conventionally managed); and vi) urban area. These land-use categories were chosen to account for potential effects of crop management intensity (organic versus conventional) and habitat (agriculture versus semi-natural habitat) on biological control (Karp et al., 2018; Zou et al., 2020). At the $1 \mathrm{~km}$ radius scale, the proportion of herbaceous semi-natural habitats ranged from 0 to $13 \%$, the proportion of woody habitats ranged from 0 to $60 \%$, the proportion of organic farming ranged from 0 to $40 \%$, and the proportion of conventional farming ranged from $5 \%$ to $87 \%$ in the landscape circles (Table S4.1).

\section{Quantification of insecticide use}

Insecticide use intensity in the adjacent field of the sampled field margin was expressed in terms of Treatment Frequency Index of applied insecticides (TFI) (Gravesen, 2003). TFI is an indicator to express insecticide dependency of cropping systems (Lechenet et al., 2014). TFI is calculated using as follows:

$\mathrm{TFI}=\Sigma\left(\mathrm{AD}_{i} / \mathrm{MD}_{i}\right)$

where $\mathrm{AD}$ is the applied dosage of formulated insecticide product $i\left(\mathrm{~kg} \mathrm{per} \mathrm{ha}^{-1}\right)$, and MD is the maximum label-recommended dosage for this product $i\left(\mathrm{~kg}_{\mathrm{ger} \mathrm{ha}}{ }^{-1}\right)$. Summing is over all applications. Information on the product and the dose was provided by farmers. In 2017 we received insecticide use information of 14 conventionally managed fields, and 20 organically managed fields, while in 2018 we received information of 9 conventionally managed fields, and 20 organically managed fields. Farmers used soil-applied and foliar insecticide applications, including mineral oils, and TFI ranged from 0 to 20 . Due to unavailability of data we were not able to include seed coatings as insecticide treatment. TFI at most organic sampling sites was zero, but some organic farmers used organically approved insecticides and these treatments were included in the calculation of TFI. Information on maximum label-recommended dosages were derived from the online database of the Dutch Board for the Authorisation of Plant Protection Products (CTGB, 2019). 
Since there are no open data bases of pesticide use, we estimated the quantity insecticides applied (QIA in kg active ingredient $\mathrm{ha}^{-1}$ ) at the landscape scale as the total input of active ingredient per crop species. First, we calculated the total area per crop type in each landscape. Second, we extracted insecticide use information (kg active ingredient $\mathrm{ha}^{-1}$ ) for 43 crops from the national pesticide data censuses of 2016 (Statline, 2019) (Table S3.1). Third, we extrapolated the 2016 insecticide use information to our crop-area data. Thus, QIA amounts to the total estimated quantity of insecticides applied per hectare within each 1$\mathrm{km}$ landscape circle around the focal field margin.

\section{Data analysis}

The relationship between biological control potential, insecticide use and landscape composition was analysed with generalized linear mixed models (GLMM). Data on egg predation and egg parasitism on the four plants per site were pooled, resulting in 145 observations over the 38 sites and four sampling periods. Seven observations were missing due to the inability to visit all sites in sampling round three, and fields for which we did not receive TFI information were considered to have missing data for the insecticide indicator TFI. Egg predation and egg parasitism were analysed as separate response variables ('A' and 'B' models, respectively; Table 4.2 and 4.4).

To estimate the effect of insecticide use on egg predation and parasitism, we used the following variables as insecticide indicators: (i) management of the field adjacent to the margin (management; organic vs. conventional), (ii) insecticide use intensity in the field adjacent to the margin (TFI), and (iii) estimated quantity insecticide applied (QIA) per ha in a $1 \mathrm{~km}$ circle around the focal field margin. We accounted for variation in field margins by categorizing field margins in three types: mown grass-dominated vegetation, unmown grass-dominated vegetation, or flower strips. This categorial explanatory variable was included as a fixed factor in all models. Landscape variables were entered as continuous covariables to account for differences in landscape composition: woody semi-natural habitat ('woodySNH'), herbaceous semi-natural habitat ('herbSNH'), proportion of land under organic management ('propORG'), and proportion of land under conventional management ('propCONV'). The proportion of pastures was omitted due to collinearity with other landscape variables. Interactions between insecticide use indicators and 'woodySNH' were added as we expected the effect of insecticide use on biocontrol services to differ in landscapes with different proportions of woody semi-natural habitat. All continuous explanatory variables were standardized prior to analysis.

'Farm pair' was included as a random factor to account for possible effects associated with the landscape context in which the paired farms were embedded. We included 'sampling period' (with four levels) as random effect to account for the effects of variation in weather conditions in interaction with phenological processes, even though we found no main effects of season (June vs. July) or year (2017 vs. 2018) for parasitism, and no main effect of season 
for predation. We tested the effect of crop type on predation and parasitism, but there was no significant relationship, and therefore we decided to not include this factor.

While the number of eggs offered was finite ( $86 \pm 44$ eggs; mean \pm SD), the actual number of eggs parasitized or removed by predation was well below this maximum. We therefore used count models without a maximum to model the stochastic variation in egg predation and parasitism, and explored two error distributions: the Poisson and the negative binomial error distribution. Here we report the analysis with the negative binomial error distribution because it provided the best fit to the data as judged by Akaike's information criterion (AIC).

Because we did not find strong support for a single 'best' model, based on corrected Akaike's criterion (AICc), we used model averaging among the set of 'best' models to interpret model results (Burnham and Anderson, 2007; Grueber et al., 2011; Feld, Segurado and GutiérrezCánovas, 2016). We compared two criteria to select the set of top models for averaging: (i) all 'top' models based on $\triangle \mathrm{AICc}<2$, and (ii) the cumulative weight of all top models is $95 \%$. Model averaging estimates were obtained using the zero-method, in which zero substitution of parameter estimates is applied to those models from which a parameter is absent (Grueber et al., 2011). Deviance residuals of the 'top' models were visually assessed using the model validation protocol of Zuur et al. (2009) to ensure that model assumptions were met.

All analyses were performed in R (R Development Core Team, 2019), using the lme4 package (Bates et al., 2015) and MASS package (Venables and Ripley, 2002). Model selection and averaging was conducted with the MuMIn package (Barton, 2019). Figures were made using ggplot2 (Wickham, 2016) and marmap (Pante and Simon-Bouhet, 2013).

\section{RESULTS}

Across 2017 and 2018, we placed a total of 576 egg batches containing 49,979 eggs at 38 sites during four sampling periods. After $48 \mathrm{hr}$ exposure in the field, the predation rate was $14 \% \pm 14 \%$ (mean \pm SD; range $0-65 \%$ ), and the parasitism rate $6 \% \pm 12 \%$ (mean \pm SD; range $0-67 \%$ ). Average predation was $48 \pm 47$ (mean \pm SD) eggs, and average parasitism was $16 \pm$ 34 (mean \pm SD) eggs per site per sampling period. We occasionally observed larvae of Chrysopa oculata feeding on eggs, but in most cases predators were not identified. Most parasitism was caused by Trichogramma spp.

\section{Egg predation and parasitism}

The univariate model with woodySNH was the most parsimonious model for egg predation for all three insecticide indicator models (management, TFI and QIA; Table 4.1). However, the marginal variance explained (marginal $\mathrm{R}^{2}$ ) by this model was only 5-7\% (Table 4.1). Competing models that included an insecticide use indicator (management or QIA) explained $8 \%$ and $7 \%$, respectively (marginal $\mathrm{R}^{2}$; Table 4.1 ). For egg parasitism, the null 
model (intercept only) was the most parsimonious for all three insecticide indicator models (management, TFI and QIA; Table 4.3).

The model averaging procedure for both egg predation and parasitism provided no support for the hypothesis that predation and parasitism rates are associated with landscape variables and insecticide use (Table 4.2 and 4.4; Fig. 4.2). Model 2A, analysing effects of insecticide indicator TFI on egg predation, showed a significant negative effect of proportion of woody habitat on egg predation (Table 4.2). However, the sample size was smaller in this model due to missing values for TFI. Local vegetation of the field margins ('field margin type') did not come up as a variable in any of the averaged models. All confidence intervals for the parameters estimates included zero, indicating that there is no statistical support for concluding that any of the variables on insecticide use or landscape were associated with egg parasitism and predation (Tables 4.2 and 4.4). 

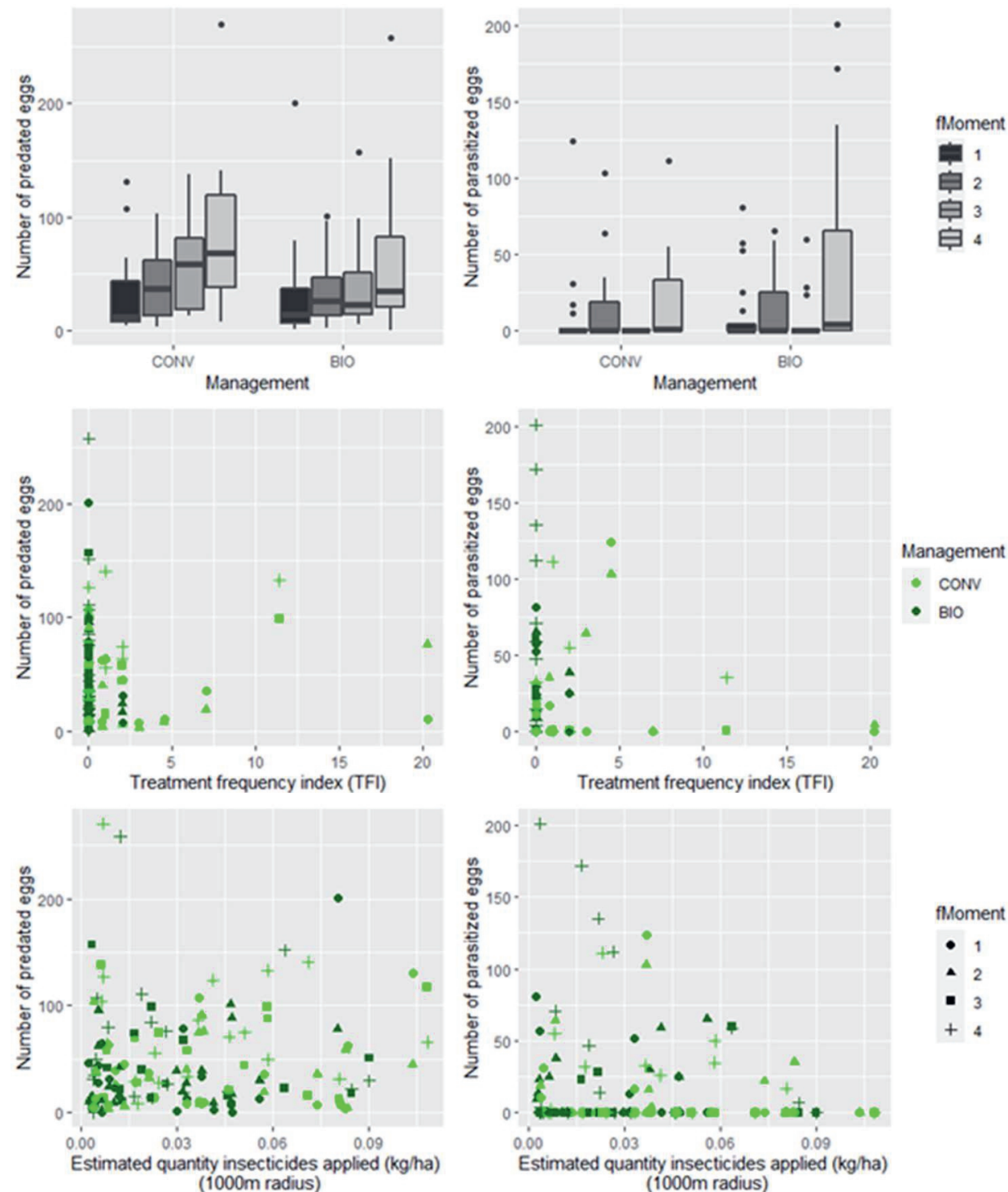

Figure 4.2: Relationships between number of parasitized (left) and predated (right) eggs and pesticide use variables; Management (top); TFI (middle), and estimated quantity insecticides applied (QIA) within a radius of $1 \mathrm{~km}$ from the focal field (bottom). Points are total number of eggs predated and parasitized per site per sampling period (1-4). Colours reflects different farming systems (conventional = light green, organic $=$ dark green), symbols indicate sampling period (1: June 20 - July 7, 2017; 2: July 24 - August 11, 2017; 3: June 12 - June 29, 2018; and 4: July 17- August 3 , 2018). 


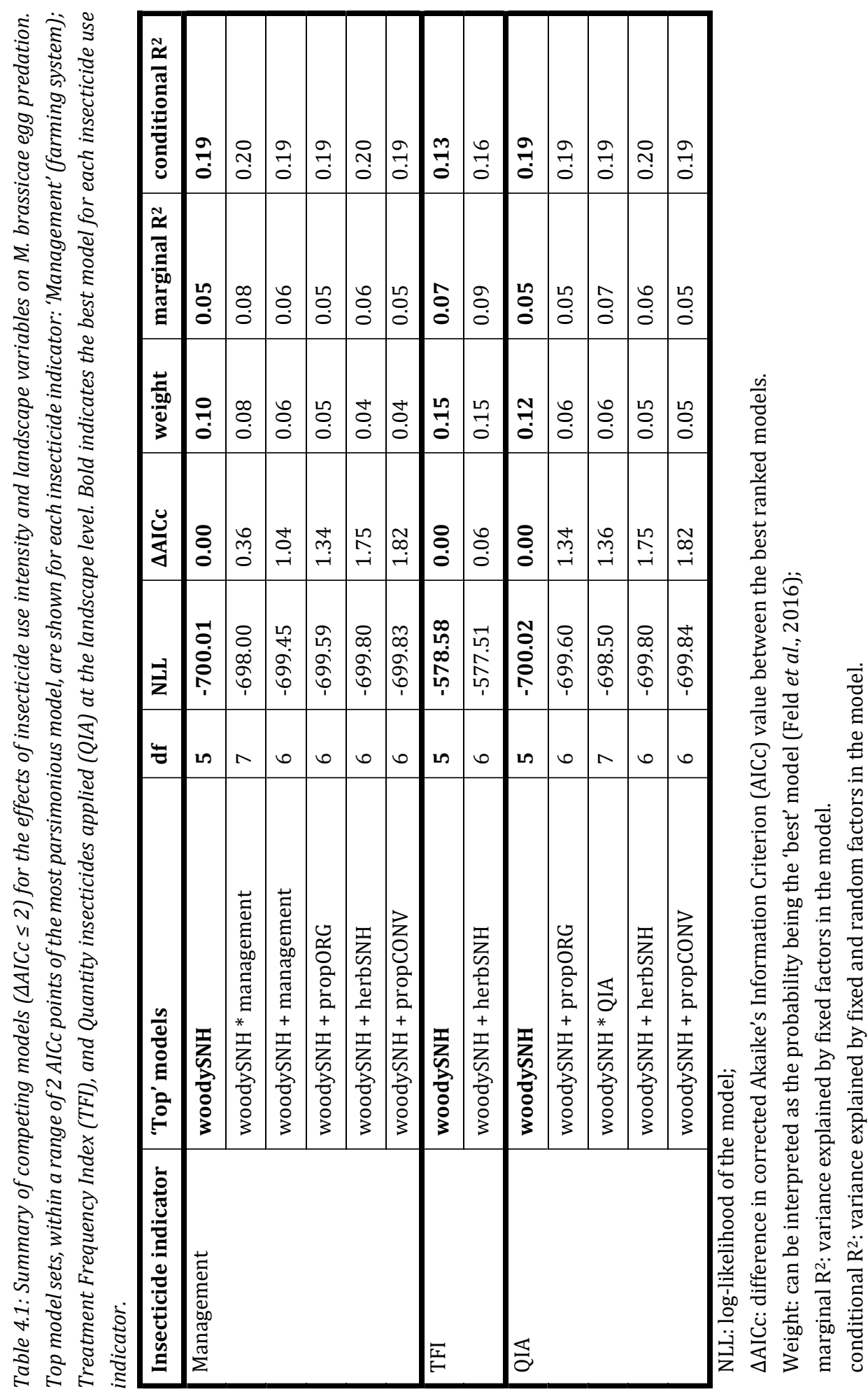




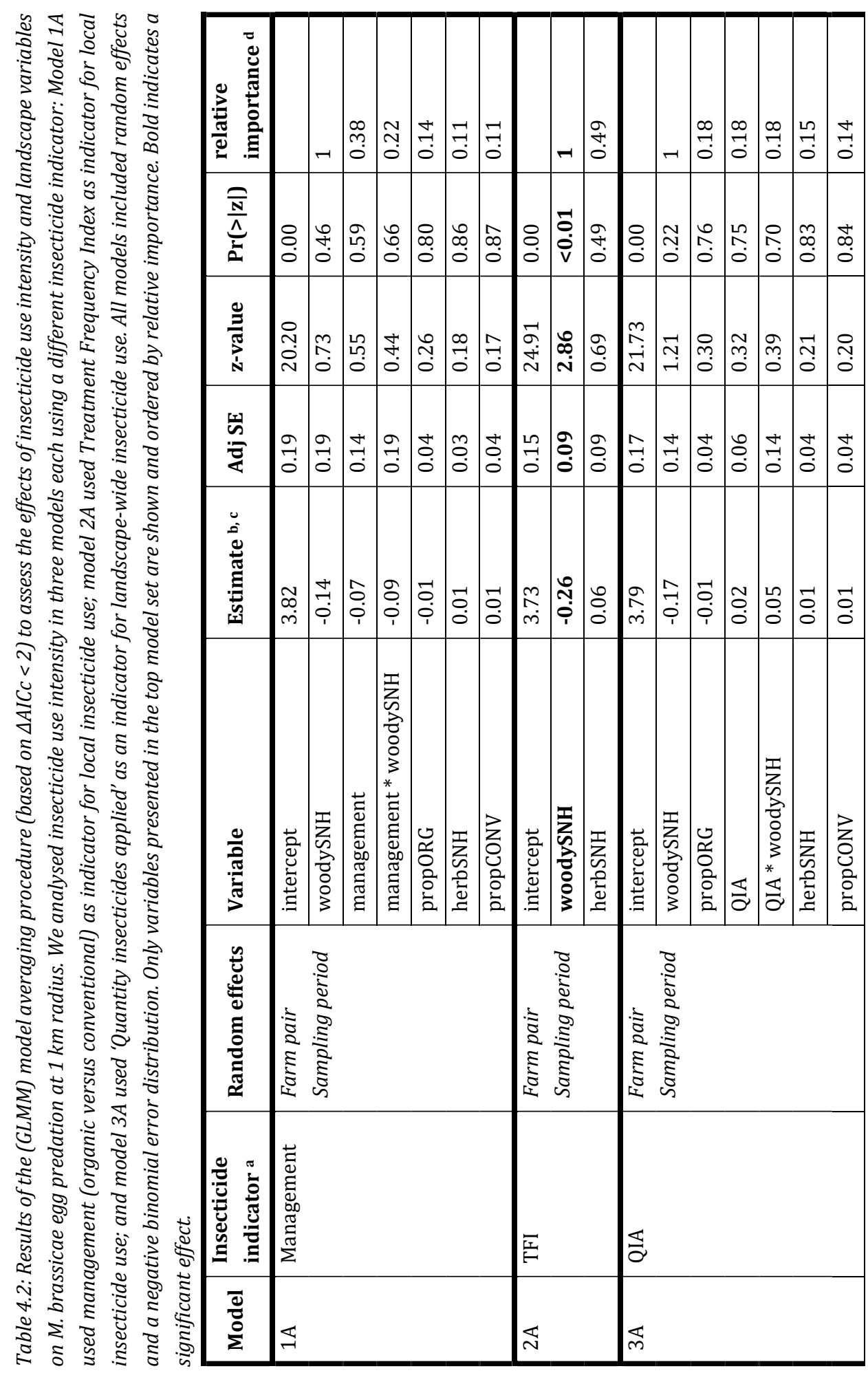




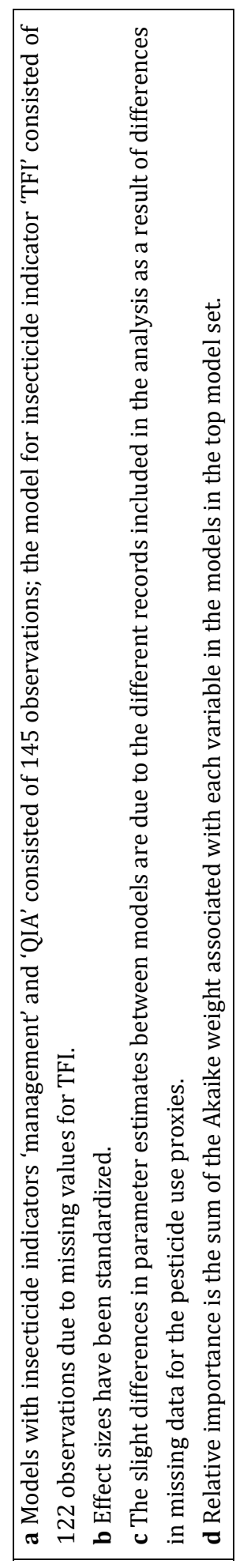




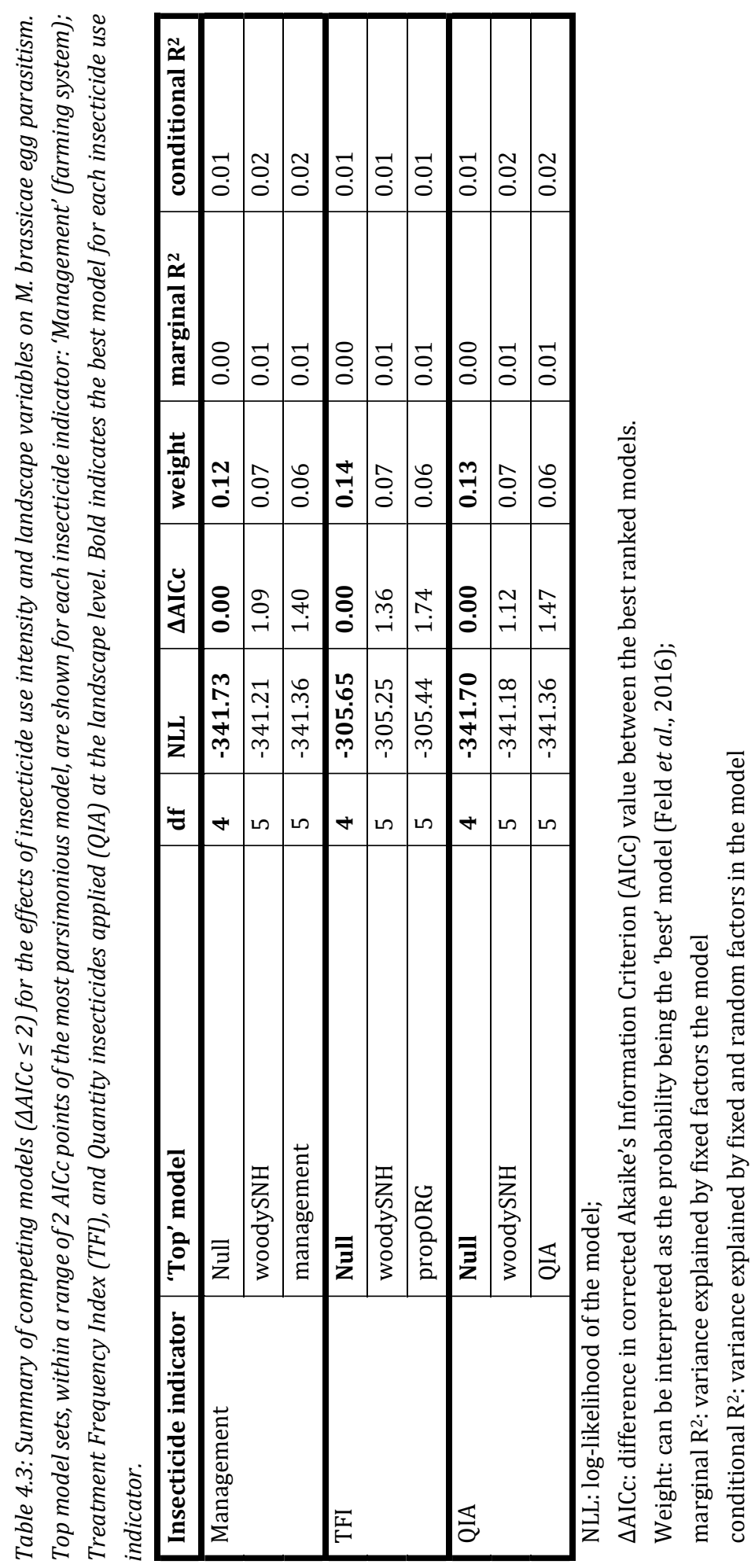




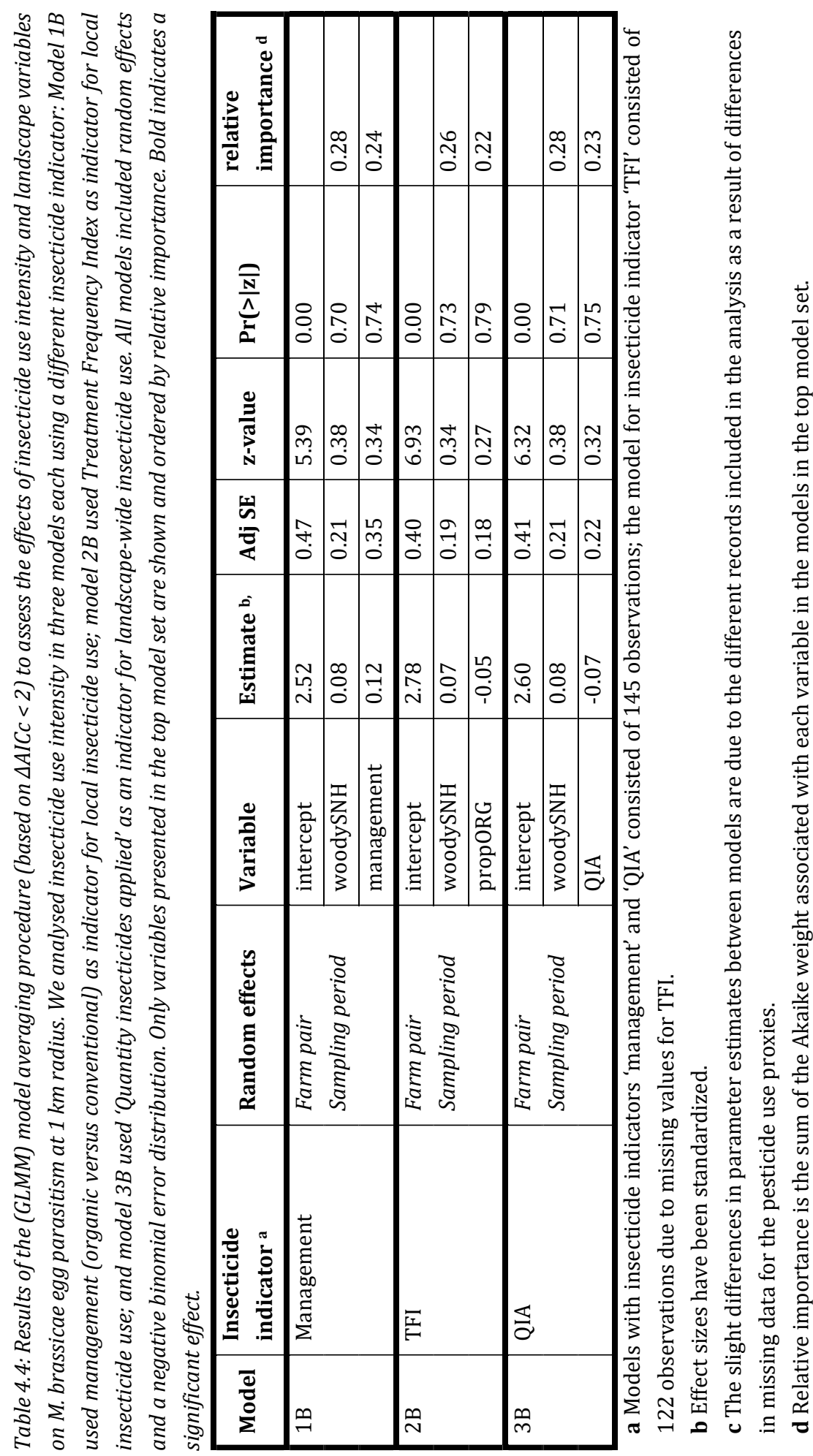




\section{DISCUSSION}

In this two-year study we assessed the effects of insecticide use at a local and landscape scale on biocontrol services in agricultural field margins. We report three key findings. First, there were no significant associations between the predation and parasitism rates of $M$. brassicae eggs and indicators for insecticide use at the field and landscape scale. Second, there was an indication that woody habitat is negatively associated with egg predation in field margins. Finally, while it has been postulated that more diverse landscapes can compensate for impacts of insecticides on natural enemies (Roubos, Rodriguez-Saona and Isaacs, 2014; Tscharntke et al., 2016), this premise was not supported by our data collected in field margins. Nevertheless, egg predation and parasitism did happen in field margins. Thus, the results suggest that field margins may provide refuge supporting natural enemies of pests, irrespective of the surrounding landscape and local management practices.

Our first hypothesis, postulating that insecticide use in adjacent fields impacts biocontrol services in field margins, was not supported by the data. Specifically, we found that indicators of insecticide use at the local field level were not significantly associated with predation or parasitism rates in field margins. Similarly, Gagic et al. (2019) did not find effects of insecticide spraying on predation of eggs of cotton bollworm in Australian cotton field margins. However, several studies on biocontrol in agricultural fields report that disturbances associated with local farm management (e.g. pesticide use) impacted on-field biocontrol. For example, Jonsson et al. (2012) found that the intensity of insecticide treatments had a negative effect on parasitism rates of two important pests (aphids and Plutella xylostella) in a brassica cropping system in New Zealand. Furthermore, a European scale study by Geiger et al. (2010) showed that local pesticide application had persistent negative effects on biological pest control. Muneret et al. (2019) found that increasing pesticide use decreased removal rates of moth eggs in vineyards, and Yang et al. (2019) conclude that ladybeetle abundance in wheat fields decreased with increasing insecticide use at the local scale. The combination of negative effects of pesticides on-field, but no effects off-field, could imply that in landscapes with high land-use intensities (e.g. more pesticide applications) field margins may be important refuges for natural enemies (Li et al., 2020). Our findings suggest that effects of direct insecticide overspray or drift to field margins are limited or at least below the detection limit of the methods used.

Our second hypothesis, in which we postulated that complex landscapes (with a relatively high proportion of semi-natural habitat) provide better biocontrol than more simple landscapes, was also not supported by our data. There was one model that indicated that egg predation was significantly negatively associated with the proportion of woody habitat in the landscape, but for parasitism this relationship was non-significant. Inconsistent effects of woody natural habitats on predation and parasitism have been reported previously (Karp et al., 2018). McHugh et al. (2020) found that herbaceous habitat was positively associated with predation of aphids, while woody linear habitat was negatively 
associated with predation of aphids. There are also studies reporting positive associations between biocontrol rates and woody elements in the landscape (Bianchi et al., 2005; Bianchi, Goedhart and Baveco, 2008; Dainese et al., 2017; Dover, 2019). Thus, these effects vary across studies and appear contextual (Karp et al., 2018). The effects of landscape composition on natural enemy communities are species-specific and dependent on species' traits, such as dispersal capacity, resource requirements, and overwintering sites (Tscharntke et al., 2005; Bianchi, Booij and Tscharntke, 2006; Chaplin-Kramer et al., 2011; Rusch et al., 2016).

Our data did not support the hypothesis that a more diverse landscape can compensate for insecticide-mediated impacts on services provided by beneficial insects (Gabriel et al., 2010; Blitzer et al., 2012; Tscharntke et al., 2016; Tooker, O'Neal and Rodriguez-Saona, 2020). Most of our locations (33 out of 38) were embedded in agricultural landscapes with relatively low proportions of semi-natural habitat $(<5 \%)$. In these 'simple' landscapes it could be expected that these small amounts of semi-natural habitat would have relatively little effect on the level of biological control (Ekström and Ekbom, 2011; Roubos, RodriguezSaona and Isaacs, 2014), let alone counterbalance any negative effect of insecticide use. There are several studies that report on interactions between pesticide use and landscape factors. Yang et al. (2019) found that beneficial insect abundance were low in areas with a frequent insecticide sprays, regardless of the landscape context, while Ricci et al. (2019) reported that negative effects of local pesticide use intensity on beneficial insects was only sometimes modified by landscape characteristics. Gagic et al. (2019) showed that the recovery time of natural enemies after insecticide spraying in cotton fields was not compensated for by the presence of semi-natural field margins. Thus, the majority of the studies report detrimental effects of insecticide use on beneficial insects, although the differences in insecticide impacts in different landscape contexts are still not well understood.

Field populations of $M$. brassicae can be controlled by a range of natural enemies, e.g. staphylinids, carabids and parasitoids (Bianchi et al., 2005; Pfiffner et al., 2009). Our study focussed on the biocontrol potential of flying natural enemies, as ground-dwelling arthropods were most likely not able to climb the pots in which the plants with egg cards were placed. While low predation rates were anticipated due to exclusion of grounddwelling predators, parasitism rates were lower than expected $(6 \pm 12 \%$; mean \pm SD). Compared to our results, Pfiffner et al. (2009) report higher levels of parasitism of $M$. brassicae in flower strips with a range between $14 \%$ to $52 \%$. Rates of parasitism assessed in arable fields were more similar to our findings. For instance, Bianchi et al. (2005) found parasitism rates of egg batches of $M$. brassicae of $14 \%$ in cabbage fields, and Balmer et al. (2014) found M. brassicae parasitism rates between 5-6.5\% in cabbage fields close to flower strips. Many factors affect parasitism levels, e.g. habitat quality, seasonality, and weather (Stilmant et al., 2008). It is not possible to ascertain why the parasitism rate in our study is 
relatively low when compared to some of these other studies. Furthermore, a limitation of using sentinel prey is that natural enemies could be discouraged by our set up of using potted plants and egg cards, potentially missing chemical cues from the plants. Still, important natural enemy groups of $M$. brassicae, including staphylinids, ladybeetles, lacewings, and spiders, were also found using sweepnet and yellow sticky trap sampling (Bakker, van der Werf and Bianchi, 2020).

One of our study limitations was missing information on seed coatings with insecticides. Seed coatings with neonicotinoids were allowed in the EU for non-flowering crops, such as sugar beets, and have been banned for use in the open field as of 2019 in the EU (EU, 2018). Our study was conducted before this ban. We were not able to quantify the use of seed coatings in the focal fields, because this information was not provided by farmers. The impacts of insecticide use on beneficial arthropod communities may depend on many factors, such as application rates, the effectiveness of the active ingredients, their toxicity, and the environment in which products are used (Kniss, 2017), but a systematic overview of data on the use of insecticides is not available or incomplete (Eurostat, 2019; FAOSTAT, 2020). This hampers assessment of insecticide use impacts on the environment. There is substantial evidence that systemic insecticides, such as neonicotinoids, have adverse impacts on the environment and beneficial insects (Furlan et al., 2018; Giorio et al., 2017; Pisa et al., 2017). Better accessibility of insecticide use data would therefore enable an improved assessment of effects of insecticide use on biocontrol services.

The absence of an effect of insecticide use on biocontrol services could be explained in at least two very contrasting ways. First, drift and/or overspray of field margins may have been negligible and field margins may therefore have been very little exposed to insecticides. In addition, natural enemies in field margins may have suffered little from insecticide applications in the adjoining field and wider surroundings when their movement between sprayed fields and field margins has been limited. Second, the wide-spread use of insecticides could have impacted natural enemy communities at a scale beyond $1 \mathrm{~km}$ radius, masking relationships between insecticide use intensity on biocontrol at the scales considered in our study. Regarding the first explanation, limited insecticide drift to field margins would indicate compliance to good agricultural practices, such as using crop-free buffer strips and usage of spray-drift-reducing nozzles (van Eerdt et al., 2014). Concerning the second explanation, it could be that pesticide drift from conventional farms to non-target areas, including organic farms, may have disrupted biocontrol in these non-target areas, and diluted potential effects of insecticide use on biocontrol services. In support of this explanation, de Jong et al. (2008) estimated that $11 \%$ of the natural areas within agricultural landscapes were affected by herbicide drift in the Netherlands in 2005.

Considering the wide-spread use of agrochemicals and potential pathways for run-off to non-target areas (de Jong, de Snoo and van de Zande, 2008; Goulson, 2013; Chagnon et al., 
2015), it could be that organic agricultural fields might have been impacted by practices of conventional agriculture, masking the effects we expected to find comparing margins of conventional and organic fields. While drift or overspray may be limited, insecticide residues may still be present in the soil and water for a period of time, e.g. half-lives of neonicotinoids in soils can be longer than 1000 days (Bonmatin et al., 2015). Sublethal toxic effects and reduced availability of food resources may affect reproduction and survival of non-target species (Desneux, Decourtye and Delpuech, 2007; Devine and Furlong, 2007). These can be subtle effects that are nevertheless relevant on population level processes, but are not captured by short-term experiments (Woodcock, Isaac, et al., 2016), and could possibly have masked effects of insecticide use on non-target organisms in field margins.

Modelling studies indicate that insecticide use in fields affect natural enemy populations in non-sprayed fields because insecticide treated fields act as sink habitats and diminish the population size of mobile natural enemies at the landscape scale (Bianchi, Ives and Schellhorn, 2013; Topping et al., 2015). Thus, the impacts of insecticide use may occur at larger scales than what we considered in our study. Indeed, recent analyses of dramatic insect declines in protected nature areas, on a national and global scale, associated these negative trends to land use intensification at the landscape scale (Hallmann et al., 2017; Seibold et al., 2019; van Klink et al., 2020). Therefore, while we do not find evidence for relationships between indicators for insecticide usage at field and landscape level and biological control in field margins, our data cannot exclude the possibility that such relationships may exists.

\section{CONCLUSION}

This study aimed to unravel the effects of (local) insecticide use and landscape complexity on biocontrol potential, but in contrast to our expectations we did not find consistent effects of insecticide use or landscape composition on egg predation and parasitism of M. brassicae. These findings imply that field margins could act as habitats supporting natural enemies in agricultural landscapes, regardless of the land-use intensity at the local and landscape scale. This suggests that with ongoing intensification of agricultural landscapes, field margins could become an increasingly important habitat for natural enemies, e.g. as refuge habitat or corridors in simplified landscapes. Furthermore, field margins should be protected from adverse agricultural practices, e.g. exposure to agrochemical drift or frequent mowing. Data on insecticide use in landscapes are required to improve environmental impact assessments but are not available for the study area because they are considered private even though the potential impacts affect public goods. Studies on insecticide usage and impacts might benefit from a landscape perspective because spill-over mechanisms are likely, particularly due to the movement of insects at a landscape scale. Finally, our study did not confirm broadly supported hypotheses, and highlights that interactions between landscape and insecticide use are complex and merit further research to obtain a better understanding of the underlying mechanisms and relevant spatial scales. 


\section{ACKNOWLEDGEMENTS}

The work reported in this paper was financially supported by the Dutch Research Council (NWO), grant 824.15.022. We thank Leon Westerd and Pieter Rouweler for provision of $M$. brassicae eggs, Rinie Verwoert and Rohan van Genderen for provision of cabbage plants (Unifarm, Wageningen University and Research). Furthermore, we would like to thank Patric Brandt for his help with the landscape analysis and work in ARCGIS. A big thanks to the following people for their assistance in the field work; Yavanna Aartsma, Liron Chen, Lenora Ditzler, Henk Eshuis, Kim van Oost, Chris Oosterhof, Julia van Oord, and Francine Pacilly. Finally, we are grateful to all farmers that participated in the study and provided us with access to their fields, and who were willing to share information on their farming practices. We thank Ben Woodcock and an anonymous reviewer for helpful feedback on an earlier version of the manuscript. 



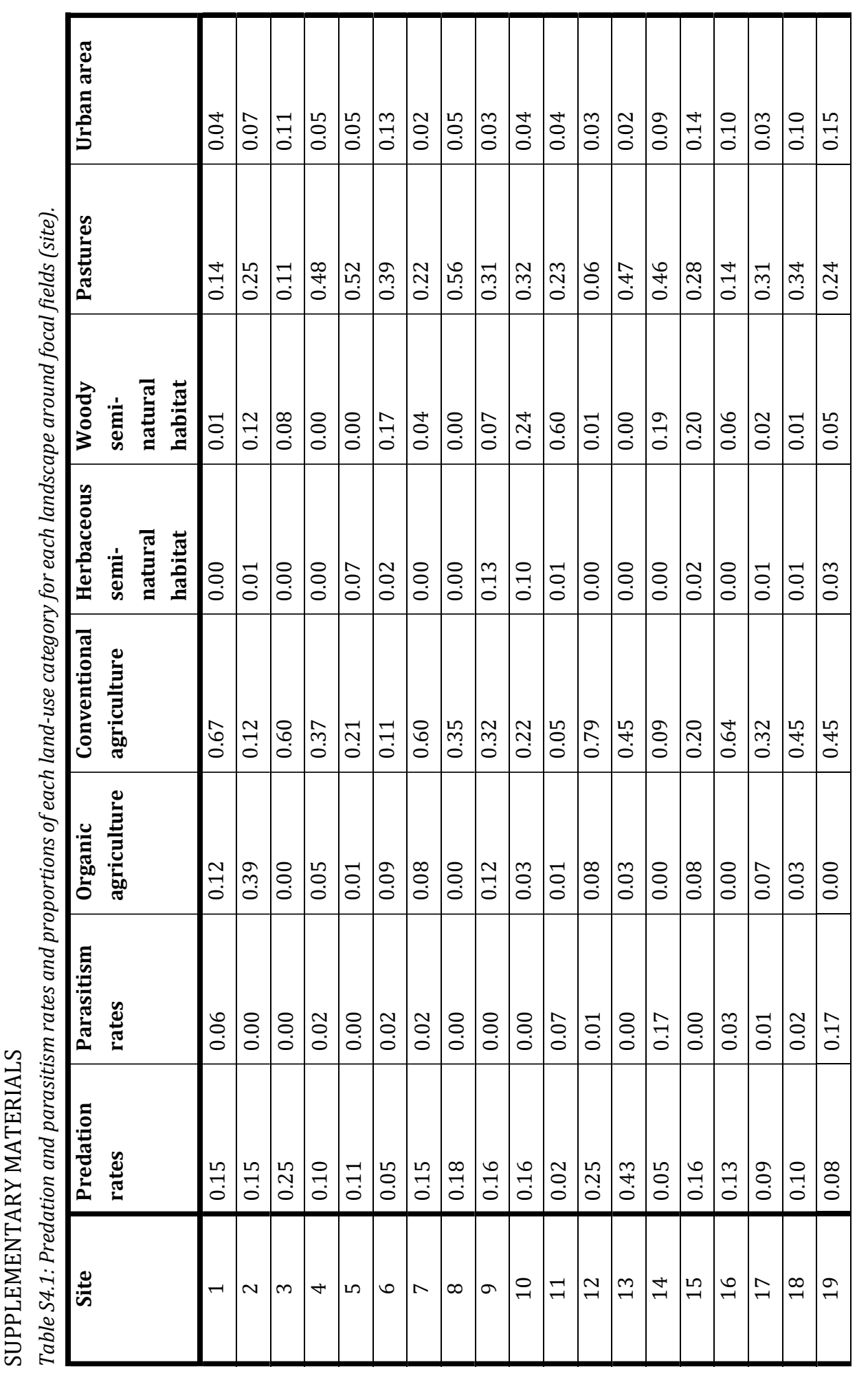




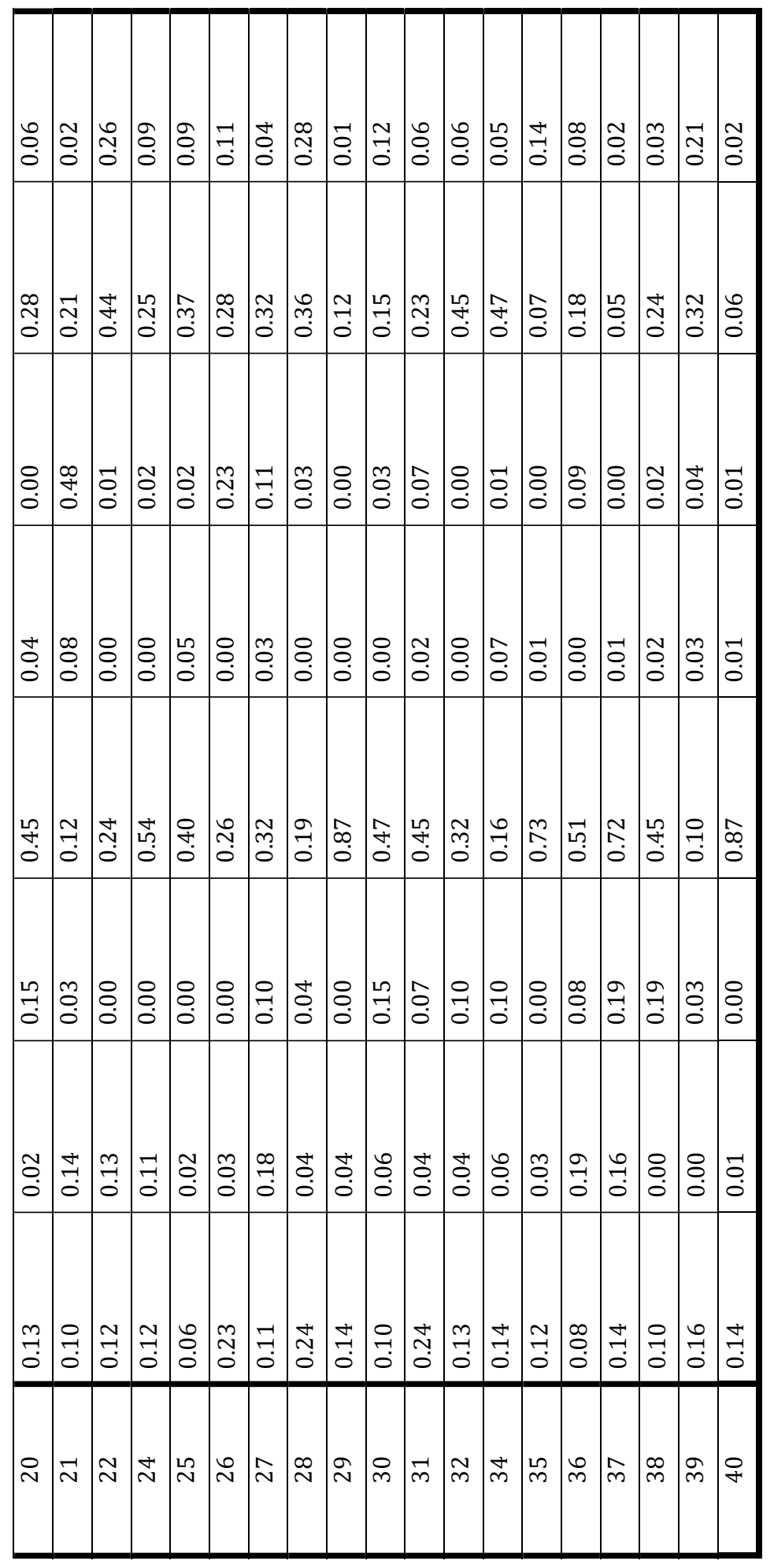




\section{CHAPTER 5}

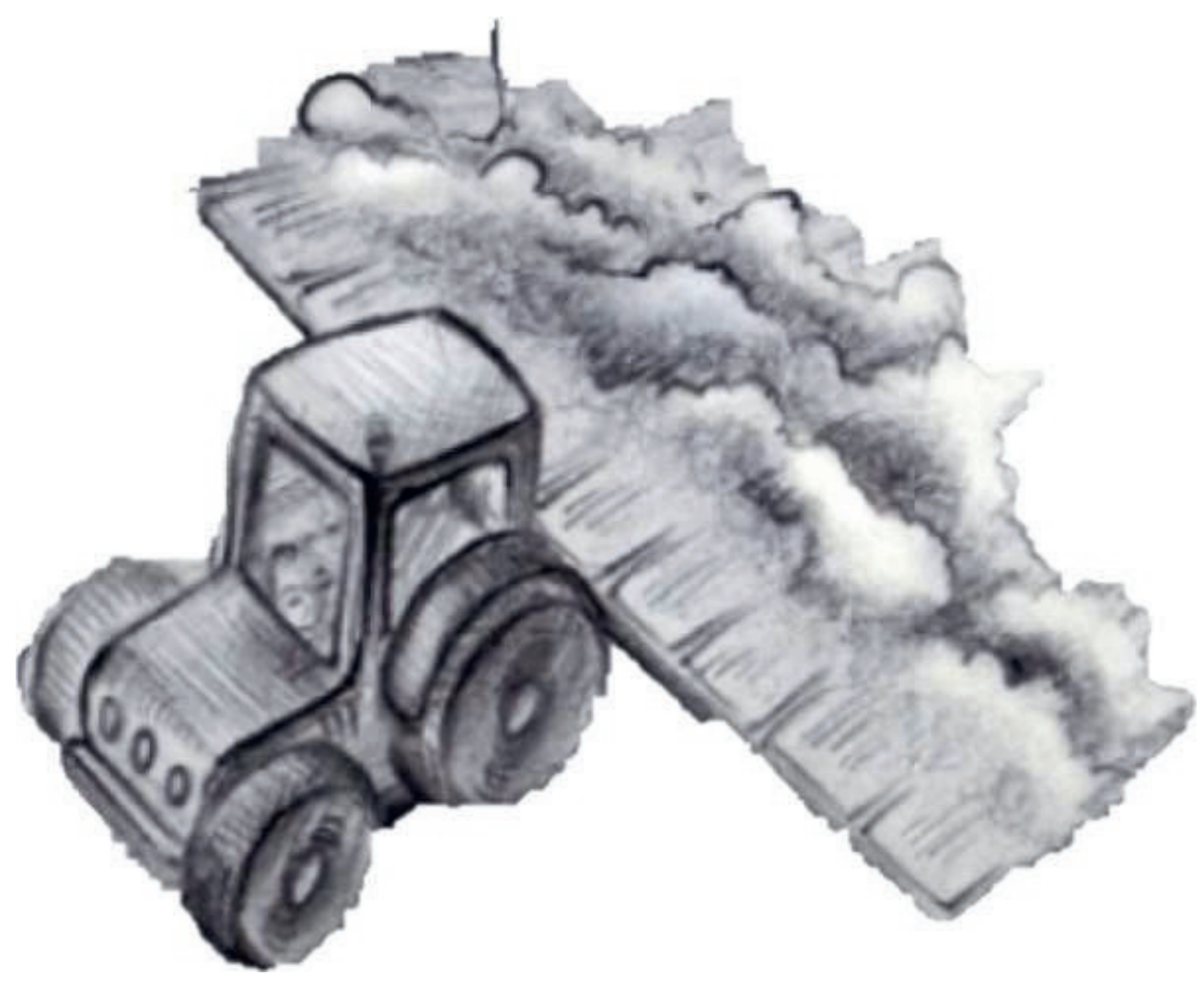




\section{KICKING THE HABIT: WHAT MAKES AND BREAKS FARMERS' INTENTIONS TO REDUCE PESTICIDE USE? \\ L. BAKKER, J. SOK, W. VAN DER WERF \& F.J.J.A. BIANCHI}

\section{PUBLISHED AS:}

BAKKER, L., SOK, J., VAN DER WERF, W., \& BIANCHI, F.J.J.A. (2021). KICKING THE HABIT: What MAKES AND BREAKS Farmers' INTENTIONS tO REDUCE PESticide USE? ECOLOGICAL ECONOMICS, 180, 106868. HTTPS://DOI.ORG/10.1016/J.ECOLECON.2020.106868 


\begin{abstract}
There is a growing concern in society about the continuing intensive usage of pesticides in farming and its effects on environmental and human health. Insight in the intentions of farmers to reduce pesticide use may help identify pathways towards farming systems with reduced environmental impacts. We used the Reasoned Action Approach to identify which social-psychological constructs determine farmers' intentions to decrease pesticide use. We analysed 681 responses to an online survey to assess which constructs drive intention, and identified which beliefs pose barriers and drive the motivation of farmers to decrease pesticide use. Our results show that the intention to reduce pesticide use is strongly determined by whether other farmers also act. Furthermore, farmers perceive limited capacity and autonomy to reduce pesticide use, and motivations to reduce pesticide use were based on environmental considerations. Finally, decreasing pesticide use was considered risky, but the relative importance of risk attitude was offset by the environmental considerations of farmers. This indicates that farmers need successful examples of how to decrease pesticide use, either via exchange with peer farmers or knowledge provisioning on alternative pest control methods. These insights may be useful to direct policy making to influence farmers' intentions to decrease pesticide use.
\end{abstract}

keywords: pest management; crop protection; barriers; environmental impact; decisionmaking; intentions; Reasoned Action Approach 
Modern conventional agriculture is dominated by intensive farming systems with highly specialized crop production systems and intensive use of external inputs such as fertilizers and pesticides to enhance and protect yield (Pretty et al., 2018). There are, however, growing concerns in society about the direct and indirect negative effects of pesticides on the environment and health (EASAC, 2015). Pesticides may cause harmful effects on nontarget organisms, such as bees and other beneficial insects, fish, and birds (Lamichhane et al., 2016; Wyckhuys et al., 2019), and many hidden costs are associated with pesticide use, including health care, and monitoring and sanitation of contamination of soils, drinking water, or food. The growing public concern about pesticide use has resulted in societal pressure for a transition towards more ecologically-based pest management. Farmers struggle, however, to change their pest management practices (Lamine, 2011). Integrated Pest Management (IPM) and biological pest control offer the potential to overcome this struggle, but adoption is generally lagging and often not resulting in major reductions in dependency on chemical control. Despite decades of promotion of alternative methods, chemical pest control is therefore still the standard pest management approach in conventional agriculture (Pretty, 2018).

In the Netherlands, pesticide use is relatively high compared to other European countries (Van't Zelfde et al., 2012). The Dutch directive on sustainable crop protection aims to reduce impacts of pesticides on the environment by 90\% in 2023 compared to 2013 (Ministerie van Economische Zaken, 2013), but environmental quality standards in aquatic habitats are still breached (Leendertse et al., 2019; Sporenberg, Verstand and Beerling, 2019). Here, we aim to provide insight into the intentions of Dutch farmers to decrease their pesticide use, in the context of reducing negative environmental impacts.

While numerous factors influence pest management decisions, there does not seem to be a clear consensus on what the main factors are for farmers to decrease (or not) the use of pesticides and reduce environmental impacts (Lamichhane et al., 2017). Reported barriers include, among others: (i) the absence of non-chemical alternatives (Sporenberg, Verstand and Beerling, 2019; Tiktak et al., 2019), (ii) lack of knowledge on pesticides and alternatives, (iii) biased information from chemical companies (van den Bosch, 1989; Wilson and Tisdell, 2001), and (iv) an insufficient advisory service on judicious pesticide use (Sherman and Gent, 2014; Lamichhane et al., 2016). In addition, Chèze et al. (2020) report that the risk of large production losses due to pests strongly limits farmers' willingness to reduce their pesticide use. Furthermore, economic barriers may arise because of technological lock-in due to past financial investments (Cowan and Gunby, 1996; Wilson and Tisdell, 2001) and market demands for undamaged produce (Skevas and Oude Lansink, 2014). It is also argued that farmers' decision-making is based on non-economic rationale, i.e., farmers' personality traits and ideological motivations (Siebert, Toogood and Knierim, 2006; Rodriguez et al., 2009; Pedersen et al., 2012). 
To understand farmers' decision-making on pesticide use to reduce environmental impacts, we need to identify what factors drive farmers in their decision-making process. In this study, we used the Reasoned Action Approach (RAA), a framework from social psychology, also known as the theory of planned behaviour. The RAA is commonly applied to identify which social-psychological constructs are the most important determinants of intention (Fishbein and Ajzen, 2011). In the field of agricultural research, the RAA has been used to understand intentions to increase soil organic matter (Hijbeek et al., 2018), the uptake of organic farming (Läpple and Kelley, 2013), the engagement in sustainable practices (Lokhorst et al., 2011), disease control in horticulture (Breukers et al., 2012), and prudent use of antimicrobials in cows (Vasquez et al., 2019). We aim to assess the main drivers of farmers' intention to decrease pesticide use to reduce environmental impacts addressing the following questions:

i) Which social-psychological constructs are the most important determinants of farmers' intention to decrease their pesticide use and reduce environmental impacts?

ii) Which underlying attitudinal, normative, and control beliefs have the greatest influence on farmers' intentions to decrease their pesticide use and reduce environmental impacts?

We address these questions through the following steps: first, we describe the theoretical framework of the RAA in section 2, then we describe our survey design and statistical analysis in section 3. In section 4 we present the most important constructs driving intention based on a structural equation modelling (SEM) analysis. We then determined for each construct the most influential underlying attitudinal, normative and control beliefs using a Multiple Indicators Multiple Causes (MIMIC) modelling approach. Section 5 provides a discussion on our key findings. We conclude with general conclusions based on our findings.

\section{THE THEORETICAL FRAMEWORK OF THE REASONED ACTION APPROACH}

The RAA is based on the assumption that a person's intention is the best predictor of whether someone will (or will not) perform the behaviour in question, i.e. one's readiness to engage in a particular behaviour (Fishbein, 2008). In this study, we assess four socialpsychological constructs that explain behaviour: attitude (A), injunctive norms (Ni), descriptive norms (Nd), and perceived behavioural control (PBC) (Fishbein and Ajzen, 2011; Fig. 5.1). Attitude is the degree to which a person thinks of the behaviour as positive or negative, i.e. 'the willingness' to perform the behaviour. Furthermore, people are influenced by social norms and morals, and in the RAA these perceptions of social pressure are identified as injunctive norms (i.e. behaviour that someone expects you to engage in) and descriptive norms (i.e. your perception of others' behaviour). Finally, perceived behavioural control is the extent to which a person thinks (s)he can perform the behaviour, namely 
his/her capacity (i.e. ease or difficulty of reducing pesticides) and autonomy (i.e. whether it is up to them) to do so (McEachan et al., 2016).

The social-psychological constructs attitude, injunctive norms, descriptive norms, and perceived behavioural control are latent variables and cannot be assessed directly. They can, however, be assessed in two ways. First, we measured indicator statements that cover different dimensions of behaviour representing each construct ('direct measures'; Fig. 5.1 blue box). For example, attitude is assessed through statements that are indicative of why a person holds a certain attitude towards the desired behaviour (Fig. 5.1, A A $_{1}$; Table S5.1). Secondly, we assessed variables indirectly derived from salient beliefs ('indirect measures'; Fig. 5.1 - red boxes), following the expectancy-value model (Fishbein and Ajzen, 2011). Indirect measures or belief variables follow from individuals' personal beliefs or expectations about performing specific behaviour, multiplied by an (e)valuation of these beliefs in terms of importance (Fishbein, 2008). For example, attitudinal belief variables (Fig. 5.1; be) were assessed with a belief statement on how likely something would occur ('belief strength' $(b)$ ), followed by an evaluation of how important that something is towards intentions to decrease pesticide use to reduce environmental impact ('outcome evaluation' (e)) (Table S5.2) (Fishbein and Ajzen, 2011). 


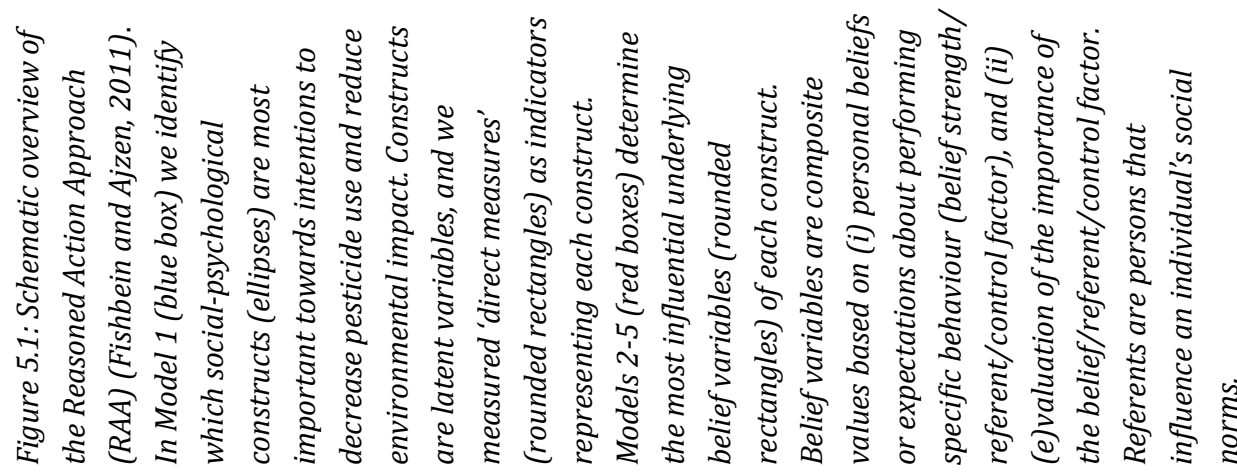

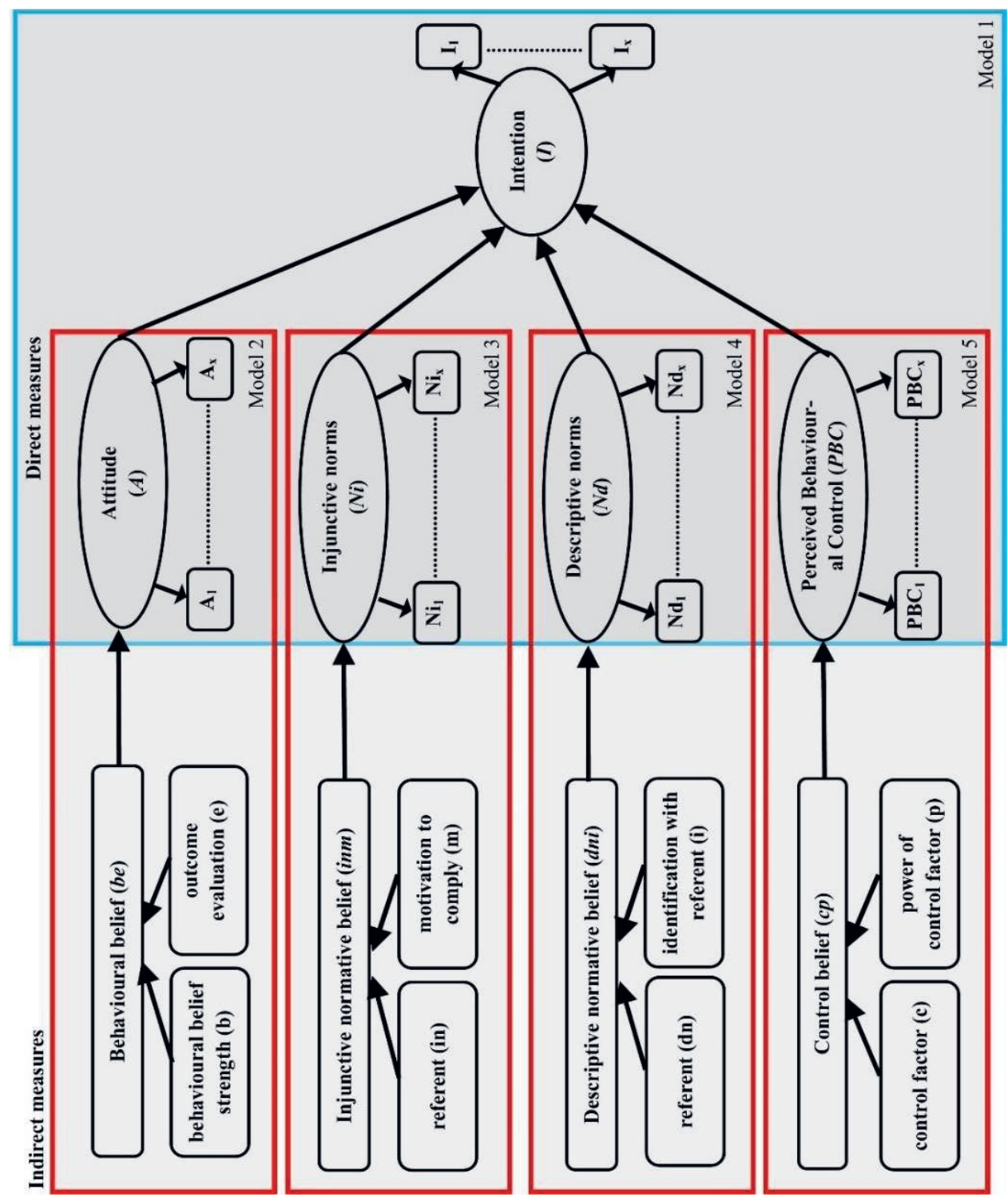




\section{METHODS}

\section{Survey design and sample}

To elicit and measure the most commonly held attitudinal, normative, and control beliefs, we first conducted a pilot study. This pilot study consisted of a series of semi-structured interviews held with eight arable farmers in October and November 2018. Interviewees were given a description of the behaviour and were asked a series of questions designed to identify these beliefs (Fishbein and Ajzen, 2011). After the eighth interview, we reached a saturation point, with no new beliefs being mentioned. The answers given by the interviewees were used in the formulation of questions in the survey to assess why people hold certain attitudes, subjective norms, and perceptions of control.

The survey consisted of three sections. First, we assessed each construct using one to four statements (Table S5.1), following "Decreasing my use of environmentally harmful pesticides within two years is ..." (Fishbein and Ajzen, 2011). Respondents were asked to rate a total of fifteen statements to measure all constructs. These statements were 'direct measures' as discussed in the previous section. Each statement was rated using a five-point Likert-like scale from 1 to 5 . A three was considered a neutral response; higher values were considered agreement, and lower values disagreement. Subsequently, respondents were asked to rank statements on underlying beliefs ('indirect measures') for each of the constructs $\mathrm{A}, \mathrm{Ni}, \mathrm{Nd}$, and PBC (Table S5.2). For each belief statement farmers were asked to rate a probability on a 5-point Likert scale from 'not likely' (1) to 'likely' (5), i.e. the belief strength. Then farmers were asked to evaluate these belief statements from 'plays no role' (-2) to 'plays a role' (+2), i.e. the valuation. A Likert score of three and zero, for belief strength and valuation, respectively, was considered a neutral response; higher values were considered agreement, and lower values disagreement. In our analysis, we used belief variables ('indirect measures') with a range from -10 to +10 . These variables are based on multiplying the belief strength with the corresponding outcome evaluation, following the expectancy-value model. For ease of interpretation, here we report for both direct and indirect measures rescaled values on a -2 to +2 range. To do so, we subtracted -3 for each direct measure indicator, and divided indirect measures ('belief variables') by five. Finally, several questions regarding demographic and farm characteristics were asked: respondents' age, gender, farm size (ha), household income (\%), type of farm (organic or conventional), education, crop rotation, main crop, landscape information (postal code and landscape description) and pest pressure, as well as which information sources farmers used to inform themselves on crop protection.

To reach the largest number of Dutch farmers possible, we collaborated with "Geelen consultancy" (https://www.geelen-consultancy.nl/) to distribute an e-mail invitation to complete an online survey to \pm 7500 farmers in the Netherlands. This sample entailed approximately two-thirds of the Dutch arable farmer population consisting of 8709 arable farmers, 959 flower bulb growers, 1318 vegetable growers and 1498 fruit growers in 2019 
(CBS, 2020) (Table 5.1). Participation was voluntary, and as an incentive to participate, respondents could win one of the 50 gift vouchers of $€ 20$. The survey was available online from February 20th, 2019 till May 23rd, 2019. We allowed farmers to answer questions with 'don't know' or 'not applicable' to reduce errors. Selection criteria for including responses in the analysis were: (i) respondents should be farmers from the arable, fruit, vegetable or flower bulb sector, and (ii) respondents should currently use pesticides on their farm. This resulted in 681 out of 1190 responses being included for analysis; 448 respondents were arable farmers, 67 flower bulb growers, 122 fruit growers and 44 were vegetable growers (Table 5.1).

Table 5.1: Overview of farm and farmer characteristics of respondents $(n=681)$ compared to data from the Netherlands (CBS, 2016, 2020).

\begin{tabular}{|c|c|c|c|c|}
\hline & & \\
\hline & & survey sample & $\%$ & Netherlands (\%) \\
\hline \multirow{4}{*}{ Income from farma } & $<25 \%$ & 30 & 4 & 7 \\
\hline & $25-75 \%$ & 115 & 17 & 16 \\
\hline & $>75 \%$ & 425 & 62 & 75 \\
\hline & no answer & 111 & 16 & 2 \\
\hline \multirow{3}{*}{ Gender ${ }^{a}$} & male & 628 & 92 & 95 \\
\hline & female & 28 & 4 & 5 \\
\hline & no answer & 25 & 4 & -- \\
\hline \multirow{6}{*}{ Education $^{a}$} & None & 1 & 0 & 0 \\
\hline & Primary school & 37 & 5 & 4 \\
\hline & High school diploma & 71 & 10 & 22 \\
\hline & Sec. prof. education & 317 & 47 & 60 \\
\hline & Higher education & 232 & 34 & 12 \\
\hline & no answer & 23 & 3 & 2 \\
\hline \multirow{4}{*}{ Farm type ${ }^{b}$} & Arable & 448 & 66 & 70 \\
\hline & Flower bulb & 67 & 10 & 8 \\
\hline & Vegetable & 44 & 7 & 11 \\
\hline & Fruit & 122 & 18 & 12 \\
\hline
\end{tabular}

a Netherlands data from 2016; b Netherlands data from 2019

The average age of the respondents was $51 \pm 11$ years, and farm size ranged from 1.6 ha to 650 ha. For most respondents (62\%) the farm provided more than $75 \%$ of the family income. Most respondents were men (92\%), and had completed either secondary professional education (47\%) or higher education (34\%) (Table 5.1). Our sample provides a reasonable reflection of the Dutch farmer population regarding age, gender, income, farm 
type and farm size (Table 5.1). In the Netherlands, all farmers that use pesticides have to comply with national regulations and need to obtain a spraying licence (LNV, 2020). Therefore, we assumed that all respondents were knowledgeable on impacts of pesticides on the environment, and that variation in knowledge level was limited.

\section{Statistical analysis}

We estimated five models following the procedure as described by Sok et al. (2015), and Vasquez et al. (2019) (Fig. 5.1). First, in Model 1 we determined the most important constructs driving intention using SEM (Fig. 5.1; blue box). In Models 2-5 we used a MIMIC modelling approach to determine the most influential underlying beliefs of each construct (Fig. 5.1; red boxes).

We used McDonalds' coefficient omega ( $\omega$ ) and average variance extracted (AVE) to determine the internal consistency of variables used for validating psychometric tests. AVE values $>0.5$ and $\omega>0.7$ are considered to indicate reliability (Padilla and Divers, 2016). Overall model fit was evaluated using criteria for good fit: Comparative Fit Index (CFI > 0.9), Tucker-Lewis fit Index (TLI > 0.9), root mean square error of approximation (RMSEA<0.08), and root mean square residual (SRMR < 0.1) (Brown, 2015; Parry, 2017). Mardia's multivariate skewness $\left(\mathrm{b} 1=27.21, X^{2}(1140)=3088.65, \mathrm{p}=0.00\right)$ and kurtosis $(\mathrm{b} 2=433.38$, $\mathrm{z} 2=35.68, \mathrm{p}=0.00$ ) tests indicated that normality assumptions were not met. Therefore, we used the Satorra-Bentler method, a robust ML estimator with robust standard errors and a Satorra-Bentler scaled test statistic (Satorra and Bentler, 1994; Kline, 2005; Brown, 2015; Cain, Zhang and Yuan, 2017). In our analysis, we refer to direct measures as 'indicators' and indirect measures as 'variables'.

\section{Model 1 - Direct measures}

For Model 1 we used a two-step approach to estimate which constructs of behaviour are the main drivers of intentions to reduce pesticide use (Fig. 5.1; blue box). First, we estimated a measurement model in which we a priori assigned indicators to constructs. These indicators were A1-A4, Ni1-Ni3, Nd1, PBC1-PBC4, and I1-I3 (Table S5.1). Using Confirmatory Factor Analysis (CFA), we assessed model fit and evaluated which indicators were representative of each construct. The measurement model was revised by deleting indicators that had very low values of factor loading and squared multiple correlation $\left(\mathrm{R}^{2}\right)$. In addition, we removed indicators that attempted to load on more than one construct, as indicated by high modification indexes (Brown, 2015). This procedure resulted in the removal of indicators A1, PBC2, I2, and I3. The results of the measurement model further showed that indicator A4 ('risky') differed from the other indicators for attitude ('necessary' and 'important'). We used these low correlations as a justification for the separation of the main A construct in two separate constructs: attitude (A) and risk attitude (' $A_{r}$ '). Descriptive statistics for each indicator and the correlation matrix are presented in Table S5.3, while the overall fit 
statistics of the original and revised measurement model (Model 1), as well as reliability measures ( $\omega$ and AVE) for each construct are reported in Table S5.4.

Second, we estimated a structural model based on the re-specified measurement model. The structural model was used to determine the relative importance of each construct $\left(A, A_{r}, N i\right.$, $\mathrm{Nd}$, and PBC) towards intention (I) (Fig. 5.2). As a robustness check, we assessed differences between farmer types by conducting a multigroup analysis. We compared the free structural model and a constrained model with fixed intercepts and path coefficients to assess whether all coefficients were significantly different across groups or not. Comparing the free and constrained multigroup model $\left(X^{2}(30)=32.936, \mathrm{p}=0.33\right)$ indicated that the coefficients did not significantly differ between groups, and therefore we kept the pooled data for further analyses. We estimated different model specifications to assess the impact of multicollinearity in the final model with all constructs included (Table 5.2).

\section{Models 2-5- Indirect measures}

The most relevant beliefs, referents (i.e. persons that influence an individual's social norms), and factors were analysed using MIMIC modelling (Fig. 5.1 - red boxes). The results of Models 2-5 provide insight into which underlying beliefs pose barriers and drive the motivation of farmers to decrease pesticide use. In Model 2 we estimated which attitudinal beliefs (be1-be5; Table S5.2) were most important determining A and Ar. Model 3 estimated the most important referents (inm1-inm6; Table S5.2) for injunctive norms (Ni), and in Model 4 we estimated the most important referents for descriptive norms (Nd) (dni1-dni4; Table S5.2). Model 5 estimated what underlying control factors (cp1 - cp8; Table S5.2) were most important for PBC. Records with missing data were discarded. This resulted in 630 observations for A, 563 observations for $\mathrm{Ni}, 510$ observations for $\mathrm{Nd}$, and 570 observations for PBC. Variance inflation factors (VIF) indicated that there was no variable redundancy $(\mathrm{VIF}<5)$. Therefore, all belief variables were kept for the analysis. Final MIMIC models were obtained after the stepwise deletion of non-significant variables (Diamantopoulos, 2011).

All analyses were conducted in R (R Development Core Team, 2019) with the lavaanpackage for SEM and MIMIC models (Rosseel, 2012). Figures were created using the semPlot package (Epskamp, 2015).

\section{RESULTS}

\section{Direct measures}

\section{Descriptive statistics}

Mean response values for indicators A1-A3 ranged from -0.45 to 0.39 (on a scale from -2 to +2 ; Table S5.3). The centering of scores around zero indicates that respondents do not perceive the behaviour of decreasing pesticide use as either 'good' or 'bad'. Interestingly, the mean value for the indicator A4 - 'risk' - was valued negatively (-1.11), which implies that farmers perceive decreasing pesticide use as risky. Farmers' injunctive norms (Ni) - what 
others expected from the farmer - were neutral ranging from -0.33 to 0.08 , indicating that important people from the sector, friends or family did not play a role in pesticide use decision-making. Descriptive norms (Nd) were assessed with a statement on respondents' expectations of whether colleague-farmers would reduce their pesticide usage. The mean valuation of this statement was -0.2 , which can be considered as a neutral opinion on whether other farmers would decrease their pesticide use. Mean rank scores for perceived control indicators PBC1-PBC4 ranged from -0.62 to -0.21 , indicating that farmers have a slightly negative perception about their ability to decrease pesticide use. Finally, respondents' intention to decrease pesticide use was neutral to moderately positive; 0 to 0.24. In other words, on average respondents showed a slight intention to decrease their pesticide use.

\section{Model 1: Identifying the main determinants of intention}

The fitted structural model of significant drivers of intention to decrease pesticide use is presented in Fig. 5.2: attitude, injunctive norms, descriptive norms, and perceived behavioural control all emerged as significant predictors of intentions. Total explained variance in intention (I) was $65 \%$, with $\mathrm{Nd}$ being the most important determinant, followed closely by PBC, A, and Ni (Fig 5.2; Table 5.2). Thus, the intention to decrease pesticide use is related to the social pressure respondents feel from expectations on what other farmers will do $\left(\beta_{\mathrm{Nd}}=0.34\right)$. Furthermore, respondents' feelings of perceived control affect intentions to decrease pesticide use $\left(\beta_{\mathrm{PBC}}=0.24\right)$, as do attitudinal considerations $\left(\beta_{\mathrm{A}}=0.23\right)$. Moreover, considerations on what a respondent ought to do (injunctive norms) $\left(\beta_{\mathrm{Ni}}=0.14\right)$ can be considered a driver of intention.

Univariate analysis indicated that all constructs, including risk attitude, were significant determinants of intention (Table 5.2). Risk attitude ( $\left.A_{r}\right)$ as a single predictor explained intention (12\%), but was not significant when other constructs were added to the model. This suggests that the relative importance of risk attitude on intentions to decrease pesticide use is offset by the other social-psychological constructs. 


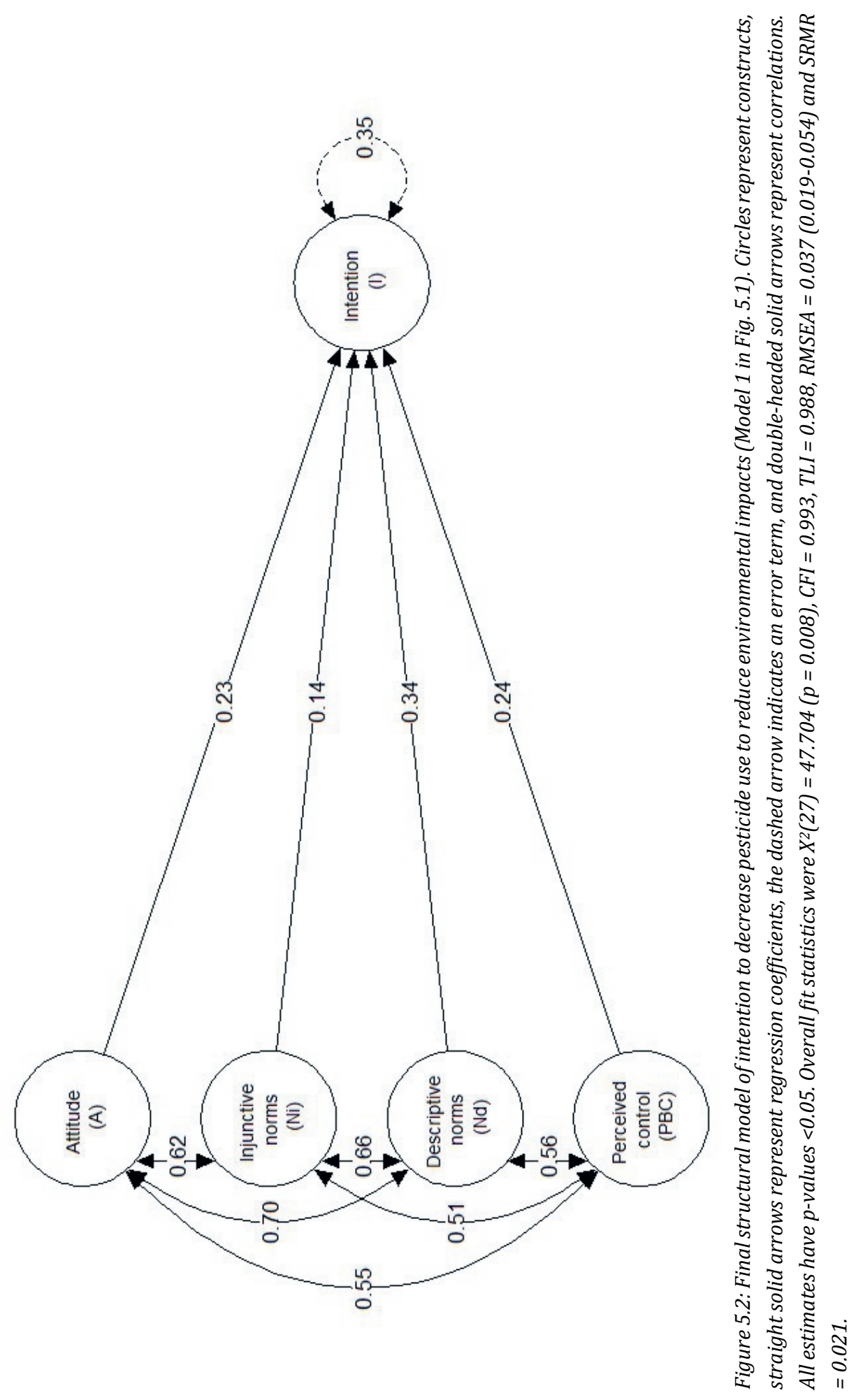




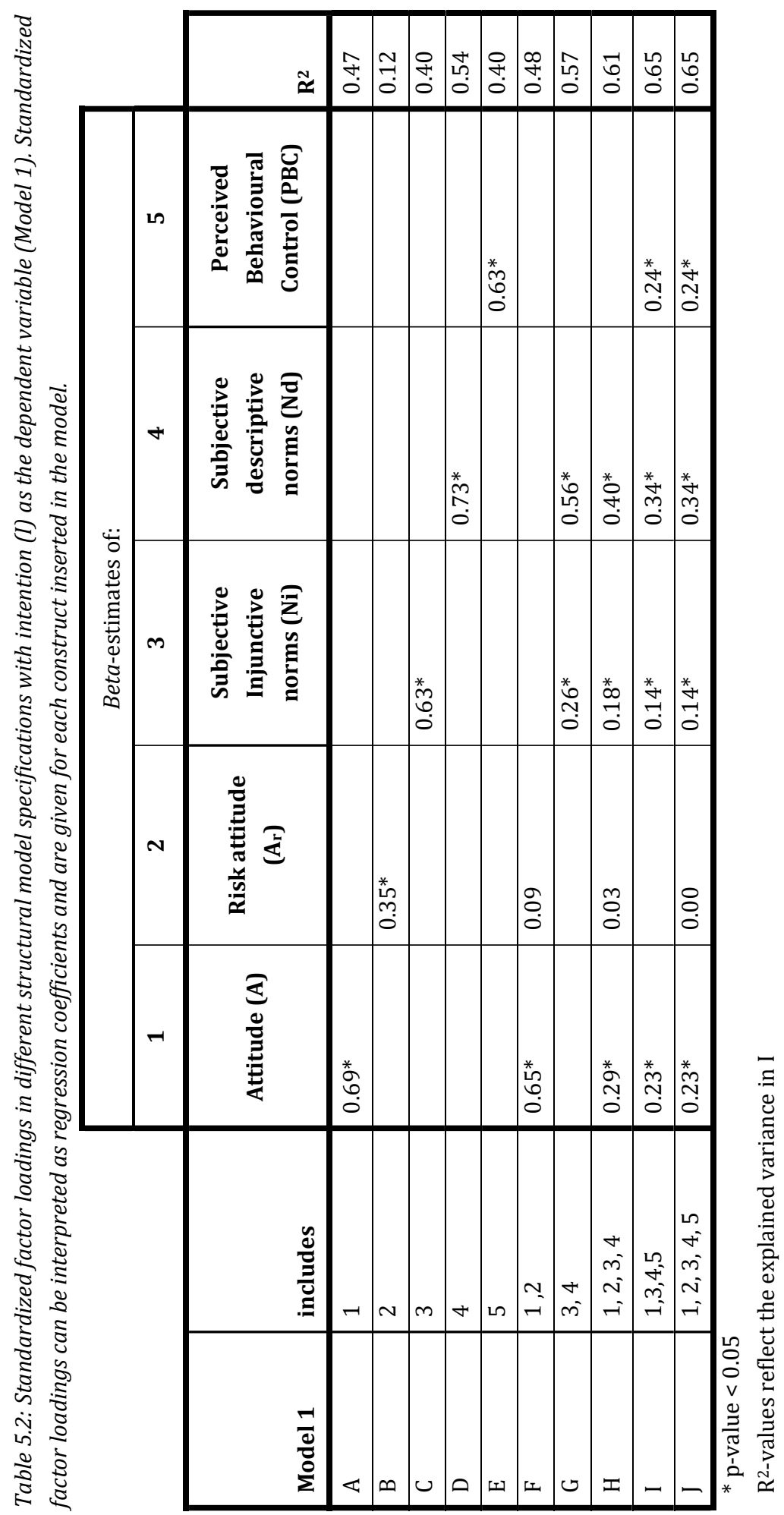




\section{Indirect measures}

\section{Descriptive statistics}

When comparing the five attitudinal beliefs, the highest mean rank score was given to 'Loss of yields' (be4) (1.49 on a scale from -2 to +2 ). This indicates that respondents expected that yields may decrease if they would decrease their pesticide use, and that they consider this very important. This belief had the highest correlation with risk attitude, suggesting that respondents' attitudinal risk considerations are mostly related to beliefs on yield losses (Table 5.3). The second highest mean rank score was given to 'Crop quality' (be3), followed by 'Pest control' (be5) (1.43 and 1.37, respectively). Both beliefs have negative correlations with attitude and risk attitude, suggesting that farmers believe that a decrease of pesticide use would make pests more difficult to control, and would reduce crop quality and yield as a result. 'Nature \& environment' (be2) had a mean rank score of 0.64 and had the strongest correlation with attitude. This implies that respondents belief that a reduction in pesticide use is likely to be positive for nature and environment, and they think it is important to reduce their pesticide use for the environment. We expected that costs and labour would influence attitude, but this was not shown in the analysis. 'Costs \& labour' (be1) had the lowest mean rank score (0.42), indicating that respondents' are not sure if it is likely that decreasing their pesticide use would result in a change in costs and labour. Besides be2, the attitudinal belief variables were weakly correlated with attitude, while they had a strong correlation with risk attitude. This indicates that the underlying attitudinal belief variables in this model are more formative of risk attitude, than farmers' willingness to decrease pesticides. However, as shown in the previous section, risk attitude has a weaker influence on intentions to decrease pesticide use than attitude. In addition, attitude (A) was mainly formed by beliefs on nature and the environment.

We assessed six normative injunctive referents, of which 'Supermarkets \& wholesale' was the most important referent with the highest mean rank score $(0.95$; Table 5.4). This suggests that farmers consider supermarkets to be in favour of a decrease in pesticide use, and that this opinion is rather important for respondents. While 'Colleagues with organic farms' came second with a mean rank score of 0.45 , this referent had the highest percentage of 'not applicable' ticks (11.6\%), i.e. more than $10 \%$ of the respondents did not know organic farmers that would expect them to decrease their pesticide use. The mean rank scores of the other four referents were centred around zero ( -0.04 to 0.25 ), implying that respondents perceive a neutral social norm from these important persons regarding their intentions to reduce their pesticide use.

Out of four descriptive normative referents, 'Members of study groups' had the highest mean rank score of 0.24 (Table 5.5), but all four referents were scored within a similar range. This implies that respondents feel little social pressure from descriptive referents, and that they do not know whether their neighbours or colleagues will decrease their pesticide use. 
'Neighbours with organic farms' had the highest number of 'not applicable' ticks, indicating that more than $20 \%$ of the respondents did not know organic farmers. Moreover, the mean rank score for this referent was 0.21 and had the lowest correlation with descriptive norms. These results suggest that most respondents have neutral to slightly positive opinions in associating themselves with organic farmers on this topic, and they consider it likely that organic farmers will reduce their pesticide use. The other three descriptive normative referents have strong correlations with descriptive norms, indicating that respondents do identify with these referents.

We identified eight control factors (Table 5.6) of which the highest mean rank score was given to 'Higher crop prices' ( $c p 3$ ) and 'Greater choice in plant protection products' (cp6) (1.38 and 1.35, respectively). Respondents thought it important that they should get higher crop prices and availability of more choice in plant protection products to make it easier to decide to reduce their pesticide use. However, the control factor 'Higher crop prices' is not correlated with $\mathrm{PBC}$, implying that this is not a determining factor for the respondents' intention to decrease pesticides. Other control factors that had low correlations are 'Advanced breeding' (cp1) and 'Quality requirements' (cp4), which suggests that these factors are not perceived as possible barriers regarding decreasing pesticide use. 'Weather conditions' has a negative mean rank score of -0.50 . This implies that farmers do not think they could rely on favourable weather conditions, and they do expect that changing weather conditions will make it more difficult to decrease their pesticide use.

Table 5.3: Descriptive statistics of indirect measures for attitude (A) and risk attitude (Ar).

\begin{tabular}{|c|c|c|c|c|c|}
\hline Variable & Attitudinal belief statement & CorrAa & $\operatorname{Corr} \mathbf{A}_{\mathbf{r}}{ }^{\mathbf{a}}$ & Mean (SD)b & $\mathbf{N}$ \\
\hline be1 & I will have less costs and labour & 0.05 & $0.14^{* *}$ & $0.42(0.45)$ & 657 \\
\hline$b e 2$ & $\begin{array}{l}\text { This will be positive for nature and } \\
\text { environment }\end{array}$ & $0.46^{* *}$ & $0.21^{* *}$ & $0.64(0.82)$ & 659 \\
\hline be3 & $\begin{array}{l}\text { This has a negative influence on my } \\
\text { crop quality }\end{array}$ & $-0.17^{* *}$ & $-0.35^{* *}$ & $1.43(0.68)$ & 662 \\
\hline be4 & I have a higher risk of reduced yields & $-0.21^{* *}$ & $-0.38^{* *}$ & $1.49(0.68)$ & 669 \\
\hline be 5 & $\begin{array}{l}\text { It will be more difficult to control } \\
\text { pests }\end{array}$ & $-0.13^{* *}$ & $-0.20^{* *}$ & $1.37(0.78)$ & 663 \\
\hline
\end{tabular}

** $\mathrm{p}$-value $<0.01$

a CorrA and CorrA $\mathrm{r}$ are correlations with the average of variables representing the constructs attitude $(\mathrm{A})$ and risk attitude $\left(\mathrm{A}_{\mathrm{r}}\right)$.

b Variables range from -2 to +2 , and are multiplicative composites of two question types; a belief strength valuation (unlikely-likely) and an outcome evaluation ((not) important) (see Table S5.2). 
Table 5.4: Descriptive statistics of indirect measures for injunctive norms (Ni).

\begin{tabular}{|l|l|l|l|l|l|}
\hline Variable & Referent & Corr & Mean (SD) & N & \%NAc $^{\mathbf{b}}$ \\
\hline inm1 & Supermarkets \& wholesale & $0.37^{* *}$ & $0.95(0.86)$ & 635 & 6.75 \\
\hline inm2 & Industry \& suppliers & $0.24^{* *}$ & $0.16(0.70)$ & 638 & 6.31 \\
\hline inm3 & Crop advisors & $0.33^{* *}$ & $0.25(0.70)$ & 646 & 5.14 \\
\hline inm4 & Family or friends & $0.40^{* *}$ & $0.23(0.64)$ & 620 & 8.96 \\
\hline inm5 & Colleagues with conventional farms & $0.29^{* *}$ & $-0.04(0.67)$ & 641 & 5.87 \\
\hline inm6 & Colleagues with organic farms & $0.30^{* *}$ & $0.45(0.64)$ & 602 & 11.6 \\
\hline
\end{tabular}

** $\mathrm{p}$-value $<0.01$

a Corr are correlations of each variable with the average of the direct measures of the construct $\mathrm{Ni}$

b Variables range from -2 to +2 and are multiplicative composites of two question types; a normative belief strength valuation ((dis)approve) and motivation to comply ((not) important) (see Table S5.2)

c \%NA refers to the percentage of respondents answering with 'not applicable'.

Table 5.5: Descriptive statistics of indirect measures for descriptive norms (Nd).

\begin{tabular}{|l|l|l|l|l|l|}
\hline Variable & Referent & Corr $^{\mathbf{a}}$ & Mean (SD) $^{\mathbf{b}}$ & $\mathbf{N}$ & \%NAc $^{\mathbf{c}}$ \\
\hline dni1 & Neighbours with organic farms & $0.29^{* *}$ & $0.21(0.64)$ & 533 & 21.73 \\
\hline dni2 & Neighbours with conventional farms & $0.47^{* *}$ & $0.11(0.60)$ & 653 & 4.11 \\
\hline dni3 & Members of study groups & $0.50^{* *}$ & $0.24(0.64)$ & 617 & 9.4 \\
\hline dni4 & Colleague from cooperation & $0.45^{* *}$ & $0.19(0.61)$ & 589 & 13.51 \\
\hline
\end{tabular}

$* *$ p-value $<0.01$

a Corr are correlations of each variable with the average of the direct measures of the construct Nd.

b Variables range from -2 to +2 and are multiplicative composites of two question types; a normative belief strength valuation ((un)likely) and identification with referent ((not) important) (see Table S5.2).

c \%NA refers to the percentage of respondents answering with 'not applicable'. 
Table 5.6: Descriptive statistics of indirect measures for perceived behavioural control (PBC).

\begin{tabular}{|c|c|c|c|c|}
\hline Variable & Control belief statement & Corra & Mean (SD) ${ }^{b}$ & $\mathbf{N}$ \\
\hline cp1 & $\begin{array}{l}\text { I would be required to use more advanced } \\
\text { breeding }\end{array}$ & 0.04 & $0.97(0.86)$ & 629 \\
\hline cp2 & $\begin{array}{l}\text { I would be required to use more precise } \\
\text { technology and mechanization }\end{array}$ & $0.21^{* *}$ & $0.78(0.92)$ & 661 \\
\hline cp3 & I should receive a higher price for my product & 0.07 & $1.38(0.86)$ & 659 \\
\hline cp 4 & $\begin{array}{l}\text { the quality requirements on my products } \\
\text { should be less stringent. }\end{array}$ & -0.06 & $0.88(0.87)$ & 646 \\
\hline cp5 & I would rely on favourable weather conditions & $0.14^{* *}$ & $-0.50(1.02)$ & 640 \\
\hline cp6 & $\begin{array}{l}\text { I would rely on a greater choice in plant } \\
\text { protection products }\end{array}$ & $-0.11^{* *}$ & $1.35(0.82)$ & 665 \\
\hline$c p 7$ & I would rely on cultivation advice & $0.15^{* *}$ & $0.67(0.79)$ & 660 \\
\hline cp8 & $\begin{array}{l}\text { I would have to consider a longer crop rotation } \\
\text { and other crop varieties }\end{array}$ & $0.20^{* *}$ & $0.49(0.96)$ & 622 \\
\hline
\end{tabular}

** $\mathrm{p}$-value $<0.01$

a Corr are correlations of each variable with the average of the direct measures of the construct perceived behavioural control (PBC)

b Variables range from -2 to +2 and are multiplicative composites of two question types; a control belief strength valuation ((un)likely) and power of control (difficult-easy) (see Table S5.2).

\section{Identifying main beliefs, referents and factors}

\section{Model 2: Identifying main attitudinal beliefs}

The attitudinal belief variables explained $31 \%$ of the variance in $\mathrm{A}$, and $34 \%$ of the variance in $A_{r}$ (Fig. 5.3; Table 5.7). The variables 'Pest control' (be5), 'Crop quality' (be3), and 'Costs \& labour' (be1) were not significant for A. Only 'Pest control' (be5) was not significant for $\mathrm{A}_{\mathrm{r}}$ and was removed from the final model. 'Nature \& environment' (be2) was the most important belief for attitude, and 'Loss of yields' (be4) was the second most important belief. In contrast, 'Loss of yields' (be4) was the most important belief for $A_{r}$, followed by 'Nature and environment' (be2). 'Loss of yields' has a strong negative coefficient towards $A_{r}\left(\gamma_{b e}=-\right.$ 0.36), indicating that the risk of reduced yields had a strong influence on risk attitude. 'Crop quality' (be3) and 'Costs \& labour' (be1) were also significant variables but had a weak effect on Ar. In summary, most attitudinal beliefs explained the risk attitude of the respondents, and the indicator 'Nature \& environment' most strongly influenced the attitude of respondents (Fig. 5.3). 

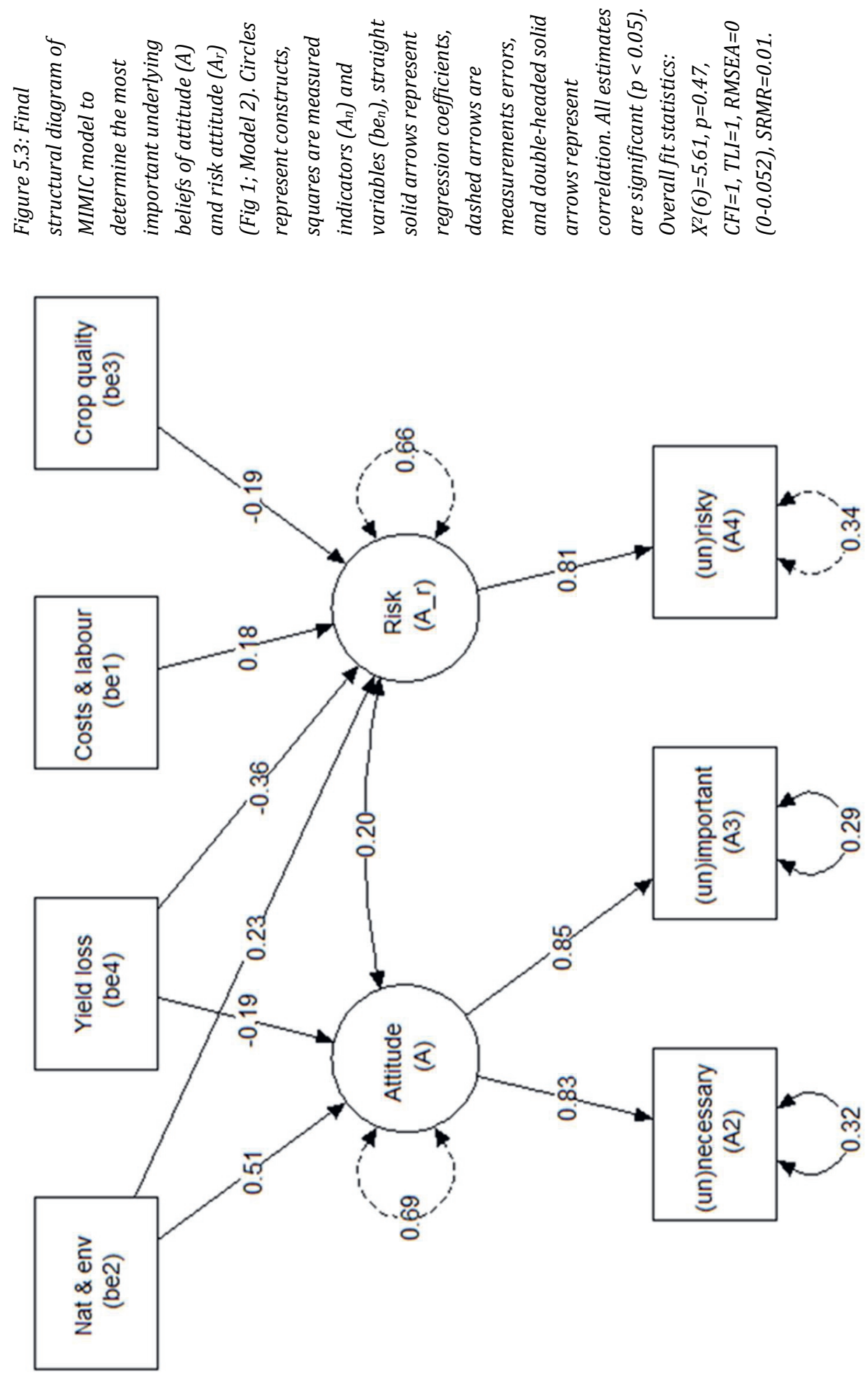
Model 3: Identifying main injunctive referents

The injunctive referents explained $29 \%$ of the variance in Ni (Fig. S5.1; Table 5.7). We removed 'Industry \& suppliers' (inm2) and 'Colleagues with conventional farms' (inm5) due to non-significance. 'Family and friends' (inm4) were the most important referents, closely followed by 'Supermarkets' (inm1). In addition, 'Crop advisors' (inm3) and 'Colleagues with organic farms' (inm6) were influential normative injunctive referents. Thus, the most influential referents that exert social pressure on respondents were relatives, business relations, and colleagues that already have set an example of less or no pesticide use.

\section{Model 4: Identifying main descriptive referents}

The descriptive referents explained $42 \%$ of the variance in Nd (Fig. S5.2; Table 5.7). The referent 'Colleagues from cooperation' (dni4) was removed due to non-significance. The referents with the strongest influence on descriptive norms were 'Neighbouring colleagues from conventional farms' (dni2) and 'Members of study groups' (dni3) ( $\gamma_{\text {dni2 }}=0.32$ and $\gamma_{\mathrm{dni} 3}=0.30$, respectively). This indicates that the opinion of people who farmers see as their equals could be important for decision-making on reduced pesticide use.

\section{Model 5: Identifying main control factors}

The eight control factors explained 16\% variance in PBC (Fig. S5.3; Table 5.7). We removed 'More advanced breeding' (cp1) and 'Higher crop prices' (cp3) due to non-significance. Important barriers were two control factors underlying a farmers' perceived capability; 'More precise technology \& mechanisation' (cp2) and 'Greater choice in plant protection products' (cp6). The latter had a negative coefficient $\left(\gamma_{\mathrm{cp} 6}=-0.17\right)$, indicating that less choice in plant protection products would negatively influence the farmers' perceived capability to decrease pesticide use. Factors associated with external conditions (e.g., 'Weather conditions', 'Advanced breeding', and 'Crop prices') had little to no influence on a farmers' perceived ability to decrease pesticide use. 


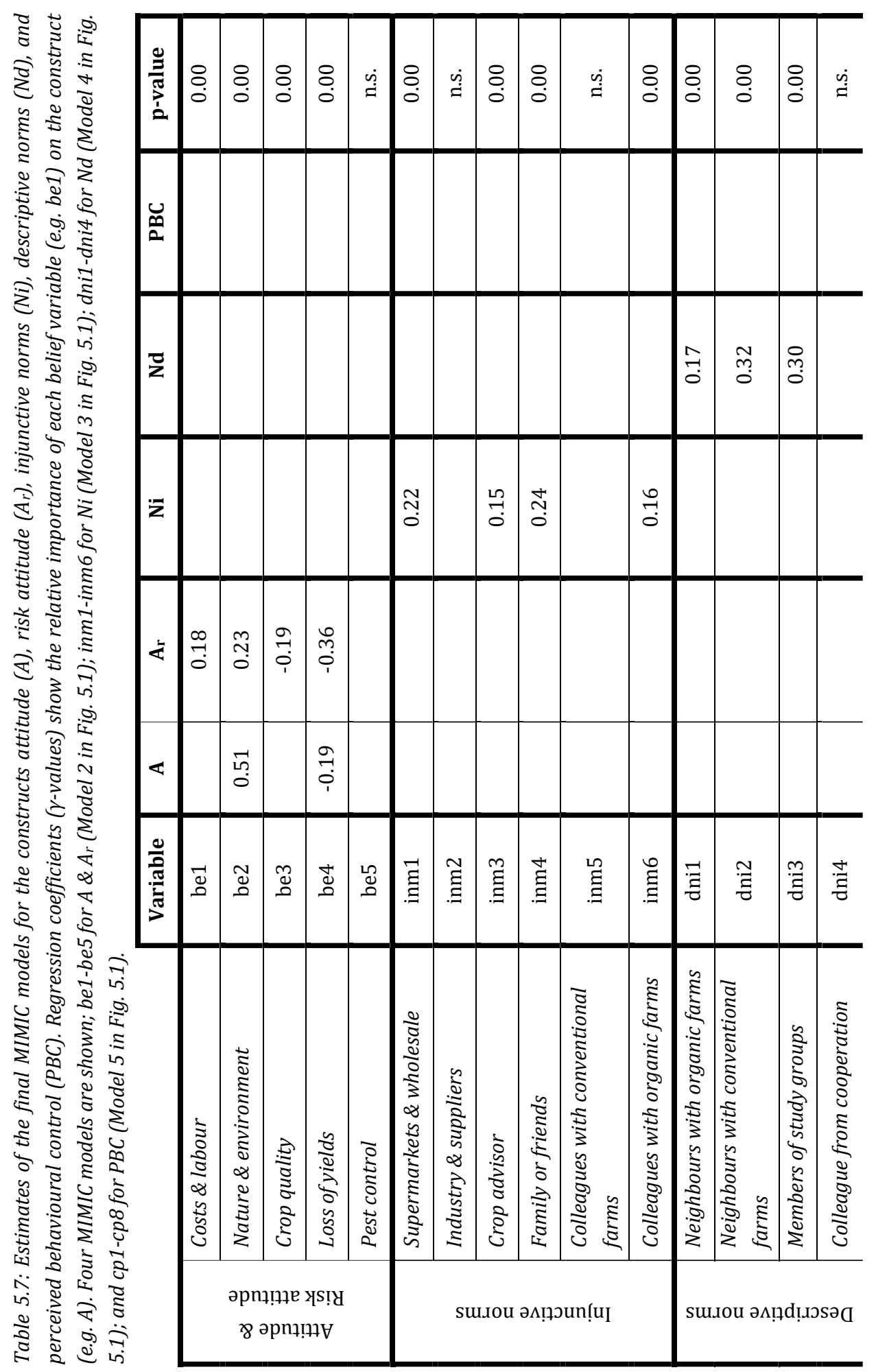




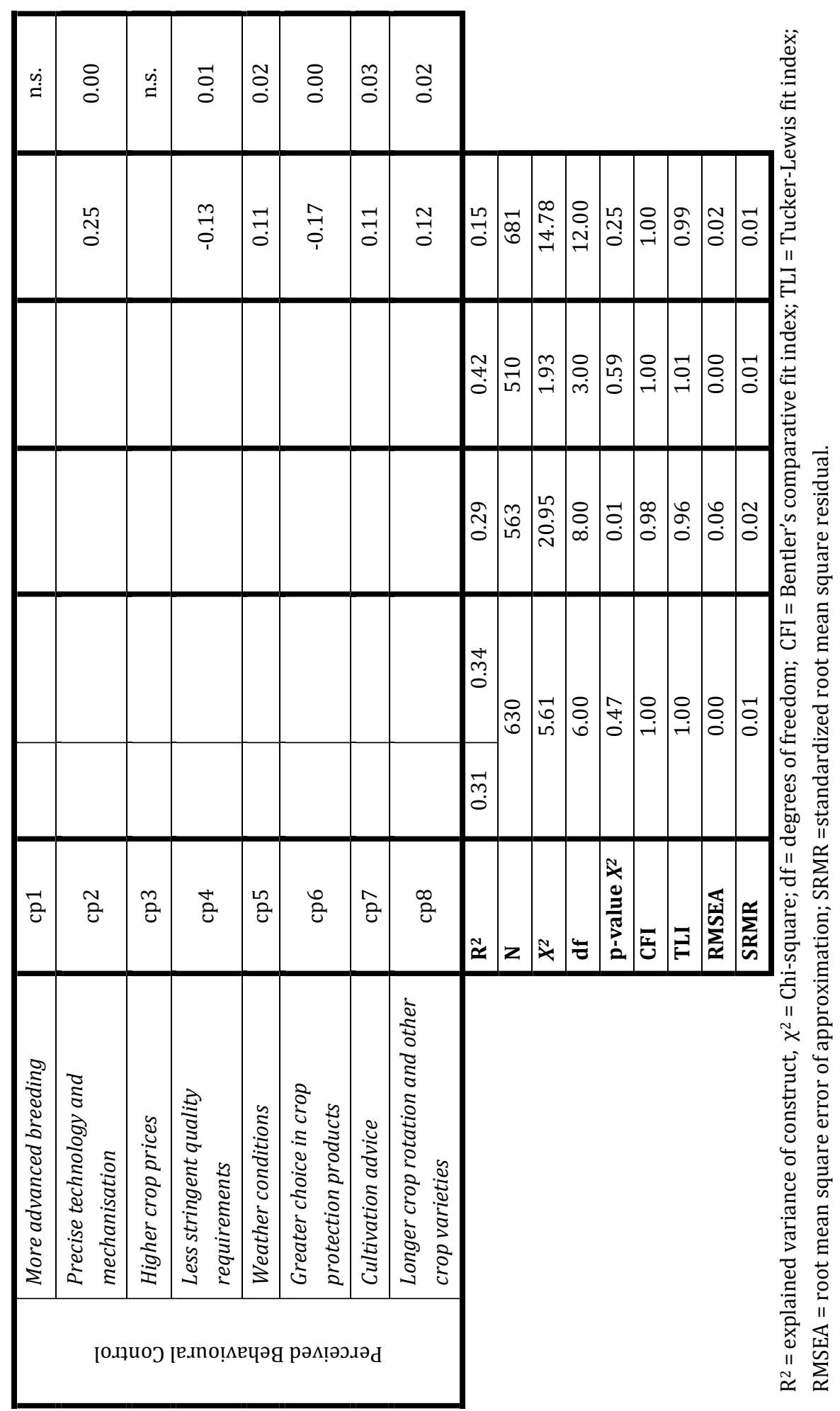




\section{DISCUSSION}

While there is a growing societal demand to reduce the environmental impacts of pesticides, farmers are struggling to become less dependent on pesticides for crop protection. To identify pathways towards reduced environmental impacts of pesticides, we aimed to understand which social-psychological constructs influence farmers' decisions on pesticide use (to reduce environmental impacts). We used a quantitative approach based on the Reasoned Action Approach to estimate the relative influence of different socialpsychological constructs on farmers' intentions to reduce pesticide use. Descriptive norms, perceived behavioural control, attitude, and injunctive norms all emerged as significant predictors of intention. We discuss four key findings. First, the intention of farmers to reduce pesticide use is strongly determined by whether other farmers also act, i.e. the perceptions on behaviour of others. Second, farmers felt little sense of control and perceive limited capacity and autonomy to reduce pesticide use. Third, farmers' motivations to reduce pesticide use were based on moral considerations regarding what is good for nature and the environment. Finally, decreasing pesticide use was considered risky, but the relative importance of risk attitude was offset by the environmental considerations of farmers.

First, farmers' intentions to decrease pesticide use were driven by descriptive norms, i.e., expectations on other farmers' behaviour. The most important referents were peers like conventional neighbouring farmers and members from study groups, i.e., those individuals who farmers view as like-minded (i.e., shared values or experiences) or credible experts (Sok et al., 2015; Perry and Davenport, 2020). These results confirm the findings of other studies about the importance of support by neighbours towards the implementation of new management strategies (Brewer and Goodell, 2012; Parsa et al., 2014; Stallman and James, 2015). For example, if a neighbour had a positive experience with conservation practice (e.g. reduced tillage), this served as a positive model for farmers who still had to apply the measure (Ahnström et al., 2009; Perry and Davenport, 2020). Farmers typically do not make radical changes in their decision-making, but rather implement new practices gradually (Chantre and Cardona, 2014). Thus, observing positive outcomes of reduced pesticide use on the environment can serve to increase intentions to decrease pesticide use. This stresses the importance of network and neighbourhood connections in influencing farmers' decision-making on pest management. For example, farmers believed that if they worked together with their neighbour, they could more effectively manage pests (Stallman and James, 2015). Indeed, farmers' decisions on IPM play out at a larger scale than their individual farms and can therefore benefit from a landscape approach (Brewer and Goodell, 2012; Parsa et al., 2014). This highlights the importance of collective action, and future strategies may build on the importance of knowledge and communication transfer to enhance these social interactions. Trust is a key element in behaviour change (Green et al., 2020), and needs to be central to supporting discussions on norms and values. This could be addressed through the facilitation of focus groups (Perry and Davenport, 2020), and 
discussions with neighbours on the positive outcomes of reduced pesticide use to enhance farmers' intentions.

Secondly, the main perceived barriers to decrease pesticide use were capacity related. This is in agreement with other studies, e.g. Sporenberg et al. (2019) and Wagner et al. (2016). These studies also indicated that the availability of crop protection products was one of the main barriers that farmers perceive in changing their decision-making on pest management. Currently, farmers consider pesticides to be the most effective method to manage pests (Atreya et al., 2011; Skevas, Stefanou and Oude Lansink, 2012). Thus, a reduction in choice availability of synthetic pesticides translates in reduced confidence in the ability to effectively control pests. This emphasizes that farmers perceive a dependency on pesticides to manage pests. Yet, our study also shows that external control factors that include nonchemical alternatives, e.g. 'more precise technology and machinery', 'expert advice' and a 'longer crop rotation and other crop varieties', were perceived as factors that could facilitate farmers' sense of control, and positively influence intentions to decrease pesticide use. Furthermore, our measured control beliefs only explained $16 \%$ of the variance of perceived behavioural control, and were mainly capacity-related. This shows that we missed out on control factors that are indicative of farmers' sense of autonomy. This is important to note, as previous studies have found that knowledge on the effects of pesticide use on the environment and personal health is an important factor determining actual use of pesticides (Calliera et al., 2013; Damalas and Koutroubas, 2014; Khan and Damalas, 2015; Bagheri et al., 2019). To strengthen the sense of autonomy it is important to support farmers in making strategic and tactical pest management decisions, e.g. through expert advice, education and knowledge transfer (Sherman and Gent, 2014). In addition, to increase farmers' confidence in their ability to decrease pesticide use, while maintaining a healthy crop, it should be made more visible to farmers what alternatives to pesticides exist. This stresses the need to inform farmers about alternative, chemical and non-chemical, methods for pest control.

Our third finding shows that the impact of pesticides on the environment seems to play a role in the intentions of our respondents. This suggests that farmers who believe that reducing their pesticide use will benefit nature and environment (i.e., decrease environmental impacts), have a stronger intention to decrease their pesticide use. This is in line with findings of Chèze et al. (2020), who found that farmers' willingness to adopt pesticide reducing practices was motivated by environmental and health gains. Furthermore, Stallman and James (2015) report that farmers who are highly concerned about the negative environmental effects of pesticides are more willing to cooperate to reduce pesticide inputs than farmers being less concerned. In addition, Ahnström et al. (2013) show that farmers' interest in nature was positively associated with higher biodiversity index levels in agricultural landscapes, and explain this as a subconscious factor influencing farm management and management intensity. Thus, here the intrinsic motivation of farmers comes into play. Recent research in the Netherlands confirms the 
finding that the environmental effects of pesticides weigh heavily in respondents' intention to decrease usage, and suggests to change environmental subsidy schemes from effortbased to result-based (Westerink et al., 2019), feeding into a farmers' feeling of autonomy and reinforcing intrinsic motivations (Reddy et al., 2017). In addition, extension services could focus more on further informing farmers about the impact of pesticides on the environment, and the use of more environmentally friendly products (Skevas and Oude Lansink, 2014).

Finally, we discuss the role of risk attitude on farmers' intentions to decrease pesticide use. We expected that risk avoiding behaviour, such as prophylactic use of pesticides (Chantre and Cardona, 2014), would influence farmer's decision making. In our study, farmers ranked reduced pesticide use as being 'risky', but the relative importance of risk attitude on intentions to decrease pesticide use was offset by the other social-psychological constructs in the model. These findings contrast with previous studies that reported that the risk of large production losses was the main obstacle for farmers to reduce pesticide use (Pedersen et al., 2012; Chèze, David and Martinet, 2020). Nevertheless, other studies also reported that farmers that were more aware of environmental risks of pesticide use had stronger environmental considerations towards decision-making on pesticide use (Pedersen et al., 2012; Chèze, David and Martinet, 2020). Yet, our study also indicated that farmers' willingness to reduce pesticide use is, in part, influenced by the belief that reduced pesticide use could reduce crop yield or quality. We cannot rule out the possibility that farmers provided socially desirable answers, but it is equally possible that farmers feel that their 'licence to produce' is at stake and are prepared to change their practices to safeguard their livelihoods in the future. This highlights the need to support farmers with developing low or no pesticide use practices that do not substantially compromise crop performance or profitability (Lechenet et al., 2017; Chèze, David and Martinet, 2020).

In summary, to trigger intentions to reduce pesticide use, social interactions between farmers should be emphasized, and discussions with peers facilitated, including those that may have opposing views or other management practices, e.g. organic farmers. Furthermore, farmers' sense of control and perceived ability should be strengthened. This can be done through communication and knowledge transfer from a credible and trusted communicator, with a specific focus on alternative pest control options and implications for crop yield and farm income. Moreover, farmers' skills to apply alternative pest control methods (e.g. IPM) should be supported. This could be fostered by, for instance, showcasing successful trials of production with low or no pesticide use at agricultural research stations, experimental farms, or frontrunner farms, and establishing farmer study groups.

\section{Limitations of the study and future research}

In the Netherlands the highest pesticide inputs are reported for flower bulb and vegetable production, which are sectors that are associated with strict quality requirements 
(Sporenberg, Verstand and Beerling, 2019). In our study 66\% of the 681 respondents were arable farmers, $10 \%$ were flower bulb growers, $7 \%$ vegetable growers and $18 \%$ were fruit growers. While the overall sample size of our study is adequate and is similar or higher than in other studies in this research domain (Breukers et al., 2012; Läpple and Kelley, 2013; Hijbeek et al., 2018), the arable and vegetable growers in our sample were slightly underrepresented, and the fruit and flower bulb growers slightly overrepresented as compared to the Dutch farmer population (Table 5.1). Nevertheless, multigroup analysis did not show significant differences between farmer groups, implying that our results are representative for the whole farmer population of the Netherlands. Even so, we cannot rule out that our survey did not capture the full heterogeneity in the behaviour and intentions of the Dutch farmer population in regard to reducing pesticide use. For example, there was relatively large variation in farm size in our sample because fruit and vegetable farms are typically smaller than arable farms. Farm size may influence farmer's perceptions and potential pesticide use decision making as larger farms are more efficient in the use of inputs, possibly because they invest more in improving the technology of their inputs (Skevas and Oude Lansink, 2014). Other characteristics, such as age, education and previous knowledge (and experiences) on pesticide use may also influence farmer's attitude and behaviour (Fishbein and Ajzen, 2011; Burton, 2014; Yang, Zhao and Meng, 2019). In the Netherlands, all farmers that use pesticides have to comply with national regulations and need to obtain a spraying licence (LNV, 2020), and therefore we assumed that all respondents were knowledgeable on impacts of pesticides on the environment, and that variation in knowledge level was limited. Nonetheless, investigating the responses of specific farm types and farmer characteristics could provide further insights about targeted interventions for particular agricultural sectors.

The RAA, also known as the theory of planned behaviour, is a well-known and frequently applied framework to explain and predict farmer behaviour (Ajzen, 2012; Sok et al., 2020). It focuses on the controlled aspects of decision making and on behaviours that are goaldirected and steered by conscious self-regulatory processes. Farmer's decision making on pesticide management takes place in a business context, and these decisions can have consequences for the private farm business as well as the provisioning of public goods. Assuming that farmers act in this environment as a homo agricola economicus, fails to account for behavioural factors that drive pesticide use, such as moral considerations, social influences and one's ability to act in order to achieve an desired outcome. These considerations and peer pressures are captured by the RAA. Furthermore, in a review on behavioural factors affecting the adoption of sustainable farming practices, scholars have recommended to employ experimental research approaches for the ex-ante evaluation of policy designs (Colen et al., 2016; Dessart, Barreiro-Hurlé and Van Bavel, 2019). While reasoned action theories have occasionally been applied in a more experimental setting (see e.g., Josefsson et al., 2017), the application of so-called hybrid choice models or integrated 
choice and latent variable models is a promising approach. In such an approach (see e.g. Sok and Fischer, 2019) a survey experiment is designed which combines the survey measurement of social-psychological constructs with a stated preference experiment (e.g. a discrete choice experiment), which can improve the validity of inductive behavioural research on farmer's behaviour.

\section{CONCLUSION}

Our study sheds some light on farmers' intentions to reduce pesticide use to decrease environmental impacts. Our results show that farmers' intention to reduce pesticide use is constrained by social norms, as well as farmers' perceived capability. This suggests that farmers keep a close eye on their neighbours' actions, and it appears that farmers are reluctant to engage in the behaviour of which others disapprove. Furthermore, farmers indicate that they have only limited capacity or autonomy to decrease pesticide use. To conclude, farmers need successful examples of how to decrease pesticide use, which can be through peer farmers or through knowledge provisioning on alternative pest control methods. These insights may be useful to direct policy making and may offer scope to influence farmers' intentions towards pesticide use.

\section{ACKNOWLEDGEMENTS}

Support for this paper was provided by the Dutch Research Council (NWO), grant 824.15.022. We would also like to thank two anonymous reviewers for their constructive and helpful comments on earlier drafts of this manuscript. 



\section{SUPPLEMENTARY MATERIALS}

Table S5.1: Overview of direct measures (indicators) and associated statements used in the survey querying intentions to decrease pesticide use and reduce environmental impacts.

\begin{tabular}{|c|c|c|}
\hline \multicolumn{3}{|l|}{ Direct measures } \\
\hline Construct & Indicator & Description of statement \\
\hline \multirow[t]{5}{*}{ Attitude } & \multicolumn{2}{|c|}{$\begin{array}{l}\text { Decreasing my use of environmentally harmful pesticides within } \\
\text { two years is ... }\end{array}$} \\
\hline & $A_{1}$ & .... disadvantageous - advantageous \\
\hline & $A_{2}$ & .... unnecessary - necessary \\
\hline & $A_{3}$ & .... unimportant - important \\
\hline & $A_{4}$ & .... risky - not-risky \\
\hline \multirow[t]{4}{*}{ Injunctive Norm } & \multicolumn{2}{|c|}{ To decrease my environmental impact within two years, ... } \\
\hline & $N i_{1}$ & $\begin{array}{l}\text {... people that have much to do with my farm } \\
\text { expect me to use less environmentally harmful } \\
\text { pesticides. }\end{array}$ \\
\hline & $\mathrm{Ni}_{2}$ & $\begin{array}{l}\text {... persons of the sector, whose opinion I value, } \\
\text { would approve if I would decrease my use of } \\
\text { environmentally harmful pesticides. }\end{array}$ \\
\hline & $\mathrm{Ni}_{3}$ & $\begin{array}{l}\text {...people who are important to me expect that I } \\
\text { will use less environmentally harmful pesticides. }\end{array}$ \\
\hline Descriptive Norm & $N d_{1}$ & $\begin{array}{l}\text { To decrease their environmental impact within two } \\
\text { years, colleague-farmers will decrease their use of } \\
\text { environmentally harmful pesticides. }\end{array}$ \\
\hline \multirow{4}{*}{$\begin{array}{l}\text { Perceived Behavioural } \\
\text { Control }\end{array}$} & $P B C_{1}$ & If I wanted to, I could decrease my use of pesticides \\
\hline & $\mathrm{PBC}_{2}$ & $\begin{array}{l}\text { It is up to me whether I will decrease my pesticide } \\
\text { use, and not dependent on other people. }\end{array}$ \\
\hline & $P B C_{3}$ & I have the possibility to decrease my pesticide use \\
\hline & $\mathrm{PBC}_{4}$ & I am capable of decreasing my pesticide use \\
\hline \multirow[t]{5}{*}{ Intention } & \multicolumn{2}{|c|}{ To decrease my environmental impact ...., } \\
\hline & $I_{1}$ & ... I plan to ... \\
\hline & $I_{2}$ & ... I want to ... \\
\hline & $I_{3}$ & ... I will try to ... \\
\hline & \multicolumn{2}{|r|}{.... decrease my use of environmentally harmful pesticides. } \\
\hline
\end{tabular}


Table S5.2: Overview of indirect measures (variables) and associated statements that were used in the survey to assess farmers' intentions to decrease pesticide use and reduce environmental impacts.

\begin{tabular}{|c|c|c|c|}
\hline \multicolumn{4}{|c|}{ Indirect measures } \\
\hline \multicolumn{4}{|l|}{ Attitude } \\
\hline Variable & $\begin{array}{l}\text { Attitudinal belief } \\
\text { statement }\end{array}$ & Belief strength $\left(b_{n}\right)$ & $\begin{array}{l}\text { Outcome evaluation } \\
\left(e_{n}\right)\end{array}$ \\
\hline & \multicolumn{3}{|c|}{ If I decrease my pesticide use within two years, ... } \\
\hline be1 & $\begin{array}{l}\text { I will have less costs and } \\
\text { labour }\end{array}$ & $\begin{array}{l}\text { unlikely (1) - } \\
\text { very likely (5) }\end{array}$ & $\begin{array}{l}\text { Not important }(-2)- \\
\text { very important (2) }\end{array}$ \\
\hline be2 & $\begin{array}{l}\text { this will be positive for } \\
\text { nature and environment }\end{array}$ & " ” & “” \\
\hline be3 & $\begin{array}{l}\text { this will have a negative } \\
\text { effect on my crop quality }\end{array}$ & “” & “” \\
\hline be4 & $\begin{array}{l}\text { I will have a higher risk } \\
\text { of reduced yields }\end{array}$ & “” & “” \\
\hline be5 & $\begin{array}{l}\text { It will be more difficult } \\
\text { to control pests }\end{array}$ & “” & “” \\
\hline \multicolumn{4}{|c|}{ Injunctive norms } \\
\hline Variable & Injunctive referents & $\begin{array}{l}\text { Injunctive normative } \\
\text { belief strength }\left(\mathrm{in}_{o}\right)\end{array}$ & $\begin{array}{l}\text { Motivation to comply } \\
\left(m_{o}\right)\end{array}$ \\
\hline inm1 & $\begin{array}{l}\text { Supermarkets \& } \\
\text { wholesale }\end{array}$ & $\begin{array}{l}\text { Strongly disapprove (-2) } \\
\text { - strongly approve (2) }\end{array}$ & $\begin{array}{l}\text { Not at all important (1) - } \\
\text { very important (5) }\end{array}$ \\
\hline inm2 & Industry \& suppliers & “” & “" \\
\hline inm3 & Crop advisors & "” & “” \\
\hline inm4 & Family or friends & "” & “” \\
\hline inm5 & $\begin{array}{l}\text { Colleagues with } \\
\text { conventional farms }\end{array}$ & “” & “” \\
\hline inm6 & $\begin{array}{l}\text { Colleagues with organic } \\
\text { farms }\end{array}$ & “” & “” \\
\hline \multicolumn{4}{|c|}{ Descriptive norms } \\
\hline Variable & Descriptive referents & $\begin{array}{l}\text { Descriptive normative } \\
\text { belief strength }\left(d n_{p}\right)\end{array}$ & $\begin{array}{l}\text { Identification with } \\
\text { referent }\left(i_{p}\right)\end{array}$ \\
\hline dni1 & $\begin{array}{l}\text { Neighbours with organic } \\
\text { farms }\end{array}$ & Unlikely (-2) - likely (2) & $\begin{array}{l}\text { Not at all important (1) - } \\
\text { very important (5) }\end{array}$ \\
\hline dni2 & $\begin{array}{l}\text { Neighbours with } \\
\text { conventional farms }\end{array}$ & “ ” & " ” \\
\hline dni3 & $\begin{array}{l}\text { Members of study } \\
\text { groups }\end{array}$ & “ ” & “” \\
\hline dni4 & $\begin{array}{l}\text { Colleague from } \\
\text { cooperation }\end{array}$ & “” & “” \\
\hline
\end{tabular}




\begin{tabular}{|c|c|c|c|}
\hline \multicolumn{4}{|c|}{ Perceived Behavioural Control } \\
\hline Variable & $\begin{array}{ll}\text { Control } & \text { belief } \\
\text { statement } & \end{array}$ & Control strength $\left(c_{q}\right)$ & Power of control $\left(p_{q}\right)$ \\
\hline & \multicolumn{3}{|c|}{ If I decrease my pesticide use within two years, ... } \\
\hline cp1 & $\begin{array}{l}\text { I would be required to } \\
\text { use more advanced } \\
\text { breeding }\end{array}$ & Unlikely (1) - likely (5) & $\begin{array}{l}\text { extremely difficult (-2) - } \\
\text { extremely easy (2) }\end{array}$ \\
\hline cp2 & $\begin{array}{l}\text { I would be required to } \\
\text { use more precise } \\
\text { technology and } \\
\text { mechanization }\end{array}$ & “ ” & “ ” \\
\hline cp3 & $\begin{array}{l}\text { I should receive a higher } \\
\text { price for my product }\end{array}$ & “" & “" \\
\hline cp4 & $\begin{array}{l}\text { the quality } \\
\text { requirements on my } \\
\text { products should be less } \\
\text { stringent. }\end{array}$ & “ ” & “” \\
\hline cp5 & $\begin{array}{l}\text { I would rely on } \\
\text { favourable weather } \\
\text { conditions }\end{array}$ & “” & “” \\
\hline cp6 & $\begin{array}{l}\text { I would rely on a greater } \\
\text { choice in plant } \\
\text { protection products }\end{array}$ & “” & “” \\
\hline$c p 7$ & $\begin{array}{l}\text { I would rely on } \\
\text { cultivation advice }\end{array}$ & “” & “” \\
\hline cp8 & $\begin{array}{l}\text { I would have to consider } \\
\text { a longer crop rotation } \\
\text { and other crop varieties }\end{array}$ & “” & “” \\
\hline
\end{tabular}




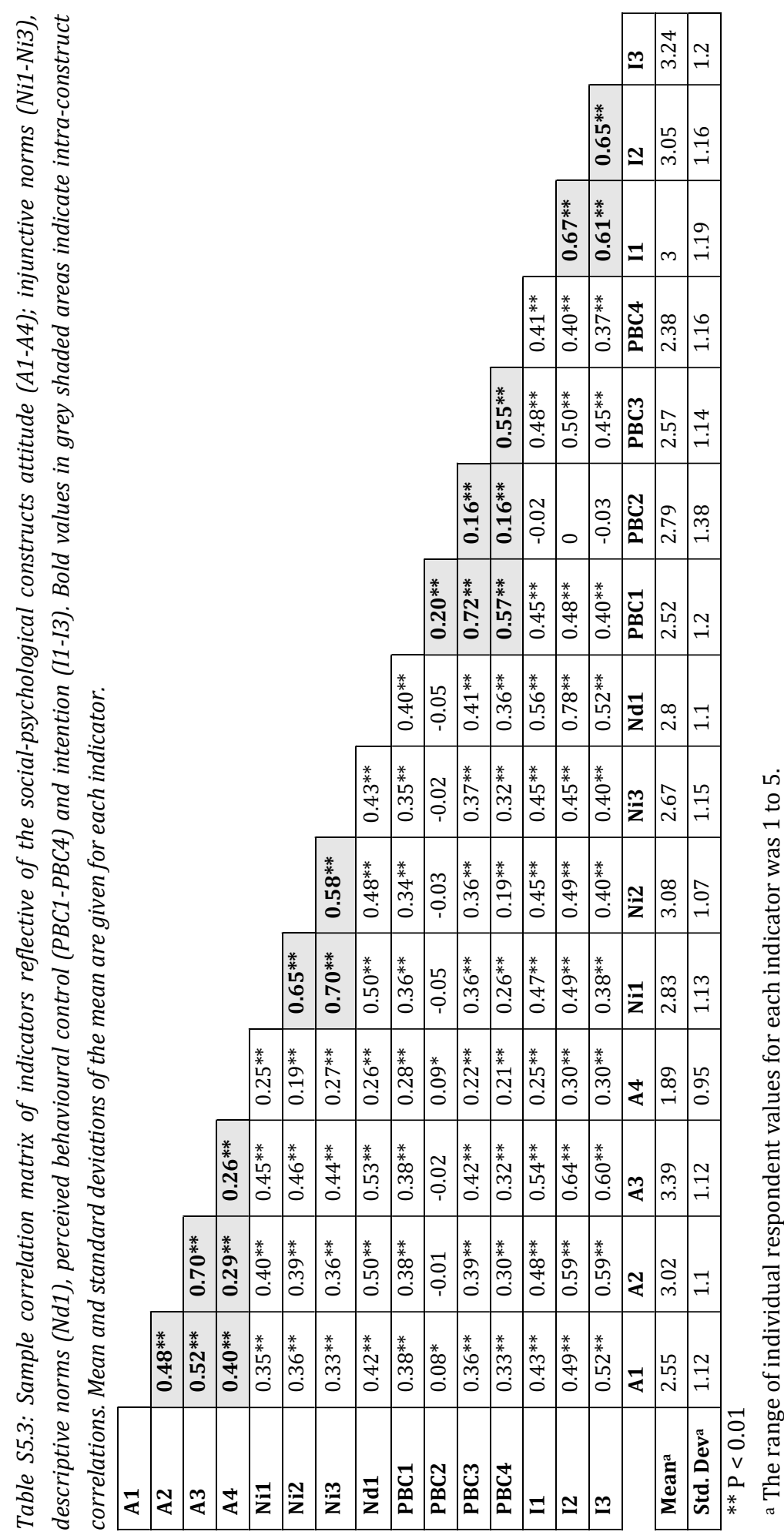


Table S5.4: Overall fit statistics of the measurement model and respecified measurement model of Model 1. The structural model is based on the respecified measurement model. Reliability measures ( $\omega$ and AVE) of constructs indicate the internal consistency of indicators.

\begin{tabular}{|c|c|c|c|c|c|c|c|c|}
\hline & & \multicolumn{7}{|c|}{ Statistics } \\
\hline & & $\chi^{2}(\mathrm{df})^{\mathrm{a}}$ & $\mathrm{CFI}^{\mathrm{a}}$ & TLIa & RMSEA $^{\mathrm{a}}$ & SRMRa $^{\mathrm{a}}$ & $\omega^{\mathrm{b}}$ & $\mathrm{AVE}^{\mathrm{b}}$ \\
\hline $\begin{array}{l}\text { Original } \\
\text { measurement model }\end{array}$ & & $\begin{array}{l}271.27 \\
(81)^{*}\end{array}$ & 0.96 & 0.94 & 0.06 & 0.05 & & \\
\hline Attitude, one construct & A & & & & & & 0.78 & 0.5 \\
\hline Injunctive norms & $\mathrm{Ni}$ & & & & & & 0.85 & 0.65 \\
\hline Descriptive norms & $\mathrm{Nd}$ & & & & & & - & - \\
\hline $\begin{array}{l}\text { Perceived behavioural } \\
\text { control }\end{array}$ & $\begin{array}{l}\mathrm{PB} \\
\mathrm{C}\end{array}$ & & & & & & 0.73 & 0.44 \\
\hline Intention & I & & & & & & 0.84 & 0.64 \\
\hline $\begin{array}{l}\text { Respecified } \\
\text { measurement model }\end{array}$ & & $\begin{array}{l}47.70 \\
(27)^{*}\end{array}$ & 0.99 & 0.99 & 0.04 & 0.02 & & \\
\hline Attitude, with removals & A & & & & & & 0.82 & 0.7 \\
\hline Risk attitude & $A_{r}$ & & & & & & - & - \\
\hline Injunctive norms & $\mathrm{Ni}$ & & & & & & 0.85 & 0.65 \\
\hline Descriptive norms & $\mathrm{Nd}$ & & & & & & - & - \\
\hline $\begin{array}{l}\text { Perceived behavioural } \\
\text { control, with removals }\end{array}$ & $\begin{array}{l}\mathrm{PB} \\
\mathrm{C}\end{array}$ & & & & & & 0.83 & 0.63 \\
\hline $\begin{array}{ll}\text { Intention, } & \text { with } \\
\text { removals } & \end{array}$ & I & & & & & & - & - \\
\hline
\end{tabular}

$*$ p-value $<0.05$

${ }^{\mathrm{a}} \chi 2$ = Chi-square; $\mathrm{df}=$ degrees of freedom; $\mathrm{CFI}=$ Bentler's comparative fit index (CFI > 0.9); TLI = Tucker-Lewis fit index (TLI > 0.9); RMSEA = root mean square error of approximation $($ RMSEA $<0.08) ;$ SRMR =standardized root mean square residual $(\mathrm{SRMR}<0.1)$

$\mathrm{b} \omega=$ McDonalds' coefficient omega $(\omega>0.7) ; \mathrm{AVE}=$ average variance extracted (AVE $>0.5$ ) 


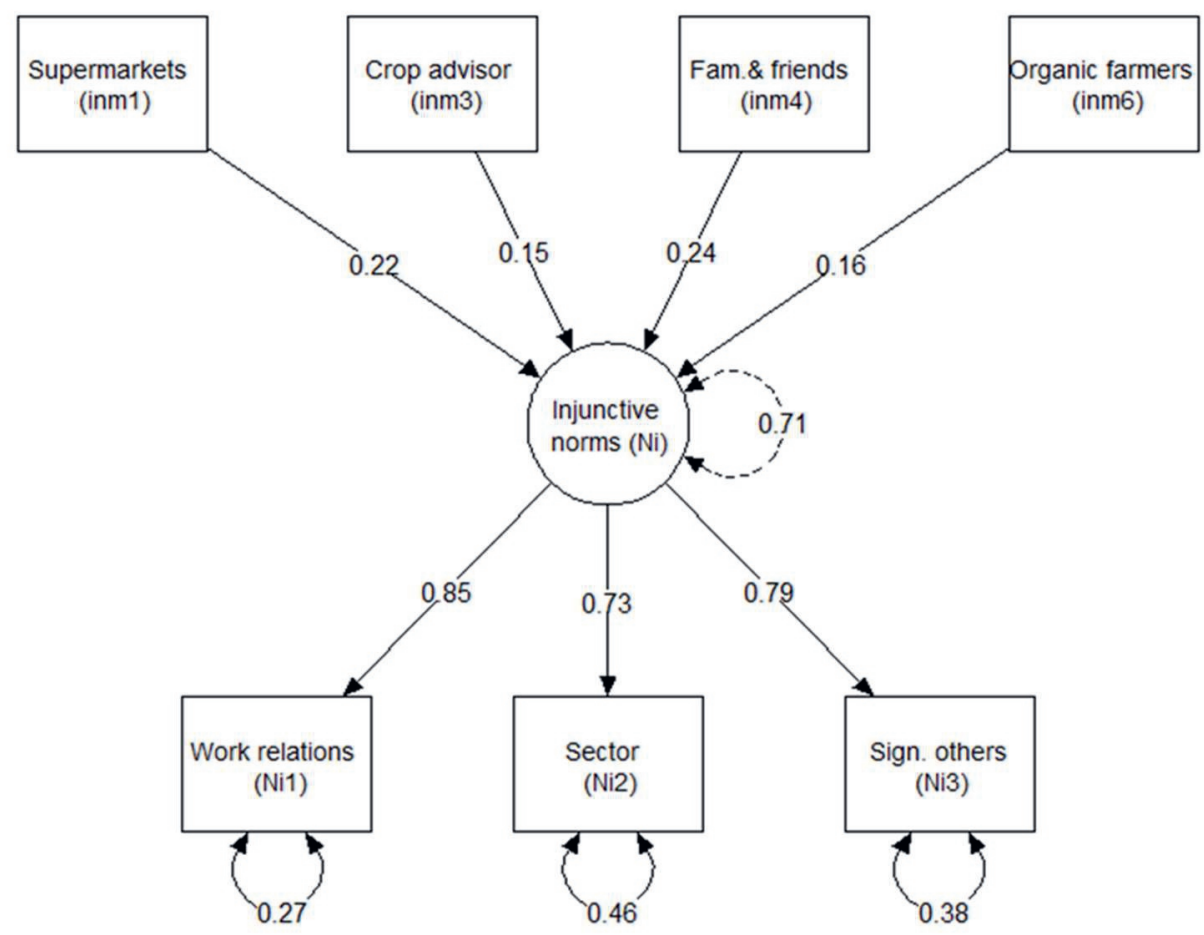

Figure S5.1: Structural diagram of final MIMIC model to determine most important referents for injunctive norms (Ni) (Model 3, Fig. 5.1). Circles represent constructs, squares show measured indicators $\left(\mathrm{Ni}_{\mathrm{x}}\right)$ and variables ( $\mathrm{inm}_{\mathrm{x}}$ ), straight solid arrows represent regression coefficients, and dashed arrows depict measurement errors. All estimates are significant $(p<0.05)$. Overall fit statistics: $X^{2}(8)=20.95, p<0.01 ; C F I=0.99, T L I=0.97, R M S E A=0.06(0.029-0.092)$, SRMR $=0.023$. 


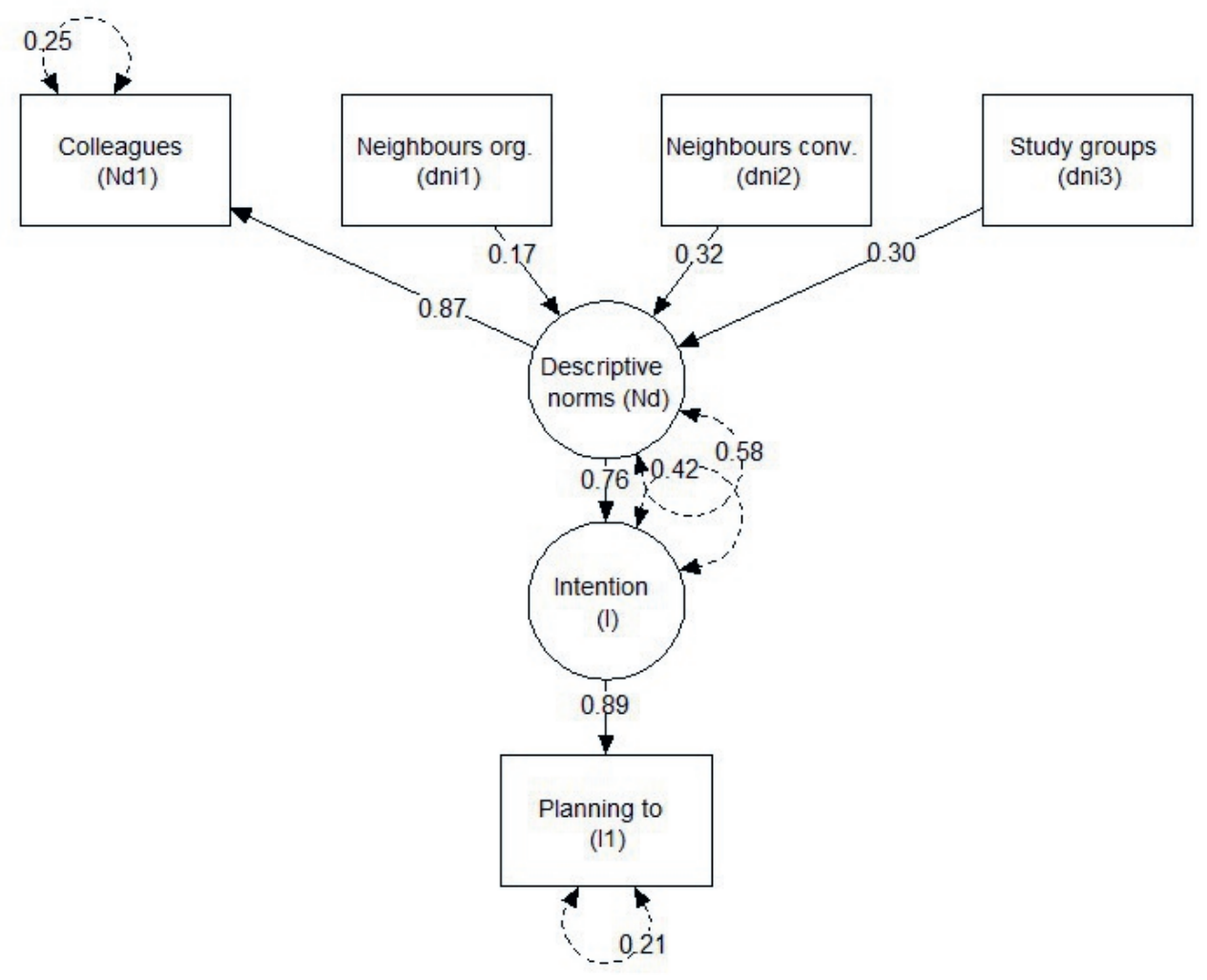

Figure S5.2: Structural diagram of final MIMIC model to determine most important referents for descriptive norms (Nd) (Model 4, Fig. 5.1). Circles represent constructs, squares show measured indicators $\left(N d_{x}\right)$ and variables $\left(d n i_{x}\right)$, straight solid arrows represent regression coefficients, and dashed arrows depict measurement errors. All estimates are significant $(p<0.05)$. Overall fit statistics: $X^{2}(3)=1.928, p=0.587 ; C F I=1, T L I=1, R M S E A=0(0-0.059), S R M R=0.009$. 


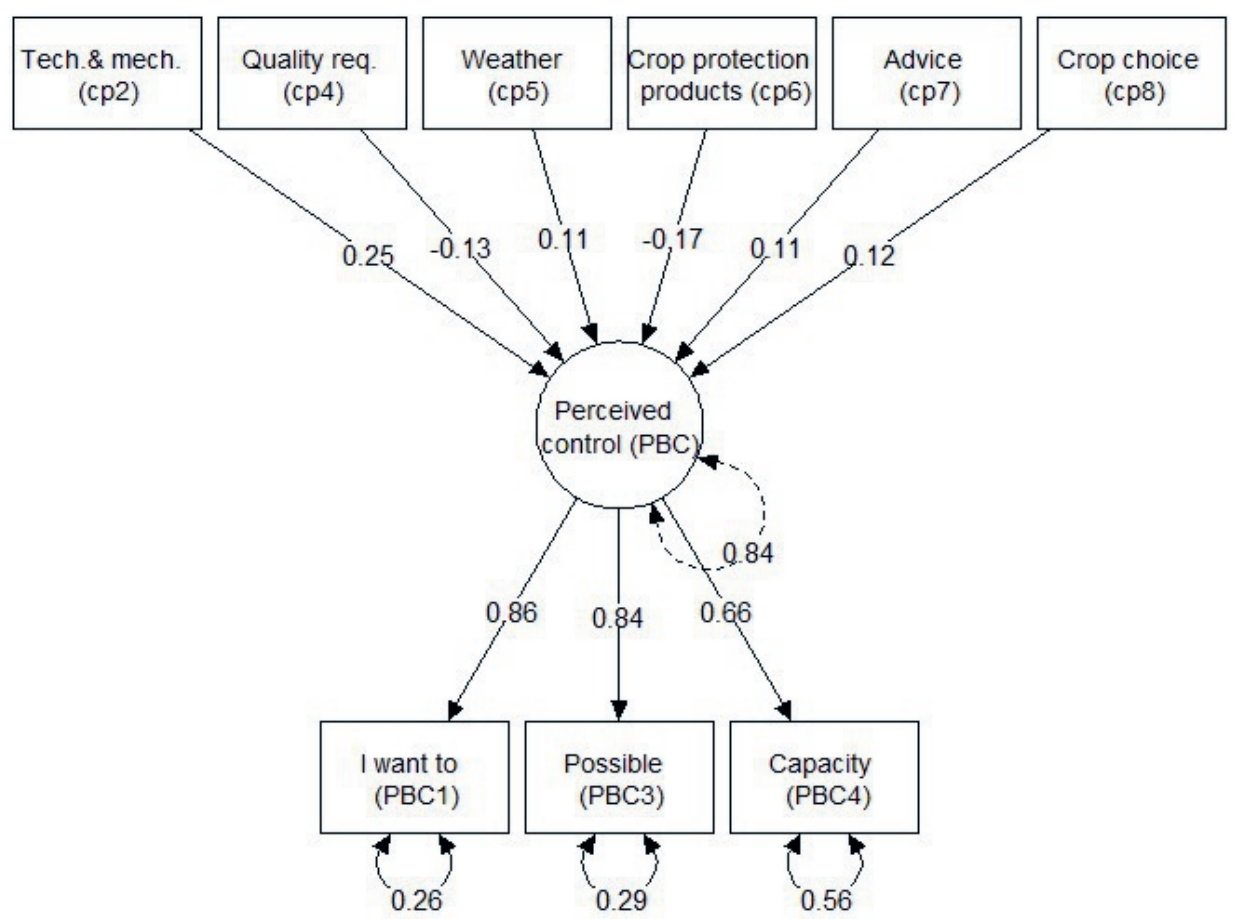

Figure S5.3: Structural diagram of final MIMIC model to determine most important control factors for perceived behavioural control (PBC) (Model 5, Fig. 5.1). Circles represent constructs, squares show measured indicators $\left(P B C_{x}\right)$ and variables $\left(c p_{x}\right)$, straight solid arrows represent regression coefficients, and dashed arrows depict measurement errors. All estimates are significant $(p<0.05)$. Overall fit statistics: $X^{2}(12)=24.172, p=0.019 ; C F I=0.98, T L I=0.98, R M S E A=0.04(0.017-0.069)$, $S R M R=0.018$. 


\section{CHAPTER G}

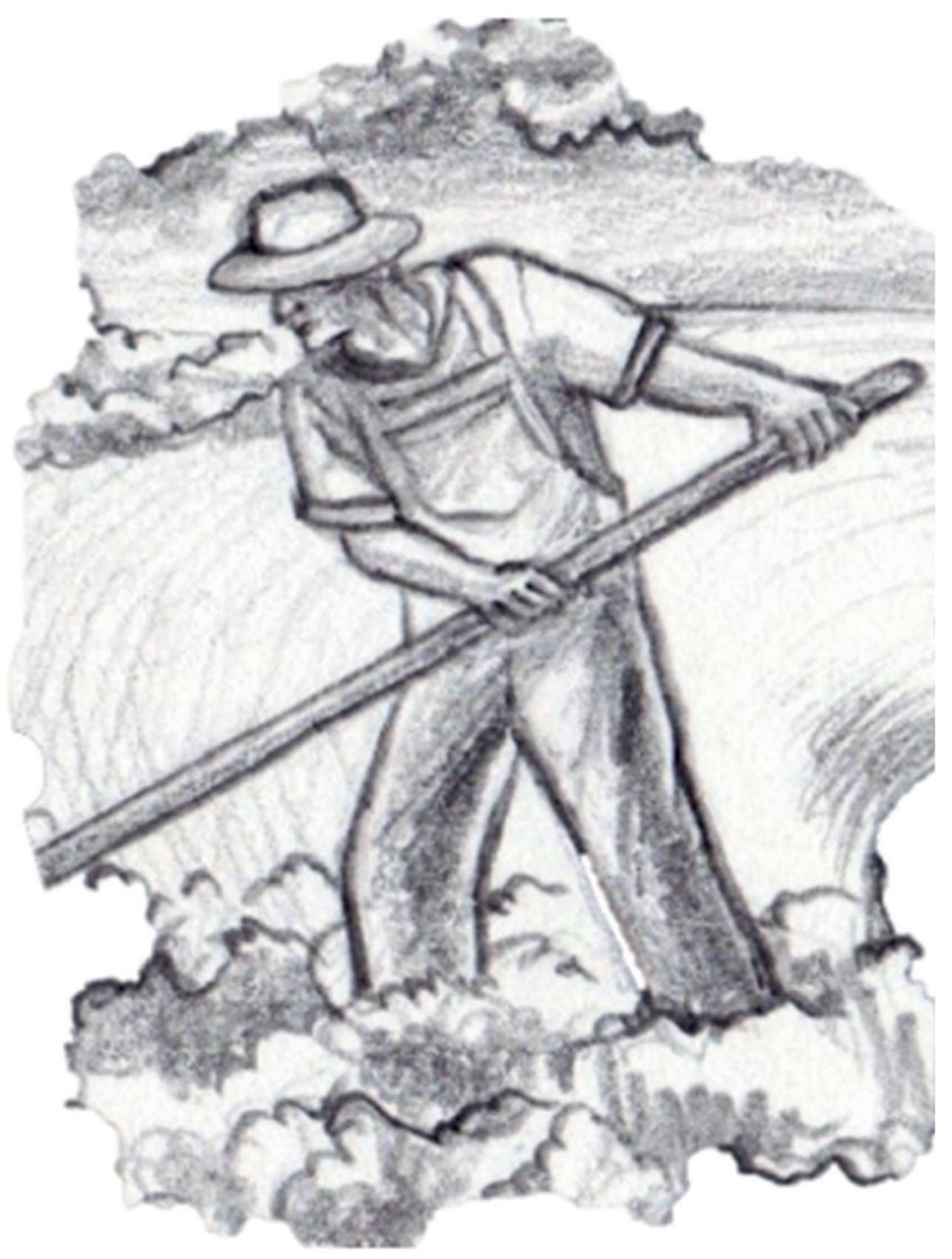




\section{GENERAL DISCUSSION}

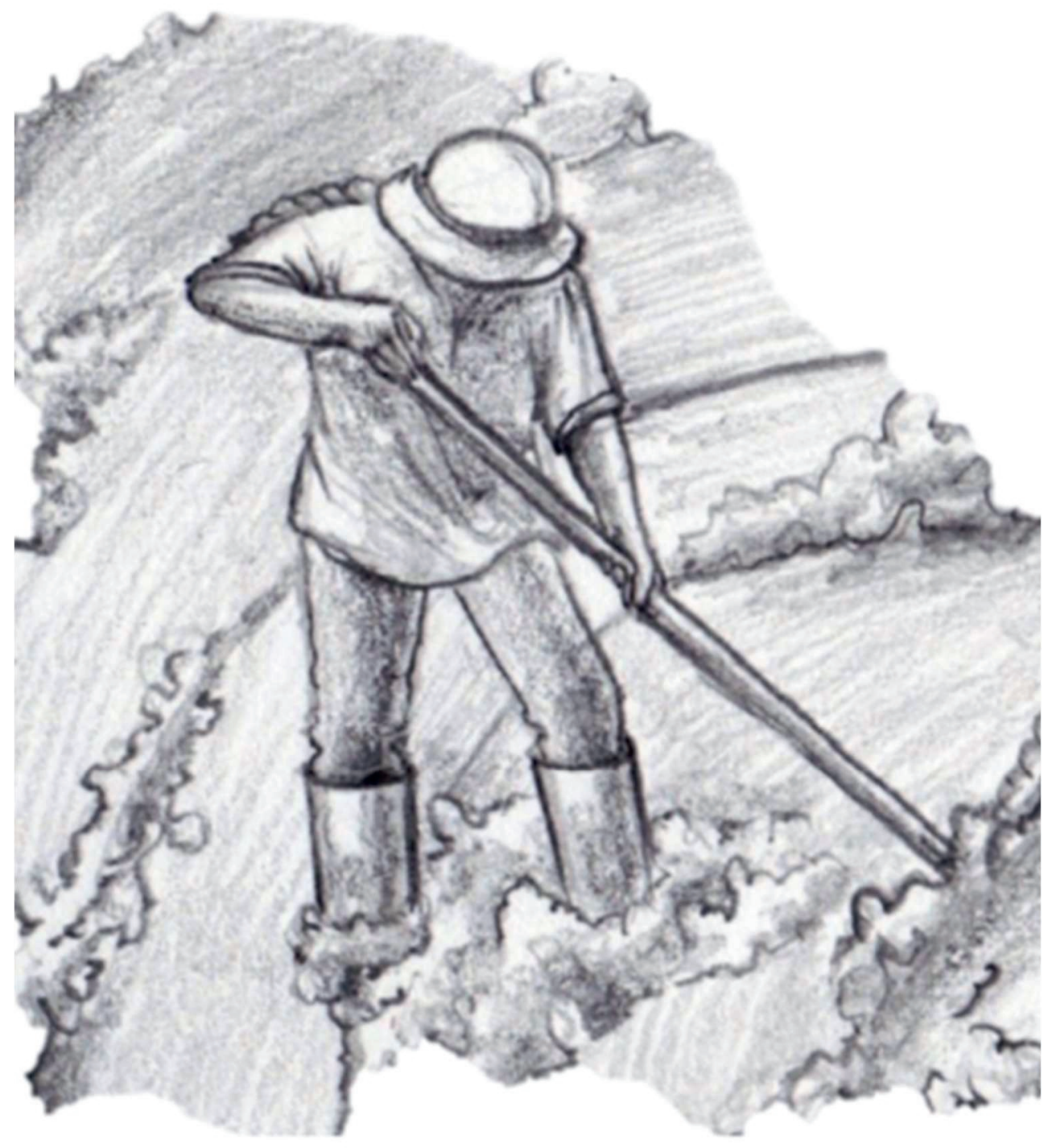


Pest management is one of the many facets of farm management, and it is one that has major implications for the environment and human health (Pretty, 2005). There is increasing recognition that a more sustainable approach in pest management is needed to ensure sustainable food production while conserving ecosystem services (Savary et al., 2012; Pretty, 2018). In this PhD project I aimed to provide critically needed insight in the system dynamics underlying farmers' pest control practices, and elucidate key principles governing a transition towards sustainable pest management.

To understand what factors influence pesticide use and pest management decision-making I conducted an analysis of historical case studies describing the pesticide treadmill (Chapter 2). I compared historical cases of pesticide use with the current case of neonicotinoids. Important differences were that the uptake of neonicotinoids occurred at a fast pace and a global scale in several crops, while documented historical examples of the pesticide treadmill were predominantly restricted to particular geographies and cash crops. Furthermore, while the pesticide treadmill in the historical case studies was only counteracted after major crop losses, current legislation to regulate the use of neonicotinoids was strongly motivated by concerns about impact on nontarget organisms and the environment and less by mitigating resistance development and the associated crop losses. I conducted the analysis from both a social and ecological perspective and concluded that lock-in mechanisms occurred in four domains: pest management decisions at the farm level, characteristics of farming landscapes, science \& technology, and societal demands (Fig. 2.1). These lock-ins enforced the pesticide treadmill.

In Chapter 3 and 4 I analysed data from an empirical landscape study to establish the influence of local and landscape-wide insecticide use on beneficial arthropods and biocontrol services in different landscape settings. Contrary to expectation, I found no associations between beneficial arthropod abundance and local in-field insecticide use (Chapter 3), nor did I find an association between biocontrol services and local insecticide usage (Chapter 4). In contrast, abundances of predators, parasitoids, and pollinators were consistently negatively associated with an indicator for landscape-wide insecticide use (Chapter 3).

Farmers are the most important actors in pesticide use decision-making, and identifying what determines farmers' intentions to decrease pesticide use is essential to support a transition towards ecologically-based pest management. In Chapter 5, I therefore analysed the results of a survey and showed that farmers' intentions to reduce pesticide use were strongly determined by whether other farmers in their social networks also acted. Furthermore, farmers perceived limited capacity and autonomy to reduce pesticide use, and motivations to reduce pesticide use were based on environmental considerations. Finally, decreasing pesticide use was considered risky, but the relative importance of risk attitude was offset by the environmental considerations of farmers. 
The remainder of this chapter is organised as follows. In section one, I will discuss the ecological and social lock-ins in pest management decision making. In section two, I will argue that a landscape-wide approach is needed to mitigate negative effects of pesticide use and reduce the reliance on pesticides. I also discuss what may be needed to overcome the socio-ecological challenges for a transition from chemical pest control to biological pest control. In section three, I will reflect on the research approach, discuss the pesticide use indicators and data availability on pesticide use, and reflect on the implications of the applied methodology on the conclusions. Finally, in section four I will describe an outlook and future perspective.

\section{LOCK-IN MECHANISMS OF PESTICIDE USE}

In Chapter 2 I presented the framework of the pesticide treadmill with four domains that encompassed feedback cycles related to pesticide use decision-making. Historic cases on pesticide use in cotton, bananas, and rice showed that the uptake and reduction of pesticide use is influenced by drivers from all four domains (Farming; Agro-landscapes; Science \& technology; Society). More importantly, analysing current neonicotinoid cases I concluded that global agriculture is still locked in the pesticide treadmill.

\section{Ecological lock-in}

The analysis in Chapter 2 showed that agroecological problems often lie at the basis of the pesticide treadmill. One of the underlying issues of many pest management problems is the potential of pests to develop resistance against pesticides (Waterfield and Zilberman, 2012). Pesticide resistance develops through selection pressure imposed by pesticides in pest populations. Some individuals of the pest population have a higher tolerance to the pesticide, which enables these individuals to survive the treatment. As a result, this resistance trait becomes prevalent in the population (Thrupp, 1990). This is not just the case with synthetic chemicals. Organic pesticides are also subject to resistance development (Waterfield and Zilberman, 2012; Dyer, 2014), and insect resistance in crops that are genetically modified with, e.g. Bacillus thuringiensis (Bt) can also be broken due to resistance development (Tabashnik, Brévault and Carrière, 2013).

Another underlying issue of pesticide use, and an ecological lock-in mechanism observed in this study, concerns the direct and indirect side effects of pesticide use. As presented in Chapter 3, beneficial arthropod abundances were negatively affected by the landscapewide pesticide load. This implies that when populations of arthropods are impacted by pesticides in the landscape and recolonization processes of agricultural fields by natural enemies are undermined, farmers may become increasingly reliant on pesticides for pest control. I did not find a direct association between local and landscape-wide insecticide use and biocontrol services (Chapter 4). However, the negative association between beneficial insect populations and landscape-wide insecticide use indicates that biocontrol may also 
have been impacted, given that a critical amount of natural enemies is required for effective pest management.

It has been hypothesized that more diverse landscapes could compensate for negative influences of insecticides on beneficial insects (Roubos, Rodriguez-Saona and Isaacs, 2014; Tscharntke et al., 2016), even if the strength of the relationship between landscape context and influence on biocontrol services is crop- and context-dependent (Karp et al., 2018). Thus, landscape diversity could be hypothesized to be a potential driver to escape the pesticide treadmill (see, e.g., Chaplin-Kramer et al., 2011; Dainese et al., 2019; Letourneau et al., 2012; Veres et al., 2013). In this study, depending on the functional group of beneficial arthropods, I found contrasting relationships between beneficial insect abundances and landscape components (Chapter 3), and I found no effect of the proportion of semi-natural habitat on biocontrol (Chapter 4). Other studies have also reported contrasting results. For example, Yang et al. (2019) found mixed effects of landscape complexity and insecticide use on ladybeetle abundances, and found no support for the hypothesis that impacts of insecticide use on ladybeetle populations can be mitigated by increased landscape diversity. Gagic et al. (2019) found that presence of semi-natural field margins was not enough to compensate for impacts of insecticide applications on natural enemy abundances. Furthermore, abundances of specialist pests with few host plant families tend to increase with the proportion of semi-natural habitat (Tamburini et al., 2020). To better understand responses of beneficial arthropods and pest populations to landscape composition, it can be helpful to consider specific aspects of semi-natural habitats that shape pest-natural enemy interactions (Chaplin-Kramer et al., 2011; Tamburini et al., 2020). Indeed, while generalist natural enemies may be abundant in a variety of crop and semi-natural habitats, and can switch prey when a pest species is temporarily unavailable, specialist natural enemies may require more specific habitat types, which are linked to specific host plant species (ChaplinKramer et al., 2011).

\section{Social lock-in}

The case studies in Chapter 2 suggest that drivers from the 'science \& technology' and 'society' domains can unlock the pesticide treadmill and initiated an 'escape \& reorganization' phase in the past. While I have not been able to study drivers of these domains in detail, other scholars have focused on this (see e.g., Cowan and Gunby, 1996; Cowan and Hultén, 1996; Vanloqueren and Baret, 2008; Pretty and Bharucha, 2015; Boyd, 2018; Hu, 2020). For example, the technology lock-in of conventional pest management with synthetic pesticides has been compared to the adoption of alternative pest management options like Integrated Pest Management (IPM) (Cowan and Gunby, 1996). The uptake of IPM has been low, despite decades of research, and the quantity of pesticides used has stabilized in Europe and the US (Liu, Pan and Li, 2015). This stabilization in pesticide use is accounted for by substituting older pesticides with new active ingredients that kill at lower 
concentrations (Lechenet et al., 2014). This, however, is an indication of continued pesticide reliance, and points towards the technological lock-in of pesticide use.

I conducted a survey among Dutch farmers and used a social-psychological model to evaluate farmers' intentions to decrease pesticide use. Furthermore, I determined potential barriers for decreasing pesticide use. The results of the survey, as presented in Chapter $\mathbf{5}$, indicate that farmers' behaviour is an important driver of the pesticide treadmill, creating a social (behavioural) lock-in. Pest management decisions (i.e. decreasing pesticide use) were strongly influenced by social comparison with other farmers within their social networks, and cultural norms on what is considered a 'good farmer'. Farm management and a 'neat' and 'tidy' appearance of the land is a way for farmers to demonstrate their occupational skills (Westerink et al., 2019). These norms could change, depending on what is considered 'good farming' and what are best practices (Green et al., 2020). In my study a higher level of environmental concern was important in determining farmers' attitude towards decreasing pesticide use. Consequently, if a farmer prioritizes biodiversity and responsibility for the environment, good farming is in balance with nature and fosters a biodiverse farming environment with natural processes that support and interact positively with production aims.

Risk attitude is another important component of social lock-in, and risk-aversive farmers are less willing to change practices (Läpple and Rensburg, 2011). For example, in current conventional farming, prophylactic pesticide applications like seed treatments with neonicotinoids are used as an insurance against pest problems (Chagnon et al., 2015). The ease of use of this type of crop protection drives the pesticide treadmill through 'deskilling' and lack of experience to implement other crop protection measures (Bakker et al., 2021a). As presented in Chapter 5, farmers considered decreasing pesticide use to be risky, influenced by the belief that reduced pesticide use could reduce crop yield or quality. The results in Chapter 5 also show another aspect of a social (technological) lock-in, as farmers showed willingness to change their practices but did not perceive the capacity to do so. Here, perceived capability was associated with the right technology and machinery, valuation of crop products, and quality requirements set by retailers. Previous studies have shown that improved technologies, e.g. spraying efficiencies and precision agriculture, can dramatically reduce pesticide volumes and off-field impacts of pesticides (IPBES, 2016). For example, improved spraying technology through a more precise spray nozzle and spray boom height minimizes the chance of drift events (Iost Filho et al., 2019). If spraying efficiencies are improved and lower pesticide quantities are used, there is also economic gain for farmers. However, while technical improvements have been made for decades, the uptake of these technologies remains low (Cowan and Gunby, 1996; Dudley et al., 2017). This highlights the need to provide farmers with knowledge and information on low or no pesticide use practices that do not substantially compromise crop performance or profitability (Lechenet et al., 2017; Chèze, David and Martinet, 2020). 


\section{FOSTERING THE TRANSITION TO ECOLOGICALLY-BASED PEST MANAGEMENT}

Decreasing pesticide use requires more than just ecosystem-service-based arguments, and farmers' expected behaviour and socially optimal decisions do not always coincide. To tackle the pesticide treadmill, ecologists will need to work with social scientists to better understand determinants of grower decisions to use pesticides (Chaplin-Kramer et al., 2019). As presented in Chapter 5, transitioning pest management from chemical to biological control is not just dependent on farmers' decisions and intentions, but is also governed by the interplay between actors from different domains. Based on the findings in this thesis I elucidated key principles governing a transition towards ecologically-based pest management.

\section{To overcome the landscape lock-in of pesticide use}

Pest management practices should not only consider the field or farm scale but need a landscape-wide approach to be successfully implemented. The results presented in Chapter 3 indicate that the landscape lock-in is enforced by the negative association between beneficial arthropod abundances and pesticide use at a larger scale. Thus, to tip the balance towards more ecologically-based pest management, pesticide use at the landscape scale needs to decrease, and several actions are suggested. First, conservation of semi-natural habitats is necessary for maintenance of ecosystem services, but these areas should ideally not be isolated islands in the agricultural ecosystem (Kremen and Merenlender, 2018). Functional connectivity between habitats is required in a landscape to provide effective ecosystem services. This could be achieved through, for example, decreasing average agricultural field sizes to provide easier access for beneficial insects to adjacent crops (Sirami et al., 2019). Second, farmers could take diversification measures like the establishment of floral plantings, which can reduce pest pressure through enhanced biological control. However, these plantings should be tailored to the requirements of natural enemy taxa (Albrecht et al., 2020). Simultaneously, to increase agricultural landscape heterogeneity there should be a focus on diversification of the whole agroecosystem to be supportive of natural enemies and pollinators (Purtauf et al., 2005; Roschewitz et al., 2005; Garratt, Wright and Leather, 2011). Crop diversification is another measure to increase landscape heterogeneity. Increased crop diversity at the landscape scale may provide multiple resources for beneficial insects (Lechenet et al., 2014; Busch et al., 2020). Furthermore, diversified cropping systems provide agronomic advantages, like pest and disease suppression, and are therefore less reliant on pesticides (IPES-Food, 2016; Lechenet et al., 2016). This contributes to lower environmental impacts on water and air quality and shows potential for mitigating negative effects of current mainstream pest management. Associated benefits of diversified cropping systems are improved productivity and energy efficiency, and a greater diversity in sowing and harvest periods, thus increasing system resilience of the economic market, and farm management through enhanced decisional flexibility throughout the year (Lechenet et al., 2014). 
Increasing landscape heterogeneity requires a change in farm management, but also in the organization of the agricultural sector and developments of (local) markets due to changes in production volumes of crops (Lechenet et al., 2014). In order to benefit from biological control, farmers may need incentives to facilitate natural enemies. Results in Chapter 5 show that farmers are influenced by what other farmers are doing through social comparison of farming practices implemented. Thus, collective action needs to be facilitated to increase landscape heterogeneity. This implies that social interactions between farmers may need to be emphasized, and discussions with peers facilitated. Also, farmers ought to receive better non-commercial information on conservation biocontrol strategies and under which conditions these strategies are likely to be most successful (Chaplin-Kramer et al., 2019; Bakker et al., 2021a). For example, campaigns showcasing the benefits of conservation strategies are necessary to generate collective action in farmer communities (Chaplin-Kramer et al., 2019). Governments can retake their role in supporting public extension services to spread information on agricultural practices that support a healthy environment as a public good. These advisory systems would be publicly driven and funded, led by advisors that are not dependent on sales and business interests from input suppliers (Lamine et al., 2010).

\section{To overcome the social lock-in of pesticide use}

As presented in Chapter 2, the ecological and social lock-ins of the pesticide treadmill are connected. Farmers are key actors in pesticide decision making, which are in part based on economic rationales (Pedersen et al., 2012). However, the results of Chapter $\mathbf{5}$ suggest that farmers' intentions are influenced by whether farmers think it is possible to decrease their pesticide use (i.e. perceived capacity). Moreover, it is important for farmers to have a sense of autonomy in their decision-making (Bakker et al., 2021a). Therefore, I suggest that two important aspects of pest management decision-making could positively influence a farmers' behaviour regarding pesticide use decision making. First, true costs of pesticides and biological control would enable farmers to effectively make a balance of real costs and benefits of different pest management options. Second, increased knowledge on pest management options could help farmers to make choices independently, which is important for their sense of capacity and autonomy (Bakker et al., 2021a).

\section{True costs of pest management options}

Costs of management practices are a major incentive for farmers, and uncertainty about yield losses are a major obstacle for switching to more environmentally friendly pest management options. Furthermore, synthetic pesticides are often considered to be 'cheap', 'quick' and 'easy' in comparison to alternatives like IPM and conservation biocontrol (Chaplin-Kramer et al., 2019). Farm profitability is important for farmers and direct benefits of pesticide use, e.g. reduced risks and increased stability of yields, are relatively clear to farmers (Chaplin-Kramer et al., 2019). Application of the 'true cost' principle would strongly increase the competitiveness of biological control versus chemical control, as hidden costs 
and benefits are taken into account. These hidden costs for pesticides include human diseases and deaths as a result of chronic exposure to pesticides, and environmental impacts such as reduced biodiversity, limited functioning of ecosystem services, or increased cleaning of drinking water (Milner and Boyd, 2017; van Lenteren et al., 2018). Moreover, the hidden benefits - the long-term profitability - of biological pest control is often unknown to farmers (Huang et al., 2018; Chaplin-Kramer et al., 2019). Consumers can support their preference for low or no pesticide usage by paying price premiums on products for the benefits of reduced human health risk from insecticides and environmental damage (Huang et al., 2018). Implementation of a traditional economic analysis including the 'true costs and benefits' of pesticides and biological control could send a strong market signal to promote widespread adoption of alternative pest control methods like conservation biological control (Meehan et al., 2011; Huang et al., 2018).

Farmers' decisions to adopt new practices are influenced by initial and transition costs, and uncertainty about implementing new practices (Rodriguez et al., 2009). Regulation can help frame the advantages of collective landscape management, e.g. through incentive programs, payments for ecosystem services, subsidies, tax credits, and compensation schemes with rewards based on production or performance targets (Milner and Boyd, 2017; Westerink et al., 2019). Governments can provide incentives or can set policies that promote a switch to ecologically-based pest management on a landscape level. However, governments need to carefully tailor whom to provide with financial incentives. For example, by targeting 'early adopters', i.e. farmers that are interested in implementing sustainable practices and need the financial support, the impact of programs aimed at influencing landscape level management can be maximized (Rodriguez et al., 2009; Buurma and Smit, 2013). Consumers and the general public can exert pressure on farmers through their market demand for certain attributes of agricultural products, e.g., pesticide-free products (ChaplinKramer et al., 2019). Still, the results in Chapter 5 indicate that farmers did not perceive consumers as important social referents, and it is important to take this into account. By contrast, farmers' intentions to decrease pesticide use were partially driven by food retailers that require more sustainably produced products (Chapter 5). Thus, involving these influential actors in the food chain is important to overcome pesticide reliance, as they are the link between producers and consumers and have the ability to influence decisionmaking at both ends of the food chain (Macfadyen et al., 2015).

\section{Knowledge and extension services}

An important driver to overcome the aforementioned social lock-in is knowledge on pest management alternatives (Seto et al., 2016). The lack of this knowledge could be a reason why some farmers do not make the switch towards biocontrol practices (van Eerdt et al., 2014; Martínez-Sastre et al., 2020). Knowledge is important to strengthen the sense of autonomy of farmers in making strategic and tactical pest management decisions (Sherman and Gent, 2014). In addition, knowledge of the effects of pesticide use on the environment 
and personal health is an important factor determining actual use of pesticides (Calliera et al., 2013; Damalas and Koutroubas, 2014; Khan and Damalas, 2015; Bagheri et al., 2019), and education, co-learning, and experiential learning can help to reduce wasteful and unnecessary use of pesticides (Dudley et al., 2017). Furthermore, farmers need evidence that informs them on the stability of biological pest control, and consequently, to adequately assess the potential trade-off between short-term losses and long-term gains (ChaplinKramer et al., 2019).

Implementation of conservation biological control in farm management requires more knowledge of the agricultural ecosystem than conventional spraying (van Eerdt et al., 2014). Therefore, farmers need actionable knowledge, i.e., knowledge that can be applied to solve a real-world problem (Evans, Terhorst and Kang, 2017). For example, to implement conservation biological control, farmers need to know which aspects of the agroecosystem are important to maintain natural enemy populations, e.g. which habitat type hosts which natural enemies (Geertsema et al., 2016). Furthermore, precision technologies support a more efficient use of inputs, and include an increasing number of stationary and mobile sensors. Farmers need to understand what the data mean and how they can turn these numbers into actionable knowledge (Evans, Terhorst and Kang, 2017).

Farmers actively seek information and use sources of information, like printed and electronic media outlets, and use expert information from input suppliers, crop consultants, and extension advisors (Sherman and Gent, 2014). Furthermore, farmers benefit from information obtained through social learning and information networks with neighbours and fellow farmers, and through experiments with new production and management methods (Lohr and Park, 2002). Public extension services, independent from input suppliers, can play an important role in providing the knowledge and expert advice that farmers need. For example, extension officers can inform farmers on the existence of tools and technology, regulations and agri-environmental schemes (Dessart, Barreiro-Hurlé and Van Bavel, 2019). These advisory systems are public driven and funded, to avoid that advise is being given by market-led extension services whom are influenced by business interests (Lamine et al., 2010). Thus, access to relevant and context-specific knowledge from public extension services is essential for farmers to make a shift from chemical-based to ecologically-based pest management.

\section{REFLECTION ON THE RESEARCH APPROACH}

\section{Linking socio-ecological systems}

\section{Conducting a historical case study analysis}

I used a historical case study analysis in Chapter 2 to identify which drivers govern the lockin and escape from the pesticide treadmill, and compared these case studies with the recent global case of neonicotinoids. As mentioned in the introduction of this chapter I found that there are important differences in the current pesticide use and the historic examples. 
Nevertheless, the comparison of historical examples gave a comprehensive picture of how the pesticide treadmill works and how it influences pest management decision-making at different levels. Moreover, I would argue that arguments to use pesticides have not fundamentally changed since the 1950s, and mainstream agriculture is still based on maximization of productivity, thus committed to intensive, industrially-driven agricultural systems (Maréchal, Aubaret-Joachain and Ledant, 2008).

\section{Reasoned Action Approach}

I have attempted to identify which factors influence farmers' decision-making regarding pesticide use and focused on the environmental externalities of pesticide use in Chapter 5. The Reasoned Action Approach (RAA) is a well-known and frequently applied framework to predict and explain behaviour and a well-established method to identify the underlying cognitive foundation of intentions which lead to a particular behaviour (Fishbein and Ajzen, 2011; Sok et al., 2020). A key assumption of RAA is that beliefs are not necessarily rational, nor instinctive or stable over time, as beliefs are formed through experiences and daily encounters in the real world (Ajzen, 2012).

The RAA provides a 'snapshot' of the respondents' cognitive foundation at a given point in time (Fishbein and Ajzen, 2011). Furthermore, farm and farmer characteristics may also influence farmers' decision-making on pesticide use but are not explicitly considered in the RAA. Farm size, age, education and previous knowledge and experiences regarding pesticide use are characteristics that may influence a farmer's decisions on pest management (Fishbein and Ajzen, 2011; Burton, 2014; Yang, Zhao and Meng, 2019). In the survey as presented in Chapter 5, most of the respondents (66\% of 681) were arable farmers. However, in the Netherlands, the highest pesticide inputs occur in flower bulb and vegetable production because of the strict quality requirements of bulbs, ornamentals and vegetables (Sporenberg, Verstand and Beerling, 2019). It is possible that the survey did not capture the full heterogeneity in behaviour and intentions of how to reduce pesticide use, which could possibly have created a bias in the results in Chapter $\mathbf{5 .}$

Social interactions among farmers influence decision-making on pesticide use. Furthermore, trust and credibility of communicators are important factors determining the success of incentives to motivate farmers to decrease their pesticide use. The RAA gives more weight to these social aspects of decision-making, and the advantage of the RAA is that it helps explain which component of a behaviour is most influential for a given behaviour. The RAA allowed me to explore why farmers hold certain attitudes, subjective norms, and perceptions of control with respect to decreasing their pesticide use. Using this method, I gained important insights into perceived barriers of decreasing pesticide use, which may help identify pathways towards farming systems with reduced environmental impacts. 


\section{Estimating pesticide effects}

Metrics for pesticide use in farming are needed to analyse the effects of pesticide use on ecosystem services and the insect species that provide them. The environmental harm and ecological recovery after pesticide use are not addressed at the appropriate scales in current risk assessments of pesticides, leading to a misrepresentation of pesticide use effects on the environment (Topping, Aldrich and Berny, 2020). Multiple field applications of a pesticide are likely to cause more severe effects on a population of organisms than a single application event with the same dose (Brühl and Zaller, 2019). Additionally, farmers often use mixtures of several pesticide products (Topping, Aldrich and Berny, 2020). The number of pesticides used within a single field and the area over which a crop is grown are also not taken into account in current risk assessments, potentially underestimating the area where insects may be exposed to pesticides (Bernhardt, Rosi and Gessner, 2017). Furthermore, the variety of pesticides that arthropods are exposed to is even more diverse within the larger landscape (Topping, Aldrich and Berny, 2020). These indirect effects of pesticide use within the landscape could lead to an underestimation of the actual risk of pesticide use for biodiversity in agricultural landscapes (Brühl and Zaller, 2019). In addition, lack of current data makes any assumption regarding the potential impacts of insecticides on non-target organisms very difficult, if not impossible. For example, without a detailed spatial and temporal resolution on pesticide usage it is difficult to predict pesticide impacts on ecosystems (Zimmermann and Stout, 2016).

\section{Pesticide proxies}

Previous analyses have attempted to quantify the environmental and health impacts of pesticides, but many of those assessments relied on incomplete data (Möhring, Gaba and Finger, 2019). For example, Hallmann et al. (2014) used measurements of pesticide concentrations in surface water provided by the Bestrijdingsmiddelenatlas (www.bestrijdingsmiddelenatlas.nl) to link pesticide risks to declines in insectivorous birds. In addition to this modelling approach, more quantitative metrics exist like Pesticide Load (Kudsk, Jørgensen and Ørum, 2018), SYNOPS (Gutsche and Rossberg, 1997) and the Environmental Yardstick for Pesticides (EYP) (Reus and Leendertse, 2000). These risk indicators were developed to assess the risk of pesticide use and require much detailed information (e.g. application technique, and soil type).

In this thesis I used quantity-based indicators, Treatment Frequency Index (TFI) and Quantity Insecticides Applied (QIA), to assess the impact of pesticides on beneficial arthropods and biocontrol services (Chapters 3 and 4). Both indicators are relatively simple to calculate, and TFI is commonly used in the EU to set targets for pesticide policies (Möhring, Gaba and Finger, 2019). TFI is the number of full doses of pesticide that are applied during a crop cycle. Hereby, two half doses count as one full dose. TFI has been used in similar contexts to express pesticide dependency of a cropping system(see e.g., Lefebvre 
et al., 2016; Kathage et al., 2018), and is perceived as a useful proxy for a pesticide risk indicator (Kudsk, Jørgensen and Ørum, 2018).

The landscape scale pesticide indicator (QIA; quantity insecticides applied) was based on national pesticide use data from 2016, as pesticide use information for 2017 and 2018 was not available. Landscape scale impacts of insecticides would be expected because insecticides can spread over larger areas through drift, emission and erosion and insecticide treated fields may act as sink habitats and reduce the population size of natural enemies at the landscape scale (c.f. the 'action at a distance' mechanism) (Sherratt and Jepson, 1993; Spromberg, John and Landis, 1998; Bianchi, Ives and Schellhorn, 2013; Topping et al., 2015; EFSA Scientific Committee, 2016). In addition, modelling studies indicate that insecticide use in fields affects natural enemy populations in non-sprayed fields because insecticidetreated fields act as sink habitats and this sink activity affects the population size of mobile natural enemies at the landscape scale (Bianchi, Ives and Schellhorn, 2013; Topping et al., 2015). I used an approximation for insecticide use at the landscape level, QIA. This indicator was consistently and significantly negatively associated with the abundance of predators, parasitoids, and pollinators, suggesting it may be a useful proxy for monitoring insecticide use and its impacts at the landscape scale.

\section{Arthropods and biocontrol potential}

I used a sentinel system to quantify biocontrol services in Chapter 4. A sentinel aims to represent actual pests, and I used M. brassicae because it is ubiquitous in many habitats and has a widespread presence in the Netherlands. I placed these sentinels in field margins to avoid direct effects of on-field farm management. Mean levels of predation and parasitism were relatively low ( $14 \%$ and $6 \%$, respectively), and it could be that I used a sentinel system that underestimated biocontrol potential and pesticide effects. Hence, I offer some explanations.

First, using potted plants, I possibly excluded ground-dwelling arthropod predators and potentially ignored their contribution to remove $M$. brassicae eggs. However, while acknowledging that both ground- and vegetation-dwelling arthropods contribute to biocontrol and complement each other (Thies et al., 2011), this study focused on landscapescale effects on mobile, flying arthropods. Previous studies have indicated that populations of parasitoids and other vegetation-dwelling arthropods are more closely linked to landscape diversity than ground-dwelling arthropods (e.g. Bianchi et al., 2005; Thies et al., 2011; Dainese et al., 2017). Many vegetation-dwelling arthropods use resources at a larger scale, and rely on semi-natural habitats for alternative food sources and overwintering sites (Bianchi, Booij and Tscharntke, 2006; Thies et al., 2011; Dainese et al., 2017). By contrast, many ground-dwelling predators are generally better adapted to landscapes dominated by agricultural fields (Dainese et al., 2017). Second, our experimental sites were placed in a variety of locations next to different crops, which were not necessarily host plants of $M$. 
brassicae. This could imply that as natural populations of $M$. brassicae were not present in the field, potential natural enemies were also not present. Third, plants emit chemical cues (semio-chemicals) which, when exposed to egg deposition, influence search behaviour of natural enemies (Colazza et al., 2010). Sentinel systems like egg cards do not induce such semio-chemicals, thus egg cards might underestimate the parasitism occurring on naturally laid eggs. However, to mimic natural conditions as much as possible I used one-day old eggs in my set-up, which emit stronger chemical cues than older eggs (Colazza et al., 2010). Fourth, identifying the natural enemies responsible for biocontrol is essential to make strong conclusions on biocontrol potential in any landscape, and to be able to target pest management at specific taxa (Zou et al., 2017; McHugh et al., 2020). However, direct observations to identify natural enemies responsible for predation or parasitism is laborious, time-consuming and difficult to conduct at six to eight sites at the same time (Zou et al., 2017). Finally, the generalization of the biocontrol potential in the landscape from predation and parasitism rates of $M$. brassicae eggs must be done with care, as the enemies of $M$. brassicae may not be effective against another pests. Habitats that favour a particular natural enemy may not be utilized by other natural enemies, and therefore landscape effects could be specific for the sentinel prey type that was used (McHugh et al., 2020). Still, given that important natural enemy groups of $M$. brassicae, including staphylinids, ladybeetles, lacewings, and spiders, which were found using sweepnet and yellow sticky trap sampling (Bakker, van der Werf and Bianchi, 2020), it could be argued that using this sentinel system I did get a good indication of biocontrol potential in each landscape.

\section{Landscape proxies}

Like most studies, I have focused on the effects of landscape composition (i.e. proportion of semi-natural habitat) in Chapters 3 and $\mathbf{4}$, while landscape configuration and connectivity are aspects of agricultural landscapes that are still underexplored. Recent studies reported stronger effects of landscape configuration than landscape composition on arthropod populations, which should get more attention in future landscape studies (Martin et al., 2019; Haan, Zhang and Landis, 2020). In addition, critical questions have been raised about the effectiveness of measuring insect abundances in landscape studies (Chaplin-Kramer et al., 2019). Insect abundances are not always a reflection of the level of natural pest control, and short-term measurements do not always reflect the longer-term dynamics of pest and natural enemy populations. Many other factors influence insect abundance, such as climate, soil type, crop type, or crop productivity (Chaplin-Kramer et al., 2019). However, I tried to account for many of these confounding factors in my field study. For example, to measure biocontrol services I placed $M$. brassicae eggs on leaves of potted cabbage plants to control for e.g. soil type, plant variety, and planting dates. I repeated measurements four times across two years to capture temporal dynamics of biocontrol. Furthermore, I sampled at sites across the Netherlands to establish a gradient in landscape complexity, and I used 
paired farms to account for potential differences in insecticide use within the same landscape type.

\section{OUTLOOK AND PERSPECTIVE}

The trade-off between environmental health and producing food is an important challenge in the current mainstream model of agriculture (Milner and Boyd, 2017). In this thesis I showed that farmers are trapped in a pesticide treadmill, and different lock-in mechanisms play a role. I showed that it is important to recognize the role of different actors in the treadmill. The complex interdependencies between social and ecological systems present challenges, but there is a way forward. Specifically, I would make the following recommendations to encourage the transition to ecologically-based pest management.

\section{Encourage landscape-scale diversification}

a. Integrate cropping systems and semi-natural habitats for a more resilient provision of biological pest control through, e.g., decreasing field sizes and implementation of diversification measures (e.g. flower strips)

b. Increase the length of crop rotations (at the landscape scale).

2. Support social networks of farmers communities to enable collective action through, e.g., farmer collectives.

A major bottleneck for the transition towards more ecologically-based pest management is the individual approach of farmers towards pest management decision making. Field-level decisions on pesticide use affect neighbouring fields due to the mobility of both pesticides and arthropods. In other words, a farmers' choice of using pesticides directly restricts a neighbouring farmer's efforts to manage pests with conservation biological control (Bell, Zhang and Nou, 2016). Thus, effective pest management should be based on community coordination wherein community members partake in efforts to increase diversity at the landscape scale, providing multiple resources for beneficial arthropods and reducing pesticide side effects (Stallman and James, 2015). Coordination can be facilitated with subsidies for cooperative practices, like regional pest outbreak alerts. Nevertheless, it is important that farmers perceive the benefits of collective action e.g. through more effective pest control because they were working together with their neighbours (Stallman and James, 2015).

3. Establish the true costs of pesticides and incorporate these into pesticide pricing

a. Develop methods that take all direct and indirect effects of pesticides into account.

b. Regularly review and continuously monitor pesticides after approval to assess potential environmental and health risks.

Currently, an estimated $50 \%$ of pesticides used are not necessary for obtaining higher yields (Pretty and Bharucha, 2015). Consequently, governments should develop well-defined agricultural policies that adequately incorporate externalities of pesticide use into pesticide 
pricing. This will enable farmers to include the 'true costs' of pesticides in comparison to alternative pest management methods. To be able to establish these true costs, methods should be developed which take the broad range of indirect spatial and temporal effects of pesticide use into account, e.g. scale of use, toxicity, and exposure of non-target organisms to pesticides (Bernhardt, Rosi and Gessner, 2017). Moreover, risk assessments of pesticide use need to consider population-level impacts at the landscape scale on beneficial insects, giving importance to populations spatial dynamics like 'action at a distance' and source-sink dynamics to obtain realistic responses of endpoints of in-field pesticide use (Topping et al., 2015; Milner and Boyd, 2017; Topping, Aldrich and Berny, 2020). These assessments may incorporate farmers' experiences, with the farmer being an active actor providing feedback on agronomic (and environmental) impacts of the pesticides used (Topping, Aldrich and Berny, 2020). Concurrently, this makes farmers more aware of potential risks and could encourage farmers to judiciously use agrochemicals. Finally, farmers and society should be informed of aspects of pesticide-free agriculture, e.g. potential crop damages and presence of pest insects in the landscape, and consider these in future choices and objectives for landscape management. Furthermore, retailers and consumers need to recognize that no or little pesticide use could mean that small amounts of pest damage may be unavoidable, with fruits and vegetables being aesthetically damaged, but qualitatively good (Chaplin-Kramer et al., 2019). Moreover, retailers could positively influence farmers' decision-making through price premiums on pesticide-free products.

4. Empower farmers' access to the right tools, knowledge and financial support that is needed for a transition to ecologically-based pest management.

Farmers need access to the right tools, knowledge, and financial support to experiment with practices and overcome risk aversiveness to implement alternative pest management methods (Lamprinopoulou et al., 2014; Macfadyen et al., 2015; Chaplin-Kramer et al., 2019). This can be facilitated by governments, farmer organisations, and non-governmental organisations like conservation groups. Support can be given e.g. through training on integrated pest management, reward-based subsidy schemes, and development of areawide management strategies in cooperation with multiple stakeholders (Westerink et al., 2019).

\section{Improve integration of disciplinary research silos.}

Pest control is an interdisciplinary problem, and we need to better integrate social sciences, like economics and behaviour, and biophysical sciences (Chaplin-Kramer et al., 2019). To advance the transition from chemical to ecologically-based pest management it is crucial that all actors are aligned, that the we look beyond ecological problems and include the social challenges to allow for linkage or integration with other fields. Thus, to encourage the transition to ecologically-based pest management, the study of pest control could benefit 
enormously from multi-disciplinary teams. Ecologists can take advantage of research from social sciences, and vice versa, to be able to integrate ecological information with social and behavioural understanding (Seto et al., 2016). By doing so, farmers could obtain the right information in the right way and be supported in their day-to-day decision-making. This is a promising approach to help farmers overcome obstacles and incorporate ecologicallybased pest management practices into farm management, finally stepping out of the pesticide treadmill. 
REFERENCES 
Adkisson, P. L. et al. (1982) 'Controlling cotton's insect pests: a new system', Science, 216, pp. 19-22.

Ahnström, J. et al. (2009) 'Farmers and nature conservation: What is known about attitudes, context factors and actions affecting conservation?', Renewable Agriculture and Food Systems, 24(1), pp. 38-47. doi: $10.1017 /$ S1742170508002391.

Ahnström, J. et al. (2013) 'Farmers' interest in nature and its relation to biodiversity in arable fields', International Journal of Ecology, pp. 30-33. doi: 10.1155/2013/617352.

Ajzen, I. (2012) 'Martin fishbein's legacy: The reasoned action approach', Annals of the American Academy of Political and Social Science, 640(1), pp. 11-27. doi: 10.1177/0002716211423363.

Albrecht, M. et al. (2020) 'The effectiveness of flower strips and hedgerows on pest control, pollination services and crop yield: a quantitative synthesis', Ecology Letters, ele.13576. doi: 10.1111/ele.13576.

Alburaki, M. et al. (2015) 'Neonicotinoid-coated Zea mays seeds indirectly affect honeybee performance and pathogen susceptibility in field trials', PLOS ONE, 10, pp. 1-20. doi: 10.1371/journal.pone.0125790.

Atreya, K. et al. (2011) 'Continuing issues in the limitations of pesticide use in developing countries', Journal of Agricultural and Environmental Ethics, 24(1), pp. 49-62. doi: 10.1007/s10806-010-9243-9.

Bagheri, A. et al. (2019) 'Modeling farmers' intention to use pesticides: An expanded version of the theory of planned behavior', Journal of Environmental Management, 248, p. 109291. doi: 10.1016/j.jenvman.2019.109291.

Bakker, L. et al. (2020) 'Neonicotinoids in global agriculture: evidence for a new pesticide treadmill?', Ecology and Society, 25(3), p. art26. doi: 10.5751/ES-11814-250326.

Bakker, L. et al. (2021a) 'Kicking the Habit: What Makes and Breaks Farmers' Intentions to Reduce Pesticide Use?', Ecological Economics, 180, p. 106868. doi: 10.1016/j.ecolecon.2020.106868.

Bakker, L., van der Werf, W. and Bianchi, F. J. J. A. (2020) 'Landscape-wide insecticide exposure impacts beneficial arthropod abundance', under review.

Bakker, L., van der Werf, W. and Bianchi, F. J. J. A. (2021b) 'No significant effects of insecticide use indicators and landscape variables on biocontrol in field margins', Agriculture, Ecosystems \& Environment, 308, p. 107253. doi: 10.1016/j.agee.2020.107253.

Bale, J. S., van Lenteren, J. C. and Bigler, F. (2008) 'Biological control and sustainable food production.', Philosophical Transactions of the Royal Society B, 363(1492), pp. 761-776. doi: 10.1098/rstb.2007.2182.

Balmer, O. et al. (2014) 'Wildflower companion plants increase pest parasitation and yield in cabbage fields: Experimental demonstration and call for caution', Biological Control., 76, pp. 19-27. doi: 10.1016/j.biocontrol.2014.04.008.

Barton, K. (2019) 'Mu-MIn: Multi-model inference.', R Package Version 0.12.2/r18. Available at: http://rforge.r-project.org/projects/mumin/.

Barzman, M. et al. (2015) 'Eight principles of integrated pest management', Agronomy for Sustainable Development, 35(4), pp. 1199-1215. doi: 10.1007/s13593-015-0327-9.

Bashir, Y. G. A., Elamin, E. M. and Elamin, E. M. (2003) 'Development and implementation of integrated pest management in the Sudan.', in K.M. Maredia, Dakouo, D., and Mota-Sanchez, D. (eds) Integrated pest management in the global arena. CAB International, pp. 131-143. doi: $10.1079 / 9780851996523.0131$.

Bass, C. et al. (2015) 'The global status of insect resistance to neonicotinoid insecticides', Pesticide Biochemistry and Physiology, 121, pp. 78-87. doi: 10.1016/j.pestbp.2015.04.004.

Bates, D. et al. (2015) 'Fitting Linear Mixed-Effects Models Using lme4', Journal of Statistical Software, 67(1), pp. 1-48. doi: 10.18637/jss.v067.i01.

Bell, A., Zhang, W. and Nou, K. (2016) 'Pesticide use and cooperative management of natural enemy habitat in a framed field experiment', Agricultural Systems, 143, pp. 1-13. doi: 10.1016/j.agsy.2015.11.012.

Berheim, E. H. et al. (2019) 'Effects of Neonicotinoid Insecticides on Physiology and Reproductive Characteristics of Captive Female and Fawn White-tailed Deer', Scientific Reports. 9(1), pp. 1-10. doi: 10.1038/s41598-019-40994-9.

Bernhardt, E. S., Rosi, E. J. and Gessner, M. O. (2017) 'Synthetic chemicals as agents of global change', Frontiers in Ecology and the Environment, 15(2), pp. 84-90. doi: 10.1002/fee.1450.

Bianchi, F. J. J. A. et al. (2005) 'Landscape factors affecting the control of Mamestra brassicae by natural enemies in Brussels sprout', Agriculture, Ecosystems and Environment, 107(2-3), pp. 145-150. doi: 10.1016/j.agee.2004.11.007.

Bianchi, F. J. J. A., Booij, C. J. H. and Tscharntke, T. (2006) 'Sustainable pest regulation in agricultural landscapes: a review on landscape composition, biodiversity and natural pest control.', Proceedings of the Royal Society B: Biological sciences, 273, pp. 1715-1727. doi: 10.1098/rspb.2006.3530. 
Bianchi, F. J. J. A., Goedhart, P. W. and Baveco, J. M. (2008) 'Enhanced pest control in cabbage crops near forest in the Netherlands', Landscape Ecology, 23(5), pp. 595-602. doi: 10.1007/s10980-008-9219-6.

Bianchi, F. J. J. A., Ives, A. R. R. and Schellhorn, N. A. A. (2013) 'Interactions between conventional and organic farming for biocontrol services across the landscape', Ecological Applications, 23(7), pp. 15311543. doi: 10.1890/12-1819.1.

Bianchi, F. J. J. A., Schellhorn, N. A. and Cunningham, S. A. (2013) 'Habitat functionality for the ecosystem service of pest control: Reproduction and feeding sites of pests and natural enemies', Agricultural and Forest Entomology, 15(1), pp. 12-23. doi: 10.1111/j.1461-9563.2012.00586.x.

Bianchi, F. J. J. A. and van der Werf, W. (2003) 'The effect of the area and configuration of hibernation sites on the control of aphids by Coccinella septempunctata (Coleoptera: Coccinellidae) in agricultural landscapes: A simulation study', Environmental Entomology, 32(6), pp. 1290-1304. doi: 10.1603/0046-225X-32.6.1290.

Blacquière, T. et al. (2012) 'Neonicotinoids in bees: A review on concentrations, side-effects and risk assessment', Ecotoxicology, 21, pp. 973-992. doi: 10.1007/s10646-012-0863-x.

Blitzer, E. J. et al. (2012) 'Spillover of functionally important organisms between managed and natural habitats', Agriculture, Ecosystems and Environment., 146(1), pp. 34-43. doi: 10.1016/j.agee.2011.09.005.

Boccaletti, S. and Nardella, M. (2000) 'Consumer willingness to pay for pesticide-free fresh fruit and vegetables in Italy', The International Food and Agribusiness Management Review, 3(3), pp. 297310. doi: 10.1016/S1096-7508(01)00049-0.

Bonmatin, J.-M. et al. (2015) 'Environmental fate and exposure; neonicotinoids and fipronil', Environmental Science and Pollution Research, 22(1), pp. 35-67. doi: 10.1007/s11356-014-3332-7.

Borel, B. (2017) 'When the pesticides run out', Nature, 543, pp. 302-304. doi: 10.1038/543302a.

van den Bosch, R. (1989) The pesticide conspiracy. University of California Press.

van den Bosch, R. and Stern, V. M. (1962) 'The integration of chemical and biological control of arthropod pests', Journal of Economic Entomology, 7, pp. 367-386.

Botías, C. et al. (2019) 'Impact of pesticide use on the flora and fauna of field margins and hedgerows', in Dover, J. (ed.) The Ecology of hedgerows and field margins. Abingdon, Oxon; New York, NY: Routledge, pp. 90-109.

Bottrell, D. G. and Schoenly, K. G. (2012) 'Resurrecting the ghost of green revolutions past: The brown planthopper as a recurring threat to high-yielding rice production in tropical Asia', Journal of AsiaPacific Entomology, 15(1), pp. 122-140. doi: 10.1016/j.aspen.2011.09.004.

Bowman, M. and Zilberman, D. (2013) 'Economic Factors Affecting Diversified Farming Systems', Ecology and Society, 18(1), pp. 1-33. doi: 10.5751/es-05574-180133.

Boyd, I. L. (2018) 'An inside view on pesticide policy', Nature Ecology and Evolution, 2(6), pp. 920-921. doi: 10.1038/s41559-018-0557-8.

Breukers, A. et al. (2012) 'Understanding Growers' Decisions to Manage Invasive Pathogens at the Farm Level', Phytopathology, 102(6), pp. 609-619. doi: 10.1094/PHYT0-06-11-0178.

Brewer, M. J. and Goodell, P. B. (2012) 'Approaches and Incentives to Implement Integrated Pest Management that Addresses Regional and Environmental Issues', Annual Review of Entomology, 57(1), pp. 4159. doi: 10.1146/annurev-ento-120709-144748.

Brooks, M. E. et al. (2017) 'glmmTMB balances speed and flexibility among packages for zero-inflated generalized linear mixed modeling', R Journal, 9(2), pp. 378-400. doi: 10.32614/rj-2017-066.

Brown, T. A. (2015) Confirmatory factor analysis for applied research. in Methodology in the social sciences. Second edition. New York: The Guilford Press.

Brühl, C. A. and Zaller, J. G. (2019) 'Biodiversity Decline as a Consequence of an Inappropriate Environmental Risk Assessment of Pesticides', Frontiers in Environemental Science, 7(177). doi: 10.3389/fenvs.2019.00177.

Brust, G. E. and King, L. R. (1994) 'Effects of crop rotation and reduced chemical inputs on pests and predators in maize agroecosystems', Agriculture, Ecosystems and Environment, 48(1), pp. 77-89. doi: 10.1016/0167-8809(94)90077-9.

Burnham, K. P. and Anderson, D. R. (2007) Model Selection and Multimodel Inference: a practical informationtheoretic approach. 2nd edn. Edited by K. P. Burnham and D. R. Anderson. New York: SpringerVerlag. doi: 10.1007/978-0-387-22456-5_7.

Burton, R. J. F. (2014) 'The influence of farmer demographic characteristics on environmental behaviour: A review', Journal of Environmental Management, 135, pp. 19-26. doi: 10.1016/j.jenvman.2013.12.005. 
Busch, A. K. et al. (2020) 'A high-diversity/IPM cropping system fosters beneficial arthropod populations, limits invertebrate pests, and produces competitive maize yields', Agriculture, Ecosystems and Environment, 292, p. 106812. doi: 10.1016/j.agee.2019.106812.

Buurma, J. S. and Smit, P. X. (2013) Groei in Het Nieuwe Telen. Kennisbehoefte van vroege volgers. Den Haag.

Byerlee, D., de Janvry, A. and Sadoulet, E. (2009) 'Agriculture for Development: Toward a New Paradigm', Annual Review of Resource Economics, 1(1), pp. 15-31. doi:

10.1146/annurev.resource.050708.144239.

Cain, M. K., Zhang, Z. and Yuan, K. H. (2017) 'Univariate and multivariate skewness and kurtosis for measuring nonnormality: Prevalence, influence and estimation', Behavior Research Methods, 49(5), pp. 17161735. doi: 10.3758/s13428-016-0814-1.

Calliera, M. et al. (2013) 'Enhance knowledge on sustainable use of plant protection products within the framework of the Sustainable Use Directive', Pest Management Science, 69(8), pp. 883-888. doi: 10.1002/ps.3579.

Calvo-Agudo, M. et al. (2019) 'Neonicotinoids in excretion product of phloem-feeding insects kill beneficial insects', Proceedings of the National Academy of Sciences, 116(34), pp. 16817-16822. doi: 10.1073/pnas.1904298116.

Carson, R. (1962) Silent Spring. Boston, MA: Houghton Mifflin.

Castle, S. J. (1999) 'Agricultural intensification and pest outbreaks: a reappraisal of events in the Sudan Gezira', Annals of the Entomological Society of America, 92, pp. 840-852.

CBS (2016) Opleiding en nevenactiviteiten bedrijfshoofden, 2016, Statistics Netherlands' database (CBS). Available at: https://www.cbs.nl/nl-nl/maatwerk/2018/10/opleiding-en-nevenactiviteitenbedrijfshoofden-2016 (Accessed: 26 August 2020).

CBS (2020) Agriculture; crops, animals and land use per farm type and region (NL: Landbouw; gewassen, dieren en grondgebruik naar hoofdbedrijfstype, regio), Statistics Netherlands' database (CBS). Available at: https://opendata.cbs.nl/\#/CBS/nl/dataset/80783ned/table?dl=2E108 (Accessed: 26 August 2020).

Chagnon, M. et al. (2015) 'Risks of large-scale use of systemic insecticides to ecosystem functioning and services', Environmental Science and Pollution Research, 22, pp. 119-134. doi: 10.1007/s11356014-3277-x.

Chantre, E. and Cardona, A. (2014) 'Trajectories of French Field Crop Farmers Moving Toward Sustainable Farming Practices: Change, Learning, and Links with the Advisory Services', Agroecology and Sustainable Food Systems, 38(5), pp. 573-602. doi: 10.1080/21683565.2013.876483.

Chaplin-Kramer, R. et al. (2011) 'A meta-analysis of crop pest and natural enemy response to landscape complexity', Ecology Letters, 14(9), pp. 922-932. doi: 10.1111/j.1461-0248.2011.01642.x.

Chaplin-Kramer, R. et al. (2019) 'Measuring What Matters: Actionable Information for Conservation Biocontrol in Multifunctional Landscapes', Frontiers in Sustainable Food Systems, 3(August), pp. 110. doi: 10.3389 /fsufs.2019.00060.

Chèze, B., David, M. and Martinet, V. (2020) 'Understanding farmers' reluctance to reduce pesticide use: A choice experiment', Ecological Economics, 167, p. 106349. doi: 10.1016/j.ecolecon.2019.06.004.

Cimino, A. M. et al. (2017) 'Effects of neonicotinoid pesticide exposure on human health: A systematic review', Environmental Health Perspectives, 125(2), pp. 155-162. doi: 10.1289/EHP515.

Clark, M. and Tilman, D. (2017) 'Comparative analysis of environmental impacts of agricultural production systems, agricultural input efficiency, and food choice', Environmental Research Letters, 12, p. 064016. doi: $10.1088 / 1748-9326 /$ aa6cd5.

Clough, Y. et al. (2005) 'Spider diversity in cereal fields: Comparing factors at local, landscape and regional scales', Journal of Biogeography, 32(11), pp. 2007-2014. doi: 10.1111/j.1365-2699.2005.01367.x.

Colazza, S. et al. (2010) 'Host Searching by Egg Parasitoids: Exploitation of Host Chemical Cues', in Consoli, F. L., Parra, J. R. P., and Zucchi, R. A. (eds) Egg Parasitoids in Agroecosystems with Emphasis on Trichogramma. Dordrecht: Springer Netherlands, pp. 97-147. doi: 10.1007/978-1-4020-9110$0 \_4$.

Colen, L. et al. (2016) 'Economic Experiments as a Tool for Agricultural Policy Evaluation: Insights from the European CAP', Canadian Journal of Agricultural Economics, 64(4), pp. 667-694. doi: 10.1111/cjag.12107.

Cooper, J. and Dobson, H. (2007) 'The benefits of pesticides to mankind and the environment', Crop Protection, 26(9), pp. 1337-1348. doi: 10.1016/j.cropro.2007.03.022.

Cowan, R. and Gunby, P. (1996) 'Sprayed to death: path dependence lock-in and pest control strategies', The Economic Journal, 106, pp. 521-542. 
Cowan, R. and Hultén, S. (1996) 'Escaping lock-in: the case of the electric vehicle', Technological Forecasting and Social Change, 53, pp. 61-79. doi: 10.1016/0040-1625(96)00059-5.

Crofton, H. D. (1971) 'A quantitative approach to parasitism', Parasitology, 62(2), pp. 179-193. doi: 10.1017/S0031182000071420.

CTGB (2019) Dutch Board for the Authorisation of Plant Protection Products and Biocides (Ctgb), Overview of authorisation. Available at: https://toelatingen.ctgb.nl/nl/authorisations (Accessed: 17 January 2020).

Culliney, T. W. (2014) 'Crop losses to arthropods', in Pimentel, D. and Peshin, R. (eds) Integrated Pest Management. Dordrecht: Springer Netherlands, pp. 202-225. doi: 10.1007/978-94-007-7796-5.

Dainese, M. et al. (2017) 'High cover of hedgerows in the landscape supports multiple ecosystem services in Mediterranean cereal fields', Journal of Applied Ecology, 54(2), pp. 380-388. doi: 10.1111/13652664.12747.

Dainese, M. et al. (2019) 'A global synthesis reveals biodiversity-mediated benefits for crop production', Science Advances, 5, pp. 1-13.

Damalas, C. A. and Koutroubas, S. D. (2014) 'Determinants of farmers' decisions on pesticide use in oriental tobacco: A survey of common practices', International Journal of Pest Management, 60(3), pp. 224231. doi: 10.1080/09670874.2014.958767.

DeBach, P. (1951) 'The necessity for an ecological approach to pest control', Journal of Economic Entomology, 44(4), pp. 443-447.

Deguine, J.-P., Ferron, P. and Russell, D. (2008) 'Sustainable pest management for cotton production. A review.', Agronomy for Sustainable Development, 28, pp. 113-137. doi: 10.1051/agro:2007042.

Desneux, N., Decourtye, A. and Delpuech, J.-M. (2007) 'The sublethal effects of pesticides on beneficial arthropods.', Annual Review of Entomology, 52, pp. 81-106. doi: 10.1146/annurev.ento.52.110405.091440.

Dessart, F. J., Barreiro-Hurlé, J. and Van Bavel, R. (2019) 'Behavioural factors affecting the adoption of sustainable farming practices: A policy-oriented review', European Review of Agricultural Economics, 46(3), pp. 417-471. doi: 10.1093/erae/jbz019.

Deutsch, C. A. et al. (2018) 'Increase in crop losses to insect pests in a warming climate', Science, 361(6405), pp. 916-919. doi: 10.1126/science.aat3466.

Devine, G. J. and Furlong, M. J. (2007) 'Insecticide use: Contexts and ecological consequences', Agriculture and Human Values, 24(3), pp. 281-306. doi: 10.1007/s10460-007-9067-z.

Diamantopoulos, A. (2011) 'Incorporating formative measures into covariance-based structural equation models', MIS Quarterly, 35(2), pp. 335-358.

DiBartolomeis, M. et al. (2019) 'An assessment of acute insecticide toxicity loading (AITL) of chemical pesticides used on agricultural land in the United States', Plos One, 14(8), p. e0220029. doi: 10.1371/journal.pone.0220029.

Douglas, M. R. and Tooker, J. F. (2015) 'Large-scale deployment of seed treatments has driven rapid increase in use of neonicotinoid insecticides and preemptive pest management in U.S. field crops', Environmental Science and Technology. American Chemical Society, 49(8), pp. 5088-5097. doi: 10.1021/es506141g.

Douglas, M. R. and Tooker, J. F. (2016) 'Meta-analysis reveals that seed-applied neonicotinoids and pyrethroids have similar negative effects on abundance of arthropod natural enemies', PeerJ, 4, p. e2776. doi: 10.7717/peerj.2776.

Doutt, R. L. and Smith, R. F. (1971) 'The pesticide syndrome - diagnosis and suggested prophylaxis', in Huffaker, C. B. (ed.) Biological Control. 3rd edn. New York - London: Plenum Press, pp. 3-15. Available at: https://link.springer.com/content/pdf/10.1007\%2F978-1-4615-6531-4.pdf.

Dover, J. W (2019) The ecology of hedgerows and field margins. Edited by J.W. Dover. Abingdon, Oxon; New York, NY: Routledge.

Doxon, E. D., Davis, C. A. and Fuhlendorf, S. D. (2011) 'Comparison of two methods for sampling invertebrates: Vacuum and sweep-net sampling', Journal of Field Ornithology, 82(1), pp. 60-67. doi: 10.1111/j.1557-9263.2010.00308.x.

Dudley, N. et al. (2017) 'How should conservationists respond to pesticides as a driver of biodiversity loss in agroecosystems?', Biological Conservation, 209, pp. 449-453. doi: 10.1016/j.biocon.2017.03.012.

Dudley, N. and Alexander, S. (2017) 'Agriculture and biodiversity: a review', Biodiversity, 18(2-3), pp. 45-49. doi: 10.1080/14888386.2017.1351892. 
Dunham, W. C. (2015) Evolution and future of biocontrol., Paper presented at the 10th Annual Biocontrol Industry Meeting (ABIM). October 20th, 2015. Basel, Switserland. Available at: http://dunhamtrimmer.com/wp-content/uploads/2018/05/Bill-Dunham-2BMonthly-EvolutionFuture-of-Biocontrol-Industry.pdf (Accessed: 20 November 2020).

Dyer, A. (2014) Chasing the Red Queen. Washington D.C. USA: Island Press.

EASAC (2015) Ecosystem services, agriculture, and neonicotinoids. Halle (Saale), Germany: European Academies Science Advisory Council (EASAC). Available at: http//www.easac.eu.

EC (2020) May 2020 Progress report on Directive 2009/128/EC. Brussels. Available at: https://ec.europa.eu/food/sites/food/files/plant/docs/pesticides_sud_report-act_2020_en.pdf.

van Eerdt, M. M. et al. (2014) 'Costs and effectiveness of on-farm measures to reduce aquatic risks from pesticides in the Netherlands', Pest Management Science, 70(12), pp. 1840-1849. doi: 10.1002/ps.3729.

EFSA (2016) Pesticides and bees: EFSA to update neonicotinoid assessments. Available at: https://www.efsa.europa.eu/en/press/news/160111 (Accessed: 19 September 2017).

EFSA Scientific Committee (2016) 'Recovery in environmental risk assessments at EFSA', EFSA Journal, 14(2). doi: $10.2903 /$ j.efsa.2016.4313.

Ekström, G. and Ekbom, B. (2011) 'Pest control in agro-ecosystems: an ecological approach', Critical Reviews in Plant Sciences, 30, pp. 74-94. doi: 10.1080/07352689.2011.554354.

Epskamp, S. (2015) 'semPlot: Unified Visualizations of Structural Equation Models', Structural Equation Modeling: A Multidisciplinary Journal, 22(3), pp. 474-483. doi: 10.1080/10705511.2014.937847.

Eschen, R. et al. (2015) 'International variation in phytosanitary legislation and regulations governing importation of plants for planting', Environmental Science and Policy, 51, pp. 228-237. doi: 10.1016/j.envsci.2015.04.021.

EU (2018) 'Commission Implementing Regulation (EU) 2018/784 of 29 May 2018 amending Implementing Regulation (EU) No 540/2011 as regards the conditions of approval of the active substance clothianidin', Official Journal of the European Union, L132/35. Available at: https://eurlex.europa.eu/legalcontent/EN/TXT/?uri=uriserv:OJ.L_.2018.132.01.0035.01.ENG\&toc=0J:L:2018:132:FULL.

European Commission (2012) 'Dutch action plan on sustainable plant protection', p. 12. Available at: https://ec.europa.eu/food/sites/food/files/plant/docs/pesticides_sup_nap_nld_en.pdf.

European Commission (2020) Farm to Fork Strategy. For a fair, healthy and environmentally-friendly food system. Available at: https://ec.europa.eu/food/sites/food/files/safety/docs/f2f_actionplan_2020_strategy-info_en.pdf.

Eurostat (2019) Agri-environmental indicator - consumption of pesticides, European Commission. Available at: https://ec.europa.eu/eurostat/statistics-explained/index.php/Agri-environmental_indicator__consumption_of_pesticides\#Analysis_at_EU_and_country_level (Accessed: 17 February 2020).

Eurostat (2020) European Commission, Agri-environmental indicators. Sales of pesticides by type of pesticide. Available at: https://ec.europa.eu/eurostat/databrowser/view/AEI_FM_SALPEST09 (Accessed: 26 November 2020).

Evans, K. J., Terhorst, A. and Kang, B. H. (2017) 'From Data to Decisions: Helping Crop Producers Build Their Actionable Knowledge', Critical Reviews in Plant Sciences, 36(2), pp. 71-88. doi: 10.1080/07352689.2017.1336047.

Eveleens, K. G. (1983) 'Cotton-insect control in the Sudan Gezira: analysis of a crisis', Crop Protection, 2, pp. 273-287. doi: 10.1016/0261-2194(83)90002-9.

FAOSTAT (2020) FAO, Pesticides Indicators. Available at: http://www.fao.org/faostat/en/\#data (Accessed: 26 November 2020).

Feder, G., Just, R. E. and Zilberman, D. (1985) 'Adoption of Agricultural Innovations in Developing Countries: A Survey', Economic Development and Cultural Change, 33(2), pp. 255-298.

Feld, C. K., Segurado, P. and Gutiérrez-Cánovas, C. (2016) 'Analysing the impact of multiple stressors in aquatic biomonitoring data: A "cookbook" with applications in R', Science of the Total Environment., 573, pp. 1320-1339. doi: 10.1016/j.scitotenv.2016.06.243.

Fera (2020) Pesticide Usage Survey reports. PUSSTATS application. Available at: http://pusstats.fera.defra.gov.uk/myindex.cfm (Accessed: 14 February 2020).

Fishbein, M. (2008) 'A reasoned action approach to health promotion', Medical Decision Making, 28(6), pp. 834-844. doi: 10.1177/0272989X08326092.

Fishbein, M. and Ajzen, I. (2011) Predicting and changing behavior: The reasoned action approach. Psychology press. 
Flor, R. J. et al. (2019) ‘Do field-level practices of Cambodian farmers prompt a pesticide lock-in?', Field Crops Research, 235, pp. 68-78. doi: 10.1016/j.fcr.2019.02.019.

Foley, J. A. et al. (2011) 'Solutions for a cultivated planet', Nature, 478, pp. 337-342. doi: $10.1038 /$ nature 10452 .

Furlan, L. et al. (2018) 'An update of the Worldwide Integrated Assessment (WIA) on systemic insecticides. Part 3: alternatives to systemic insecticides', Environmental Science and Pollution Research., pp. 123. doi: $10.1007 / \mathrm{s} 11356-017-1052-5$.

Furlan, L. and Kreutzweiser, D. (2015) 'Alternatives to neonicotinoid insecticides for pest control: case studies in agriculture and forestry', Environmental Science and Pollution Research, 22, pp. 135-147. doi: 10.1007/s11356-014-3628-7.

Gabriel, D. et al. (2010) 'Scale matters: The impact of organic farming on biodiversity at different spatial scales', Ecology Letters, 13(7), pp. 858-869. doi: 10.1111/j.1461-0248.2010.01481.x.

Gagic, V. et al. (2017) 'Combined effects of agrochemicals and ecosystem services on crop yield across Europe', Ecology Letters, 20(11), pp. 1427-1436. doi: 10.1111/ele.12850.

Gagic, V. et al. (2019) 'Biocontrol in insecticide sprayed crops does not benefit from semi-natural habitats and recovers slowly after spraying', Journal of Applied Ecology, 56(9), pp. 2176-2185. doi: 10.1111/1365-2664.13452.

Garratt, M. P. D., Wright, D. J. and Leather, S. R. (2011) 'The effects of farming system and fertilisers on pests and natural enemies: A synthesis of current research', Agriculture, Ecosystems and Environment, 141(3-4), pp. 261-270. doi: 10.1016/j.agee.2011.03.014.

Ge, L. et al. (2016) 'Why we need resilience thinking to meet societal challenges in bio-based production systems', Current Opinion in Environmental Sustainability, 23, pp. 17-27. doi: 10.1016/j.cosust.2016.11.009.

Geertsema, W. et al. (2016) 'Actionable knowledge for ecological intensification of agriculture', Frontiers in Ecology and the Environment, 14(4), pp. 209-216. doi: 10.1002/fee.1258.

Geiger, F. et al. (2010) 'Persistent negative effects of pesticides on biodiversity and biological control potential on European farmland', Basic and Applied Ecology, 11(2), pp. 97-105. doi: 10.1016/j.baae.2009.12.001.

Giannakas, K. and Fulton, M. (2005) 'Process Innovation Activity in a Mixed Oligopoly: The Role of Cooperatives', American Journal of Agricultural Economics, 87(2), pp. 406-422. Available at: http://www.jstor.org/stable/3697854.

Gibbons, D. W., Morrissey, C. A. and Mineau, P. (2015) 'A review of the direct and indirect effects of neonicotinoids and fipronil on vertebrate wildlife', Environmental Science and Pollution Research, 22(1), pp. 103-118. doi: 10.1007/s11356-014-3180-5.

Giorio, C. et al. (2017) 'An update of the Worldwide Integrated Assessment (WIA) on systemic insecticides. Part 1: new molecules, metabolism, fate, and transport', Environmental Science and Pollution Research, doi: 10.1007/s11356-017-0394-3.

Goulson, D. (2013) 'An overview of the environmental risks posed by neonicotinoid insecticides', Journal of Applied Ecology, 50(4), pp. 977-987. doi: 10.1111/1365-2664.12111.

Goulson, D. (2018) 'Call to restrict neonicotinoids', Science, 360(6392).

Goulson, D. (2019) 'The insect apocalypse, and why it matters', Current Biology, 29(19), pp. R967-R971. doi: 10.1016/j.cub.2019.06.069.

Gravesen, L. (2003) 'The Treatment Frequency Index: an indicator for pesticide use and dependency as well as overall load on the environment', in Reducing pesticide dependency in Europe to protect health, environment and biodiversity, Copenhagen, Pesticides Action Network Europe (PAN), Pure Conference.

Green, L. et al. (2020) 'Influencing Change: When "Best Practice" Changes and the Prototypical Good Farmer Turns Bad', Frontiers in Veterinary Science, 7, pp. 1-12. doi: 10.3389/fvets.2020.00161.

Gross, K. and Rosenheim, J. A. (2011) 'Quantifying secondary pest outbreaks in cotton and their monetary cost with causal-inference statistics', Ecological Applications, 21(7), pp. 2770-2780. doi: 10.1890/11-0118.1.

Grueber, C. E. et al. (2011) 'Multimodel inference in ecology and evolution: Challenges and solutions', Journal of Evolutionary Biology, 24(4), pp. 699-711. doi: 10.1111/j.1420-9101.2010.02210.x.

Gutsche, V. and Rossberg, D. (1997) 'SYNOPS 1.1: A model to assess and to compare the environmental risk potential of active ingredients in plant protection products', Agriculture, Ecosystems and Environment, 64(2), pp. 181-188. doi: 10.1016/S0167-8809(97)00037-6. 
Haan, N. L., Zhang, Y. and Landis, D. A. (2020) 'Predicting Landscape Configuration Effects on Agricultural Pest Suppression', Trends in Ecology and Evolution, 35(2), pp. 175-186. doi: 10.1016/j.tree.2019.10.003.

Hallmann, C. A. et al. (2014) 'Declines in insectivorous birds are associated with high neonicotinoid concentrations', Nature, 511(7509), pp. 341-343. doi: 10.1038/nature13531.

Hallmann, C. A. et al. (2017) 'More than 75 percent decline over 27 years in total flying insect biomass in protected areas', Plos One, 12 (10), p. e0185809. doi: 10.1371/journal.pone.0185809.

Hambäck, P. A. et al. (2020) 'Predatory arthropod community composition in apple orchards: Orchard management, landscape structure and sampling method', Journal of Applied Entomology, 00:p1-9. doi: $10.1111 /$ jen.12832.

Hammond Wagner, C. R., Cox, M. and Bazo Robles, J. L. (2016) 'Pesticide lock-in in small scale Peruvian agriculture', Ecological Economics., 129, pp. 72-81. doi: 10.1016/j.ecolecon.2016.05.013.

Hansen, M. (1988) Escape from the pesticide treadmill: alternatives to pesticides in developing countries. Mount Vernon, USA: Institute for Consumer Policy Research.

Harvey, J. A. et al. (2020) 'International scientists formulate a roadmap for insect conservation and recovery', Nature Ecology \& Evolution, 4(2), pp. 174-176. doi: 10.1038/s41559-019-1079-8.

Hijbeek, R. et al. (2018) 'What drives farmers to increase soil organic matter? Insights from the Netherlands', Soil Use and Management, pp. 1-16. doi: 10.1111/sum.12401.

Hill, M. P., Macfadyen, S. and Nash, M. A. (2017) 'Broad spectrum pesticide application alters natural enemy communities and may facilitate secondary pest outbreaks', PeerJ, 5, p. e4179. doi: 10.7717/peerj.4179.

Holland, J. M. et al. (2016) 'Structure, function and management of semi-natural habitats for conservation biological control: a review of European studies', Pest management science, 72(9), pp. 1638-1651. doi: $10.1002 /$ ps.4318.

Holzschuh, A. et al. (2007) 'Diversity of flower-visiting bees in cereal fields: Effects of farming system, landscape composition and regional context', Journal of Applied Ecology, 44(1), pp. 41-49. doi: 10.1111/j.1365-2664.2006.01259.x.

$\mathrm{Hu}, \mathrm{Z}$. (2020) 'What socio-economic and political factors lead to global pesticide dependence? A critical review from a social science perspective', International Journal of Environmental Research and Public Health, 17(21), pp. 1-22. doi: 10.3390/ijerph17218119.

Huang, J. et al. (2018) 'Uncovering the economic value of natural enemies and true costs of chemical insecticides to cotton farmers in China', Environmental Research Letters, 13(6). doi: 10.1088/17489326/aabfb0.

Humann-Guilleminot, S. et al. (2019) 'A large-scale survey of house sparrows feathers reveals ubiquitous presence of neonicotinoids in farmlands', Science of the Total Environment, 660, pp. 1091-1097. doi: 10.1016/j.scitotenv.2019.01.068.

Iost Filho, F. H. et al. (2019) 'Drones: Innovative Technology for Use in Precision Pest Management', Journal of Economic Entomology, 113(1), pp. 1-25. doi: 10.1093/jee/toz268.

IPBES (2016) The assessment report of the Intergovernmental Science-Policy Platform on Biodiversity and Ecosystem Services on pollinators, pollination and food production. Edited by S. G. Potts, V. L. Imperatriz-Fonseca, and H. T. Ngo. Available at: www.ipbes.net.

IPES-Food (2016) From Uniformity to Diversity: a paradigm shift from industrial agriculture to diversified agroecological systems, International Panel of Experts on Sustainable Food systems. Available at: www.ipes-food.org.

Jactel, H. et al. (2019) 'Alternatives to neonicotinoids', Environment International, 129, pp. 423-429. doi: 10.1016/j.envint.2019.04.045.

Jepson, P. C. et al. (2014) 'Measuring pesticide ecological and health risks in West African agriculture to establish an enabling environment for sustainable intensification', Philosophical Transactions of the Royal Society B, 369, 20130491, doi: dx.doi.org/10.1098/rstb.2013.0491.

Jeschke, P. et al. (2011) 'Overview of the status and global strategy for neonicotinoids', Journal of agricultural and food chemistry, 59, pp. 2987-2908. doi: 10.1021/jf101303g.

de Jong, F. M. W., de Snoo, G. R. and van de Zande, J. C. (2008) 'Estimated nationwide effects of pesticide spray drift on terrestrial habitats in the Netherlands', Journal of Environmental Management, 86(4), pp. 721-730. doi: 10.1016/j.jenvman.2006.12.031.

Jonsson, M. et al. (2012) 'Agricultural intensification drives landscape-context effects on host-parasitoid interactions in agroecosystems', Journal of Applied Ecology, 49(3), pp. 706-714. doi: 10.1111/j.1365-2664.2012.02130.x. 
Jørgensen, P. S. et al. (2018) 'Antibiotic and pesticide susceptibility and the Anthropocene operating space', Nature Sustainability, 1(11), pp. 632-641. doi: 10.1038/s41893-018-0164-3.

Josefsson, J. et al. (2017) 'Effects of a coordinated farmland bird conservation project on farmers' intentions to implement nature conservation practices - Evidence from the Swedish Volunteer \& Farmer Alliance', Journal of Environmental Management, 187, pp. 8-15. doi: 10.1016/j.jenvman.2016.11.026.

Juma, C. (2016) Innovation and Its Enemies: Why People Resist New Technologies. Oxford, UK: Oxford University Press (OUP Catalogue). Available at: https://ideas.repec.org/b/oxp/obooks/9780190467036.html.

Kallis, G. and Norgaard, R. B. (2010) 'Coevolutionary ecological economics', Ecological Economics, 69, pp. 690699. doi: 10.1016/j.ecolecon.2009.09.017.

Karp, D. S. et al. (2018) 'Crop pests and predators exhibit inconsistent responses to surrounding landscape composition', Proceedings of the National Academy of Sciences of the United States of America, 115(33), pp. E7863-E7870. doi: 10.1073/pnas.1800042115.

Kathage, J. et al. (2018) 'The impact of restrictions on neonicotinoid and fipronil insecticides on pest management in maize, oilseed rape and sunflower in eight European Union regions', Pest Management Science, 74(1), pp. 88-99. doi: 10.1002/ps.4715.

Kennedy, C. M. et al. (2013) 'A global quantitative synthesis of local and landscape effects on wild bee pollinators in agroecosystems', Ecology Letters, 16(5), pp. 584-599. doi: 10.1111/ele.12082.

Khan, M. and Damalas, C. A. (2015) 'Factors preventing the adoption of alternatives to chemical pest control among Pakistani cotton farmers', International Journal of Pest Management, 61(1), pp. 9-16. doi: 10.1080/09670874.2014.984257.

Kim, K. H., Kabir, E. and Jahan, S. A. (2017) 'Exposure to pesticides and the associated human health effects', Science of the Total Environment, 575, pp. 525-535. doi: 10.1016/j.scitotenv.2016.09.009.

Kinzig, A. P. et al. (2006) 'Resilience and regime shifts: assesing cascading effects', Ecology and Society, 11, pp. 20-43. http://www.ecologyandso ciety.org/vol11/iss1/art20/.

Kleijn, D. et al. (2006) 'Mixed biodiversity benefits of agri-environment schemes in five European countries', Ecology Letters, 9(3), pp. 243-254. doi: 10.1111/j.1461-0248.2005.00869.x.

Kleijn, D. et al. (2019) 'Ecological intensification: bridging the gap between science and practice', Trends in Ecology and Evolution, 34(2), pp. 154-166. doi: 10.1016/j.tree.2018.11.002.

Kline, D. (2001) 'Positive feedback, lock-in, and environmental policy', Policy Sciences, 34, pp. 95-107. doi: 10.1023/A:1010357309367.

Kline, R. B. (2005) Principles and practice of structural equation modeling. 2nd ed., Methodology in the social sciences. New York: The Guilford Press.

van Klink, R. et al. (2020) 'Meta-analysis reveals declines in terrestrial but increases in freshwater insect abundances', Science, 368(6489), pp. 417-420. doi: 10.1126/science.aax9931.

Kniss, A. R. (2017) 'Long-term trends in the intensity and relative toxicity of herbicide use', Nature Communications, 8, p. 14865. doi: 10.1038/ncomms14865.

Krauss, J., Gallenberger, I. and Steffan-Dewenter, I. (2011) 'Decreased functional diversity and biological pest control in conventional compared to organic crop fields', PLOS ONE, 6(5), pp. 1-9. doi: 10.1371/journal.pone.0019502.

Kremen, C. and Merenlender, A. M. (2018) 'Landscapes that work for biodiversity and people', Science, 362(6412). doi: 10.1126/science.aau6020.

Kremen, C., Williams, N. M. and Thorp, R. W. (2002) 'Crop pollination from native bees at risk from agricultural intensification.', Proceedings of the National Academy of Sciences of the United States of America, 99(26), pp. 16812-16816. doi: 10.1073/pnas.262413599.

Krupke, C. H. et al. (2017) 'Planting of neonicotinoid-treated maize poses risks for honey bees and other nontarget organisms over a wide area without consistent crop yield benefit', Journal of Applied Ecology, 54, pp. 1449-1458. doi: 10.1111/1365-2664.12924.

Kudsk, P., Jørgensen, L. N. and Ørum, J. E. (2018) 'Pesticide Load-A new Danish pesticide risk indicator with multiple applications', Land Use Policy, 70, pp. 384-393. doi: 10.1016/j.landusepol.2017.11.010.

Labarthe, P. (2009) 'Extension services and multifunctional agriculture. Lessons learnt from the French and Dutch contexts and approaches', Journal of Environmental Management, 90, pp. S193-S202. doi: 10.1016/j.jenvman.2008.11.021.

LaCanne, C. E. and Lundgren, J. G. (2018) 'Regenerative agriculture: Merging farming and natural resource conservation profitably', PeerJ, 2, pp. 1-12. doi: 10.7717/peerj.4428. 
Lamichhane, J. R. et al. (2016) 'Toward a Reduced Reliance on Conventional Pesticides in European Agriculture', Plant Disease, 100(1), pp. 10-24. doi: https://doi.org/10.1094/PDIS-05-15-0574-FE.

Lamichhane, J. R. et al. (2017) 'Identifying obstacles and ranking common biological control research priorities for Europe to manage most economically important pests in arable, vegetable and perennial crops', Pest Management Science, 73(1), pp. 14-21. doi: 10.1002/ps.4423.

Lamine, C. et al. (2010) 'Reducing the dependence on pesticides: a matter of transitions within the whole agrifood system', in Transitions towards sustainable agriculture: from farmers to agro-food system. Vienna, Austria: 9th European IFSA Symposium, pp. 1943-1954.

Lamine, C. (2011) 'Transition pathways towards a robust ecologization of agriculture and the need for system redesign. Cases from organic farming and IPM', Journal of Rural Studies, 27, pp. 209-219. doi: 10.1016/j.jrurstud.2011.02.001.

Lamprinopoulou, C. et al. (2014) 'Application of an integrated systemic framework for analysing agricultural innovation systems and informing innovation policies: Comparing the Dutch and Scottish agrifood sectors', Agricultural Systems, 129, pp. 40-54. doi: 10.1016/j.agsy.2014.05.001.

Landis, D. A., Wratten, S. D. and Gurr, G. M. (2000) 'Habitat management to conserve natural enemies of arthropod pests in agriculture', Annual Review of Entomology, 45, pp. 175-201.

Läpple, D. and Kelley, H. (2013) 'Understanding the uptake of organic farming: Accounting for heterogeneities among Irish farmers', Ecological Economics, 88, pp. 11-19. doi: 10.1016/j.ecolecon.2012.12.025.

Läpple, D. and Rensburg, T. Van (2011) 'Adoption of organic farming: Are there differences between early and late adoption?', Ecological Economics, 70(7), pp. 1406-1414. doi: 10.1016/j.ecolecon.2011.03.002.

Larsen, A. E. and Noack, F. (2020) 'Impact of local and landscape complexity on the stability of field-level pest control', Nature Sustainability. doi: 10.1038/s41893-020-00637-8.

Larsen, A. E., Patton, M. and Martin, E. A. (2019) 'High highs and low lows: Elucidating striking seasonal variability in pesticide use and its environmental implications', Science of the Total Environment, 651, pp. 828-837. doi: 10.1016/j.scitotenv.2018.09.206.

Lechenet, M. et al. (2014) 'Reconciling Pesticide Reduction with Economic and Environmental Sustainability in Arable Farming', PLoS ONE., 9(6), p. e97922. doi: 10.1371/journal.pone.0097922.

Lechenet, M. et al. (2016) 'Profiling farming management strategies with contrasting pesticide use in France', Agricultural Systems, 149, pp. 40-53. doi: 10.1016/j.agsy.2016.08.005.

Lechenet, M. et al. (2017) 'Reducing pesticide use while preserving crop productivity and profitability on arable farms', Nature Plants, 17008, pp. 1-6. doi: 10.1038/nplants.2017.8.

Leendertse, P. C. et al. (2019) Tussenevaluatie Gezonde Groei Duurzame Oogst (GGDO): Geïntegreerde gewasbescherming. Culemborg, the Netherlands.

Lefebvre, M. et al. (2016) 'The impact of landscape composition on the occurrence of a canopy dwelling spider depends on orchard management', Agriculture, Ecosystems and Environment, 215, pp. 20-29. doi: 10.1016/j.agee.2015.09.003.

van Lenteren, J. C. et al. (2018) 'Biological control using invertebrates and microorganisms: plenty of new opportunities', BioControl, 63(1), pp. 39-59. doi: 10.1007/s10526-017-9801-4.

Letourneau, D.K. (2012) 'Integrated Pest Management - Outbreaks Prevented, Delayed, or Facilitated?', in Barbosa, P., Letourneau, Deborah K., and Agrawal, A. A. (eds) Insect Outbreaks Revisited. Hoboken, New Jersey, USA: Blackwell Publishing Ltd, pp. 371-394.

Letourneau, D. K., Bothwell Allen, S. G. and Stireman, J. O. (2012) 'Perennial habitat fragments, parasitoid diversity and parasitism in ephemeral crops', Journal of Applied Ecology, 49(6), pp. 1405-1416. doi: 10.1111/1365-2664.12001.

Lewis, W. J. et al. (1997) 'A total system approach to sustainable pest management', Proceedings of the National Academy of Sciences of the United States of America, 94(23), pp. 12243-12248. doi: 10.1073/pnas.94.23.12243.

Li, P. et al. (2020) 'The relative importance of green infrastructure as refuge habitat for pollinators increases with local land-use intensity', Journal of Applied Ecology, pp. 1-10. doi: 10.1111/1365-2664.13658.

Lichtenberg, E. M. et al. (2017) 'A global synthesis of the effects of diversified farming systems on arthropod diversity within fields and across agricultural landscapes', Global Change Biology, 23(11), pp. 4946-4957. doi: 10.1111/gcb.13714.

Liebowitz, S. J. and Margolis, S. E. (1995) 'Path dependence, lock-in, and history', The Journal of Law, Economics \& Organization, 11, pp. 205-226. Available at: https://www.utdallas.edu/ liebowit/paths.html.

Liu, B. et al. (2016) 'Landscape diversity enhances parasitism of cotton bollworm (Helicoverpa armigera) eggs by Trichogramma chilonis in cotton', Biological Control, 93, pp. 15-23. doi: 10.1016/j.biocontrol.2015.11.004. 
Liu, Y., Pan, X. and Li, J. (2015) 'A 1961-2010 record of fertilizer use, pesticide application and cereal yields: a review', Agronomy for Sustainable Development, 35, pp. 83-93. doi: 10.1007/s13593-014-0259-9.

LNV (2020) Artikel 71: Wet gewasbeschermingsmiddelen en biociden. https://wetten.overheid.nl/jci1.3:c:BWBR0021670\&hoofdstuk=6\&paragraaf=1\&artikel=71\&z=2 020-01-01\&g=2020-01-01.

Lohr, L. and Park, T. A. (2002) 'Choice of insect management portfolios by organic farmers: Lessons and comparative analysis', Ecological Economics, 43(1), pp. 87-99. doi: 10.1016/S09218009(02)00184-2.

Lokhorst, A. M. et al. (2011) 'What's in it for Me? motivational differences between farmers' subsidised and non-subsidised conservation practices', Applied Psychology, 60(3), pp. 337-353. doi: 10.1111/j.1464-0597.2011.00438.x.

Lundgren, J. G. and Fausti, S. W. (2015) 'Trading biodiversity for pest problems', Science Advances, 1(6), pp. 1-6. doi: 10.1126/sciadv.1500558.

Macfadyen, S. et al. (2015) 'The role of food retailers in improving resilience in global food supply', Global Food Security, 7, pp. 1-8. doi: 10.1016/j.gfs.2016.01.001.

MacMillan, T. and Benton, T. (2014) 'Engage farmers in research', Nature, 509, pp. 25-27. doi: $10.1038 / 509025 a$.

Magrini, M. B. et al. (2016) 'Why are grain-legumes rarely present in cropping systems despite their environmental and nutritional benefits? Analyzing lock-in in the French agrifood system.', Ecological Economics, 126, pp. 152-162. doi: 10.1016/j.ecolecon.2016.03.024.

Mancini, F., Woodcock, B. A. and Isaac, N. J. B. (2019) 'Agrochemicals in the wild: Identifying links between pesticide use and declines of nontarget organisms', Current Opinion in Environmental Science and Health, 11, pp. 53-58. doi: 10.1016/j.coesh.2019.07.003.

Maréchal, K., Aubaret-Joachain, H. and Ledant, J.-P. (2008) The influence of economics on agricultural systems: an evolutionary and ecological perspective. 08/028. Available at: http://hdl.handle.net/2268/208733.

Marshall, E. J. P. and Moonen, A. C. (2002) 'Field margins in northern Europe: Their functions and interactions with agriculture', Agriculture, Ecosystems and Environment, 89(1-2), pp. 5-21. doi: 10.1016/S0167-8809(01)00315-2.

Martin, A. E. et al. (2020) 'Effects of farmland heterogeneity on biodiversity are similar to-or even larger than-the effects of farming practices', Agriculture, Ecosystems and Environment, 288, p. 106698. doi: $10.1016 /$ j.agee.2019.106698.

Martin, E. A. et al. (2019) 'The interplay of landscape composition and configuration: new pathways to manage functional biodiversity and agroecosystem services across Europe', Ecology Letters, 22(7), pp. 1083-1094. doi: 10.1111/ele.13265.

Martínez-Sastre, R. et al. (2020) 'Farmers' perceptions and knowledge of natural enemies as providers of biological control in cider apple orchards', Journal of Environmental Management, 266. doi: 10.1016/j.jenvman.2020.110589.

Matteson, P. C. (2000) 'Insect pest management in tropical asian irrigated rice', Annual Review of Entomology, (45), pp. 549-574. doi: 0066-4170/00/0107-0549.

McEachan, R. et al. (2016) 'Meta-Analysis of the Reasoned Action Approach (RAA) to Understanding Health Behaviors', Annals of Behavioral Medicine. Annals of Behavioral Medicine, 50(4), pp. 592-612. doi: 10.1007/s12160-016-9798-4.

McHugh, N. M. et al. (2020) 'The contribution of semi-natural habitats to biological control is dependent on sentinel prey type', Journal of Applied Ecology, pp. 1-12. doi: 10.1111/1365-2664.13596.

Meehan, T. D. et al. (2011) 'Agricultural landscape simplification and insecticide use in the Midwestern United States.', Proceedings of the National Academy of Sciences of the United States of America, 108, pp. 11500-11505. doi: 10.1073/pnas.1100751108.

Meehan, T. D. et al. (2013) 'Ecosystem-service tradeoffs associated with switching from annual to perennial energy crops in Riparian zones of the US Midwest', PLoS ONE, 8(11), pp. 1-13. doi: 10.1371/journal.pone.0080093.

Meehan, T. D. and Gratton, C. (2016) 'A landscape view of agricultural insecticide use across the conterminous US from 1997 through 2012', PLoS ONE, 11(11), pp. 1-17. doi: 10.1371/journal.pone.0166724.

Meek, D. (2016) 'The cultural politics of the agroecological transition', Agriculture and Human Values. Springer Netherlands, 33(2), pp. 275-290. doi: 10.1007/s10460-015-9605-z.

Mills, J. et al. (2017) 'Engaging farmers in environmental management through a better understanding of behaviour', Agriculture and Human Values, 34(2), pp. 283-299. doi: 10.1007/s10460-016-9705-4. 
Milner, A. M. and Boyd, I. L. (2017) 'Toward pesticidovigilance', Science, 357(6357), pp. 1232-1234. doi: $10.1126 /$ science.aan2683.

Ministerie van Economische Zaken (2013) 'Gezonde Groei, Duurzame Oogst Tweede nota duurzame gewasbescherming', p. 46.

Mitchell, E. A. D. et al. (2017) 'A worldwide survey of neonicotinoids in honey.', Science, 111(6359), pp. 109111. doi: $10.1126 /$ science.aan 3684.

Mogren, C. L. and Lundgren, J. G. (2016) 'Neonicotinoid-contaminated pollinator strips adjacent to cropland reduce honey bee nutritional status', Scientific Reports, 6, p. 29608. doi: 10.1038/srep29608.

Möhring, N. et al. (2020) 'Pathways for advancing pesticide policies', Nature Food, 1(9), pp. 535-540. doi: 10.1038/s43016-020-00141-4.

Möhring, N., Gaba, S. and Finger, R. (2019) 'Quantity based indicators fail to identify extreme pesticide risks', Science of the Total Environment, 646, pp. 503-523. doi: 10.1016/j.scitotenv.2018.07.287.

Morrissey, J. E., Mirosa, M. and Abbott, M. (2014) 'Identifying transition capacity for agri-food regimes: application of the multi-level perspective for strategic mapping', Journal of Environmental Policy \& Planning, 16, pp. 281-301. doi: 10.1080/1523908X.2013.845521.

Mota-Sanchez, D. and Wise, J. C. (2020) The Arthropod Pesticide Resistance Database, Michigan State University. Available at: http://www.pesticideresistance.org (Accessed: 14 February 2020).

Mourtzinis, S. et al. (2019) 'Neonicotinoid seed treatments of soybean provide negligible benefits to US farmers', Scientific Reports, 9(11207), pp. 1-7. doi: 10.1038/s41598-019-47442-8.

Muneret, L. et al. (2018) 'Evidence that organic farming promotes pest control', Nature Sustainability, 1(7), pp. 361-368. doi: 10.1038/s41893-018-0102-4.

Muneret, L., Auriol, A., Thiéry, D., et al. (2019) 'Organic farming at local and landscape scales fosters biological pest control in vineyards', Ecological Applications, 29(1), pp. 1-15. doi: 10.1002/eap.1818.

Muneret, L., Auriol, A., Bonnard, O., et al. (2019) 'Organic farming expansion drives natural enemy abundance but not diversity in vineyard-dominated landscapes', Ecology and Evolution, 9(23), pp. 1353213542. doi: 10.1002/ece3.5810.

Murray, D. L. (1994) Cultivating crisis: the human cost of pesticides in Latin America. University of Texas Press.

Myers, C. and Hill, E. (2014) Benefits of neonicotinoid seed treatments to soybean production. Washington D.C. USA: United States Environmental Protection Agency.

Naranjo, S. E. and Ellsworth, P. C. (2009) 'Fifty years of the integrated control concept: Moving the model and implementation forward in Arizona', Pest Management Science, 65(12), pp. 1267-1286. doi: $10.1002 /$ ps.1861.

Nauen, R. and Denholm, I. (2005) 'Resistance of insect pests to neonicotinoid insecticides: current status and future prospects', Archives of Insect Biochemistry and Physiology, 58(4), pp. 200-215. doi: 10.1002/arch.20043.

Norgaard, R. B. (1976) 'The economics of improving pesticide use', Annual Review of Entomology, 21, pp. 4560. Available at: http://www.annualreviews.org/doi/pdf/10.1146/annurev.en.21.010176.000401.

Oerke, E.-C. (2006) 'Crop losses to pests', The Journal of Agricultural Science, 144(01), p. 31. doi: $10.1017 /$ S0021859605005708.

Ohnesorg, W. J., Johnson, K. D. and O'Neal, M. E. (2009) 'Impact of reduced-risk insecticides on soybean aphid and associated natural enemies', Journal of Economic Entomology, 102(5), pp. 1816-1826. doi: 10.1603/029.102.0512.

Oka, I. N. (1991) 'Success and challenges of the Indonesia national Integrated Pest Management Program in the rice-based cropping system', Crop Protection, 10, pp. 163-165. doi: 10.1016/02612194(91)90037-R.

Oka, I. N. (2003) 'Integrated Pest Management in Indonesia: IPM by Farmers', in Maredia, K. M., Dakouo, D., and Mota-Sanchez, D. (eds) Integrated pest management in the global arena. CAB International, pp. 223-237.

Oreskes, N. and Conway, E. M. (2011) Merchants of doubt: How a handful of scientists obscured the truth on issues from tobacco smoke to global warming. London, UK: Bloomsbury Publishing USA.

Orr, A. (2003) 'Integrated pest management for resource-poor African farmers: Is the Emperor naked?', World Development, 31(5), pp. 831-845. doi: 10.1016/S0305-750X(03)00015-9.

Oskam, A. J. et al. (1992) Pesticide use and pesticide policy in the Netherlands: an economic analysis of regulatory levies in agriculture, Wageningen economic studies. Wageningen, the Netherlands: Wageningen Agricultural University. Available at: http://en.scientificcommons.org/1076370\%5Cnpapers://62b5880a-9dca-4c73-a7b568e18ca4833e/Paper/p24983. 
Padilla, M. A. and Divers, J. (2016) 'A Comparison of Composite Reliability Estimators: Coefficient Omega Confidence Intervals in the Current Literature', Educational and Psychological Measurement, 76(3), pp. 436-453. doi: 10.1177/0013164415593776.

Pante, E. and Simon-Bouhet, B. (2013) 'marmap: A Package for Importing, Plotting and Analyzing Bathymetric and Topographic Data in R', PLOS ONE, 8(9), pp. 6-9. doi: 10.1371/journal.pone.0073051.

Pardey, P. G., Alston, J. M. and Ruttan, V. W. (2010) 'The economics of innovation and technical change in agriculture', in Handbook of the Economics of Innovation. Amsterdam, the Netherlands: Elsevier B.V., pp. 939-984. doi: 10.1016/S0169-7218(10)02006-X.

Parry, S. (2017) 'Fit Statistics commonly reported for CFA and SEM', Cornell Statistical Consulting Unit: Cornell University. Available at: https://www.cscu.cornell.edu/news/Handouts/SEM_fit.pdf.

Parsa, S. et al. (2014) 'Obstacles to integrated pest management adoption in developing countries', Proceedings of the National Academy of Sciences of the United States of America, 111(10), pp. 38893894. doi: 10.1073/pnas.1312693111.

Pavlis, E. S. et al. (2016) 'Patterns of agri-environmental scheme participation in Europe: Indicative trends from selected case studies', Land Use Policy, 57, pp. 800-812. doi: 10.1016/j.landusepol.2015.09.024.

PDOK (2018) Dutch Ministry of Economics and Climate, Basisregistratie Gewaspercelen. Available at: https://www.pdok.nl/introductie/-/article/basisregistratie-gewaspercelen-brp- (Accessed: 1 November 2018).

Pedersen, A. B. et al. (2012) 'Optimising the effect of policy instruments: A study of farmers' decision rationales and how they match the incentives in Danish pesticide policy', Journal of Environmental Planning and Management, 55(8), pp. 1094-1110. doi: 10.1080/09640568.2011.636568.

Perkins, R. (2003) 'Technological "lock-in".', in Neumayer, E. (ed.) Online Encyclopaedia of Ecological Economics. The International Society for Ecological Economics, pp. 1-8. Available at: isecoeco.org/pdf/techlkin.pdf.

Perry, V. and Davenport, M. A. (2020) 'An inductive framework of self-efficacy to understand and support farmers in conservation agriculture', Journal of Soil and Water Conservation, 75(2), pp. 198-208. doi: $10.2489 /$ jswc.75.2.198.

Pfiffner, L. et al. (2009) 'Impact of wildflower strips on biological control of cabbage lepidopterans', Agriculture, Ecosystems and Environment, 129(1-3), pp. 310-314. doi: 10.1016/j.agee.2008.10.003.

Pimentel, D. et al. (1977) 'Pesticides, Insects in Foods, and Cosmetic Standards', BioScience, 27(3), pp. 178185. doi: $10.2307 / 1297579$.

Pimentel, D. (2009) 'Pesticides and pest control', in Peshin, R. and Dhawan, A. K. (eds) Integrated pest management: innovation-development process. Dordrecht: Springer Netherlands, pp. 83-88.

Pisa, L. et al. (2017) 'An update of the Worldwide Integrated Assessment (WIA) on systemic insecticides. Part 2: impacts on organisms and ecosystems', Environmental Science and Pollution Research. doi: 10.1007/s11356-017-0341-3.

Pisa, L. W. et al. (2015) 'Effects of neonicotinoids and fipronil on non-target invertebrates', Environmental Science and Pollution Research, 22, pp. 68-102. doi: 10.1007/s11356-014-3471-x.

Popp, J., Peto, K. and Nagy, J. (2013) 'Pesticide productivity and food security. A review', Agronomy for Sustainable Development, 33(1), pp. 243-255. doi: 10.1007/s13593-012-0105-x.

Pretty, J. (2005) The Pesticide Detox. Edited by J. Pretty. Earthscan.

Pretty, J. et al. (2018) 'Global assessment of agricultural system redesign for sustainable intensification', Nature Sustainability, 1(8), pp. 441-446. doi: 10.1038/s41893-018-0114-0.

Pretty, J. (2018) 'Intensification for redesigned and sustainable agricultural systems', Science, 362(6417), p. eaav0294. doi: 10.1126/science.aav0294.

Pretty, J. and Bharucha, Z. (2015) 'Integrated Pest Management for Sustainable Intensification of Agriculture in Asia and Africa', Insects, 6(1), pp. 152-182. doi: 10.3390/insects6010152.

Purtauf, T. et al. (2005) 'Landscape context of organic and conventional farms: Influences on carabid beetle diversity', Agriculture, Ecosystems and Environment, 108(2), pp. 165-174. doi: 10.1016/j.agee.2005.01.005.

Pywell, R. F. et al. (2015) 'Wildlife-friendly farming increases crop yield: Evidence for ecological intensification', Proceedings of the Royal Society B: Biological Sciences, 282(1816). doi: 10.1098/rspb.2015.1740.

R Development Core Team (2019) R: A language and environment for statistical computing. Vienna, Austria: R Foundation for Statistical Computing. Available at: http://www.r-project.org. 
Reddy, S. M. W. et al. (2017) 'Advancing Conservation by Understanding and Influencing Human Behavior', Conservation Letters, 10(2), pp. 248-256. doi: 10.1111/conl.12252.

Reus, J. A. W. A. and Leendertse, P. C. (2000) 'The environmental yardstick for pesticides: A practical indicator used in the Netherlands', Crop Protection, 19(8-10), pp. 637-641. doi: 10.1016/S02612194(00)00084-3.

Ricci, B. et al. (2019) 'Local pesticide use intensity conditions landscape effects on biological pest control', Proceedings of the Royal Society B: Biological Sciences, 286(1904). doi: 10.1098/rspb.2018.2898.

Rodriguez, J. M. et al. (2009) 'Barriers to adoption of sustainable agriculture practices: Change agent perspectives', Renewable Agriculture and Food Systems, 24(1), pp. 60-71. doi: $10.1017 / \mathrm{S} 1742170508002421$.

Roschewitz, I. et al. (2005) 'The influence of landscape context and farming practices on parasitism of cereal aphids', Agriculture, Ecosystems and Environment, 108(3), pp. 218-227. doi: 10.1016/j.agee.2005.02.005.

Rosseel, Y. (2012) 'lavaan: An R Package for Structural Equation Modeling', Journal of Statistical Software, 48(2), pp. 1-36. doi: 10.18637/jss.v048.i02.

Roubos, C. R., Rodriguez-Saona, C. and Isaacs, R. (2014) 'Mitigating the effects of insecticides on arthropod biological control at field and landscape scales', Biological Control., 75, pp. 28-38. doi: 10.1016/j.biocontrol.2014.01.006.

Roush, R. T. and Tabashnik, B. E. (1990) Pesticide Resistance in Arthropods. Edited by R. Roush and Bruce E. Tabashnik. New York: Chapman \& Hall. doi: 10.1007/978-1-4684-6429-0.

Rundlöf, M. et al. (2015) 'Seed coating with a neonicotinoid insecticide negatively affects wild bees', Nature, 521, pp. 77-80. doi: 10.1038/nature14420.

Rusch, A. et al. (2010) Chapter Six - Biological control of insect pests in agroecosystems. Effects of crop management, farming systems, and seminatural habitats at the landscape scale: A review, in Sparks, D.L. (ed.) Advances in Agronomy. Academic Press (Advances in Agronomy), pp. 219-259. doi: 10.1016/B978-0-12-385040-9.00006-2.

Rusch, A. et al. (2016) 'Agricultural landscape simplification reduces natural pest control: A quantitative synthesis', Agriculture, Ecosystems and Environment, 221, pp. 198-204. doi: 10.1016/j.agee.2016.01.039.

Ruttan, V. W. (1996) 'Induced innovation and path dependence: A reassessment with respect to agricultural development and the environment', Technological Forecasting and Social Change, 53(1), pp. 41-59. doi: 10.1016/0040-1625(96)00055-8.

Sánchez-Bayo, F. and Wyckhuys, K. A. G. (2019) 'Worldwide decline of the entomofauna: A review of its drivers', Biological Conservation, 232, pp. 8-27. doi: 10.1016/j.biocon.2019.01.020.

Satorra, A. and Bentler, P. M. (1994) 'Corrections to test statistics and standard errors in covariance structure analysis.', in Latent variables analysis: Applications for developmental research. Thousand Oaks, CA, US: Sage Publications, Inc, pp. 399-419.

Savary, S. et al. (2012) 'A review of principles for sustainable pest management in rice', Crop Protection, 32, pp. 54-63. doi: 10.1016/j.cropro.2011.10.012.

Schellhorn, N. A. et al. (2008) 'Managing ecosystem services in broadacre landscapes: What are the appropriate spatial scales?', Australian Journal of Experimental Agriculture, 48(12), pp. 1549-1559. doi: 10.1071/EA08112.

Schellhorn, N. A., Bianchi, F. J. J. A. and Hsu, C. L. (2014) 'Movement of Entomophagous Arthropods in Agricultural Landscapes: Links to Pest Suppression', Annual Review of Entomology, 59(1), pp. 559581. doi: 10.1146/annurev-ento-011613-161952.

Schmidt, M. H. et al. (2005) 'Differential effects of landscape and management on diversity and density of ground-dwelling farmland spiders', Journal of Applied Ecology, 42(2), pp. 281-287. doi: 10.1111/j.1365-2664.2005.01014.x.

Schmidt, N. P., O'Neal, M. E. and Dixon, P. M. (2008) 'Aphidophagous predators in Iowa soybean: A community comparison across multiple years and sampling methods', Annals of the Entomological Society of America, 101(2), pp. 341-350. doi: 10.1603/0013-8746(2008)101[341:APIISA]2.0.C0;2.

Schmitz, J., Hahn, M. and Brühl, C. A. (2014) 'Agrochemicals in field margins - An experimental field study to assess the impacts of pesticides and fertilizers on a natural plant community', Agriculture, Ecosystems and Environment, 193, pp. 60-69. doi: 10.1016/j.agee.2014.04.025.

Schut, M. et al. (2014) 'Systems approaches to innovation in crop protection. A systematic literature review', Crop Protection, 56, pp. 98-108. doi: 10.1016/j.cropro.2013.11.017.

Seagraves, M. P. and Lundgren, J. G. (2012) 'Effects of neonicitinoid seed treatments on soybean aphid and its natural enemies', Journal of Pest Science, 85, pp. 125-132. doi: 10.1007/s10340-011-0374-1. 
Seibold, S. et al. (2019) 'Arthropod decline in grasslands and forests is associated with landscape-level drivers', Nature, 574(7780), pp. 671-674. doi: 10.1038/s41586-019-1684-3.

Seto, K. C. et al. (2016) 'Carbon Lock-In: Types, Causes, and Policy Implications', Annual Review of Environment and Resources, 41, pp. 425-452. doi: 10.1146/annurev-environ-110615-085934.

Settle, W. H. et al. (1996) 'Managing tropical rice pests through conservation of generalist natural enemies and alternative prey', Ecology, 77, pp. 1975-1988.

Sherman, J. and Gent, D. H. (2014) 'Concepts of sustainability, motivations for pest management approaches, and implications for communicating change', Plant Disease, 98(8), pp. 1024-1035. doi: 10.1094/PDIS-03-14-0313-FE.

Sherratt, T. N. and Jepson, P. C. (1993) 'A metapopulation approach to modelling the long-term impact of pesticides on invertebrates', Journal of Applied Ecology, 30(4), pp. 696-705.

Siebert, R., Toogood, M. and Knierim, A. (2006) 'Factors affecting european farmers' participation in biodiversity policies', Sociologia Ruralis, 46(4), pp. 318-340. doi: 10.1111/j.14679523.2006.00420.x.

Sigsgaard, L. (2000) 'Early season natural biological control of insect pests in rice by spiders - and some factors in the management of the cropping system that may affect this control', European Arachnology, 2000, pp. 57-64.

Simon-Delso, N. et al. (2015) 'Systemic insecticides (neonicotinoids and fipronil): Trends, uses, mode of action and metabolites', Environmental Science and Pollution Research, 22, pp. 5-34. doi: $10.1007 / \mathrm{s} 11356-014-3470-\mathrm{y}$.

Sirami, C. et al. (2019) 'Increasing crop heterogeneity enhances multitrophic diversity across agricultural regions', Proceedings of the National Academy of Sciences of the United States of America, 116(33), pp. 16442-16447. doi: 10.1073/pnas.1906419116.

Sjerps, R. M. A. et al. (2019) 'Occurrence of pesticides in Dutch drinking water sources', Chemosphere, 235, pp. 510-518. doi: 10.1016/j.chemosphere.2019.06.207.

Skevas, T. and Oude Lansink, A. (2014) 'Reducing Pesticide Use and Pesticide Impact by Productivity Growth: The Case of Dutch Arable Farming', Journal of Agricultural Economics, 65(1), pp. 191-211. doi: 10.1111/1477-9552.12037.

Skevas, T., Stefanou, S. E. and Oude Lansink, A. (2012) 'Can economic incentives encourage actual reductions in pesticide use and environmental spillovers?', Agricultural Economics, 43(3), pp. 267-276. doi: 10.1111/j.1574-0862.2012.00581.x.

van der Sluijs, J. P. et al. (2015) 'Conclusions of the Worldwide Integrated Assessment on the risks of neonicotinoids and fipronil to biodiversity and ecosystem functioning', Environmental Science and Pollution Research, 22(1), pp. 148-154. doi: 10.1007/s11356-014-3229-5.

Sok, J. et al. (2015) 'Farmers' beliefs and voluntary vaccination schemes: Bluetongue in Dutch dairy cattle', Food Policy, 57, pp. 40-49. doi: 10.1016/j.foodpol.2015.09.006.

Sok, J. et al. (2020) 'Farmer Behaviour as Reasoned Action: A Critical Review of Research With the Theory of Planned Behaviour', Journal of Agricultural Economics. pp. 1477-9552.12408 doi: 10.1111/14779552.12408.

Sok, J. and Fischer, E. A. J. (2019) 'Farmers' heterogeneous motives, voluntary vaccination and disease spread: an agent-based model', European Review of Agricultural Economics, pp. 1-22. doi: 10.1093/erae/jbz041.

Sparks, T. C. and Lorsbach, B. A. (2017) 'Agrochemical discovery - building the next generation of insect control agents', in Gross, A. D., Ozoe, Y., and Coats, J. R. (eds) Advances in Agrochemicals: Ion Channels and G Protein-Coupled Receptors (GPCRs) as Targets for Pest Control. Washington, DC: American Chemical Society, pp. 1-17. doi: 10.1021/bk-2017-1264.ch001.

Sponsler, D. B. et al. (2019) 'Pesticides and pollinators: A socioecological synthesis', Science of the Total Environment, 662, pp. 1012-1027. doi: 10.1016/j.scitotenv.2019.01.016.

Sporenberg, P., Verstand, D. and Beerling, E. (2019) Tussenevaluatie van de nota Gezonde Groei Duurzame Oogst. Wageningen, the Netherlands. doi: https://doi.org/10.18174/478387.

Spromberg, J. A., John, B. M. and Landis, W. G. (1998) 'Metapopulation dynamics: Indirect effects and multiple distinct outcomes in ecological risk assessment', Environmental Toxicology and Chemistry: An International Journal, 17(8), pp. 1640-1649. doi: 10.1002/etc.5620170828.

Stallman, H. R. and James, H. S. (2015) 'Determinants affecting farmers' willingness to cooperate to control pests', Ecological Economics., 117, pp. 182-192. doi: 10.1016/j.ecolecon.2015.07.006.

Stam, P. A., Abdelrahman, A. A. and Munir, B. (1994) 'Comparisons of control action thresholds for Heliothis armigera, Bemisia tabaci and Aphis gossypii on cotton in the Sudan Gezira and Rahad regions', Crop Protection, 13, pp. 503-512. 
State of Maryland (2016) Neonicotinoid pesticides - restrictions on sales and use (Pollinator protection act of 2016). General Assembly of Maryland. Available at:

http://mgaleg.maryland.gov/webmga/frmMain.aspx?id=sb0198\&stab=01\&pid=billpage\&tab=su bject3\&ys=2016RS.

Statline (2019) Use of crop protection products in agriculure (Dutch: Gebruik gewasbeschermingsmiddelen in de landbouw), Statistics Netherlands' database (CBS). Available at:

https://opendata.cbs.nl/statline/\#/CBS/nl/ (Accessed: 26 August 2019).

Stephens, C. S. (1984) 'Ecological upset and recuperation of natural control of insect pests in some Costa Rican banana plantations', Turrialba, 34(1), pp. 101-105.

Stilmant, D. et al. (2008) 'Host specialization in habitat specialists and generalists', Oecologia, 156(4), pp. 905912. doi: $10.1007 / \mathrm{s} 00442-008-1036-8$.

Swezey, S. L., Murray, D. L. and Daxl, R. G. (1986) 'Nicaragua's revolution in pesticide policy', Environment: Science and Policy for Sustainable Development, 28, pp. 6-36. doi: 10.1080/00139157.1986.9929866.

Tabashnik, B. E., Brévault, T. and Carrière, Y. (2013) 'Insect resistance to Bt crops: Lessons from the first billion acres', Nature Biotechnology, 31(6), pp. 510-521. doi: 10.1038/nbt.2597.

Tamburini, G. et al. (2020) 'Species traits elucidate crop pest response to landscape composition: a global analysis', Proceedings. Biological sciences, 287(1937), p. 20202116. doi: 10.1098/rspb.2020.2116.

Thies, C. et al. (2011) 'The relationship between agricultural intensification and biological control: Experimental tests across Europe', Ecological Applications, 21(6), pp. 2187-2196. doi: 10.1890/10-0929.1.

Thies, C., Steffan-Dewenter, I. and Tscharntke, T. (2003) 'Effects of landscape context on herbivory and parasitism at different spatial scales', Oikos, 101(1), pp. 18-25. doi: 10.1034/j.16000706.2003.12567.x.

Thorburn, C. (2015) 'The rise and demise of integrated pest management in rice in Indonesia', Insects, 6, pp. 381-408. doi: 10.3390/insects6020381.

Thrupp, L. A. (1988) 'Pesticides and Policies: Approaches to Pest-Control Dilemmas in Nicaragua and Costa Rica', Latin American Perspectives, 15(4), pp. 37-70. Available at: https://www.jstor.org/stable/2633638.

Thrupp, L. A. (1990) 'Entrapment and escape from fruitless insecticide use', International Journal of Environmental Studies, 36, pp. 173-189.

Tiktak, A. et al. (2019) Geïntegreerde gewasbescherming nader beschouwd. Tussenevaluatie van de nota Gezonde Groei, Duurzame Oogst. Leiden, the Netherlands.

Tooker, J. F., Douglas, M. R. and Krupke, C. H. (2017) 'Neonicotinoid seed treatments: limitations and compatibility with Integrated Pest Management', Agriculture, Ecosystems and Environment, 2, pp. 1-22. doi: 10.2134/ael2017.08.0026.

Tooker, J. F., O'Neal, M. E. and Rodriguez-Saona, C. (2020) 'Balancing Disturbance and Conservation in Agroecosystems to Improve Biological Control', Annual Review of Entomology, 65(1), pp. 81-100. doi: 10.1146/annurev-ento-011019-025143.

Topping, C. J. et al. (2014) 'Recovery based on plot experiments is a poor predictor of landscape-level population impacts of agricultural pesticides', Environmental Toxicology and Chemistry, 33(7), pp. 1499-1507. doi: $10.1002 /$ etc. 2388.

Topping, C. J. et al. (2015) 'Towards a landscape scale management of pesticides: ERA using changes in modelled occupancy and abundance to assess long-term population impacts of pesticides', Science of the Total Environment, 537, pp. 159-169. doi: 10.1016/j.scitotenv.2015.07.152.

Topping, C. J., Aldrich, A. and Berny, P. (2020) 'Overhaul environmental risk assessment for pesticides', Science, 367(6476), pp. 360-363. doi: 10.1126/science.aay1144.

Tracy, E. (2014) 'The promise of biological control for sustainable agriculture: a stakeholder-based analysis', Journal of Science Policy \& Governance, 5(1): pp. 1-13.

Tscharntke, T. et al. (2005) 'Landscape perspectives on agricultural intensification and biodiversity Ecosystem service management', Ecology Letters, 8(8), pp. 857-874. doi: 10.1111/j.14610248.2005.00782.x.

Tscharntke, T. et al. (2007) 'Conservation biological control and enemy diversity on a landscape scale', Biological Control, 43(3), pp. 294-309. doi: 10.1016/j.biocontrol.2007.08.006.

Tscharntke, T. et al. (2012) 'Landscape moderation of biodiversity patterns and processes - eight hypotheses', Biological Reviews, 87(3), pp. 661-685. doi: 10.1111/j.1469-185X.2011.00216.x.

Tscharntke, T. et al. (2016) 'When natural habitat fails to enhance biological pest control - Five hypotheses', Biological Conservation., 204, pp. 449-458. doi: 10.1016/j.biocon.2016.10.001. 
Turnbull, L. and Hector, A. (2010) 'How to get even with pests', Nature, 466, pp. 36-37.

US-EPA (2020) Schedule for review of reonicotinoid pesticides. Available at: https://www.epa.gov/pollinatorprotection/schedule-review-neonicotinoid-pesticides (Accessed: 24 March 2020).

USGS (2019) U.S.Geological Survey National Water-Quality Assessment (NAWQA) Project: The pesticide national synthesis project. Available at: https://water.usgs.gov/nawqa/pnsp/usage/maps/ (Accessed: 23 August 2019).

Van't Zelfde, M. T. et al. (2012) 'Linking land use with pesticides in Dutch surface waters.', Communications in Agricultural and Applied Biological Sciences, 76(2), pp. 407-414.

Vandermeer, J. (1991) 'Environmental Problems Arising from National Revolutions in the Third World: The Case of Nicaragua', Social Text, 28, pp. 39-45. doi: 10.2307/466374.

Vandermeer, J. and Andow, D. A. (1986) 'Prophylactic and Responsive Components of an Integrated Pest Management Program', Journal of Economic Entomology, 79(2), pp. 299-302. doi: 10.1093/jee/79.2.299.

Vanloqueren, G. and Baret, P. V. (2008) 'Why are ecological, low-input, multi-resistant wheat cultivars slow to develop commercially? A Belgian agricultural "lock-in" case study', Ecological Economics, 66(23), pp. 436-446. doi: 10.1016/j.ecolecon.2007.10.007.

Vanloqueren, G. and Baret, P. V. (2009) 'How agricultural research systems shape a technological regime that develops genetic engineering but locks out agroecological innovations', Research Policy, 38, pp. 971-983. doi: 10.1016/j.respol.2009.02.008.

Vasquez, A. K. et al. (2019) 'Understanding the effect of producers' attitudes, perceived norms, and perceived behavioral control on intentions to use antimicrobials prudently on New York dairy farms', PLoS ONE, 14(9), pp. 1-21. doi: 10.1371/journal.pone.0222442.

Venables, W. N. and Ripley, B. D. (2002) Modern Applied Statistics with S. Fourth. New York: Springer. Available at: http://www.stats.ox.ac.uk/pub/MASS4.

Veres, A. et al. (2013) 'Does landscape composition affect pest abundance and their control by natural enemies? A review', Agriculture, Ecosystems and Environment, 166, pp. 110-117. doi: 10.1016/j.agee.2011.05.027.

Vitousek, P. M. et al. (2009) 'Nutrient imbalances in agricultural development', Science, 324(5934), pp. 15191520. doi: $10.1126 /$ science. 1170261.

Wagner, D. L. (2020) 'Insect Declines in the Anthropocene', Annual Review of Entomology, 65(1), pp. 457-480. doi: 10.1146/annurev-ento-011019-025151.

Waterfield, G. and Zilberman, D. (2012) 'Pest Management in Food Systems: An Economic Perspective', Annual Review of Environment and Resources, 37(1), pp. 223-245. doi: 10.1146/annurev-environ040911-105628.

Westerink, J. et al. (2019) 'Kan een goede boer natuurinclusief zijn? De rol van culturele normen in een beweging richting natuurinclusieve landbouw'. doi: 10.18174/508108.

Whalon, M. E., Mota-Sanchez, D. and Hollingworth, R. M. (2008) 'Analysis of global pesticide resistance in arthropods.', in Whalon, M. E., Mota-Sanchez, D., and Hollingworth, R. M. (eds) Global pesticide resistance in arthropods. Wallingford: CABI, pp. 5-31. doi: 10.1079/9781845933531.0005.

Whitehorn, P. R. et al. (2012) 'Neonicotinoid pesticide reduces bumble bee colony growth and queen production', Science, 336, pp. 351-352. doi: 10.1126/science.1215025.

Wickham, H. (2016) ggplot2: Elegant Graphics for Data Analysis. Springer-Verlag New York. Available at: https://ggplot2.tidyverse.org.

Wiedenmann, R. N. and Smith, J. W. (1997) 'Attributes of natural enemies in ephemeral crop habitats', Biological Control, 10(1), pp. 16-22. doi: 10.1006/bcon.1997.0544.

Wilson, C. and Tisdell, C. (2001) 'Why farmers continue to use pesticides despite environmental, health and sustainability costs', Ecological Economics, 39(3), pp. 449-462. doi: 10.1016/S09218009(01)00238-5.

Woodcock, B. A., Isaac, N. J. B., et al. (2016) 'Impacts of neonicotinoid use on long-term population changes in wild bees in England', Nature Communications, 7, p. 12459. doi: 10.1038/ncomms12459.

Woodcock, B. A., Bullock, J. M., et al. (2016) 'Spill-over of pest control and pollination services into arable crops', Agriculture, Ecosystems and Environment, 231, pp. 15-23. doi: 10.1016/j.agee.2016.06.023.

Wyckhuys, K. A. G. et al. (2018) 'Maximizing farm-level uptake and diffusion of biological control innovations in today's digital era', BioControl, 63(1), pp. 133-148. doi: 10.1007/s10526-017-9820-1.

Wyckhuys, K. A. G. et al. (2019) 'Ecological illiteracy can deepen farmers' pesticide dependency', Environmental Research Letters, 14, p. 093004. doi: https://doi.org/10.1088/1748-9326/ab34c9. 
Yang, L. et al. (2019) 'Mixed effects of landscape complexity and insecticide use on ladybeetle abundance in wheat fields', Pest Management Science, 75(6), pp. 1638-1645. doi: 10.1002/ps.5281.

Yang, M., Zhao, X. and Meng, T. (2019) 'What are the driving factors of pesticide overuse in vegetable production? Evidence from Chinese farmers', China Agricultural Economic Review, 11(4), pp. 672687. doi: 10.1108/CAER-08-2018-0170.

Yletyinen, J. et al. (2019) 'Understanding and managing social-ecological tipping points in primary industries', BioScience, 69(5), pp. 335-347. doi: 10.1093/biosci/biz031.

Zadoks, J. C. (1991) 'A hundred and more years of plant protection in the Netherlands', Netherlands Journal of Plant Pathology, 97(1), pp. 3-24. doi: 10.1007/BF01995781.

Zalucki, M. P., Adamson, D. and Furlong, M. J. (2009) 'The future of IPM: Whither or wither?', Australian Journal of Entomology, 48(2), pp. 85-96. doi: 10.1111/j.1440-6055.2009.00690.x.

Zhang, Y., Haan, N. L. and Landis, D. A. (2020) 'Landscape composition and configuration have scaledependent effects on agricultural pest suppression', Agriculture, Ecosystems and Environment, 302(May). doi: 10.1016/j.agee.2020.107085.

Zimmermann, J. and Stout, J. C. (2016) 'Underestimating neonicotinoid exposure: how extent and magnitude may be affected by land-use change', Environmental Science and Pollution Research, 23, pp. 70507054. doi: 10.1007/s11356-016-6159-6.

Zou, Y. et al. (2017) 'Video monitoring of brown planthopper predation in rice shows flaws of sentinel methods', Scientific Reports, 7, pp. 1-9. doi: 10.1038/srep42210.

Zou, Y. et al. (2020) 'Do diverse landscapes provide for effective natural pest control in subtropical rice?', Journal of Applied Ecology. 57(1): pp. 170-180. doi: 10.1111/1365-2664.13520.

Zuur, A. F. et al. (2009) Mixed effects models and extensions in ecology with R, Statistics for Biology and Health. Edited by M. Gail et al. New York, NY: Springer New York (Statistics for Biology and Health). doi: 10.1007/978-0-387-87458-6. 
SUMMARY 
Pest management is essential to prevent crop losses. Pest management is one of the many facets of farm management, but it is one that has major implications for the environment and human health. Pesticide residues and pesticide degradation products in ecosystems create environmental problems through, e.g. pollution, accumulation in wildlife and alterations in species community composition. Furthermore, pesticides can be harmful to people that are exposed to pesticides through polluted water and air, via residues on food products, and due to occupational exposure. Chemical-based pest management can lead to lock-in because of an interplay of reinforcing environmental factors, science and technology, and socio-political factors. This leads to a trajectory which is difficult (and costly) to change, and tends to be inflexible and path-dependent, giving rise to the so-called pesticide treadmill. The transition to a form of agriculture with more ecologically-based pest management is difficult to achieve because it needs to break the pesticide treadmill. To reduce farmers' dependency upon pesticides and to lessen the associated environmental burden, a solid understanding of the socio-ecological features of pest management decision making is needed. Using a multidisciplinary approach, I aimed to provide critically needed insight in the system dynamics underlying farmers' pest control practices, and elucidate key principles governing a transition towards sustainable pest management.

I conducted a literature review to identify drivers of the pesticide treadmill in Chapter 2. Overreliance on synthetic insecticides in global agriculture is the outcome of a 'pesticide treadmill', in which insecticide-induced pest resistance development and the depletion of beneficial insect populations aggravate farmers' pesticide dependencies. Examples of the pesticide treadmill have been witnessed repeatedly over the past seven decades, prompting the question whether the rapid uptake and usage patterns of neonicotinoid insecticides and their associated environmental impact are in accordance with this recurrent phenomenon. I developed a conceptual framework in which treadmills are enforced by enabling or disabling drivers within four domains: pest management decisions at the farm level, characteristics of farming landscapes, science \& technology, and societal demands. These drivers then tend to create a self-enforcing pesticide 'lock-in'. I then analysed several post1950s historical case studies with reference to this framework, e.g., those involving sprays of the highly-hazardous DDT and methyl-parathion, in which the pesticide treadmill was initiated, sustained and broken, and compare these with current patterns in neonicotinoid use. Historical case studies further illustrated how treadmills occur in three phases in which (i) a limited number of insecticides are routinely used, (ii) resistance development of pests results in increased crop injury, prompting increased frequency of applications with a wider range of products, (iii) breaking out of the pesticide 'lock-in' due to policy change and adoption of alternative technologies that lowered chemical inputs and improved agroecosystem functioning. The analysis showed that important differences were that I studied neonicotinoids at a global scale and in several crops, while documented historical examples of the pesticide treadmill were reported more locally and on a few cash crops. Furthermore, 
while the pesticide treadmill in the historic case studies was only counteracted after major crop losses, current legislation to regulate the use of neonicotinoids was strongly motivated by concerns about impacts on nontarget organisms and the environment, and less by mitigating resistance development and the associated crop losses. Neonicotinoid use has triggered a new, globe-spanning cycle of the pesticide treadmill, yet promising and resolute steps are being taken to escape this 'lock-in'. When paired with adequate technological innovation, supporting policies, sound public education and institutional change, the current product bans can enable a large-scale, lasting adoption of ecologically-underpinned farming schemes that will concurrently benefit farmers, consumers and the environment.

In Chapter 3 and $\mathbf{4}$ I assessed in a two-year landscape study how beneficial arthropods and biocontrol services are jointly impacted by local and landscape-wide pesticide use and by semi-natural habitats in the surrounding landscape, which may provide resources for natural enemies and pollinators. The impacts of local and landscape-wide insecticide use are still poorly understood, and it is unclear to what extent impacts of insecticides on beneficial arthropod populations can be mitigated by landscape context. In Chapter 3 I assessed how the abundance of predators, parasitoids and pollinators are influenced by local and landscape wide insecticide use across landscapes that span a range in proportion of seminatural habitat. In Chapter 4, I studied local and landscape-scale insecticide use interacts with landscape variables to govern natural biocontrol in field margins. I sampled beneficial arthropod populations by sweep netting and placing yellow sticky traps at 38 focal field margins of paired conventional and organic arable fields in June and July of 2017 and 2018. As a proxy for biocontrol potential, I assessed predation and parasitism rates of eggs of the cabbage moth (Mamestra brassicae) on potted cabbage plants in the same field margins. Paired fields were located in landscapes with different proportions of semi-natural habitat. I used three indicators of insecticide use: management in the adjacent field (conventional vs. organic), Treatment Frequency Index of insecticides of the field adjacent to the sampling site, and the estimated quantity insecticide applied within a $1 \mathrm{~km}$ radius around the sampling site. Landscape variables were used as covariables to account for landscape effects.

I collected a total of 2803 predators, 24004 parasitoids, and 895 pollinators by sweep netting and placing sticky traps in field margins. Beneficial arthropod populations in field margins, assessed by sweep-netting, were negatively associated with insecticide use at the landscape scale, while arthropod sampling by sticky traps did not show such a relationship. Pollinator abundance was negatively associated with conventional farming in the adjacent field and with the frequency of insecticide applications, while predator and parasitoid abundance did not show significant associations with local insecticide use indicators. Finally, I found that the negative associations between beneficial arthropods and insecticides were, for some functional groups, moderated in landscapes with higher amounts of woody semi-natural habitat. Estimated insecticide load at the landscape scale 
was the variable most strongly influencing the measured arthropod abundances. Insecticide impacts on arthropod populations thus do extend beyond the fields in which they are used.

Mean egg predation and parasitism rates of $M$. brassicae were $14 \%$ and $6 \%$, respectively. There were no significant associations between predation and parasitism rates in field margins with insecticide use in the adjacent field or the wider landscape. Risk assessments of environmental impacts of insecticides and regulations on the safe use of pesticides need to account for potential spill-over effects and consider a landscape approach. My findings further suggest that field margins can be valuable habitats for natural enemies in agricultural landscapes, irrespective of the insecticide use intensity at the local and landscape scale.

In Chapter 5, I conducted an online survey among Dutch farmers to identify barriers towards reducing pesticide use. Insight in the intentions of farmers to reduce pesticide use may help identify pathways towards farming systems with reduced environmental impacts. I used the Reasoned Action Approach to identify which social-psychological components of behaviour (constructs) determine farmers' intentions to decrease pesticide use. I analysed 681 responses to an online survey to assess which constructs drive intention, and identified which beliefs pose barriers and drive the motivation of farmers to decrease pesticide use. My results show that the intention to reduce pesticide use is strongly determined by whether other farmers also act. Furthermore, farmers perceive limited capacity and autonomy to reduce pesticide use, and motivations to reduce pesticide use were based on environmental considerations. Finally, decreasing pesticide use was considered risky, but the relative importance of risk attitude was offset by the environmental considerations of farmers. This indicates that farmers need successful examples of how to decrease pesticide use, either via exchange with peer farmers or knowledge provisioning on alternative pest control methods. These insights may be useful to direct policy making to influence farmers' intentions to decrease pesticide use.

Balancing trade-offs between food production and environmental health is a major challenge in mainstream agricultural production systems. In this thesis I showed that current mainstream agriculture is trapped in a pesticide treadmill, which is reinforced by different lock-in mechanisms. First, beneficial arthropod abundances were negatively affected by the landscape-wide pesticide load, implying a landscape lock-in of pesticide use. Thus, landscape management and increasing heterogeneity is essential to facilitate beneficial arthropods and overcome the landscape lock-in with respect to pesticide use. I also showed that it is important to recognize the role of different actors in the treadmill, and farmers are key actors in pest management decision-making. Farmers' behaviour is an important driver of the pesticide treadmill, creating a social lock-in through social norms, peer pressure and social comparison. Furthermore, perceived capability is reducing the willingness to decrease pesticide use. Here, true costs of pesticide use and knowledge 
development on pest management alternatives could help to overcome this social lock-in of the pesticide treadmill. Thus, to advance the transition from chemical to ecologically-based pest management it is crucial that ecological information is integrated with social and behavioural understanding of pest management decision-making. This approach may help farmers with the transition towards more ecologically-based pest management practices and reduce the reliance on chemical insecticides. 

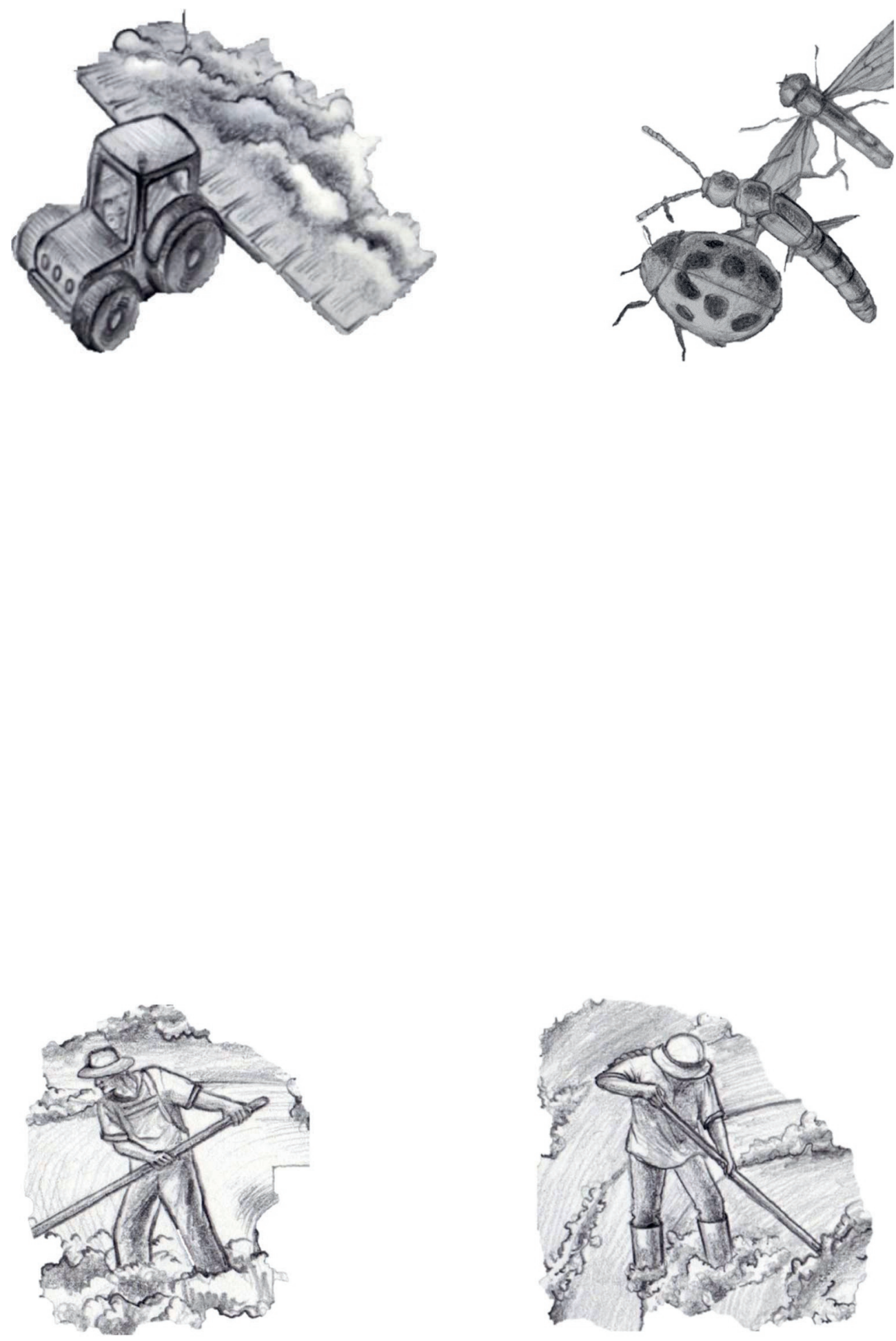
SAMENVATTING 
Gewasbescherming in de landbouw is essentieel om oogstverliezen te voorkomen. Echter, gewasbeschermingsmiddelen zijn in meerdere of minder mate toxisch en het gebruik kan onbedoelde neveneffecten hebben op de gezondheid van mens, dier en milieu. Vermindering van de afhankelijkheid van pesticiden is daarom maatschappelijk gewenst. In dit proefschrift geef ik, met behulp van een multidisciplinaire aanpak, inzicht in i) het effect van pesticiden en landschapscontext op de abundantie en functionele rol van nuttige geleedpotigen in het agrarische landschap en ii) de sociale factoren die van invloed kunnen zijn op besluitvorming van boeren omtrent gewasbescherming.

Gewasbescherming op basis van synthetische pesticiden kan leiden tot een vicieuze cirkel (pesticide treadmill), een zogenoemde 'lock-in', waarbij het ontsnappen uit een bepaalde productiewijze moeilijk en kostbaar is. Milieufactoren, wetenschap \& technologie en sociopolitieke factoren spelen een rol in de 'lock-in'. In hoofdstuk 2 heb ik een literatuuronderzoek uitgevoerd waarin ik voorbeelden van de pesticide treadmill heb verzameld. De pesticide treadmill heeft zich in het verleden verschillende malen voorgedaan voor diverse combinaties van plagen en synthetische pesticiden. Op basis van deze studies heb ik de belangrijkste componenten en patronen van de pesticide treadmill in kaart gebracht. Dit resulteerde in een conceptueel raamwerk met vier domeinen: i) beslissingen over gewasbescherming op bedrijfsniveau, ii) het karakter van agrarische landschappen, iii) ontwikkelingen op het gebied van wetenschap en technologie, en iv) maatschappelijke wensen en doelstellingen. Processen binnen deze domeinen kunnen de 'lock-in' ten aanzien van pesticidengebruik versterken of doorbreken.

Aansluitend heb ik onderzocht in hoeverre het patroon dat zich nu ontvouwt bij het gebruik van neonicotinoïden parallellen vertoont met de aangehaalde case studies over het gebruik van andere pesticiden. Uit mijn studie blijkt dat het huidige patroon in het gebruik van neonicotinoïden wijst op een wereldwijde pesticide treadmill. Een verschil met de case studies is dat het gebruik van neonicotinoïden op een wereldwijde schaal en voor een groot aantal gewassen plaats vindt, terwijl de case studies over de pesticide treadmill specifiek waren voor bepaalde regio's en marktgewassen. Verder is de pesticide treadmill in de case studies tegengegaan naar aanleiding van grote oogstverliezen die plaatsvonden door resistentieontwikkeling, terwijl vermindering van neonicotinoïdengebruik voornamelijk gebaseerd wordt op maatschappelijke bezorgdheid over de gevolgen voor het milieu en niet door bezorgdheid over resistentieontwikkeling en/of oogstverliezen. Er zijn in Europa stappen gezet om de vicieuze cirkel van neonicotinoïdengebruik te doorbreken, met onder andere een verbod op drie neonicotinoïden. Dit verbod op neonicotinoïden kan in combinatie met adequate technologische innovatie, ondersteunend beleid, onderwijs en voorlichting en institutionele verandering bijdragen aan een vermindering van de afhankelijkheid van pesticiden . 
De interactie tussen natuurlijke vijanden van plaagsoorten, pesticidengebruik en de rol van het landschap wordt nog steeds onvolledig begrepen. In hoofdstuk $\mathbf{3}$ en $\mathbf{4}$ presenteer ik de resultaten van een tweejarige landschapsstudie waarin is geïnventariseerd hoe bestuivers, natuurlijke vijanden en biologische plaagbestrijding worden beïnvloed door insecticidengebruik op veldniveau en op landschapsschaal enerzijds, en door seminatuurlijk habitat in het omringende landschap anderzijds. Voor deze studies heb ik metingen verricht aan bestuivers en natuurlijke vijanden van plaagsoorten in de akkerranden van 38 conventionele en biologische akkerbouwpercelen. In een radius van 1 $\mathrm{km}$ rondom alle onderzoekslocaties heb ik het landgebruik gekarakteriseerd, bijvoorbeeld het percentage semi-natuurlijk habitat. Natuurlijke vijanden en bestuivers heb ik bemonsterd door middel van plakvallen en een vangnet. Verder heb ik de mate van predatie en parasitisme van de eitjes van de koolmot (Mamestra brassicae) in deze akkerranden bepaald als indicator voor biologische plaagbestrijding. Voor het gebruik van insecticiden gebruikte ik drie indicatoren: i) type beheer in het aangrenzende veld (gangbaar vs. biologisch), ii) de frequentie van insecticidentoepassing in het veld naast de bemonsteringslocatie, en iii) de geschatte hoeveelheid insecticiden die werd toegepast binnen een straal van $1 \mathrm{~km}$ rondom de onderzoekslocaties. Om rekening te houden met mogelijke effecten van het omliggende landschap werden landschapsvariabelen gebruikt als co-variabelen in een regressie-analyse.

In totaal heb ik met het vangnet en de plakvallen 2803 predatoren, 24004 sluipwespen, en 895 bestuivers in akkerranden bemonsterd. Van drie indicatoren voor management en insecticidengebruik was de geschatte insecticidenbelasting op landschapsschaal het sterkst gerelateerd met de dichtheden van geleedpotigen (hoofdstuk 3). Het aantal bestuivers dat bemonsterd was met het vangnet was zowel negatief geassocieerd met gangbaar beheer van het aanliggende veld als met het aantal insecticidenbehandelingen op dat veld. Voor predatoren en sluipwespen heb ik geen relatie gevonden met indicatoren van insecticidengebruik op veldschaal. Tenslotte waren er zowel positieve als negatieve verbanden tussen nuttige geleedpotigen en de aanwezigheid van semi-natuurlijk habitat. Dit zou erop kunnen duiden dat, ondanks dat een semi-natuurlijke habitat hulpbronnen kan leveren aan natuurlijke vijanden en bestuivende insecten, de respons van functionele groepen op insecticidengebruik en semi-natuurlijk habitat soortspecifiek is. Het aantal met plakvallen gevangen geleedpotigen werd niet beïnvloed door insecticidengebruik. De gemiddelde percentages predatie en parasitisme van $M$. brassicae eitjes was respectievelijk $14 \%$ en $6 \%$. Ik heb geen significante verbanden gevonden tussen predatiegraad en parasitisme in akkerranden en insecticidengebruik in het aangrenzende veld of het omliggende landschap (hoofdstuk 4).

De bevindingen suggereren dat de effecten van insecticiden op de populaties van geleedpotigen verder reiken dan de percelen waarin ze worden gebruikt, en dat akkerranden een waardevolle habitat zijn voor natuurlijke vijanden in agrarische 
landschappen. Verder kan op basis van deze gegevens geconcludeerd worden dat bij de risicobeoordeling van milieueffecten en het opstellen van regelgeving voor het veilig gebruik van pesticiden rekening moet worden gehouden met mogelijke 'spillover'-effecten en dat een landschapsbrede benadering voor de evaluatie van de impact van pesticiden waardevol zou kunnen zijn.

In hoofdstuk 5 heb ik onderzocht welke factoren bij boeren een rol spelen bij vermindering van pesticidengebruik. Hierbij het ik gebruik gemaakt van een sociaalpsychologische analysemethode, de Reasoned Action Approach. In een online enquête heb ik Nederlandse boeren gevraagd naar de belemmeringen die ze ervaren met betrekking tot het verminderen pesticidengebruik. Ik heb 681 reacties geanalyseerd en bepaald welke gedragscomponenten het belangrijkst zijn om pesticidengebruik te verminderen. Ook heb ik onderzocht welke algemene overtuigingen ten grondslag liggen aan de intentie om pesticidengebruik te verminderen. De resultaten laten zien dat het pesticidengebruik van boeren sterk afhankelijk is van het pesticidengebruik van andere boeren. Verder voelen boeren zich maar beperkt in staat om zelf de keuze te maken om het gebruik van pesticiden te verminderen. Ten slotte wordt een afname in het gebruik van pesticiden over het algemeen als risicovol beschouwd, maar dit wordt gecompenseerd door de milieuoverwegingen van boeren. Deze uitkomsten geven aan dat de respondenten geïnteresseerd zijn in om hun pesticidengebruik te verminderen en dat ze hiervoor behoefte hebben aan goede (praktijk)voorbeelden, bijvoorbeeld via uitwisseling van ervaringen met collega-boeren of via informatie over alternatieven voor chemische gewasbescherming. Deze inzichten kunnen een nuttige input vormen voor het formuleren van beleid dat gericht is op een vermindering van het gebruik van pesticiden en de afhankelijkheid van pesticiden.

In dit proefschrift heb ik laten zien dat de huidige reguliere landbouw gevangen zit in een pesticide treadmill en dat deze vicieuze cirkel wordt versterkt door een 'lock-in' in verschillende domeinen. Het doorberekenen van de 'werkelijke' kosten van pesticidengebruik, dat wil zeggen de kosten voor natuur en milieu, en de ontwikkeling van alternatieven voor chemische gewasbescherming kunnen helpen om de pesticide treadmill te doorbreken. Om de transitie van chemische naar biologische gewasbescherming te bevorderen is het cruciaal dat ecologische kennis geïntegreerd wordt met inzichten vanuit de gedrags- en sociale wetenschappen. Een dergelijke multidisciplinaire aanpak kan de afhankelijkheid van insecticiden verminderen en bijdragen aan een transitie naar een meer duurzame gewasbescherming. 
ACKNOWLEDGEMENTS 
Five years after I started this PhD project I can finally write down my word of thanks to all the people that supported me, inspired me and helped me grow professionally and personally. I have been able to create this thesis thanks to all your support, and I could not have done it without you.

First of all, I want to thank my promotor and co-promotor Wopke and Felix. I have been very lucky with you as my supervisors, and I cannot thank you enough for giving me the space to determine my own path in this project, and more importantly for supporting me whenever I needed it, joining me during field work and exploring the world of social science. I also appreciate that you both have invited me, and your other $\mathrm{PhD}$ students, for dinner to give us the opportunity to get to know each other beyond work. Wopke, as busy as you always are, I really appreciate how approachable you have stayed to discuss my work whenever I needed it. Felix, I cannot thank you enough for the continuous support during my PhD. Whenever I knocked on your door you would take time to help me, and I appreciate your attention to detail and critical reviews of my work. I want to thank you both for your critical questions, thoughts and insights, and continuous support and feedback on my work.

Jaap, thank you for introducing me to the world of social research, for developing and interpreting the survey together with me and for taking the time to answer every question I had. I really appreciate your patience and dedication.

A special thanks to all farmers that participated in my project, who provided me with access to their fields, and who were willing to share information on their farming practices. I appreciate their conversations with me, as it gave me valuable insights into the lives of farmers in the Netherlands.

A big thank you goes to my paranymphs, colleagues, and good friends Roos and Lenora. You are both amazing people who supported me when I needed it most, listened when I got stuck in some work, joined me for some field work. It was always an extra motivation to come to the office knowing you were there! I am grateful for all our talks, your support and the fun dinners and lunches we had together. I will miss sharing an office with you, but I hope we can continue our 'domibo' or 'vrimibo' to get together and discuss many project and notproject related topics.

I am happy to have worked in such a diverse group as FSE. I have seen many PhD and postdocs come and go, and some of you I want to give special thanks. Victoria thank you for being my friend and for organizing social events for the PhDs at FSE, and organizing fun nights out. Pablo, you are so kind and welcoming that anyone new to the group felt part of it straight away. It didn't matter how busy you were or how much you had to commute, you were always up for a beer after work and I am happy that I can still call you my friend! Heitor, you were one of the first people I met and your energy is inspiring! Anne, thank you for the fun talks during long office hours. I am sure we disturbed some people in the PhD- 
room sometimes, sorry about that! Yavanna, I could relate most to your project and I am glad we have been able to do some field work together. Your help with statistics has been great and the fact that I can contact you with any questions on insects is really appreciated. I love your pictures and the creativeness you put in your work and I hope to see much more of it. Francine, it was fun talking to you about working together with farmers in the Netherlands, getting your perspective on doing research and a $\mathrm{PhD}$ and you were always up to join a social event that was organized! A big thank you goes to Hennie. It is funny how you never had to do any lab work for me, but still helped me out with so much of my work. You noisy entrance in the PhD-room was always a good break for everyone! Thank you for all the tasty (hand-picked) fruit you would bring to the office every summer :). Wampie, Gemma and Annemieke, thanks for making the administrative part of the project much easier! Your presence in the group cannot be missed and you helped me whenever I needed it!

Many more people were part of my PhD life; graduated colleagues Yodit, Daniel, Mirja, Georges, Carl, Lucas and Walter, FSE staff members Annemiek, Blair, Dirk, Ischani, Jeroen, Kees, Merel, Rogier and Walter, and of course current PhD colleagues Jiali, Qingbo, Walter, Ghina, Tharic, Loekie, Stella, Jonas, Kristine, Ignacio, Mariana, Kari, and everyone else I might have forgotten to mention. Thank you!

Of course all of this could not have been done without support of my family and friends. Pap en mam, Gerbert, Meyke, Petra, Cathal, Geerke, Maickel, Mirjam, Marlot, Henk, Kim en Ralph dank jullie voor jullie steun en interesse in mijn werk. Henk en Kim, jullie hebben mij fantastisch geholpen bij mijn veldwerk! Het was elke keer weer gezellig en behulpzaam. En lieve Wieke, jij bent mijn zonnetje na een lange dag werken. Thuiskomen en door jou geknuffeld worden is het fijnste dat er is.

Last, but certainly not least, I want to thank my husband Chris. Your support has been endless, whatever my mood, and no matter the distance we were apart. You experienced a $\mathrm{PhD}$ life yourself and knew sometimes even better than I did when I needed to take a step back. Dank je dat je mij zo goed kent, mij uitdaagt en er altijd voor mij bent. 



\section{ABOUT THE AUTHOR}

Lieneke Bakker was born on September $7^{\text {th }}, 1986$ in 's Gravenhage, the Netherlands, and grew up in Ter Apel in the province of Groningen. Lieneke enrolled in a BSc Forest and Nature Conservation at Wageningen University in 2004, and obtained her Bachelor's degree in 2008. She continued with the MSc Forest and Nature Conservation (at Wageningen University), specializing in Ecology. For completion of her MSc-degree she finished a minor and a major thesis. Her minor thesis was on the subject of invasive plant species, plant traits and disturbances, with fieldwork in India and under supervision of Prof. Dr Frank van Langevelde (Resource Ecology Group). Her major thesis focused on seed dispersal by agouti's in Panama, supervised by Dr Patrick Jansen at the Forest Ecology Group. After completion of her MSc she moved in 2011 to Ottawa, Canada with her husband. In Canada she worked for grassroots organisations and focused on promoting sustainability in the city. In 2014 she started working for $\mathrm{MGPoF}$, an organization addressing Major Groups involvement in the United Nations Forum on Forests (UNFF). Among other activities she organised workshops in Brazil, Ghana, and Nepal, and attended the UNFF11 in New York, USA. It was during her work in Canada that she became interested in societal relevant topics, including nature conservation and food security issues. In September 2015 Lieneke moved back to the Netherlands, and applied for the present PhD project. She started her PhD in March 2016 at the Farming Systems Ecology Group at Wageningen University. This thesis is the result of her work in the past five years. 


\section{PEgRC TRAINING AND EDUCATION}

STATEMENT

With the training and education activities listed below the $\mathrm{PhD}$ candidate has complied with the requirements set by the C.T. de Wit Graduate School for Production Ecology and Resource Conservation (PE\&RC) which comprises of a minimum total of 32 ECTS ( $=22$ weeks of activities).

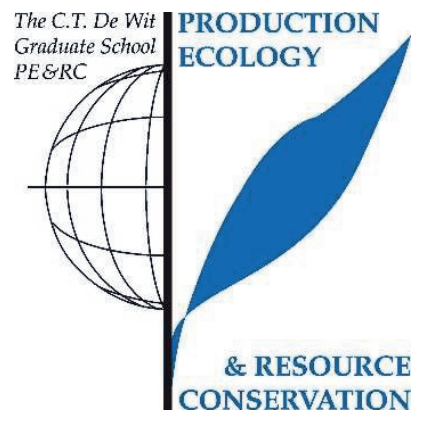

\section{Review of literature/ writing of project proposal (6 ECTS)}

Neonicotinoids in global agriculture: evidence for a new pesticide treadmill? (review) Tipping the system: the difficult transition from chemical towards natural pest control in agriculture (proposal)

\section{Post-graduate courses (6.3 ECTS)}

Tipping points discussion meeting; PE\&RC, the Netherlands

Meta-analysis; PE\&RC, the Netherlands

Training week on agroecology; RHEA Research Centre, Belgium

Geostatistics; PE\&RC, the Netherlands

Introduction to zero inflated models with R; PE\&RC, the Netherlands

\section{Invited review of (unpublished) journal manuscripts (2 ECTS)}

Ecological Applications: Landscape complexity and biocontrol

Nature Sustainability: Intercropping modelling

\section{Deficiency, refresh, brush-up courses (12 ECTS)}

Systems analysis, simulation and systems management; PPS

Ecological modelling and data analysis in R; CSA

\section{Competence strengthening / skills courses (2.3 ECTS)}

PhD Workshop carousel; WGS

Reviewing a scientific paper; WGS

PhD Workshop carousel; WGS

Critical thinking and argumentation; WGS

Efficient writing strategies; WGS 
Scientific integrity / ethics in science activity (0.3 ECTS)

Ethics in plant and environmental sciences; WGS

(2019)

PE\&RC Annual meetings, seminars and the PE\&RC weekend (1.6 ECTS)

PE\&RC First years weekend

Tipping points in pest management: what is the evidence

PE\&RC Day

$(2017,2019)$

Discussion groups / local seminars / other scientific meetings (4.5 ECTS)

Voedsel anders; Wageningen

Van chemie naar ecologie, perspectieven voor ecologische gewasbescherming; KNAW symposium; Amsterdam

Frontiers in resilience symposium; PE\&RC; Wageningen

Discussion group; SIAS; Wageningen

Relatiedag, innovatie en toelating; CTGB; Ede

Efficiëntie in de landbouw van de 21e eeuw; RIDLV; Ede

Resilience symposium; Investment Theme WUR project; Wageningen

Resilience symposium; WUR; Klarenbeek

Agriculture-climate-forests-food $\mathrm{PhD}$ discussion group; Wageningen

Symposium towards ecological intensification; Wageningen

International symposia, workshops and conferences (3.5 ECTS)

NAEM

IOBC Dundee; oral presentation

NAEM; poster presentation

\section{Lecturing / supervision of practicals / tutorials (4.5 ECTS)}

Agroecology

$(2016,2017,2020)$

Population and systems ecology

Systems analysis, simulation and systems management

$(2017,2018,2019)$ 
The research described in this thesis was funded by the Netherlands Organization for Scientific Research (NWO) Earth and Life Sciences (ALW), project number 824.15.022.

Financial support from Wageningen University for printing this thesis is gratefully acknowledged.

\section{Cover design}

Designed by Lisa Sánchez Aguilar

Created by design studio 'Tierra de Luciérnagas Estudio de Ilustración y Diseño'

\section{Printed by}

Proefschriftmaken, The Netherlands || www.proefschriftmaken.nl 



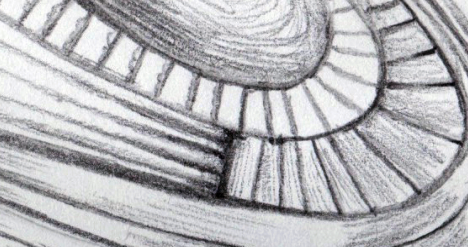

n. $\quad 1$ 